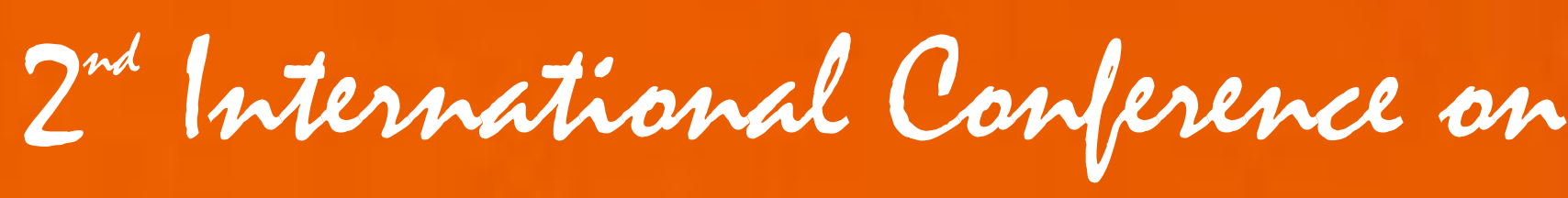
Education $X$ Educational

Psychalogy DCEAPSY

Abstracts

www.iceepsy.org

Dr. Zafer Bekirogullari, BA (Hons), MEd, PhD, CPsychol BPS, HPC Registered, Organizer \& Director of ICEEPSY \& Editor, ICEEPSY 2011 Abstract Bock
Ottp://dx.doi.org/10.15405/iceepsy2011(1986-3020)
ISSN: 1986-20111 


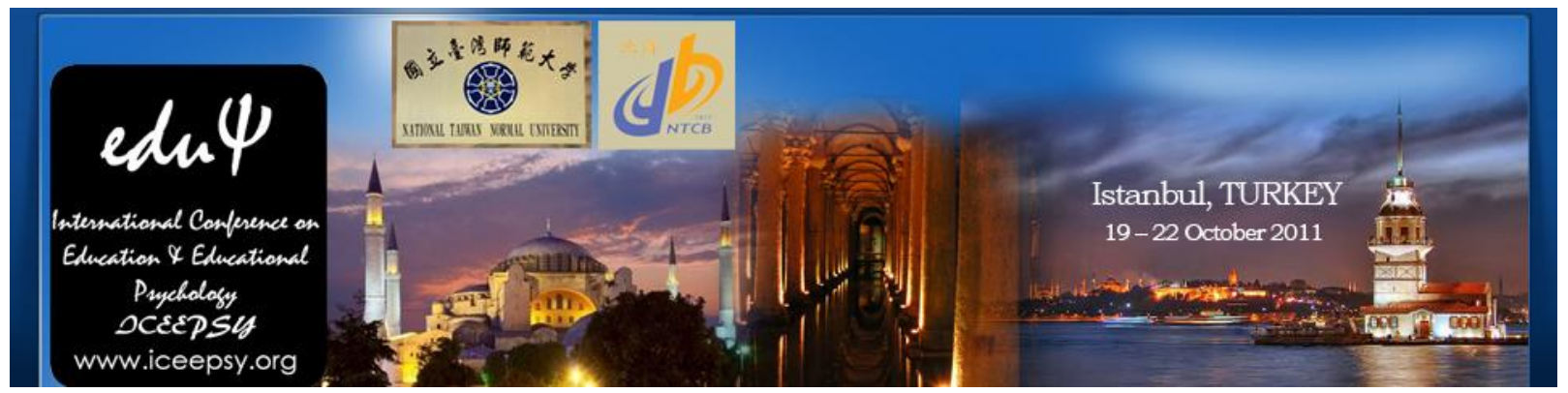

Each abstract provides its own significant contribution toward identifying problems, clarifying concepts, discussing phenomena, and examining different approaches to the challenging topics of Education and Educational Psychology

Previous Volume

Volume 1: 2010

Publisher (c) C-crcs (Counselling, Research \& Conference Services)

Editor (C 2011 Dr. Zafer Bekirogullari, BA (Hons), MEd, PhD,

CPsychol BPS, HPC Registered

Individual contributions (C) 2011 their authors

ISBN 1986-3020

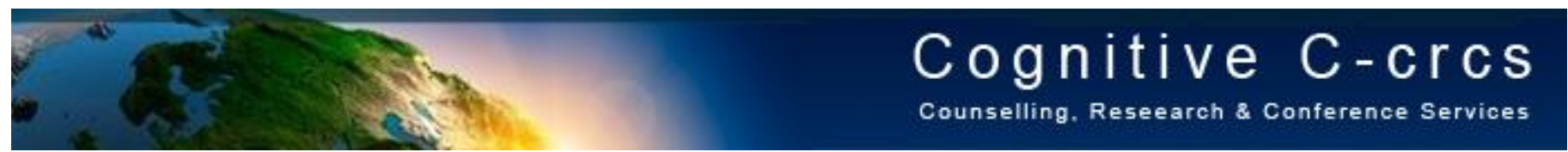


$2^{\text {nd }}$ International Conference on Education \& Educational Psychology ICEEPSY

2011

Abstracts

Volume 2

Thematic Sections' Chairs

Dr. Hugh Glenn PhD, Educational Consultant, USA

Prof. Dr. Ugur Oner PhD, Cankaya University, Turkey

Prof. Dr. Figen Cok PhD, Baskent University, Turkey

Prof. Dr. Carmel McNaught PhD, The Chinese University of Hong Kong\& Assoc. Prof. Dr. David M Kennedy PhD, Lingnan University, Hong Kong \&

Dr. Emre Cetin PhD, Eastern Mediterranean University, Cyprus

Dr. James Ogunleye, Middlesex University, UK

Dr. Gordon Ade Ojo PhD, The University of Greenwich, UK 
ICEEPSY 2011 marks the fourth international conference for which I have served as managing director. I am grateful that the ICEEPSY family continues to increase each year.

At last year's ICEEPSY conference, I welcomed participants from more than 30 countries. During ICEEPSY 2011 , I am pleased to announce that participants represented almost 50 countries. Even more pleasing is that $\% 50$ of participants attended ICEEPSY 2010.

I extend a special thanks to Mr. Ali Uner, Mrs Eroglu, Mrs Karagozoglu, Prof. Dr. Bedestenci, Prof. Dr. Johnson, Prof. Dr. Yesilyaprak, Dr. Ogunleye, Dr. Ade Ojo, and Dr. Navehe Brahim.

And I thank these persons for their support of this conference: Mr. Gokhan Ecesoy, Miss. Ceren Etci, Miss. Natalie Pollard, and Mr. Evangelos Aidiniou.

I also thank Dr. Hugh Glenn, a colleague and dear friend, for his ongoing guidance and support. Finally, I would be remiss if I did express my thanks to my parents, Yildiz Bekirogullari and Yusuf Bekirogullari, who continue to inspire and motivate me.

You may be wondering why ICEEPSY 2012 is scheduled in Istanbul again. Istanbul is one of the world's most beautiful cities. It is impossible to see all of it in 3 or 4 days, so we decided to meet here once more in 2012. We promise that ICEEPSY 2012 will be as enlightening and pleasurable as this conference. Next year's conference will have richer social activities as well as events in Anatolia and other areas in Istanbul.

We look forward to seeing you at ICEEPSY 2012. I hope you enjoy ICEEPSY 2011 and your visit to Istanbul.

Editor 


\section{The ICEEPSY 2011 Conference Scientific Committee \& Board of Reviewers}

Binnur Yesilyaprak
Ugur Oner
Figen Cok
Selahattin Gelbal
Shahrokh (Sharo) Sh
Carmel McNaught
Jim Johnson
Fidan Korkut Owen
Hasan Bacanli
Marie J. Myers
Ana Canen
Gregory Poole
Macleans Geo-Jaja
Bekir Ozer
Ozcan Demirel
Leonor Santos
Tapio Tovanen
Heikki Ruismaki
Inkeri Ruokenen
Kauko Komulainen
David M Kennedy
Ergun Gide
Yasemin Kepenekci
Alois Ghergut
Ahmad Iftikhar

Prof. Dr. PhD

Prof. Dr. PhD

Prof. Dr. PhD

Prof. Dr. PhD

Prof. Dr. PhD

Prof. Dr, PhD

Prof. Dr. PhD

Prof. Dr. PhD

Prof. Dr. PhD

Prof. Dr. PhD

Prof. Dr. PhD

Prof. Dr. PhD

Prof. Dr. PhD

Prof. Dr. PhD

Prof. Dr. PhD

Prof. Dr. PhD

Prof. Dr. PhD

Prof. Dr. PhD

Prof. Dr. PhD

Prof. Dr. PhD

Assoc. Prof. Dr. PhD

Assoc. Prof. Dr. PhD

Assoc. Prof. Dr. PhD

Assoc. Prof. Dr. PhD

Assoc. Prof. Dr. PhD

Assoc. Prof. Dr. PhD Assoc. Prof. Dr. PhD Assoc. Prof. Dr. PhD Assoc. Prof. Dr. PhD Assoc. Prof. Dr. PhD Assoc. Prof. Dr. PhD Assoc. Prof. Dr. PhD Assoc. Prof. Dr. PhD Assoc. Prof. Dr. PhD Assoc. Prof. Dr. PhD Dr. PhD

Dr. $\mathrm{PhD}$

Dr. PhD

Dr. PhD

Dr. $\mathrm{PhD}$

Dr. $\mathrm{PhD}$

Dr. $\mathrm{PhD}$

Dr. PhD

Dr. PhD

Dr. PhD

Dr. $\mathrm{PhD}$

Dr. PhD

Dr. PhD

Dr. $\mathrm{PhD}$

Dr. $\mathrm{PhD}$

Dr. PhD

Dr. PhD

Dr. $\mathrm{PhD}$

Dr. $\mathrm{PhD}$

Dr. PhD

Dr. PhD

Turkey
Turkey
Turkey
Turkey
USA
Hong Kong
USA

Turkey

Turkey

Canada

Brazil

Japan

USA

Cyprus

Cyprus

Lisbon

Finland

Finland

Finland

Finland

Hong Kong

Australia

Turkey

Romania

Pakistan

Malaysia

Libya

Italy

Taiwan

USA

Turkey

Turkey

Turkey

Cyprus

Cyprus

USA

Iran

Thailand

Romania

Romania

Romania

Romania

Romania

Romania

Poland

Turkey

Turkey

Turkey

Turkey

UK

Australia

UK

USA

Portugal

Cyprus

Cyprus
Ankara University

Cankaya University

Baskent University

Hacettepe University

Southeast Missouri State University

The Chinese University of Hong Kong, Shatin, N.T.

Chairman ICEEPSY 2011,

Point Loma Nazarene University

Hacettepe University

Gazi University

Queens University

Federal University of Rio de Janeiro

University of Tsukuba

Brigham Young University, Utah

Eastern Mediterranean University

Cyprus International University

Fundacoa Da Faculdade De Ciencias DA

Universidade De Lisboa

Helsinki University

Helsinki University

Helsinki University

Helsinki University

Lingnan University

CQUniversity Sydney

Ankara Univesity

University "Alexandru Ioan Cuza" láli

University of Management and Technology. C-II, Johar Town, Lahore

Sultan Idris Education University (UPSI)

Al Fateh University

University of Bologna

National Taipei College of Business

Delta State University

Middle East Technical University

Ankara University

Balikesir University

Cyprus International University

Cyprus International University

Independent Educational Consultant

Ferdowsi University of Mashhad, Iran

Bangkok University

Al. I. Cuza University lasi

University of Ploiesti Petroleum Gas

University of Ploiesti Petroleum Gas

University of Ploiesti Petroleum Gas

University "Stefan cel Mare" of Suceava

University "Stefan cel Mare" of Suceava

Adam Mickiewicz University in Poznap

Gazi University

Usak University

Abant Izzet Baysal University

Middle East Technical University

Middlesex University

Independent researcher and artist/curator, University of Wollongong, NSW

University of Worcester

Point Loma Nazarene University

University of Aveiro

Eastern Mediterranean University

Eastern Mediterranean University 
Thematic Sections

Assessment and Evaluation

Teacher Education

Basic Education - basic skills

Guidance and Counseling Psychology

Educational Psychology

Adolescent Growth and Development

Learning Theories

Effective Teaching Practices

Second Language Teaching

Leadership and Collaborative Policy

Adult and Continuing Education

Higher Education

Quality Assurance/

Institutional Effectiveness

Special Education

Education and Technology

ICT

Distance Learning

\section{Chair}

Dr. Hugh Glenn, Educational Consultant, USA

Prof. Dr. Ugur Oner

Cankaya University, Turkey

Prof. Dr. Figen Cok

Baskent University, Turkey

Prof. Dr. Carmel McNaught, PhD

The Chinese University of Hong Kong\&

Assoc. Prof. Dr. David M Kennedy, PhD

Lingnan University, Hong Kong\&

Dr. Emre Cetin,

Eastern Mediterranean University, Cyprus

Dr. James Ogunleye

Middlesex University, UK

Dr. Gordon Ade Ojo

The University of Greenwich, UK 


\section{Supervision within educational psychology practice: the development of guidelines and their application in the UK and} Singapore

Dr Sandra Dunsmuir, University College London, UK; Jane Marriott, Principal Educational Psychologist, Medway Council, England, UK \& Dr Mariam Aljunied, Lead Specialist, Educational Psychology, Ministry of Education, Singapore

\section{Problem Statement:}

Good supervision is central to the delivery of high quality psychological services and in changing times it is important that psychologists have professional guidance wherever they may be working. This seminar will describe the process underpinning the development of national guidelines by a working party convened by the British Psychological Society (BPS) Division of Educational and Child Psychology (DECP). Applications in practice in two contexts will be explored in a series of linked seminars.

Purpose of Study:

To review the involvement and implementation processes within two different Educational Psychology service delivery contexts.

\section{Research Methods:}

Qualitative research methodology was considered appropriate and indeed is increasingly used in applied policy research (Bryman \& Burgess, 1994) as it provides a means of tapping attitudes and perceptions of the features of implementation as experienced by the individuals within a system. This can provide important information about how elements of an initiative operate to inform future planning and system improvement.

Paper 1

Professional supervision: The development of guidelines and competency frameworks

Dr Sandra Dunsmuir

Co-Director, Doctorate in Educational and Child Psychology,

University College London, UK

This paper will address broad issues linked to professional supervision of practitioner psychologists, as well as the topic of EPs supervising staff from other professions. The guidelines contain a comprehensive framework of supervision competencies which aims to support reflection and appraisal of supervisory competence and to assist identification of individual professional development needs. Practicalities relating to the development of supervisor competence and training implications will be discussed.

Paper 2

Using the DECP supervision guidelines to develop policy and practice

Jane Marriott

Principal Educational Psychologist, Medway Council, England, UK

\section{Problem Statement:}

To build supervision competence and capacity within a team of applied psychologists working in challenging multiagency contexts.

Purpose of Study:

To review the use of the the use of the DECP Guidelines as the basis for policy development within a local authority setting in England.

\section{Research Methods:}

Focus group methodology was used i.e. planned sessions where individuals discuss ideas and perceptions focused around a topic of interest (Krueger \& Casey, 2009).

\section{Findings:}

As well as offering supervision to qualified educational psychologists and students, the Psychology Service is increasingly being bought in to provide supervision to a range of other professionals. The need to quality assure the supervision on offer as well as the need to clarify within the service the different functions supervision should fulfil were raised as important issues. The Supervision Guidelines were used as a tool to review and change current policy and practice in relation to the range of supervision activities engaged in by educational psychologists within the service. Application of the competence framework to support self-review and identification of professional development needs by supervisors was another important feature identified.

\section{Conclusions:}

The Supervision Guidelines can be an effective tool when used to support collaborative policy development within public services. 
Paper 3

Changing times and emerging demands for educational psychologists as professional supervisors

Dr Mariam Aljunied

Lead Specialist, Educational Psychology,

Ministry of Education, Singapore

Problem Statement:

The need to build supervison capacity and expertise.

Purpose of Study:

To review the development of a supervision framework and policy for psychologists in the Ministry of Education in Singapore.

\section{Research Methods:}

A series of generative conversations was conducted to facilitate the development of shared understanding of and framework for the supervision of psychologists. The goal of generative conversation process is to provide support and guidelines for participants who wish to collaborate in creating new knowledge within organizations (Topp, 2000).

Findings:

Although relatively young, the psychological service in Singapore has evolved rapidly in the last few years in terms of its expansion of manpower and services to mainstream schools. This sharing will illustrate how the changing landscape in special educational needs support had prompted the need to refine and strengthen the supervision capacity of psychologists in the service. Given the role of psychologists in the Ministry, the articulation of competencies of supervising EPs has to address the different functions of supervision, namely educative, managerial and restorative, as well as outlining the guidelines for effective group and peer supervision. Issues and challenges in the practical implementation of the supervision framework are highlighted.

\section{Conclusions:}

A supervision framework, which clearly articulates the functions, goals, expectations and competencies involved in supervision is helpful to address the capacity building efforts of a newly developed psychological service.

Keywords: Supervision, competence, guidelines, policy development

\section{ELEMENTS IN STUDENTS MOTIVATION IN TECHNOLOGY EDUCATION Ossi Autio, University of Helsinki}

Problem Statement: What are the main elements motivating comprehensive school students to study technology education?

Purpose of Study: The purpose of this article was to determine the elements motivating comprehensive school students to study technology.

Research Methods: The study was carried out as a qualitative case study and the collecting of the material was performed with the help of individual theme interviews. The study group consisted of six 15-16 year old students, which represented six totally different cases in motivation towards technology education.

Findings: The artifact to be made in the school lessons and the freedom of choice had the most significant effect on motivation. Other special elements in motivation: e.g., hobbies, friends, school curriculum, values in society, grandparents, and evaluation, had some effect on motivation among test participants, but proved to be less important in the formation of motivation in technology education in this study. 
Conclusions: Although, we must be careful with final conclusions as the research group was relatively small, we can conclude that there were more signs of intrinsic motivation in technological talents and extrinsic motivation was emphasized in others.

Keywords: motivation; technology education; gender in technology education

The Impact of a Hybrid Degree Program (Face-To-Face and Asynchronous Online) on Student Academic Outcomes, Satisfaction, Enrollment, and Retention: A 3-Year Review

\author{
Dr. Shawn Fitzgerald \\ Ipek Ozer \\ Kent State University (USA)
}

Problem Statement:

While alternative approaches to face-to-face instruction have increased dramatically over the past twenty years, and much is know about the benefits of such approaches (Smith, Clark, \& Blomeyer, 2005), much of the research continues to focus on anecdotal accounts of useful resources for technology integration. Furthermore, much of the research focuses on comparing online formats to face-to-face formats ignore the potential of hybrid courses and programs which combine elements of both instructional formats (see for example, Smith, Clark, \& Blomeyer, 2005). While several recent studies have focused on the effects of hybrid courses, these primarily have focused on k-12 education (Doering \& Veletsianos, 2008; Doering, 2006; Doering, Miller, \& Veletsianos, 2008) and this researcher could not locate any evaluations of hybrid programs (courses offered in multiple formats). Because very little is know regarding the effectiveness of hybrid programs a study of this topic is warranted.

Purpose of Study:

The purpose of this formative evaluation review was to assess the effectiveness of a hybrid masters degree program offered at a large public university in the Mid-West.

\title{
Research Methods:
}

Participants in the evaluation engaged in discussion groups and responded to a series of surveys which asked them to describe their experiences and perceptions of a fifteen month hybrid masters degree program. For the quantitative data, descriptive statistics were used to identify percentages of respondents selecting categories from closed-ended question and a dependent measures t-test was used to determine if there was change in the knowledge and confidence of the participants. To identify patterns and themes in the qualitative data a constant comparative method was employed (Glaser \& Struass, 1967).

Findings:

Findings suggest that the program format was related to improved student knowledge, improved student confidence in talking to others about value-added assessment, data-driven decision making and evidence-based practices, increased enrollment, positively impact graduation rates, and positively reduced time to degree completion.

\section{Conclusions:}

Data collected revealed positive impacts of the program as it relates to student knowledge and confidence in understanding how to use data in their teaching practice. Furthermore, when comparing this program experience to prior experience(s) of completing a program(s) the majority believed the format resulted in a more enjoyable experience, believed they were more engaged in the course work, felt more connected to other students, and believed the experience made them feel that other students in the program were important resources for them during the program.

Keywords: Online Programs, Distance Learning,Teacher Education 


\section{The relationship between headmaster leadership behaviour and teachers commitment in primary school in the district of sarikei, Sarawak.}

\section{Tan Meow Huang (Utara Malaysia University, Sintok Kedah, Malaysia)}

Problem Statement: to identify whether there was existence of relationship between leadership behaviour and teachers commitment in the school as well as toward the working groups in the school. What inspired this study was the fact that there were contradictory findings in past studies and also the study on the subject affecting primary school teachers in Sarawak was surprisingly rare.

Purpose of Study: to determine a) different in standard of commitment between male teachers and female teachers, b) relationship between headmaster instrumental leadership behaviour and teachers commitment toward school, c) relationship between headmaster supportive leadership behaviour and teachers commitment toward school, d) relationship between headmaster participative behaviour and teachers commitment toward school, e) relationship between headmaster instrumental behaviour and teachers commitment toward group, f) relationship between headmaster supportive behaviour and teachers commitment toward group, and $\mathrm{g}$ ) relationship between headmaster participative behaviour and teachers commitment toward group.

Research Methods: There were 125 teachers from 12 various schools participated in this study. They represented two categories of services namely graduate teachers and non-graduate teachers. The questionnaires consisted of 28 items using 5 point scale to measure the response from the respondents for instrumental, supportive and participative leadership, the researcher used measurement developed by Harris and Ogbonna (2001) and whereas to measure teachers' commitments, the commitment scale developed by Celep (2000) was used. There were 8 hypothesis constructed for this study. Independent sample t-test and Person correlation were used to test these hypotheses.

Findings: The result of this study shows that a) there was no significant different between the commitment of male teachers and female teachers, b) instrumental leadership behaviour had positive relationship and significant to teachers commitment toward school, c) supportive leadership behaviour has positive relationship and significant with teachers commitment toward school, d) participative leadership behaviour had positive relationship and significant with teachers commitment toward school, e) instrumental leadership behaviour had positive relationship and significant with teachers commitment toward works, f) supportive leadership behaviour had positive relationship and significant with teachers commitment toward group works, g) participative leadership behaviour had positive relationship and significant with teachers commitment toward group works.

Conclusions: Consequent to this finding, recommendations were offered to further enhance the relationship between behaviour and teachers commitment in schools. 
Inge Raudsepp, Tallinn University

Maie Vikat, Tallinn University

\section{Problem Statement:}

In today's world it is difficult for a small nation to keep its national identity, since globalisation challenges the survival of the model of a small state and nation. How has the dynamics of Estonian society influenced the development and survival of national identity at different stages of history? In Estonia joint singing has had an important role in the development, consolidation and survival of national identity. Changes in Estonian society have raised a question about the influence of joint singing on the development of national identity from the perspective of music education.

\section{Purpose of Study:}

The aim of this study is to find out the influence of joint singing on the development of Estonian national identity during various social formations (1950-2010), taking a cultural-historical perspective.

\section{Research Methods:}

The study relies on the hermeneutic approach which views types of joint singing during different periods in history. The analysis proceeds from the views of an Estonian music pedagogue Professor Riho Päts on the importance of joint singing in the development of national identity through youth's joint singing and song festival. By means of comparative analysis the trends of the content and developmental tendencies of joint singing in the years 1962-2010 are investigated.

\section{Findings:}

The study reveals that joint singing, thus combining the past and the future, still serves the functions as on consolidator of Estonian national identity. In the development of joint singing the 1930s play an important role: Riho Päts laid the basis for the system of music education in Estonia, popularised the role of joint singing at school and in the song festival process. Joint singing acquired a symbolic status in the period of the Soviet occupation and magnified with Estonia regaining its independence.

Conclusions:

In historical-cultural perspective joint singing enjoys an important role in the development of national identity. The proof of that is the 'singing revolution' in 1988, which relied on joint singing, demonstrated the possibility of an efficient way for peaceful social change. Thus the tradition of joint singing is one of the most significant lasting values of Estonian national identity.

Keywords: joint singing, national identity, song festival, music education.

Relationship between cyberbullying and readiness for aggressive behavior in middle adolescence

Jana Marie Havigerova, Ph.D.

Lecturer and researcher in psychology

\section{Problem Statement:}

The study aims to determine whether there is a relationship between cyberbullying and readiness for aggressive behavior in middle adolescence.

\section{Purpose of Study:}

The paper deals with the cyberbullying and aggression in adolescence. There are in the paper defined the basic terms of aggression, bullying, cyber violence and cyber bullying. The theoretical issues and typological approaches to cyber bullying are described: methods and techniques of cyberbullying, types of aggressors. The aim of our study is to explore relationship between cyberbullying and aptitude to aggressive behaviour in middle adolescence (age 12-15). There were tested 197 pupils.

\section{Research Methods:}

Questionary, model situations, hand test. 
There is positive correlation between cyberbullying and readiness to aggressive behaviour in middle adolescence pupils.

\title{
Conclusions:
}

The Czech schools typically work with the aggressor in terms of repression. Our results are one of the arguments for a change of approach in schools: it is desirable to provide early identification of people with greater readiness for aggressive behavior and work with these students in ways to learn the power to manifest a desirable way (eg. Pesso Boyden Psychomotor System), which should support prevention of cyberbullying in schools and treat the whole system.

\section{Keywords:}

Cyberbullying, aggression, adolescence, victim, aggressor

\section{Reflective Teaching Strategies used by Faculty to Enhance Teaching, Learning and Professional Development}

\author{
Dr. Cindy Giaimo-Ballard, Dr. L. Hyatt, Dr. Mark B. Goor, and Dr. Nancy T. Walker \\ University of La Verne
}

Problem Statement: It is well documented that reflective teaching strategies are important for instruction, learning, meeting standards of accrediting organizations, and professional development (e.g., Brookfield, 1998; Drevdahl, Stackman, Purdy, \& Louie, 2002; Killion \& Todnem, 1991; NBPTS, 2009; NCATE, 2009; Rogers, 2001; Schön, 1983, 1987). Zeichner (2007) noted that when educators reflect, they are able to take control over their own continuing professional development while making improvements to the quality of practice. Ostorga (2006) remarked that reflection informs teaching practices, and if programs want to promote reflection, the inclusion of strategies that aim to enhance reflective skills should be developed.

Literature addresses the importance of reflective strategies however, there is little direction given to faculty regarding reflective methods and processes. Further, methods for standards of reflection are not prescribed and it is not clear to what extent faculty describes, understands, and applies the process of reflection.

Purpose of Study: The purpose of this study was to discover the reflective teaching strategies used by faculty to enhance teaching, learning and professional development.

Research Methods: Fifteen participants were selected from universities who met the study criteria. Interviews were conducted using an instrument with semi-structured questions. Participants were asked to define reflection and to describe their reflective teaching strategies. Content analysis was used to discover themes.

Findings: The study data illustrates that the participants value reflection and use it as a strategy to change and improve practices. The findings revealed five reflective teaching strategies used by the study participants: (a) note taking, (b) requesting feedback, (c) setting up checkpoints, (d) reviewing course materials, and (e) adjusting to improve practices.

Conclusions: The conclusions of this study are an indicator that reflection is important for teaching, learning, and professional development. A major finding of this study provides higher education faculty with five strategies that serve as a model for reflection. This study contributes to the literature by offering new perspectives on reflection and will assist universities to meet standards of accrediting organizations.

Keywords: Reflection, Higher Education Faculty, Professional Development, Accreditation

Emotional Intelligence and Academic Achievement in High and Low Achievers School Children in Pakistan

Farah Malik, Ph D and Sultan Shujja

GC University, Lahore Pakistan

The study investigated the relationship between emotional intelligence and academic achievement in high and low achiever children. A stratified sample comprised 204 children; 102 boys and 102 girls of $4^{\text {th }}$ to $8^{\text {th }}$ grades with age $9-13$ 
years $(M=11.48, S D=1.43)$. Children's percentage of marks obtained in their final examination of pervious grades was taken as indicator of academic achievement which was taken from school's records. Urdu version of Bar-On EQ-i: YV (1997) was used to measure emotional intelligence of children (Malik, Humphereys, \& Gul, 2008). A bio-data form was used to obtain information about demographic variables like gender and type of schools (private and government). The measure was administered in small groups of 10-15 students during class time with the help of class teachers. The results indicate that there was significant correlation between academic achievement and emotional intelligence. High achievers and low achievers showed significant differences on overall emotional intelligence. Results further revealed that neither high achiever nor the low achiever boys and girls showed significant difference on total EQ. Children from government schools were high on EQ than private school children but low in overall academic achievement. The results of the current study may help in enhancing awareness regarding association of EQ with academic achievement as well as some cultural specific concepts related to these issues. The results are discussed in the light of specific cultural context of Pakistan.

\section{Keywords: Emotional Intelligence, Academic Achievement, Culture}

\section{Project Based Learning in Computer Science - A Review of More Than 500 Projects} Robert Pucher $^{*}$ and Martin Lehner ${ }^{+}$

${ }^{*}$ Department of Computer Science, ${ }^{+}$Department of Social Competence \& Management Methods University of Applied Sciences - Technikum Wien, Austria

\section{Problem Statement:}

Project Based Learning $(\mathrm{PjBL})$ has become a widely used method of teaching in technical subjects. In the last ten years our experiences with PjPL reveal a very complex picture. On the one hand PPL does have benefits, on the other hand the handling of numerous projects is complex and the evaluation of the results difficult to standardize. Teaching with projects quite often turned out to be chaotic in the perception of students. Remarks, based on the results of projects turned out to be highly depended on the subjective point of view of the teacher.

\section{Purpose of Study:}

Most teachers agree that teaching with PjPL has numerous advantages, especially in computer science. Students are able to apply their technical knowledge, acquire practical skills in programming and get involved into team processes. However, IT projects in teaching environments behave very oddly when one tries apply standardized frameworks onto them. The authors try to identify critical success factors for such projects. Four main reasons could be identified:

1. Students are no experienced project managers and frequently run into problems in early phases of the projects.

2. The motivation of students to finish the project varies between low and extremely high values.

3. Interactions of teachers with students, dependent on factors like specific experience of a given teacher with a specific project, or students who are shy to ask seemingly stupid questions.

4. Origin of the project or project idea.

One of the factors which severely influenced the outcome of the projects turned to be the origin of the project idea [(a) from the environment of the students; (b) targeted by the UAS]. The purpose of the study is to identify differences between these two types of projects.

\section{Research Methods:}

Comparative analysis of marks and other factors concerning the respective origin of the project

Findings:

The result of the study is a framework of "Best practices" for teaching with projects in Computer Science.

Conclusions:

Project Based Learning in Computer Science is of high value for the students, but requires much attention in the organization. Details in the proposed paper. 


\title{
THE RELATIONSHIP BETWEEN THE LEVEL OF ACCURACY, FLUENCY AND COMPLEXITY OF SIMULTANEOUS INTERPRETATION \\ Niloufar Shahmirzadi \\ Tehran University, Faculty of Foreign Languages- \\ Center of Public Education-English Department
}

\begin{abstract}
Setting the standards for interpretation assessment has usually been problematic for authorities, theoreticians, and most commonly instructors. It is often difficult to tell the difference between interpretation evaluation, criticism, and assessment due to hardships of bridging the gap between theory and practice. The main aim of the present study is to create a rubric against which interpretation can be assessed. To this end, the accuracy, fluency and complexity of simultaneous interpretations (Persian to English) produced by four professional interpreters, working at the Islamic Republic of Iran's broadcasting International Network, were analyzed. For the analysis of the corpora, the researchers adapted three frameworks for evaluating the accuracy, fluency and complexity of oral interpretation. Based on the results obtained, the researchers found a noticeable negative correlation between the complexity and fluency of interpreter performance. Interestingly, among the four interpreters, the one with the highest accuracy rate scored the highest fluency results and the lowest complexity and lexical richness ranking. Also, the interpreter with the highest level of lexical richness produced the lowest level of accuracy and did not fare very highly in the overall ranking. Besides, the accuracy, fluency and complexity of all the four interpreters showed almost consistently a general downward trend from the beginning to the end of the 30-minute period. Finally, a high correlation was observed between the analytic scoring of interpreter performance on the one hand, and the holistic ratings provided by three experienced raters on the other. The results of the study support some of the research findings in the field that found a negative correlation between complexity and fluency in task performance. The findings also support the standard practice of limiting an interpreters' task to less than 20 minutes at a time, due to a decline in most of the major indices of performance. The high correlation between analytic and holistic ratings of interpreter performance corroborates the very idea of utilizing analytic scales in order to increase objectivity, especially in the absence of experienced raters.
\end{abstract}

\section{Keywords:}

accuracy, complexity, fluency, interpretation assessment, performance analysis, simultaneous interpretation

The Enabling Constraints of Building an Assessment Pedagogy Don A. Klinger, Lyn M. Shulha, Rebecca. A. Luce-Kapler, \& Stephen Elliott

\section{Introduction}

Teachers' assessment practices can influence students' learning by supporting instruction and, more importantly, by developing students' self-monitoring skills and regulation of their learning. Contemporary notions of classroom assessment have moved beyond the traditional concepts of formative and summative assessment. These contemporary approaches require teachers to reconceptualize their orientation towards teaching and learning.

\section{Purpose of Study}

Our ongoing work highlights the challenges in helping pre-service teachers incorporate current conceptions of classroom assessment. Foremost are their own assessment experiences and belief that as beginning teachers, they only require a teaching and assessment toolbox. As a consequence, pre-service teachers struggle to move beyond simplistic notions of learning and assessment. The purpose of our research is to examine how using the concept of "Enabling Constraints" with beginning teachers will help them to better understand the complexity underlying contemporary teaching and assessment practices. Enabling constraints are based on the foundation that learning is not a matter of accumulating information but rather is a complex process that incorporates a diversity of experiences. 
Surveys, focus groups, and assessments of pre-service teachers' thinking and reflections about classroom assessment collected as part of in-class assessment activities will provide the data for our findings. The analyses to be completed in the Spring of 2011 (including Repeated Measures ANOVA and thematic analysis of qualitative data) will focus on these pre-service teachers changing conceptions of classroom assessment, teaching and learning.

\section{Conclusions}

Our intention is to create an instructional context where pre-service teachers are motivated to go beyond a simplistic, primarily instrumental orientation towards teaching and classroom assessment given the structural constraints of a Bachelor of Education program. If these pre-service teachers can begin to understand the complex relationships between teaching and assessment, they will be better prepared to develop an assessment pedagogy that integrates assessment practices and theories into their teaching and learning. We believe our findings will provide insights into a pedagogy that creates a professional learning approach to developing classroom assessment competency, and highlight the central teaching and assessment concepts beginning teachers need to value.

Keywords:

Assessment and Evaluation, Teacher Education, Professional Learning

\section{Constructivism Behind the Techniques of Problem-Solving: the process of doing things in Children's Literature} Hsing-chin Lee, National Taipei College of Business

This paper proposes the use of Arthur Ransome's Swallows and Amazons as extensive reading material in addition to what is used for conventional English teaching in Taiwan. It argues the use of literature for purposes of teaching problem solving. It is intended as a report of how problem-solving skills are learned by using the novel to the teachers in Taiwan. Examples of problem-solving skills are extracted from the novel and analyzed. A comparison of West and East in problem solving is also made to tackle the difference between the two cultures. Work on establishing language and literature approaches in foreign and second language teaching to engage students' analytical ability is discussed. In particular, teaching problem-solving techniques in accordance with observing the process of doing things through the reading of the novel Swallows and Amazons. The Author reviewed some examples underlying the problem-solving techniques. They are extracted from the description of the process of doing things detailed in the novel. Pedagogy of constructism is used to analyze and justify the writer's argument in emphasizing the value of linking the techniques of problem solving and the process of doing things in a Taiwanese vocational college.

Keywords: problem-solving, children's literature, Swallows and Amazons, constructism Problem Statement:

It argues the use of literature for purposes of teaching problem solving.

Purpose of Study:

To justify the writer's argument in emphasizing the value of linking the techniques of problem solving and the process of doing things in a Taiwanese vocational college.

\section{Research Methods:}

Qualitity Research

\section{Pre-service teachers` beliefs about evaluation}

\section{Qiaoyan He, Martin Valcke \& Antonia Aelterman}

Department of Educational Studies, Ghent University

Impacted deeply by the many years of experience as learners, pre-service always keep their educational beliefs as what evaluation is when they step into the normal university. Meanwhile, instructed by the theory of progressivism and traditionalism, fifty-six Chinese pre-service teachers from three four-year teacher normal universities in this qualitative study were interviewed by writing, group and individual interviews about their evaluation beliefs through two perspectives: student-centered(PSSC) and teacher-centered(PSTC). The analysis yielded five areas(who, when, how, why to evaluate students and what to be evaluation beliefs) of evaluation belief structure with various subcomponents: content, reasoning, applications and procedures. Yet, all fifty-six pre-service teachers prone to compromise their beliefs in the future teaching practice. Implications for reformers, educators and pre-in-service teachers include the need to provide a firmer grounding in teacher training, to explore the reliability of evaluation belief systems, and to develop feasible instrument based the analysis of interview data to confirm pre-service teachers` evaluation beliefs on a big scale. All of these endeavors are paid for the new educational policies carried on 
smoothly and descending the confliction among different beliefs from reformers, researchers and pre-in-service teachers.

\section{Keywords:}

Assessment of Competence; Beliefs; Primary school

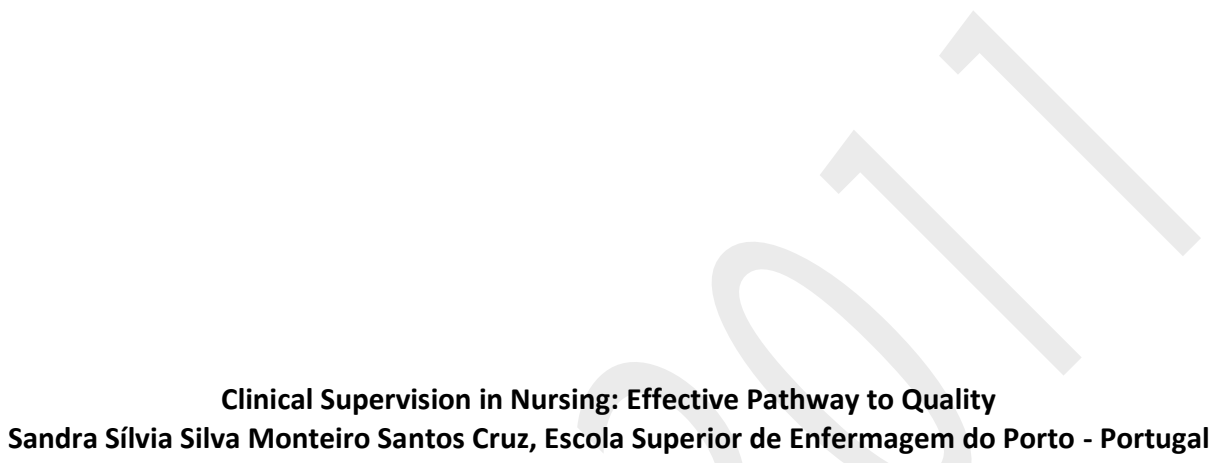

Problem Statement: Nurses need to have a great flexibility and be prepared to complex and demanding clinical situations. According to Hyrkäs \& Lethi (2003), the effects of clinical supervision on the quality of care, are a key aspect in improving the quality and they were defined as a targeted area by the World Health Organization. Nowadays, in Portugal, we are increasing our experience and research on clinical supervision in nursing. So, we decided to carry out a research which problem was: what clinical supervision in nursing model best supports the nurses' professional practice?

Purpose of Study: The aim of this study was to develop a clinical supervision in nursing model that best supports the nurses' professional practice.

Research Methods: We carried out an exploratory, descriptive and longitudinal study. This research was done in several Health Care Institutions. We used a focus group to build the model. The nursing director had the responsability to select the units for its implementation. We interviewed all chief nurses and the nursing director with the aim to evaluate the model and we used the Manchester Clinical Supervision Scale ${ }^{\circ}$ (MCSS ${ }^{\circ}$ ) to evaluated it as well.

Findings: This study grew in several wards of an Hospital Centre. 61 filled out questionnaires were obtained. MCSS Cronbach's alpha value for the total score was 0,938 and in the sub-scales were 0,522 (Personal issues) and 0,899 (Improved care/skills).

Conclusions: Effective evaluation of clinical supervision is a tool for quality in nursing. Manchester Clinical Supervision Scale evaluates the quality and effectiveness of the supervision provided and the supervisees' opinion of the effect of clinical supervision in his/her professional development, improvement in skills, time for reflection and the quality of the supervisory relationship. These results pointed out the positive effects of the clinical supervision in nursing model that we have created.

Keywords: Effects, Quality, Clinical Supervision in Nursing Model, Manchester Clinical Supervision Scale 


\section{ENTERING SCHOOL: THE DRAMA OF FAMILIES WITH DEAF CHILDREN Cátia Marlene Silva Monteiro Santos, Universidade Lusófona do Porto - Portugal}

Problem Statement: Hearing loss, in a child, can impair his/her normal cognitive and social development. (Plaja et al, 2006). Therefore, a deaf child who does not receive proper follow-up can acquire irreversible communicative disorders, thereby fostering the adoption of maladaptive and anti social behaviors (Goldfeld, 1997). Thus, the beginning of school may become a cause of stress, leading to feelings of anxiety and insecurity in the child, family and school community, so the question is: what is the Portuguese sign language interpreter role as an element of the educational team in an inclusive school?

Purpose of Study and Research Method: Through a literature review this paper aims, by emphasizing some propositions of deaf culture and deaf identity, to understand the role that he/she can represent in the school organization, and how can it be a facilitator for the stress reduction for the children and their relatives, as well to improve their knowledge and skills.

Findings: Given the multicultural context of our society, school is a place where the "difference" converges. However, many professionals are not sufficiently prepared to carry out their duties with an audience so diverse. Many teachers don't know what to teach and how to do it, so they can facilitate the participation of their deaf students.

The interpretation / translation in sign language is no easy task. Garinello, et al (2008) explain that "between one language and another there is a person who gives directions in a language and tries to be felt in another" (p.67).

Conclusions: This Professional is a resource for the initial contacts with the deaf community as well the promoter of communication between family and school. The sign language interpreter with the family can create groups of support parents to help their children to improve and develop skills (Bittencourt \& Hoene, 2009), and additionally it's a way to reduce child and parents stress.

Because the Portuguese sign language interpreter is a professional who works between cultures, we point out the fact that he/she can't be reduce to the act of translation, he/she is characterized by the complexity of his/her role, deepness and dimension of his/her actions.

Keywords: Deafness; Family; School; Sign Language Interpreter; Support 


\section{Post-Secondary Attainment in a First Nations Community over a 25 Year Period \\ Lorraine Frost, Nipissing University \\ Ron Common, Sault College}

\section{Problem Statement:}

In 1985, we conducted a study of educational attainment in a First Nations (Native North American) community. At that time, we found that very few members of the community continued to college or university, and of those who did, most dropped out. In 2010, we had the opportunity to return to this community and examine post-secondary attainment again. During the intervening years, many changes have occurred in Canada in the education and general circumstances of First Nations persons. Notably, local control of education has resulted in education by and for First Nations people being determined in the community and not by external federal government personnel. Support for First Nations business development has resulted in more employment opportunities in some communities. Local control of health and other services has also resulted in more support for individuals in some First Nations communities, including the community we have studied. We wanted to determine if post-secondary attendance and graduation rates had changed during the 25 years since we conducted our original study.

\section{Purpose of Study:}

The purpose of the study was to determine if post-secondary rates of attendance and graduation had changed during the 25 years since we conducted our original study, and to compare these rates to those of Canada in general. We also wanted to determine specific information such as types of post-secondary programs chosen, high school graduation status and years between high school education and enrollment in post-secondary education, male/female participation and success rates, age at enrollment in post-secondary education, We were particularly interested in mature students (mature students are those who have not completed high school and have either been out of school for a year or have attained the age of 21 years) as our previous research had determined that most First Nations post-secondary students were mature students and the pressures of family and financial responsibilities were an important factor in attrition from programs of study.

\section{Research Methods:}

Data were gathered by the First Nations post-secondary education office members from their records. The records for all students attending post-secondary institutions for the years 2005-2010 were used and the progress of individual students was followed over this time frame. The following data were collected for individuals attending post-secondary education during the five year period: date of birth, sex, year the student left high school, high school level completed, program of study, year to year status (i.e. still enrolled, dropped out, graduated), expected date of graduation, and actual date of graduation.

\section{Findings:}

We found that post-secondary participation and graduation rates have improved considerably since our original study in 1985. Drop-out rates have been greatly reduced. Graduation rates are approaching those of all students in Ontario, the province in which the First Nation is located. Many more students are attending post-secondary education after first having completed high school, rather than attending as mature students. We also found that the performance of mature students was similar to that of students who had graduated from high school.

\section{Conclusions:}

Compared to the rest of the Canadian population, and compared to the performance of community members 25 years ago, the members of the First Nation under study have improved their post-secondary participation and attainment levels quite dramatically. We concluded that local control of education has been a factor in this improved post-secondary attainment.

Keywords: post-secondary education, First Nations students, local control of education, First Nations post-secondary participation and attainment

\section{NATIONAL POLICIES ON EDUCATION AND STRATEGIES FOR INCLUSION; CASE STUDY - ROMANIA Assoc. Prof. PhD Alois Ghergut, Faculty of Psychology and Education Sciences University „Alexandru loan Cuza” lasi, Romania}

Problem Statement: In last decades more countries have encouraged the idea of inclusive society, open and flexible to the human diversity phenomenon. In this context the implementation of inclusive policies to integrate students with special educational needs in schools calls actions from different fields: psychology, pedagogy, sociology, social work, nursing, organizational, legal, political, etc.

Purpose of Study: An analysis of the nationally situation has revealed a number of strands in the improvement and development of educational services for integration of children with special needs and disabilities in normal schools. 
In this context our study emphasizes the evolution, strengths and weaknesses of inclusive programs developing in the Romanian education system.

Research Methods: Research methods are based on case studies and analysis of official documents elaborated by the Romanian state authorities.

Findings: Gradually and in differing degrees, our normal schools have tried to open and to adapt the educational offer in relation with the new directions of change in educational activities (the result of integration and inclusion programs). Also, they attempted to develop partnerships with special schools, to access sources of information and continuous training of teachers to be able to adapt at specific requirements and challenges of inclusive schools.

Conclusions: Like other countries, education of children with special needs in Romania on inclusive schools it's the consequence of education policies from the last years, after Salamanca Statement and Framework for action on special needs education. Another hand, inclusion and integration remain a controversial concept in education and many discussions about inclusion or integration should address several important questions for educators and specialists in education.

Keywords: inclusion, special education, children with special needs, policies on education

\title{
The influence of musical games and role-play activities upon primary school children's self-concept and peer relationships
}

\author{
Kouvava $^{1}$, S., Zioga ${ }^{1}$, S., Karali ${ }^{1}$, C., Vlachos ${ }^{1}$, K. and Christopoulou $^{2}$, E.
}

${ }^{1} 4^{\text {th }}$ Glyfada's Primary School, Athens, Greece

${ }^{2}$ LEA of $4^{\text {th }}$ Division of Athens, Greece

The present ongoing study examines whether musical games and role-play activities can enhance children's self-concept and ameliorate their peer relationships.

Self-concept, a fundamental component of personality development, refers to the set of knowledge, attitudes and perceptions we have about ourselves and the characteristics or attributes we use to describe ourselves.

Children's peer relationships are essential to their development, since they contribute not only to cognitive growth, but also to the acquisition of social values and skills, necessary for social interactions.

Participants were 11 boys and 9 girls, between 7 and 8 years of age, attending the second grade at an inclusive primary mainstream school, of a suburb of Athens. The particular classroom was selected, because the children who attend it present poor interpersonal skills and relationship difficulties with teachers and peers (ranging from social isolation and loneliness to aggression). 
Questionnaires of self-perception, standardized in Greek population of the age-group of our sample, were administered to 20 primary school children. The self-concept questionnaire has 4 sub-scales, where children's perceptions of their academic achievement, their relationships with peers, their physical appearance and their relationship with their parents can be measured. In addition, a social network mapping was conducted and sociometric scores were collected, in order to form an explicit idea of whom children perceive as their friends.

The project lasted 8 weeks and involved three teachers of our school. During the first 5 weeks, a 30-minute session of musical games twice a week took place, followed by a 3-week equivalent sessions of role-play activities. There was a month's interval between musical games and role play activities, in order for an external examiner to evaluate the outcome of each type of interference. Both musical games and role-play activities were highly structured and aimed at offering children successful experiences, motivation, empathy and opportunities to express their thoughts and feelings.

The results of this study revealed that musical games and role-play activities cultivated children's social development and skills. However, the lasting effects of this project have not been estimated.

Keywords: musical games, role-play activities, self-concept, peer relationships

Knowing how to learn and how to teach motivation: Contributions from Self-Regulation of Motivation to more a effective learning

Paula Paulino \& Adelina Lopes da Silva

University of Lisbon - Psychology Faculty (FPUL)

Fundação para a Ciência e Tecnologia (FCT)

Problem Statement:

Given the importance of school achievement in the promotion of a more favourable future for youth, it becomes crucial to understand the factors that influence academic success. Previews studies refer that students can regulate their motivation to learn [Self-Regulation of Motivation (SRM)] and this process has an impact on achievement and school learning. Recently, motivation researchers state that students need to self-regulate their effort and their motivation for learning. In other words, students must initiate activities that set the scene for learning, assign value to the learning task, and motivate themselves to actually get started on learning assignments and sustain effort till the task is completed; more specifically students must regulate their motivation for learning process.

Purpose of Study: The present work explores SRM process at adolescence through three studies. Our purpose is to study the relationship between student's motivational beliefs and their use of motivation regulation strategies to increase and sustain their effort and persistence for academic activities. Within motivational beliefs, research has identified the extent to which students value the material they are learning, student's perceived self-efficacy and the goals they adopt for wanting to complete academic tasks, as ways to understand student's motivation and persistence to academic activities. 


\section{Research Methods:}

On the first, a group of seventh to ninth grade students will complete a self-report questionnaire, assessing determinants of SRM (i.e. goals, task value and self-efficacy expectancies) and SRM strategies. On the second study, will be accomplished two focus groups with teachers of the same grades, exploring educative practices to promote SRM. Finally, based on the above studies is our goal to elaborate SRM program to empower adolescent students to engage in more positive, self-motivating cycles of learning.

\section{Findings:}

Overall we expect this work to be a contribution to a better understanding of SRM in the global process of selfregulated learning.

\section{Keywords:}

Self-Regulation of Motivation, Students, Adolescents, Goals, Task value, Self-efficacy

Sources of FNE Among First Year LMD Students of Abderrahmane Mira University

Nadia Idri

\section{Problem Statement:}

In this research, we have established a link between evaluation in EFL and Foreign Language Anxiety (FLA). This psychological construct is an educational crisis from which we have selected a more particular problem related to its varieties; Fear of Negative Evaluation (FNE). Our problem, then, is stated as follows:

The central problem of the present research project is to determine how can negative evaluation related to peers interaction, the foreign language, the teacher's error correction, assessment and testing experienced by first year LMD students learning EFL at Béjaia University cause fear, and how it can be handled to reduce the felt anxiety.

\section{Purpose of Study:}

The aim of this study is to check whether the causes mentioned in the problem are the anxiety triggers (sources of FNE) or not and to which extent. Our focus is also made on the learners' perception of this fear and their learning strategies they use to overcome this kind of fear.

\section{Research Methods:}

To collect data, we have gone through two phases. First, we used Horwitz, Horwitz and Cope's (1986) FLCAS to diagnose the existence of the feeling of anxiety in our learners as part of the quantitative investigation of our study. Here, 108 randomly chosen first year university students participated in the survey. The second phase data collection is the semi-structured interview. Eight volunteers participated and helped us understand the sources of FNE from a student standpoint. Hence, our study is based on mixed methods relying on both quantitative and qualitative data.

\section{Findings:}


From the questionnaire, we found that many of the learners suffer from FNE. Yet, the interview showed many sources of FNE. These can be summed up in: instructor and peers interaction, low language proficiency, low self-confidence and previous negative experiences.

\section{Conclusion:}

To conclude, we may say that this study has shed light onto potential sources of FNE in our classes. In fact, we found that this phenomenon exists in our classes. Thus, this research has not only confirmed the existence of FNE but also revealed its causes. Therefore, this may give hints for future researches in order to try to identify and cope with it.

EFL, LMD system, FLA, FNE, Interaction

Keywords:

Dyslexics' acquisition of noun infection in the Greek language. A follow up study.

\section{Grammenou Anastasia}

Democritus University of Thrace

Problem Statement: Inflection morphology modifies verbs, nouns and adjectives in the Greek language. Trianatfyllidis (1932) identified thirty two types of nouns which are differentiated by the way the three types of cases (nominative, genitive and causative) are formulated in the singular and the plural number. Spelling of correct noun infection is regarded to be problematic for the elementary school children due to different type of allomorphs the Greek language has, e.g. - $\mathrm{L}$ /i/ (nominative case, singular number of neutral nouns) and -ol, /i/ (nominative case, plural number of mesquline and famine nouns).

Purpose of Study: This paper describes the rate of acquisition of noun inflection morphology by dyslexics in the Greek language.

Research Methods: Twelve dyslexic children were tested at the end of Grade 6 and eighteen months later. They were given a battery of non standardized tests which required identification of noun inflection in the nominative and genitive case of singular and plural number. Those infections were either grammatically correct $(N=10)$ or inconsistent, with regard to word stress $(\mathrm{N}=8)$, orthography (allograph substitution of /i/, /o/ and /e/ sound) ( $\mathrm{N}=11$ ) and combination of the two type of inconsistencies $(\mathrm{N}=3)$.

Findings: Dyslexics' performance was above 70\%, in the detection of orthographic inconsistencies of masculine and neutral inflections, in real words, and was slightly improved at time 2 testing. On the other hand, detection of orthographic and stress inconsistencies were found to be at the chance level for famine nouns. Dyslexics' performance in nonwords improved over time $1 \& 2$ testing with regard to the detection of stress violation in neutrals and famine inflections and the orthographic inconsistencies detection of famine pseudonouns. Moreover, dyslexics were more able to detect correct types of nonword inflections at time 2 testing.

Conclusions: Findings of the present study clearly demonstrate that dyslexics are successful in decomposing polymorphematic words into component morphemes when they have to focus only in one factor e.g. orthographic violation. What seems to be problematic during this procedure is the number of possible allomorphs each infection has. So, when it comes to the genitive case of the plural number for neutral and masculine nouns, in which only two alternatives are possible, dyslexics are above $70 \%$ correct. On the contrary, famine nouns have five possible allographs to represent the genitive singular case and dyslexics acquire this skill only in early adolescence.

Inflection morphology, dyslexia, Greek language, spelling

\section{Keywords:}


The competence of learning to learn in vocational training: Promoting critical thinking of the trainer of trainers, mediated by reflexive portfolio.

Maria Joana Inácio (PhD student) Institute of Education, University of Lisbon

Maria Helena Salema (Supervisor) Institute of Education, University of Lisbon

\section{Problem Statement:}

Developing the competence of learning to learn in the context of training practices, including training course of trainers has, among others, the aim of promoting critical thinking trainers of trainers, as metacognitive tutors. The reflective portfolio is constituted as a tool for supervision of professional practice and as a potential training program in the context of training of trainers. We aim with this study to develop critical thinking of the trainer of trainers, mediated by reflexive portfolio, which fosters the development of learning to learn competence in professional practice.

\section{Purpose of Study:}

In the current context of education and adult education in Portugal, in general, and vocational training, in particular, it is pertinent to understand the practices of their players, including the trainers of training courses for trainers. The design, testing and evaluating a training program that aims to promote competence of learning to learn is the underlying assumption that practices of adult education and training is needed to develop strategies that encourage learners the ability to self-regulate the learning process. Accordingly, the portfolio will be an instrument of selfevaluation and joint evaluation between the researcher / supervisor and trainers. This will enable planning, monitoring and evaluation of practices, beliefs and attitudes of his players, with an underlying model of collaborative and reflective participation.

\section{Research Methods:}

Develop an action research using a qualitative approach of interpretative nature. As participants include the researcher as a trainer and tutor training course for trainers and another trainers of trainers. The questionnaires, design, testing and evaluation of training program titled portfolio as a regulatory instrument of learning the trainer of trainers, and the use of blog as daily training of the researcher, are the tools of data collection.

\section{Findings/Conclusions:}

With the PhD project in its early stages, is intended to present results from the questionnaires to trainers of trainers that perspective a characterization of the functions of the trainer as adult educator, features professional practices and strategies of self-regulation conveyed in their practices.

Keywords: Learning to learn, Critical Thinking, Trainer of Trainers, Supervision and Guidance of Professional Practice, Education and Training of Adults. 
Problem Statement: Internationally there is a shift from an emphasis on solely summative assessment to ongoing classroom assessment that enhances student learning. Seminal research shows that assessment for learning (AfL) improves student achievement (Black \& Wiliam, 1998). Yet, assessment experts lament that educators are not implementing AfL. Why not? How can educators be motivated? Does AfL connect with what they already know and value? How?

Purpose of Study: The purpose of this study is to explore the best assessment experiences of elementary and secondary teachers and administrators and what they value about assessment.

Research Methods: This is a three year qualitative study in 2 schol boards in southern Ontario, Canada. This study took place just before the formal implementation of a new assessment policy and when all boards knew the direction of the Ministry mandates. One hour interviews were conducted with all participants (elementary and secondary teachers and administrators) in Year $1(n=37)$ and Year $3(n=26)$. In Year 2, six focus groups were conducted. Each year participants were asked to describe their most positive experience of assessment and what they most valued about assessment. Data were analysed for categories and themes (Creswell, 2008).

Findings: Participants best stories aligned with the philosophy embedded in AfL and included some of the best "strategies" of AfL such as self-assessment and ongoing feedback without grades. Some stories offered unique methods of classroom assessment. Participants valued student growth and developing relationships with students. The greatest obstacle was the predominant mark culture.

Conclusions: These stories add to the knowledge base of AfL as called for by Black and Wiliam (2009, 2010). Understanding what positive assessment practices look like through living examples of both teachers and administrators can help educators see themselves in the process. Given that educator values were aligned with AfL practices, this insight may motivate teachers and educators to implement AfL more consciously.

\title{
Research funded by Social Sciences Research Council of Canada
}

Keywords: Assessment for learning, classroom assessment, motivation

\author{
INCREASING THE QUALITY OF LEARNING TROUGH CHANGES IN MOTIVATION \\ Duarte, A. \& Figueira, A.
}

Problem Statement: Students' approaches to learning theory (SAL) states a significant relation between variables like motivation and strategies of learning with the quality of learning. Studies in this area show that students with a deep approach to learning (i.e. intrinsic motivation and deep learning strategies) tend to to have a higher quality of learning, as measured by the SOLO taxonomy (Biggs, 1987; Biggs \& Collins, 1982). Considering this fact, a problem is to access the possibility of experimentally enhancing intrinsic motivation in order to facilitate an increase in the quality of students' learning.

Purpose of Study: The present study has the aim of testing a procedure to enhance the quality of learning, by changing learning motivation through cognitive restructuring 
Research Methods: Case study; Single case experiment; Qualitative analysis of learning products; Content analysis of interview

Findings: The results showed an increase in the quality of the learning outcome as measured through the SOLO taxonomy, in conformity with approaches to learning theory.

Conclusions: Results demonstrate the possibility of changing motivation to learn through cognitive restructuring with a consequent impact on the quality of learning. The quality of the learning product increased with the intervention on motivation - this supports the relation between the later and the former variable but also the efficacy of cognitive restructuring on changing academic motivation.

Keywords: Approaches to Learning; Cognitive Restructuring, Motivation; Quality of learning

Achieving Maturity In Higher Education Administration: Discretion, Conscience and Practical Wisdom

Corresponding Author: Michael Manley-Casimir, Professor of Education, 905-688-5550, x3710

Brock University, 500 Glenridge Avenue, St. Catharines, L2S 3A1, Ontario, Canada

The administration of post-secondary institutions requires mature leadership from those charged with the responsibility of providing that leadership. The argument in this paper is that such leadership requires evidence of good judgment, ethical sensibility and practical wisdom - what Aristotle referred to in the Nicomachean Ethics as phronesis. The purpose of this paper is to explore the connections between these elements of administrative behavior on the part of post-secondary administrators.

The research approach deployed uses conceptual analysis of discretion, conscience and practical wisdom as necessary and related elements of a continuum yielding maturity in educational leadership. Common to these elements is the role of experience and reflection, leavened by knowledge.

The basis for the analysis is a substantial body of literature drawn from studies in various social science disciplines that describe and document the use of discretion and ethical deliberation in organizational life. Such disciplines include psychology, criminology, higher education, administration, inter alia.

In simple terms, the conclusion is that the use of judgment (together with experience in its use) is the foundation of acquiring maturity in administrative decision-making, that such use leads to an appreciation of the ethical nexus in such decision-making, which in turn yields - over time and through experience and reflection - a sense of practical 
wisdom. Maturity requires the acquisition and development of such practical wisdom which Aristotle called phronesis. The paper, thus, is an explication of a theoretical position that is philosophically grounded but psychologically relevant to our understanding and practice in leadership in higher education.

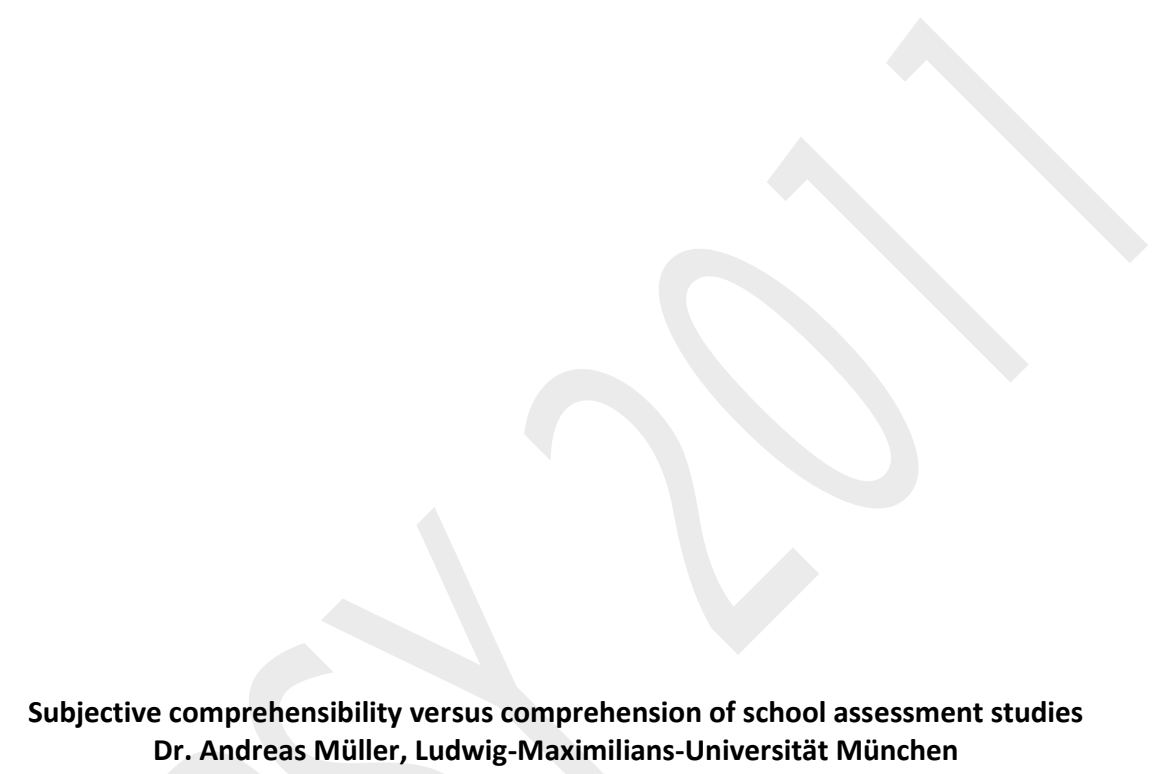

In the last years (in the course of the PISA and TIMSS studies) quantitative school assessment in various forms has gained increased recognition worldwide. This is particularly true for Germany; here external statewide surveys have become compulsory for several class levels since 2008. The results are reported back to participating schools and teachers. This feedback process is connected with the hope to initiate or accompany qualitative improvements at schools.

The comprehension of reported results after school assessment studies can be considered an initial barrier for further reception. So far, studies regarding the reception of feedback have (at least in Germany) just focused on the subjective comprehensibility of submitted results. Thus, predictions about the actual comprehension of the reported data are limited regarding their validity.

The present study has been conducted with $\mathrm{N}=209$ students who want to become a teacher. The comprehension of feedback is operationalised by means of the estimated need for action and the comparison with a standard solution which has been generated ex ante. The study indicates that the recipients understand the feedback only rudimentary. The deviation to a social benchmark influences the appraisal more than the statistical significance of the discrepancy. Over all, the correct interpretation depends on the complexity of the presented content. The subjective estimation of the comprehensibility does not permit valid conclusions about the actual comprehension of the data. This applies in particular to complex parts of the written feedback report.

The findings indicate that surveys regarding the reception of feedback with questions to assess the subjective comprehensibility should be complemented by instruments that operationalise the real comprehension. In practice social standards of comparison should only be reported if they differ significantly.

Keywords: school assessment studies, feedback, comprehensibility, comprehension 
A Study of the Effects of Music Therapy on Sustaining attention of Children with Attention Deficit-Hyper Activity Disorder

\author{
Leila sadat Karimi
}

M.A. student, Payamenoor University, Tehran, Iran

Hossein Zare

Associate professor, Payame noor University, Tehran, Iran

Maryam Parsanejad

M.S. Cell \& Mollecular Biology Uottawa \& Medical student, Irland Medical School Bahrain Brunch

Problem Statement: Such researches aid to appreciate the different methods used in treating children with ADHD, as well as the application of various techniques in musical therapy.

Purpose of Study: The aim of this research was to study of the impacts of the music therapy on Sustaining attention of children with attention deficit- hyper activity disorder in years 2009-2010 in Shiraz.

Research Methods: forty male students from grade four and five (elementary school) with attention deficit- hyper activity disorder were selected based on DSM-IV diagnostic methods and randomized to case and control groups, using duster random sampling. A series of musical activity interventions (including a music therapy program based on Orff-Schulwerk's theory) were performed on the students of the case group. This study was performed for twelve sessions, ninety minutes per session. To assess their Sustaining attention, both groups underwent continues performance test (CPT) which was available as software, before and after the interventions. The multi variable variance analysis and dependent T-test were used for data analysis.

Findings: Our results demonstrated that there was a significant difference in the correct score $(p<0.002)$ and the Omission errors (indicative of impulsivity) $(p<0.02)$ in the pre-and post-intervention averages between the two groups. Although the difference in the the level of the Commission errors (indicative of ignorance to stimulation) was higher in the case group and Commission errors was decreased in post-intervention scores compared to pre-intervention, the results were not found to be statistically significant.

\title{
Conclusions:
}

Our data suggested a positive impact of music therapy on the attention of children with attention deficit-hyper activity disorder. The rhythmic and musical acts lay the ground for the focused and motivated activities in children with ADHD, aiming to improve the level of awareness and further increase in their attention threshold.

\section{Keywords:}




\section{Evidence for the importance of popularity, rational thinking style and nonverbal sensitivity to achieve academic success Loredana, Ivan}

University of Bucharest (ROMANIA)

Problem Statement: Generally speaking, college students' social network behavior has been positively associated with their academic achievements (Thomas, 2000; Steinfield, 2008). More specific analysis presented the importance of peculiar ties in achieving academic success, as friendship, communication or adversarial ties. Cognitive Experiential Self Theory proposes a relation between different type of thinking - rational and experiential - and individual's behavior. Several researches (e.g. Sladek et al. 2008) have investigated the relationship between the two ways of information processing and knowledge, proving that rational style of thinking positively influence the level of acquisitions in different areas of activity. Studies connecting nonverbal sensitivity with academic success (Nowicki \& Marshall, 1992), especially on children, have produced evidence for the association of subjects' nonverbal decoding abilities, popularity, and academic achievement.

Purpose of Study: To investigate wether popularity in the academic related networks and the way students proccess information - rational or experiential (Pacini\& Epstein, 1999) predict their academic achievements. Additionally, the role of nonverbal sensitivity is discussed in relation to rational or experiential information processing and popularity in different types of peer networks. This research is financed by FSE POSTDRU 62259 program.

Research Methods: First year college students $(\mathrm{N}=72)$ completed a sociometric questionnaire on both academic related ties and non-academic related ties in order to assess popularity in peer social networks. Popularity indicators, using Social Netweork Analysis were correlated with self-reported measures of their thinking style (REI), their scores on a nonverbal sensitivity test (PONS) and the academic grades in the end of the semester.

Findings: The level of popularity in academic related ties predict the total grade in the end of the semester. Being popular in the 'information' social network proved to be a predictor for the academic achievements. Rational thinking style positively correlates with the academic grades and the ability to decode nonverbal cues positively correlates with the popularity in the 'support' network.

Conclusions: Findings support the idea that individual's way to process emotional and rational information as well as relational factors contribute to academic achievement not only on primary and secondary education, where learning is mainly an interactional process, but also on tertiary education. 


\author{
PERSONAL AND PEDAGOGICAL INTERACTION FACTORS AS DETERMINANTS OF ACADEMIC ACHIEVEMENT \\ Ana Paula Cardoso, Instituto Politécnico de Viseu \\ Manuela Ferreira, Instituto Politécnico de Viseu \\ José Luís Abrantes, Instituto Politécnico de Viseu \\ Claudia Seabra, Instituto Politécnico de Viseu \\ Cesário Costa, Instituto Politécnico de Viseu
}

\title{
Problem Statement:
}

This study intends to relate self-esteem, teacher-student interaction, interaction between students, and learning performance and its direct and indirect relationships with academic achievement.

\section{Purpose of Study:}

The dynamics of interaction in the classroom and self-esteem of pupils in schools are considered essential to understand the quality of student learning. Despite the complexity of interpersonal relationships, the empathy is considered one of the most appropriate to establish an effective climate of the classroom. Thus, this study seeks to analyze the interaction between the key players in the pedagogical act, and students' self-esteem and the influence these factors have in creating a productive learning environment and therefore a greater academic achievement.

\section{Research Methods:}

This is a quantitative research that aims to analyse the relationship between constructs like academic achievement, learning performance, teacher-student interaction, student-student interaction and self-esteem. Lisrel software was used to develop the Structured Equation Model of academic achievement determinants. The constructs addressed are measured through existing scales, which were used in prior educational studies and have been shown to exhibit sound psychometric properties.

\section{Findings:}

An empirical study was undertaken, involving a representative sample of 1986 high students. The sample includes $38,5 \%$ male and $61,5 \%$ female students, with ages between 14 and 22 years old, of the different levels of secondary education; $78 \%$ of the students failed at least one time, $36 \%$ study less than an hour per day whereas $45 \%$ study one to two hours, and $8 \%$ study between three and five hours.

A structural model reveals that low self-esteem influences negatively teacher-student interaction and student-student interaction, and also learning performance. The teacher-student interaction influences positively the student-student interaction and learning performance. The student-student interaction influences positively learning performance that in turn influences directly the academic achievement.

\section{Conclusions:}

This study was motivated by a desire to gain a better understanding of the relationships between personal learning factors, pedagogical interactions and learning results. The findings reveals that an appropriate instructional' interaction provide an effective learning environment that has a positive influence on academic achievement.

Keywords: Academic achievement, learning performance, teacher-student interaction, student-student interaction, self-esteem

A Study of Friendship Quality of Students With Mental Disability in Iran

Vahideh Salah

Special Education Organization, Shiraz, Iran

Sima Shahim

Assistant Professor, Shiraz University, Department of Special Education 
Problem Statement: The advantages of healthy peer relationships for children living with chronic illness have been widely documented, and yet the nature and quality of friendships in children with mental disabilities have rarely been studied.

Purpose of Study: The purpose of present study was to investigate the friendship quality of students with mental disability.

Research Methods: The participants were 119 students with mental disability (60 boys \& 59 girls) aged 13 to 22 years recruited based on cluster sampling from second and third grades at guidance school in Shiraz, in southern Iran . A sociometric study was conducted in the class and students with reciprocal friendship and non-reciprocal friendship were distinguished, $30 \%$ of mentally disabled adolescents had reciprocal friendship and the rest were without reciprocal friendship. Then, the Friendship Quality Questionnaire (Parker \& Asher, 1993) was individually administered to all subjects. The validity and reliability of the FQQ was proved to be satisfactory for use in this population.

Findings:. The result indicated that students with reciprocal friendship in comparison to those without reciprocal friendship acquired higher mean scores in most of the subscales of Friendship Quality using analysis of variance. Also, significant differences were not found between the mean scores of friendship quality in girls and boys using analysis of variance. Moreover, there were not significant differences between the mean scores of friendship quality for student studying at different grade levels using analysis of variance.

Conclusions: The results showed that the quality of friendship did not change with age in this population of mentally disabled children, therefore, the professionals should pay more attention to applying better training methods of social skills for youth with mental disabilities in Iran to prepare them for joining inclusive education in near future.

Keywords: Friendship quality, reciprocal friendship, mental disability

\section{VOICE TEACHER'S STRATEGIES TO OVERCOME PERFORMANCE ANXIETY}

Vaike Kiik-Salupere, Institute of Educational Sciences, Tallinn University, Estonia Jaan Ross, Department of Musicology, Estonian Academy of Music and Theatre, Estonia

Problem Statement: Increasing competition among musicians on the contemporary scene implies additional requirements for them in terms of versatility and competitiveness. In addition to stable and high-level technical skills, young vocalists do need to cope with the competitive environment, which inevitably accompanies public performances. Performance anxiety usually manifests itself in negative changes in mental and physical sense of self before the performance. Almost all musicians feel anxiety before the performance but experienced artists are able to exercise control over the anxiety-related feelings as well as over possible physical disturbances.

Purpose of Study: The purpose of this study is to learn how professional classical singers and voice teachers cope with the performance anxiety. We are interested in how they maintain well-being and mental balance needed for a successful performance, as well as in which pre-performance anxiety-suppressing activities they find the most efficient and which ones suggested to their students.

Research Methods: Semi-structured interviews with the average duration of 150 minutes were conducted with 12 professional classical singers and vocal pedagogues from the Estonian national music institutions. The interviews were recorded, transcribed and subjected to analysis with the qualitative data processing software NVivo7.

Findings: The results show that all respondents had developed a day routine for coping with problems related to the performance anxiety. They all had their own strategies to ensure the physical and mental balance. The most commonly 
taught to students with breathing exercises. The voice teachers admitted, however, that despite of the majority of their students experiencing problems with performance anxiety, those problems were rarely addressed in a focussed manner during the course of training.

Conclusions: The voice teachers stressed the importance to be aware of how to adjust their cognitive activities in order to achieve the best results for the performance.

To ensure a better quality of music education more emphasis should be turn on problems related to performance anxiety.

Keywords: Vocal Pedagogy, Performance Anxiety, Classical singing

ACADEMIC PROCRASTINATION BEHAVIOUR OF PRE-SERVICE TEACHERS' OF CELAL BAYAR UNIVERSITY Ass.Prof.Dr. Aynur Pala*, Ph.D. Murat Akyıldız**, Can Bağcı***

\section{Abstract}

Procrastination is extremely prevalent behaviour, mainly in school settings. It is decribed as" knowing that one is supposed to and perhaps even wanting to complete an academic task but failing to perform the activity within the expected or desired time frame." Procrastination also appears to be a troubling phenomenon. People most strongly characterize it as being bad, harmful, and foolish (Briody, 1980), and over 95\% of procrastinators wish to reduce it (O'Brien, 2002). The aim of this study is to investigate the impact of variables such as sex, department, grade level, and income on students' academic procrastionation. Participants were the 366 students attending Faculty of Education and Faculty of Science and Letters of Celal Bayar University in Manisa, Turkey. The results of the study show that procrastination means are different for gender groups. Girls are more likely to procrastinate their academical works. Means are also different according to department. English Literature students are more procrastinators than Biology and Turkish Literature students. There are no differences according to class or socio-economical degree.

Future research on academic procrastination should be made to help to decrease it. The results are discussed in view of the findings of previous research. The implications for educational practise are also analyzed .

Key words: academic procrastination, pre-service teachers 
"Alpha Plus": Description and evaluation of an innovative reading and writing training program for German adult functional illiterates

Jascha Rüsseler - Department of Psychology, University of Bamberg, Germany

Ivonne Gerth, Department of Psychology II, University of Magdeburg, Germany

Melanie Boltzmann, Department of Psychology II, University of Magdeburg, Germany

Problem Statement: Functional illiteracy is present if the level of literacy of a person is not adequate for fully effective participation in society. In Germany, approximately $4 \%$ of the population is considered functionally illiterate. The present study describes and evaluates an innovatve training program teaching adults to read and write.

Purpose of Study: The pupose of the present study is to evaluate the effectiveness of a reading and writing training program for German functionally illiterate adults.

Research Methods: The program "AlphaPlus" consists of the following modules: (1) training of basic perceptual abilities with the BrainBoy ${ }^{\circledR}$ / Audio-Trainer AT-3000; (2) training of brain-hemisphere coordination in the processing of spoken and written language ("Lateraltrainer"); (3) training of phoneme discrimination ("Lautdiskriminationstrainer"); (4) training of reading and writing skills with pen and paper-based material; (5) use of the learning portal www.ich-will-lernen.de developed by the German Volkshochschulverband (VHS); (6) social activities such as cooking, shopping etc.; (7) three weeks internship at possible employers. The effectiveness of the training was evaluated in two courses with 18 participants each. Reading and writing tests as well as event-related brain potentials and functional magnetic resonance imaging were used while subjects performed word, pseudo-word, picture or symbol-matching tasks.

Findings: Reading and writing improved signitifcantly in all participants. The N170 component of the event-related brain potential did not differ for words and symbols in the pre-training measurement. After training, N170 amplitude increased for words but not for symbols. In line with these findings, fMRI showed an increase in the activity of the visual word form area as a result of the reading and writing training.

Conclusions: The training program "Alpha Plus" is effective in teaching reading and writing to German adult functional illiterates. Event-relaed brain potentials and fMRI data indicate that learning to read and write in adulthood leads to a tuning of the neurons in the visual word form area that is comparable to that previously described for school-age children.

Keywords: functional illiteracy, adults, training, reading and writing, evaluation 


\author{
INTERACTIVE PRESENTATION TOWARDS STUDENTS ENGAGEMENT \\ K. Jelemenská, P. Čičák, V. Dúcky \\ Faculty of Informatics and Information \\ Technologies, Slovak University of Technology Bratislava, Slovakia
}

Problem Statement: Today's lecturing styles are usually based on static slides presentation using computer and data projector. Although enriched with drawings, photos etc. the presentations often fail to catch students' attention. One of the main reasons is the loss of interactivity with students which was the advantage of the previously used blackboard-and-chalk presentation style. To solve the issue the newest information and communication technologies (ICT) should be used to combine the advantages of various presentation styles in a modern presentation system.

Purpose of Study: The integration of the latest ICT into education is not an easy task. In the area of presentation technology most of the available presentation applications for huge auditoriums do not support active entries into the presentation that is necessary to improve student-teacher interaction. The teachers should be able to annotate the presentation using attention catching marks, writing illustrating examples, drawing pictures etc. and the students to follow the presentation on the laptop, to add their own notes or to take part in the feedback tests.

Research Methods: Thorough analysis of nowadays ICT led to the potential techniques identification that could broaden the presentation system functions. The prototyping was then used to verify the integration possibilities and the expected impact. The impact of interactive presentation style on students' engagement was observed in three courses and descriptive analytical method was used to evaluate the collected data.

Findings: The interactive presentation system based on current ICT was designed and implemented. It allows lecturers to prepare a presentation in an easy and flexible way. It supports presentation annotation accompanied with handwriting recognition and conversion as well as a lot of other editing and basic import/export possibilities. Considerable improve in students' engagement was observed.

Conclusions: Attracting students' attention during a lecture presentation is a common issue. An approach to its solution using pen-based technologies has been designed and implemented. The results show that nowadays Tablet PC proved to be the most suitable technology for this purpose when accompanied with modern presentation system.

Keywords: interactive presentation, ICT, lecture improvement 


\section{Problem Statement:}

The use of L1 in language classroom has been debated in language teaching theory and practice for decades. However, Minimal research attention has been directed towards the classroom discourse as a multidimensional process. Previous studies have looked at parts of this process (e.g teacher talk) focusing on a single dimension of the use of L1 or they have just relied on teacher and learners' perceptions. Moreover, most of the major studies in this area have been conducted in countries in which English is the learners' mother tongue.

\section{Purpose of Study:}

The aim of this study is to contribute furthur to the investigation of the use of L1 in EFL classroom by exploring classroom discourse through quantitative and qualitative approaches.

\section{Research Methods:}

The study was coducted in Qazvin, Iran. 23 adult English learners and their teacher participated in this study. The class was observed and video recorded for 12 weeks. Data was collected using COLT instrument (Spada \& Fröhlich,1995) and analyzed through inductive and deductive approaches.

\section{Findings:}

a) Results from COLT(B) revealed that Students use L1 51\% more than teacher. However, teacher's turns of L1 use are much longer. Communicative features of students and teacher's use of L1 was organized in a table.

b) Results from $\operatorname{COLT}(\mathrm{A})$ showed that generally L1 is used in classroom activities like grammar teaching/learning $(30 \%)$, understanding check (32\%), home work discussions (10\%) and dialogue practices (15\%)

c) Socio-pedagogical functions like "face saving", "fun making" and "metalinguistic explanation" also emerged from the data.

d) Similar patterns of L1 use came out.

\section{Conclusions:}

This study confirmed the results of earlier research regarding the functions of L1 use. However, observed Sociopedagogical uses of L1 had not been reported in previous works. The two level analysis (micro/macro) of classroom discourse revealed that there are systematic patterns of first language use which can be used as effective learning/teaching strategies in the classroom.

Keywords: L1 use, first language, classroom discourse,teaching/learning strategis

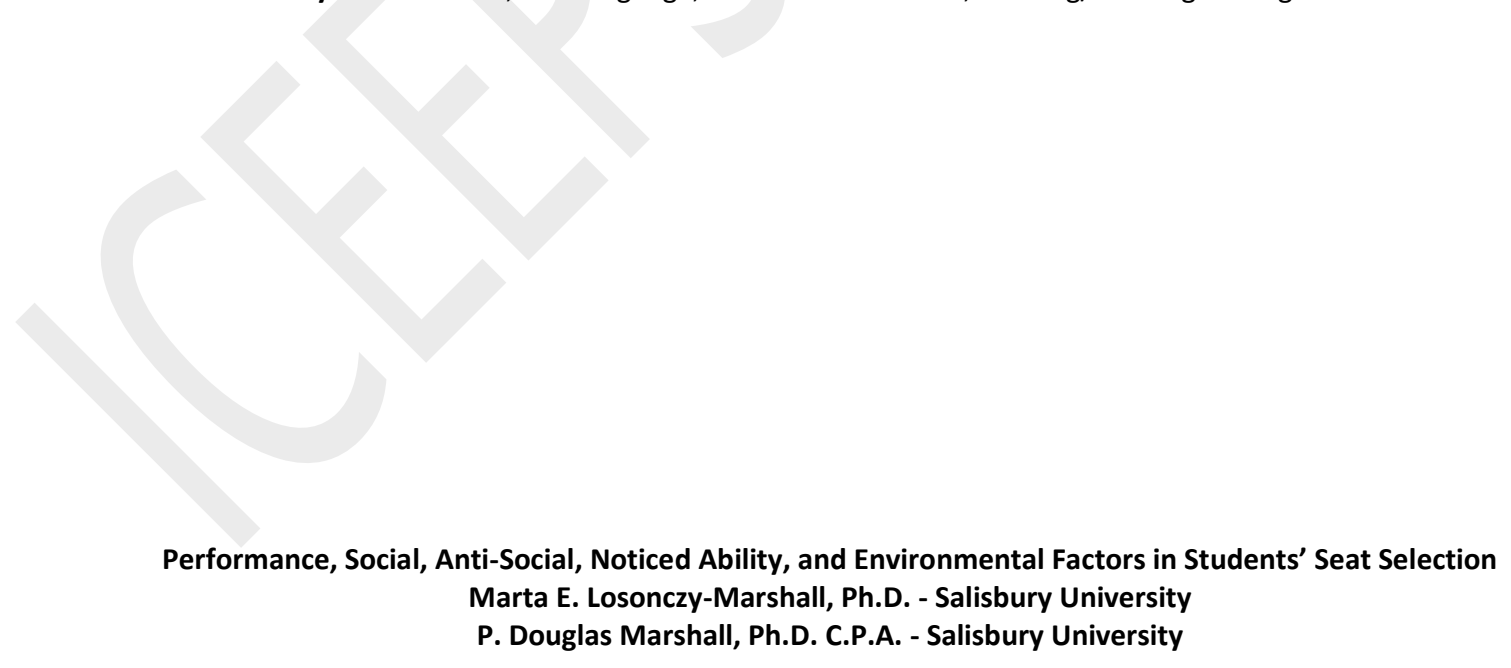

Problem Statement: What motivates students to pick a particular seat location in class? Is it related to performance in class or other factors?

Purpose of Study: This was an exploratory study interested in finding out students' motivations for seat selection in class. 
the classroom. Responses ranged from 5 (strongly agree) to 1 (strongly disagree). Students' attendance, grades and specific seat location (row and column) were obtained from grade books, with permission from informed consent.

Findings: Exploratory factor analysis was used to identify factors in choosing classroom seats. Five factors emerged: performance, social, anti-social, noticed ability and environment. ANOVA was used to determine if there were differences in factors based on seat location. Performance factor decreased from the front toward the back of the room, as did the noticed ability factor. Students who wanted to perform well or who wanted to be noticed were more likely to sit near the front. Those with antisocial reasons for seat selection were more likely to sit in the back of the room. Students sitting in the center of the room tended to choose their seats for environmental reasons.

Conclusions: $\quad$ Students' reasons for choosing particular seats in the classroom fall into five factors. Those who are motivated by performance, want to see well, hear well, and pay attention or concentrate well; they do not want any distractions. Others are motivated by social reasons, wanting to sit next to a friend or acquaintance. Those who are anti-social choose not to sit next to others, and do not want to be noticed in class. Some students want to be noticed by other others, including the professor, and want to actively participate in class; they are in the noticed ability group. The environmental factor revealed that some students selected their seat to stay away from or be near the heating or air conditioning unit, or to sit next to or away from a door or window.

\title{
Keywords: Factors, Seat Selection, Motivation, Student
}

\author{
Knowledge of adolescents about contraceptive methods: Impact of one training intervention \\ Paula Nelas - Polytecnic Institut of Viseu (CI\&DETS), - Higher School of Health, Portugal \\ Carlos Fernandes da Silva - University of Aveiro, Portugal \\ Manuela Ferreira- Polytecnic Institut of Viseu (CI\&DETS), - Higher School of Health, Portugal \\ João Duarte- Polytecnic Institut of Viseu (CI\&DETS) - Higher School of Health, Portugal \\ Cláudia Chaves - Polytecnic Institut of Viseu (CI\&DETS) - Higher School of Health, Portugal
}

Problem Statement: The approach of contraceptive methods in the classroom, must integrate harmoniously the various facets of human sexuality, expand knowledge and be an capacitor instrument, through which young people can acquire competences to care and improve their sexual health through acquisition of means that promote individual and social empowerment.

Purpose of Study: Test the efficacy of an formative intervention program in terms of knowledge about family planning among adolescents and their effectiveness in a large sample.

Research Methods: The Fieldwork was developed in two studies, the first experimental field, attended 90adolescents (48 in the control group, average age 14:15 years, and 42 in experimental, average age 14.2 years). In the second, descriptive and correlational attended 840 adolescents, 441 males and 399 females, with an average age of 14.44 years old. The 
evaluation protocol includes a questionnaire to characterize the sample and one ordinal Likert scale constructed for this purpose to evaluate the knowledge about family planning.

Findings: After the formative intervention there were higher average values recorded in the experimental group (average $=$ 58.19) than in controls (average $=42.82$ ) with differences being statistically significant $(t=-6,564, p=0.000)$. In the enlarged sample, despite the differences found, after the formative intervention didn't prove to be significant $(t=-0,017, p$ $=0986$ ), there was an increase in knowledge about family planning. In the enlarged sample $12.2 \%$ of boys and $8.8 \%$ of girls have already had sex. The age of first intercourse occurred in average at 14.2 years old for males and 13.7 years old for girls.

Conclusions: : Sexual behaviour is one area of potential risk for adolescents, due to precocious sexual activity. Some studies have shown that teenagers want to see introduced in the curricular plans, topics in family planning.

Keywords: Sexual education, school, family planning, adolescent

\author{
Language Learning Strategies Used by Successful and Unsuccessful Iranian EFL Students \\ Mohammad Hossein Gerami \\ Islamic Azad University - Soofian Branch - Iran
}

\title{
Problem Statement:
}

The important part language learning strategies play in second language acquisition (SLA) has been noted by many SLA researchers and also, many studies have been conducted to explore them (Rubin, 1975 and 1981; Naiman et al, 1978; Fillmore, 1979; O'Malley et al, 1985 and 1990; Ellis, 1985; Oxford, 1990 and Cohen, 2000). Since language is socially mediated and context dependent, it would be expected that learners' use of language learning strategies may vary with the environment.

\section{Purpose of Study:}

This study examines the application of language learning strategies by successful and unsuccessful Iranian EFL students.

\section{Research Methods:}

To do so, memory, cognitive, compensation, metacognitive, affective and social language learning strategies were investigated. To collect data, the Strategy Inventory for Language Learning (SILL; Oxford, 1990) was administered to successful and unsuccessful EFL students. They, then, were analyzed using descriptive and inferential statistics methods.

\section{Findings:}

The findings of the study indicated that successful EFL students used a wider range of learning strategies and different from those often preferred by their unsuccessful peers. The former often used metacognitive strategies while the latter tended to use surface level cognitive strategies.

\section{Conclusions:}

The results of this study can be beneficial for Iranian language teachers in terms of raising their awareness on narrowing the gap between the students' language learning strategies and their teaching methodologies preferences. 


\section{Keywords:}

Language Learning Strategies (LLS) - Successful EFL Students - Unsuccessful EFL Students

Types of Self-Hurt Behavior Among Chinese Adolescents in Malaysia

Guan Teik Ee

Teacher Education Institute

Campus Tuanku Bainun

Penang Malaysia

See Ching Mey Ph.D

University Science Malaysia

Penang Malaysia

Problem Statement: Self-hurt among young people has raised a concern internationally (Burns, Dudley, Hazell \& Patton, 2005). Many research suggests that self-hurt is growing significantly among young people and is becoming a public health problem in the west. Surveys revealed that adolescents and young adults are at higher risk of engaging in self-hurt behavior (Hoyt, 2002). It is believed that the onset of puberty was an associated factor of self-hurt (Cleaver, 2007) and it usually lasts five to ten years. Malaysia, as a developing country, with a population of 28.25 millions in 2010 has a relatively young population (Department of Statistics, Malaysia, 2010). Relatively little self-hurt research has been done in Malaysia. Although there were some counseling records found, there is virtually no research study that has been designed to identify young people's self-hurt behavior. Thus, this study is going to identify the types of self-hurt behavior that is prevalent among the Chinese adolescents in Malaysia and the duration of premeditation before the self-hurt act.

Purpose of Study: To state the types of self-hurt behavior among Chinese adolescents in Malaysia.

To identify the duration of premeditation before actually doing the self-hurt act among Chinese adolescents in Malaysia.

Research Methods: 1. Questionnaire (Self-Hurt Assessment)- to state the types of self-hurt behavior and duration of premeditation.

2. Interview will be carried out to examine the duration of premeditation before self-hurt.

Findings: The findings would only be available in May 2011.

Conclusions: Conclusion would follow once the findings are finalized. 
Preservice Teachers' Use of Educational Theories in Classroom and Behavior Management Course: A Case Based Approach

Chin Phoi Ching PHd

IPG Tuanku Bainun campus, Bukit Mertajam

Penang Malaysia

Problem Statement: Teaching is a complex activity that requires one to make many decisions in a short span of time. Decision making by teachers in their daily lives is therefore inevitable. Most of the decisions made are mostly based on teachers' personal belief system which are usually related to educational theories and principles but the issue is most teachers are not aware of such relationships. They have actually put these thoeries into in their daily decision making practices. In view of this situation, this study intends to explore the preservice teachers' use of educational theories, principles and concept in making decisions to solve problems in the classroom using a five-step case analysis model. This model would be used by the preservice teachers as a framework for analysing classroom and behavior management cases. In addition, this study also hope to find out the attitude of preservice teachers towards the course after using a case based approach.

Purpose of Study: i. To delineate the types of educational theories, principle and conceptual knowledge used by preservice teachers in solving classroom and behavior management cases?

ii. To find out preservice teachers' attitudes towards this classroom and behavior management course after using a case based approach.

Research Methods:

i. Case analysis by preservice teachers using a five step decision making model

ii. Evaluation of case analysis reports by categorising the theories, principles or concepts used.

iii. Administrating a questionnaire to find out attitude of students towards the classroom \& behavior management course after using a case based approach

iv. Interviewing students regarding the case based approach

Findings: $\quad$ The findings would only be available when the above course ends in May 2011

Conclusions: Conclusions would only be made when the findings are ready

Keywords: case based learning; preservice teachers' decision making, educational and pyschological theories'prinicples and concepts; classroom and behavior management 
SELF-FOCUS AND CONCEIT IN THE TEACHER'S PERSONALITY

Gabriel Albu - Petroleum-Gas University of Ploiesti, Cristian Vasile- Petroleum-Gas University of Ploiesti, Adina Pescaru Petroleum-Gas University of Ploiesti

Problem Statement: Although this phenomenon is happening for a long time, lately increasingly more teachers are focused more on their own than on how students react to the lessons and to the dynamics of the learning process. This behavior leads to a lack of efficiency in the teaching process and, of course in the learning demarche. The article presents a psychological research on teachers' personality.

Purpose of Study: The study focuses on assessment of important features of personality of school and high school teachers. Because of the dynamics and complexity of self-focus and conceit processes several personality factors that are characteristic for the two processes mentioned were isolated and measured.

Research Methods: The psychological study was conducted on a sample of 50 teachers from schools and high schools, using a personality questionnaire which assesses five factors (Big Five). As a major factor we took into consideration the Agreeableness (tendency to be compassionate and cooperative rather than suspicious and antagonistic towards others). On the other hand disagreeable individuals place self-interest above getting along with others. Other factors were also discussed.

Findings: The study findings will help in understanding the dynamics of the teachers' personality in the educational environment. The findings could stand on the basis of another research for the identification of the appropriate solutions to the low efficiency due to self-focus and conceit in the teachers activity.

Conclusions: This study presents results of a major impact on education process. Statistical results together with qualitative research and field work lead us to a broad vision of the self-focus and conceit in the educational area.

Keywords: self-focus, conceit, teacher, personality

SECURITY NEEDS AMONG TEACHERS

Cristian Vasile - Petroleum-Gas University of Ploieşti, Alina Mărgăriţoiu - Petroleum-Gas University of Ploieşti, Simona Eftimie - Petroleum-Gas University of Ploieşti

Problem Statement: According to the major theories of motivation, the security need is placed among the basic human necessities. In his hyerarchy of needs, Maslow stated that the security needs are located on the second level from basis, after the physiological needs and before belonging and esteem needs. He also had shown that a person could not pursue 
the next higher need in the needs ladder until his or her currently recognized need was substantially or completely satisfied. The article presents a research on teachers security need in terms of protection.

Purpose of Study: The study try to assess important features of motivation of school and high school teachers. The focus is on security need (or protection need). Some correlations with other manifest or latent characteristics of the teachers were also made. The dynamics of the security need was observed and several conclusions were drawn.

Research Methods: The study was conducted on a sample of 55 teachers from schools and high schools (49 women and 6 men), using a motivation evaluation and several other instruments among which Weathley Stress Profile (WSP) had an important position. Other factors were also discussed.

Findings: The study findings will help in understanding the dynamics of the teachers' beliefs and behavior in the educational environment in Romania. The results indicate also the existence of a problem which has negative effects on the efficiency of education. The findings could stand on the basis of a comparative international research on teachers' need for security.

Conclusions: An approach of this important problem was rarely made in the educational environment, at least in Romania. The study results could have a major impact on the efficiency of the educational system in which the teacher play one of the most important roles. Statistical results together with qualitative research and field work lead us to a broad vision on the security need of the teachers.

\section{Keywords: security need, motivation, teacher}

The Impact of Students' Training in Questioning the Author Technique on EFL Reading Comprehension

Sasan Bleghizadeh

Shahid Beheshti University, Tehran, Iran

The purpose of the present study was to examine the effect of student-generated questions on reading comprehension of EFL students. Ninety-eight adult students participated in this study. There were three experimental groups and one control group. The participants in the first experimental group read two unmodified reading passages and answered fifteen multiple-choice comprehension questions. These participants were asked to generate a number of questions based on the given texts and discuss them with a peer before answering the reading comprehension questions. Similarly, the participants in the second experimental group were asked to generate a number of questions and discuss them with a partner. However, they were trained in questioning the author technique (QTA).The participants in the third experimental group read the simplified version of the same passages and answered the same comprehension questions without generating any questions. Finally, the participants in the control group read the unmodified texts and answered the same comprehension questions without any linguistic support. The results revealed that the participants in all the experimental groups outperformed their peers in the control group. Nevertheless, the participants' reading scores who had been trained in QTA were significantly higher than the scores 
of their peers in the other three groups. This points to the value of training students in generating their own comprehension questions.

\section{Factors affecting the sustainability of a teaching career}

Leida Talts, prof. em. ,Tallinn University, Estonia

Airi Kukk, PhD, Tallinn University, Estonia

Maia Muldma, PhD, Tallinn University, Estonia

Problem Statement: Class teachers' understanding of their mission and daily work often collides with society's heightened and ambivalent expectations. Teachers realise how crucial their work is, but expect greater attention and more versatile (including material) recognition from the society. The need to acknowledge the views and values teachers rely on in their daily work and what being a teacher means to them at different stages of their career is becoming increasingly more important.

Purpose of Study: The objective of the study is to find out about the factors influencing the sustainability of a teacher's career while focusing more on the prerequisites for becoming a teacher, relationships with pupils and colleagues, teachers' perception of their professional role and their vision of a teacher of the future.

Research Methods: The research relies on biographic interviews of 25 class teachers, in which teachers participated on a voluntary basis. Proceeding from the research objective, four content categories were formulated: the prerequisites for becoming a teacher, working environment, relationships with pupils and parents, and teachers' perception of their professional role today and in the future.

Findings: The respondents' childhood is characterised by their lively interest in creative activities. They have noted an early interest in reading, creative outdoor and indoor games, love for nature. Characteristically, several class teachers have wanted to become singers or actors in their childhood but then chosen a teacher's career. They successfully 
apply skills acquired in their childhood and schooldays in their teaching work. It is also typical that in their schooldays they were often organisers of activities for younger pupils. The respondents' teaching career has also been supported by favourable working environment and colleague's and parent's support. As other factors facilitating teachers' work, the role of information technology in designing teaching materials and preparing lessons has been mentioned. Teachers have also pointed out as positive their greater freedom in selecting teaching methods and self-improvement opportunities.

Conclusions: The main factors of the sustainability of class teachers' career are primarily related to substantial values of teaching profession. The majority of the respondents emphasise creativity of teachers' work and their own role in the development of children's learning skills, personality traits and learning motivation.

Keywords: prerequisites for becoming a teacher, teachers' working environment, valuing teachers' work

\section{ATTITUDES TOWARDS FUTURE POLITICAL PARTICIPATION AMONG STUDENTS WITH AND WITHOUT BEHAVIORAL PROBLEMS}

\section{Kristi Kõiv}

University of Tartu Estonia

\section{Problem Statement:}

It is documented that there is a link between civic participation and students behavior problems (Vieno et al, 2007), but there is no research examining links between expected participation in political activities and students behavior problems.

\section{Purpose of Study:}

The aim of the research is to identify differences between groups of students with and without behavioural problems in expected political participation through an analysis of four aspects of future actions: political obligations, political rights, voluntary activities and protest.

\section{Research Methods:}

The three-staged cluster sampling included students from seven mainstream schools and the Strengths and Difficulties Questionnaire (SDQ; Goodman, 1997) self-reported version was completed for 1625 students for 11 to 16 years. A total of 174 of boys and girls were classified as abnormal in the total difficulties score and these pupils determined as a group of students with behavioral problems, whereby the matched pair's method was used to contain the group of students without difficulties.

Measured with Expected Participation in Political Activities Questionnaire (Schultz, 2005) the four-domain structure for students' expected political activities has yielded valuable information about the differences between the structure of adolescents' views on future political participation in terms of political obligations, political rights, voluntary activities and protest.

Findings:

Research results show that students with and without behavioral problems construct a quite different conception of expected political participation: students with problems tended to evaluate more highly protest as a component of their future political participation and students without problems emphasised more political rights and voluntary activities.

\section{Conclusions:}

The findings of the present work provided clear support for the hypothesis that the role of the behavior problems might influence students' attitudes toward their future political participation. 
Keywords: political particpation, behavioral problems

\title{
Personality traits, the tendency towards irrational attitudes and their connection with Physical Education activities
}

\author{
Elena Lupu-University Lecturer Ph.D.
}

Petroleum-Gas University, Bucharest Bvd., no. 39, Ploieşti, 100520 Romania

Problem Statement: There is an indestructible connection between person and personality, at which the individual's capacity of movement is added, along with their relation with other people, and their capacity of manifesting in different situations as those linked with Physical Education activities.

Purpose of Study: The research undertaken has started from the hypothesis according to which people who constantly participate at physical activities and do not have medical exemptions are inclined more towards rational thinking and positive attitudes, as compared to those who possess medical exemptions and have a different way of thinking. In order to prove this aspect, we have used Ellis tests, which helped us to track in due time, one's own irrational initiatives. The research has been undertaken on a group of 60 randomly chosen students.

Research Methods: The bibliographic study method; the observation method; the enquiry method (conversation, etc.); the method of pedagogical experiment; the statistical-mathematical method; the graphic method.

Findings: the purpose of this research has been that of emphasizing that people who constantly participate in physical activities, and do not have medical exemptions are inclined more towards rational thinking and positive attitudes.

Conclusions: The tendency towards irrational thinking and the denial of participating at Physical Education activities of individuals who have medical exemptions is apparently generated by a general predisposition of personality. The subjects of this test have registered high values on the scales of dominance and dogmatism.

Keywords: irrational attitudes, personality traits, students, medical exemptions, Ellis tests 


\title{
Identifying the attitude of healthy individuals towards disabled children - a chance to be educated for all
}

\author{
Constantin Cernat- Manager, Elena Lupu-University Lecturer Ph.D., Cristina Petre- Teacher
}

Ideas for the Future Association Romania

Petroleum-Gas University, Bucharest Bvd., no. 39, Ploieşti, 100520 Romania

School of Arts and Crafts, Thomas Caragiu, in Ploiesti Str.Minerva No.4 100215 Romania

Problem Statement: The main dimensions polarizing attitudes and behaviours of the implied actors in the education of disabled children are: the degree of tolerance and level of implication in their education. According to these two coordinates, we can distinguish four attitudinal and behavioural models: the emphatic model, the "militant" model, the apathetic model, the "routine" model. Recognizing these models, and seeing their percentage in social life, we can think to a solution and a program which will open a door to education in a natural school environment, and not as a special institution for disabled children.

Purpose of Study: This research started from the hypothesis according to which the lack of competence and specific instruments for working with these children makes it difficult for a real integration for these children in a school. In spite of this, we believe that through constructive conversations with healthy children in the same class with their disabled colleagues, with their parents. Moreover, with the help of the teachers we think we could change the existent negative opinion, offering a chance for education for disabled children, thus becoming an impediment for school abandonment. This research has been undertaken on a group of 90 people: children (boys and girls), teachers and parents.

Research Methods: The bibliographic study method; the observation method; the enquiry method (conversation, etc.); the method of pedagogical experiment; the statistical-mathematical method; the graphic method.

Findings: The purpose of this research was to emphasize that the lack of competence and specific instruments for working with disabled children makes it difficult for the real integration process of this children in school to occur. This becomes the main cause of school abandonment for disabled children, as well as their labeling and marginalization.

Conclusions: The adults within the system (teachers, school counselors) need a period of formation for working with disabled children. An efficient formation is, in the others opinion, one based on concrete examples, working models which can be easily implemented. For this, a special program would be necessary, that will have certain activities. The participation of healthy children at the educational process, in the same time as their disabled colleagues, could increase the level of cohesion for the class and diminish the rate of school abandonment.

Keywords: attitudes, disabled children, healthy children, activity programs, teachers, parents, education

\author{
EMOTIONAL AND SOCIAL COMPETENCIES OF BEGINNING TEACHERS \\ Usharani Shanmugasundaram \\ Teachers' Training Institute Campus Tuanku Bainun \\ Penang, Malaysia
}

Problem Statement: The conceptual model of teacher education used in Malaysia is based on the National Philosophy of Education. This teacher education conceptual framework requires trainee teachers to have a holistic and balanced development intellectually, physically, spiritually and emotionally. In our local teachers training institutes, teacher 
preparation programs ensure students are well trained before they are posted to schools as confirmed teachers. They need to pass centralized examinations every semester and they have to complete internship programs (classroom experience) for three semesters (6,7 and 8) and undergo school based experience from semester 1 to 5 in government primary schools. Equipped with sound pedagogical knowledge and skills they enter mainstream primary schools facing a plethora of challenges in the schools. But do our teacher preparation programs produce new teachers who are emotionally competent? Thus this study would like to find out how well beginning teachers from teaching training institutes can handle challenges faced in schools. What kind of personal and social competencies are being used by beginning teachers to face new challenges in schools?

Purpose of Study: This study aims to examine the types of social and personal competencies used by beginning teachers in coping with various challenges faced in schools.

Research Methods: Quantitative method will be used .Questionnaires will administered to 50 beginning teachers who are recently posted to schools in February 2011. Emotional and social competency inventory (ESCl) by Boyatzis, Goleman and Hay Group(2007) will be used in this study. This instrument measures four clusters of competencies that constitute self-awareness, self-management, social awareness, and social skills

Findings: still in the proccess of collecting data

Conclusions: Conclusion will follow suit after the findings are analysed.

Keywords:

Emotional intelligence; personal competence; social competence

\section{PSYCHOMETRIC PROPERTIES OF THE TEACHER ASSESSMENT LITERACY QUESTIONNAIRE FOR PRE-SERVICE TEACHERS IN OMAN}

Hussain Alkharusi and Sultan Qaboos University, Oman

Problem Statement: Assessment literacy refers to teachers' knowledge and skills in the educational assessment of students. Recognizing the need for teachers to possess an adequate knowledge in educational assessment, Plake and Impara (1992) developed an instrument titled the "Teacher Assessment Literacy Questionnaire (TALQ)" consisting of 35 items to measure teachers' assessment literacy based on the "Standards for Teacher Competence in Educational Assessment of Students" (AFT, NCME, \& NEA, 1990). Given the growing interest on teachers' assessment literacy, research is needed to support the assertion that score interpretations from the available instruments such as the TALQ are accurate representations of the teachers' assessment literacy.

Purpose of Study: The purpose of this study was to examine the psychometric properties of the TALQ for pre-service teachers in Oman terms of validity, reliability, and norms.

Research Methods: Pre-service teachers $(N=259)$ enrolled in an educational measurement course at Sultan Qaboos University in Oman completed the TALQ. Data were analyzed using classical item analysis, confirmatory factor analysis, internal consistency coefficient, Pearson product correlation coefficient, and percentile ranks.

Findings: Analyses showed that (a) the items demonstrated acceptable levels of item difficulty and item discrimination, (b) the TALQ measures a unitary construct of the assessment literacy, (c) the scores of the TALQ had an adequate internal consistency reliability coefficient, and (d) a significant positive relationship exist between TALQ's 
scores and academic achievement scores in the course. Percentile ranks were extracted as norms for the raw scores of the sample on the TALQ.

Conclusions: The results point to a conclusion that the TALQ provides reliable and valid interpretations of the pre-service teachers' assessment literacy in Oman, making it a valuable instructional and assessment tool for teacher educators responsible for preparing teachers in educational assessment.

Keywords: Assessment literacy; Pre-service teachers; Psychometric analysis; educational assessment

An Educational Psychologist and Adolescents' Goal-setting

Zhilinskaya Alisa, Moscow State Psychological and Educational University

\section{Problem Statement:}

There are schools, where adolescents spend their time after lessons. It is important to work with adolescent's initiatives in these schools. Adolescents have many ideas for their actions in school after lessons; they like to discuss them with adults often. However many of these ideas are embodied never.

\section{Purpose of Study:}

Purposes of study are:

1) to find the reasons why adolescent's ideas are not embodied by them often,

2) to find the way to discuss adolescent's ideas effective,

3) to find factors that lead adolescent's ideas to embodiment.

\section{Research Methods:}

Case-study. The researcher had been working with adolescents during four years (8-11 form).

\section{Findings:}

There are different problems that lead adolescents to stop their idea's embodiment. There are goal-setting problems and goal-achievement problems. We had found following goal-setting problems:

1) adolescents may have some "image of the future", but stop to achieve it, when they are asked to explain their reasons of the choice, it may be caused by missing conscious reasons of the choice,

2) adolescents are interested in technology of action, but not in the meaning of it, so they stop action when technology is tried out but the main goal isn't achieved,

3) adolescents discuss with adults many initiatives and goals but don't achieve them because they need only to have an interesting discussion.

One of the main goal-achievement problems is that adolescents don't account people, who make decisions, because they don't know that they have to coordinate their actions with anybody. 
Conclusions:

It is important to teach adolescents to set goals. One of tasks is to teach adolescents to analyze situation, to find people, who make decisions related with adolescents' goal-achievement. It is important to teach adolescents to realize their reasons to choose the definite image of future. Another task of educational psychologist may be to show adolescents different ways of adolescents' ideas embodiment. One of serious principles is to teach adolescents to analyze different goal-setting cases and methods.

Keywords: Goal-setting, reason to choose an image of future, goal-achievement, adolescents

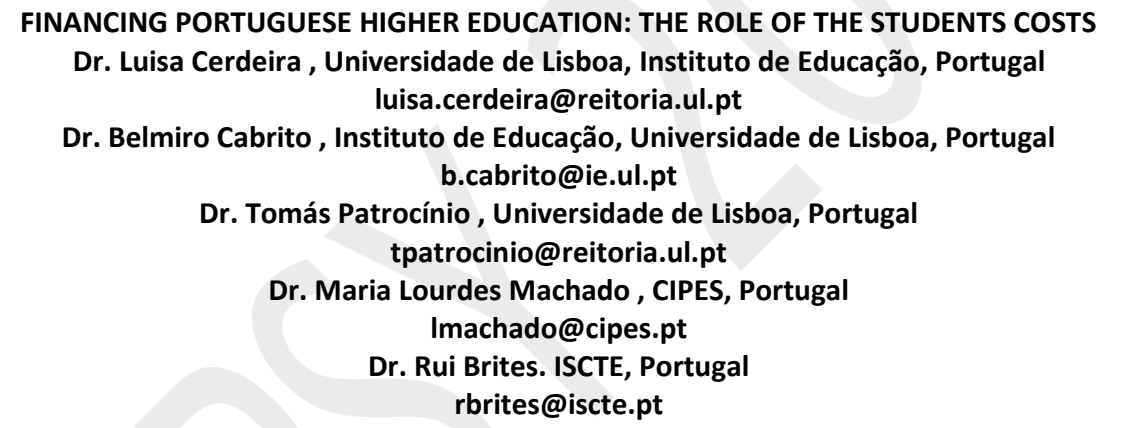

Problem Statement: In the scope of the Economics of Education, based on the Cost-Sharing theory, the research on student costs in higher education (HE) assumes particular relevance. This paper is focused on the socioeconomic characterization of Portuguese HE students and on the research of the costs these students endure whiles their studies, as well as the cost of the remaining stakeholders (e.g. families, governments/ taxpayers and others).

Purpose of Study: Two studies (Cabrito, 2000; Cerdeira 2008) provide comprehensive data on Portuguese HE student costs. An ongoing study to support and sustain the definition of funding policies within this sector and allowing periodical access to updated statistical data on HE student costs is being developed. In 2010/2011, a new research is being launched and intends to apply a national survey with the following research objectives:

- to characterize the socioeconomic condition of higher education' students;

- to identify and collect data on educational and living costs endured by Portuguese higher education students,

- to compare the costs of Portuguese higher education students with the costs of higher education students from other countries.

Research Methods: Using the same methodology of the 2000 and 2008' studies, a new research is being launched and intends to apply a national survey in 2010/2011. The sample aims to reach 1050 students of all institutional types of Portuguese Higher Education institutions, including public, private, universities and polytechnics' institutions.

Findings: Previous studies revealed that around $30 \%$ of student expenses were related to educational expenses and $70 \%$ were related to current expenses. Moreover it was clear that the annual total costs of the students varied according to the type of institution and education attended, as the highest total costs were in private universities, followed by private polytechnics, public universities and, finally, public polytechnics.

Conclusions: The cost value students have to endure in order to attend higher education unquestionably depending on the conjugation of three fundamental variables: the type of education attended, the regional location of the higher education institution and the student situation regarding lodging. 
Keywords: Higher Education, Cost-Sharing, Education and Living Costs

\title{
WHAT WILL I BE WHEN I GROW UP? An Analysis of Occupations Found in Children's Picture Books
}

\author{
Lecturer Ozana Ramljak, Croatian language and literature prof., at VERN University \\ Lecturer Maja Kolega, Psychology prof., at VERN University
}

\section{Problem Statement:}

Picture books are an important media through which preschool children acquire values and norms of a certain culture as well as acquaint themselves with the social world in different aspects. These books appear as co-shapers of children's reality and one of the starting points for the construction of relations and attitudes in the future. Alongside the picture books, children acquire basic assumptions of the grown-up world as well as adult occupations. Picture books can also be considered as first step in the process of entering the formal education which will be consequently continued.

\section{Purpose of Study:}

In the 100 picture book samples, different occupations of main and supporting characters were analyzed.

\section{Research Methods:}

The method used was an analysis of content. Since there is very little text in picture books the focus of the research is based on a quantitative analysis, but also discourse analysis was used.

\section{Findings:}

We found a relatively wide spectrum of various occupations but predominantly we found occupations dealing with traffic, regular working class, agricultural occupations, as well as occupations relating to social services. We found a huge discrepancy between male and female characters in specific occupations, namely, males appear in a much larger number than females whether it be in main or supporting roles. We also found that males appear in a much wider range of different kinds of occupations.

\section{Conclusions:}

Characters who have specific occupations basically prove the gender stereotypes and the reinforcement of gender stereotypes was confirmed by the analysis of language used since it showed how the females were often found grammatically and lexically imperceptible.

\section{Keywords:}

picture books, occupations, education, gender stereotypes 


\title{
The INSynC-study: Testing the effectiveness of Synchronous Coaching on changes in the levels of fulfilment of basic
} psychological needs of teachers and trainee teachers in Dutch elementary schools

\author{
Dr. P. (Patricia) Vuijk
}

Senior Researcher Inholland University of Aplied Sciences

Problem Statement: The fulfilment of basic psychological needs (competence, autonomy, relatedness) is essential to psychological health and growth, well-being, optimal functioning, and self-actualisation. It is well known that the complexity of situations in classrooms can impede healthy levels of fulfillment of basic psychological needs of teachers and trainee teachers. Despite this knowledge, the development and testing of classroom-based interventions aimed at directly influencing these levels of fulfilment of basic psychological needs during the daily routines of teachers and trainee teachers in classrooms is a relatively neglected topic in Dutch research, as well as in the education and training of trainee teachers.

Purpose of Study: During Synchronous Coaching, a well-trained coach and (trainee) teacher are connected via a Bluetooth connection. The coach whispers instructions (key words) directly to a (trainee) teacher via an earpiece. These interventions will be videotaped by the coach, so that the effects of the pedagogical effects of the intervention on the (trainee) teacher and the pupils can be discussed after the lesson. The primary aim of the INSynC-study is to test the effectiveness of Synchronous Coaching on changes in the levels of fulfilment of basic psychological needs of Dutch (trainee) teachers. Morover, the effectiveness of Synchronous Coaching on child-reported teacher-pupil interaction will be tested, as well as observed on-task behavior, rule-breaking behavior and child-reported behavioral and emotional problems of their pupils. Finally, the influence of several characteristics of the Synchronous Coaches, their implementation expectations and implementation fidelity on effectiveness will be studied.

Research Methods: In the winter of 2010, 35 teacher and trainee teachers were included in this study who met predetermined criteria for low levels of fulfilment of basic psychological needs. Baseline-measures of the above described target variables will be conducted in the spring of 2011. Follow-up measures will be conducted in the summer of 2011.

Keywords: Synchronous Coaching, basic psychological needs

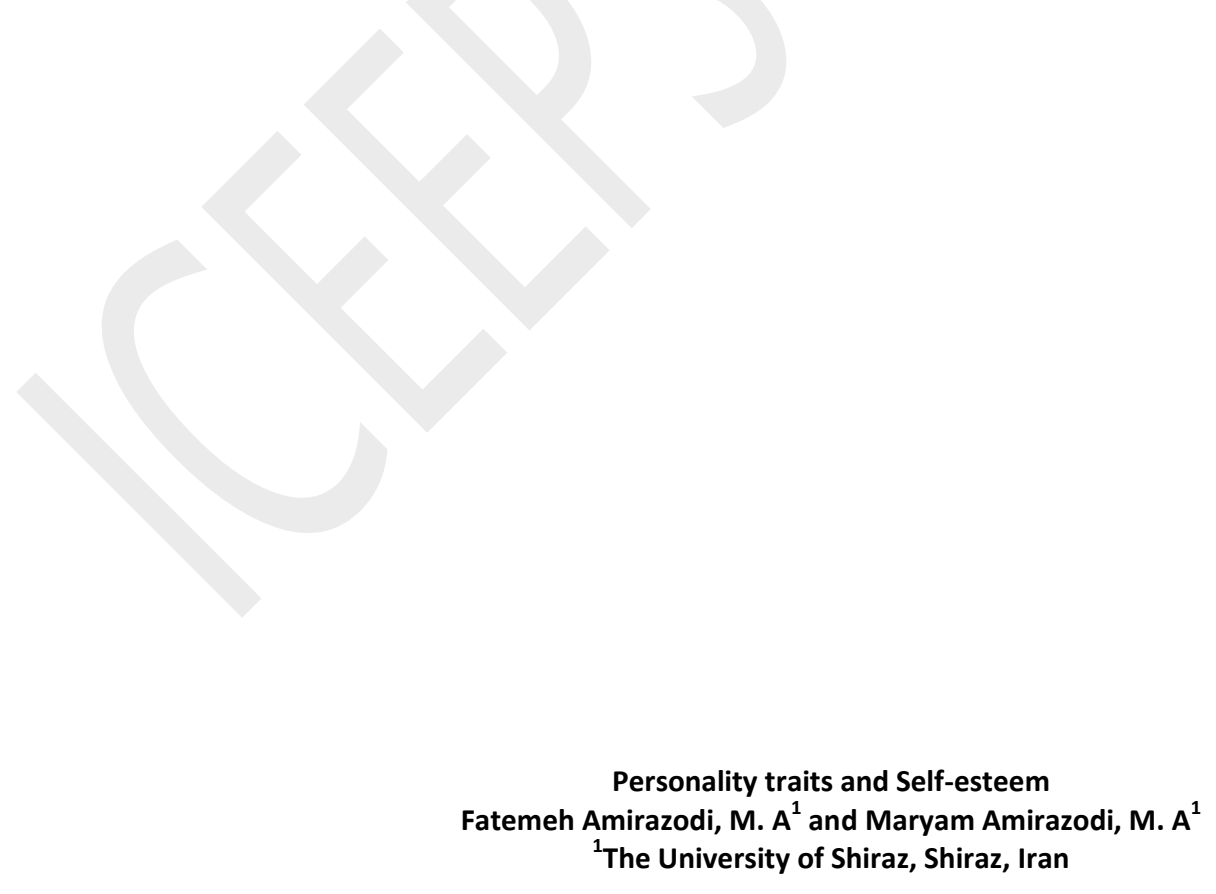

Problem Statement: Self-esteem refers to a person's sense of worth and the extent to which a person values or likes himself (Blascovich \& Tomaka, 1991). Rosenberg (1965) described self-esteem as a favorable or unfavorable attitude toward the self. The limiting research investigated the relationship between self-esteem and personality (Robins, 
Tracy, Trzesniewski, Potter \& Gosling, 2001). According to Pervin and John (2001), personality is defined as the characteristics of a person as a consistent pattern of feeling, thinking, and behaving.

Purpose of Study: The purpose of this study was to investigate of the relationship between personality traits and selfesteem.

Research Methods: Participants of this stydy were 310 Shiraz University students(147 girls and 163 boys) that selected by multi-stages cluster random sampling and assessed by Big Five personality factors Scale (Goldberg, 1999) and Self-esteem Scale (Coopersmith, 1967).

Findings: Simultaneous multiple regression of self-esteem score on the big-five personality showed that the extraversion versus introversion, agreeableness versus antagonism, conscientiousness versus lack of direction and openness versus closeness to experience were significant positive predictor and neuroticism versus emotion stability was significant negative predictor of the self-esteem score.

Conclusions: The facets of openness to experience factor correspond to the areas where a subject can exhibit more or less openness: aesthetics, feelings, actions, ideas, and values (Costa \& McCrae,1992). Individuals achieve to higher self-esteem through obtain new experience in society.

Keywords: Self-esteem, Personality traits, Openness to experience.

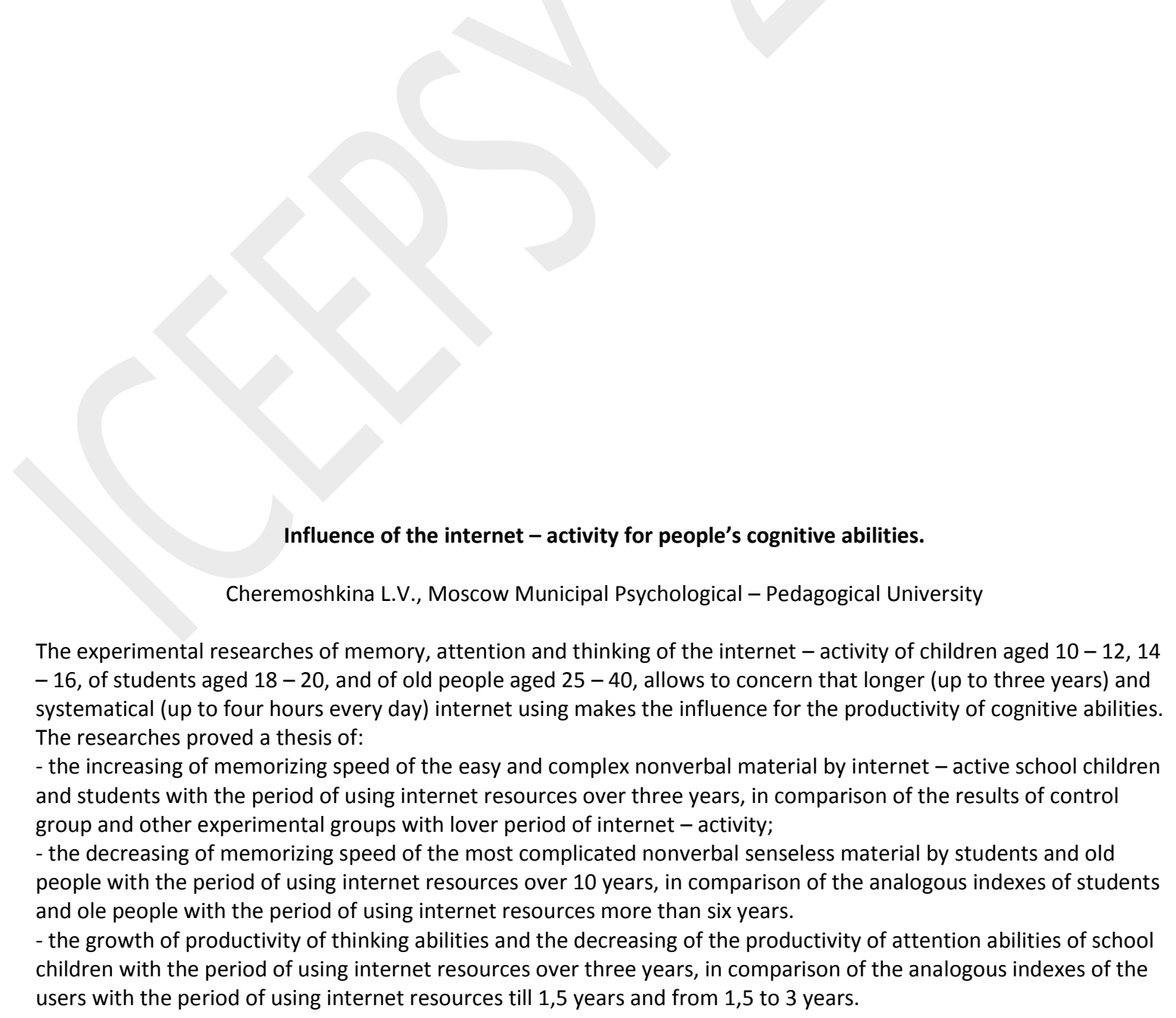


2. Psycho-physiological research of meta-memory processes of internet - active students aged $18-19$ with the period of using internet resources over ten years, revealed non-favorable signs for the effective functioning of theirs memory: lower level of the nervous system activity; non-appropriate species of the hemisphere's activity for the produced load; the activity level of theirs' nervous system was non - appropriate for the load's complication (high activity of the nervous system with the memorizing of relatively easy material).

The researches carried out by the financial support of the Russian Human Scientific Foundation, the project's number: 08-06-00378a

\section{STUDENT'S PERCEPTIONS AND EXPERIENCES OF UTILIZING THE ADVISORY AND COUNSELING SERVICES: CASE STUDY APPROACH}

Ambreen Tharani (Sr. Instructor) \& Tazeen Ali (Assistant Professor)

Aga Khan University School of Nursing, Karachi Pakistan

Problem Statement:

Entering into the university education is a paradigm which is a shift for students from basic to professional education and it often impacts on their health and they do come to know how to cope up with the challenges of education; similar is the case in nursing education. At the selected school of nursing, accessibility of supportive services is the integral part of the university for its students, where every student has a faculty advisor who guides them in their academic issues. Simultaneously, the student counselor, a professional psychologist, is also made available to provide support to students on basis of needs. While discussing the concerns related to students' academic performance at various faculty meetings at the selected school of nursing, the faculty members have several times reported students' resistance to utilize these guiding and support services. Hence, students' perception about the use of these services may explain it's under utilization.

\section{Purpose of Study:}

This study aimed to explore the perceptions and experiences of utilizing the available advisory and counseling services by students' of General Nursing Diploma programme at a private School of Nursing in Karachi, Pakistan.

\section{Research Methods:}


Qualitative explorative approach was considered and Diploma programme was selected as a 'Case.' Data was collected through semi structured interview from 15 participants equally representing all three years of Diploma programme. Both day scholar and hostel residents were considered for participation in this study.

\section{Findings:}

The participants rationalized confidentiality, stigmatization and time management as major concerns that obstruct their utilization of advisory and counselling services. Various changes are also suggested to make these services friendly towards students.

\section{Conclusions:}

Though the advisory and counselling services are meant to support and guide students with the challenges of university education, privacy and confidentiality, and the associated stigma were found to be major constraints of its utilization. As this study is firstly selected in the school of nursing, the application of suggestive changes given by the participants will assist in making these services more friendly towards students.

Keywords: advisory and counseling services, confidentiality, stigmatization, nursing students

\section{DO WE PRACTICE WHAT WE PREACH? A QUALITATIVE ASSESSMENT OF NURSING STUDENTS' PERCEPTION OF FACULTY ROLE MODELS \\ Ambreen Tharani (Sr. Instructor) \& Tazeen Ali (Assistant Professor) Aga Khan University School of Nursing, Karachi Pakistan}

\section{Problem Statement:}

Professional role modeling is key component in educational arena, where teachers serve as best role models for the students. It serves as a primary way to impact students search for meaning, purpose, and value in their personal and professional life, along with the development of conceptual learning. Nurse educators have to take prime position to ingrain the knowledge, skills and attitude to be self-directed learner. Considering the drop out of faculty members at the selected school of nursing, students' perception and experiences need to be taken into account to foresee the revamping the faculty development.

\section{Purpose of Study:}

To explore the students' perceptions and experiences about the faculty role modeling at a private School of Nursing in Karachi, Pakistan.

\section{Research Methods:}

This study followed qualitative framework, considering group of Diploma programme students as a 'case,' data was collected through semi structure interviews from fifteen representatives of all three years of diploma programme. Tape record interviews were transcribed with major thematic analysis of the verbatim.

Findings:

Participants in the study mentioned their disappointment with the ambiguity in their faculty as role models. While the faculty reinforced students to be equipped with the expected knowledge and demonstration of discipline, they themselves did not follow the same. The findings revealed that 'Professional role modeling' needs to be encouraged with the provision of appropriate mentoring and continued education of nurse educators. Participants strongly felt that though the nurse educators are well equipped with clinical skills, but lack in clinical and classroom teaching skills.

\section{Conclusions:}

There is significant association between professional role modeling by nurse educators and students learning outcomes. Therefore, faculty members should demonstrate proper role modeling and practice what they preach while reinforcing 
professionalism. Along with that, provision of appropriate mentoring and continued education can facilitate nurse educators to become the role models for nursing students to follow.

Keywords: Nurse educator, professional role modeling, student's learning outcomes

\author{
Assessment of Quality of Material Educational Tools for Technical Education \\ Jiří Dostál, Čestmír Serafín, Martin Havelka, Josef Minarčík \\ Palacky University, Žižkovo nám. 5, 77140 Olomouc, Czech Republic
}

\title{
Problem Statement:
}

The article deals with issues related to quality assessment of material educational tools for technical education. In particular it focuses on the creation of an assessment system for educational tools for the realization of electrical circuits. In its first section the article presents research conclusions capturing the process of the creation of a quality assessment system for educational tools and its evaluation. The second section contains the proper tool for quality assessment of educational tools that consists of three successive levels.

\section{Purpose of Study:}

Should the teaching material positively support the educational process, it has to have certain qualitative characteristics of which the most important can be deemed in particular to be the psychological and didactic ones. Not even the best approach to the usage of teaching materials during lessons on the part of the teacher or the student can ensure a positive effect. However, the theory of pedagogy is not capable of offering an evaluation system according to which it would be possible to evaluate and, based on specific criteria, explicitly recognize and identify the quality of many teaching materials and their suitability. Mainly for the purposes of the assessment of technical teaching tools for the realization of electrical circuits, the evaluation systems are not of sufficient quality.

\section{Research Methods:}

Q Methodology research method, theoretical analysis, questionnaire.

\section{Findings and Conclusions:}

On the grounds of theoretical analyses, synthesis, contemporary approaches to the evaluation of technical educational tools for the implementation of electrical circuits and through the medium of research methods a set of evaluation criteria suitable for implementation into the developed tool for the evaluation of educational tools has been created. In further steps, the created set of evaluation criteria has been verified. Because there was a requirement that the developed tool should offer a broad application, the research also dealt with effects that could be demonstrated during its usage by different groups of users.

The set of evaluation criteria verified by the mentioned steps would not reliably ensure practical usage, the proper tool for evaluation of technical educational tools has been developed allowing practical usage in a differentiated nature consisting of three successive levels. The evaluation tool therefore has its basic, additional and upgrading level.

Keywords: technical educational tool, electrical engineering, quality, assessment, education. 


\section{E-ACTIVITY AS A RESOURCE FOR FOUR GRADE IN HIGHER EDUCATION \\ S. Urréjola ${ }^{1} *$, A. Cancela, R. Maceiras, A. Sánchez \\ Defense University Center at the Naval Academy. University of Vigo \\ Chemical Engineering Department, University of Vigo}

Problem Statement:

The New European Higher Education System implies the adoption of different education systems than the traditional ones. In this way, the teachers must use some new mechanisms to teach the matter under study.

\section{Purpose of Study:}

In this work, an e-activity is proposed to promote the student learning process in the subject of "Complementary Fuels" of Energy Engineering degree. The proposed activity is based on carrying out a simple global analysis about the biofuel production. For that reason, the student will be able to analyze the production of bioethanol from a specific raw material and the economic viability of the process.

The overall objectives are: to study in depth the process of bioethanol production and to analyze the different variables of the process. The specific objectives are: to train the search, selection and organization of relevant information; to learn to design an industrial process; to learn how to do a feasibility study. In addition, the development of the activity requires a range of basic skills, such as team work, the use of virtual tools, and oral, written or visual communications skills.

\section{Research Methods:}

A hypothetical case, although it could be real, is setting out to carry out the e-activity. It is intended that the student analyzes the feasibility of the process and to know different methods of bioethanol production and bioethanol situation in Spain. From a pedagogical point of view, the activity ensures that students acquire certain skills.

The instructor specifies the methodology to the realization of e-activity, including: problem identification, information on the calculations or necessary steps to complete its resolution. Moreover, the teacher temporalizes the activity, and the evaluation system using rubrics.

Findings:

The e-activity has been evaluated for experts of other universities and they have considered that the e-activity is well designed and it could be useful to achieve the overall and specific objectives.

\section{Conclusions:}

An e-activity has been designed to enhance the student learning process and to adapt the subject of "Complementary Fuels" to the guidelines of the new European area of Higher Education.

Keywords: e-activity, biofuels, higher education, design e-activities 
different development cognitive process. This condition will make different condition problem in learning disability. The children have impairment cognitive process easy to cognitive distortion and emotional problem because they have difficult in interpreting information in communication and transform information process in learning. That condition will cause academic failure, disorder physical and body coordination, low motivation, ambiguous neurosis and impulsive behaviour of children (Velvet in Soekadji 2000). That condition will cause characteristic learning disability such short attention span, difficulties in following directions, social immaturity, language difficulties, inflexibility, poor planning and organizational skills, absentmindedness, clumsiness, lack of impulse control in children (Smith \& Strick, 1999). This situation will be misunderstood by the teachers, so the children will get inappropriate teaching and learning methods at school.

Purpose of Study: This study was aimed to parameter test cognitive process for children (age 6-16) with learning disability in Indonesia

Research Methods:

Participant: 60 children (6-16 years) with learning disability Instrument: WISC and Reading Test with picturial story books

Procedure: Participants were given Wechsler Intelligence Scale for Children and Reading Test using picturial story books in order identify their cognition process capability ( Proceess Journal CEEPSY-I,)

Findings:

The Children had eight stages cognition process as concentration, memory, comprehension, control behaviour, analyze, synthesis, evaluate, creativity thinking. this step develop from six stages Taxonomy Bloom for evaluate learning (krathwol, 2001)

Melani's cognitive process for children:

1.Concentration: target to keep concentration with control emotional problem as motoric coordination, reading interested reading tehnical, attention focus, reading speed, sitting attitude.

2.Memory : capability to kept vocabulary in the memory as recognize and recalling.

3.Comprehension : communication and interaction as interpretating, exemplifying, explaning, arrangement.

4.Control behaviour : self awareness and self regulation to control emotional and behavior as executing and implementation.

5.Analyze :ability to analize problem as Differensiasi and Organizing

6.Synthesis :ability to synthesis as similariti, statement and summary

7.Evaluate : ability for decision making process as Chek and critical

8.Creativity thinking : flexibility thinking to over come problem and adaptation in real situation such as alternative, generating, producing.

Conclusions:

The children had eight stage cognitive process to thinking such as concentration, memory, comprehension, control behaviour, analyze, synthesis, evaluate, creativity thinking. These step was parameter to show which one step had main problem cause learning disability of children. This is very important to support wisc test and projection test. We will know what children had achieved cognitive development optimal or no. Obstacle at one stage cognitive process will disturb process transfer information and this condition so easy causes cognitive distortion and difficulty for learning. All stage cognitive process must develope optimal appropriate with their developmental cognitive age. This achievement is very important to increase fleksibility thinking in adaptation process in real situation.

\section{Keywords:}

concentration, memory, comprehension, control behaviour, analyze, synthesis, evaluate, creativity thinking.

\section{Effectivity methode intervenes Melani's Mecatognition for learning disability of children in Indonesia. Faculty of psychologi University of Indonesia}

Problem Statement: Cognitive distortion is cognitive process disturbance that will cause children to have "false belief" in interpreting information and their experiences. That condition will cause academic failure, disorder physical and body coordination, low motivation, ambiguous neurosis and impulsive behaviour of children (Velvet in Soekadji 2000). That condition will cause characteristic learning disability such short attention span, difficulties in following directions, social immaturity, language difficulties, inflexibility, poor planning and organizational skills, absentmindedness, clumsiness, lack of impulse control in children (Smith \& Strick, 1999). Conflict and pressure from environment such as giving a bad labelling, will make emotional condition worsen. This situation will be misunderstood by the teachers, so the children will get inappropriate teaching and learning methods at school. At the same time the children will be misunderstood by their parents and get inappropriate parenting. This condition will have negative impact on children development in general, and especially in learning activities. The complexity of the problems causes difficulty to do intervention separately.

Purpose of Study: This study was aimed to test a metacognitive intervention for school age children with learning disability in Indonesia

Research Methods: 
The study was conducted in three phases

Phase 1

Participants: 20 children (6-16 years) with learning disability

Instrument: A scale to measure cognitive distortion

Procedure: Participants were given a list of vignettes representing Freeman's 17 cognitive distortions (2005). They

had to choose which situations were presenting their conditions. (Process juournal UI)

Phase 2

Participant: 60 children (6-16 years) with learning disability

Instrument: WISC and Reading Test with picturial story books

Procedure: Participants were given Wechsler Intelligence Scale for Children and Reading Test using picturial story books in order identify their cognition process capability ( Proceess Journal CEEPSY-I,)

Phase 3

Participant: 150 children (6-16 years) with learning disability

Instrument: Story books with social interaction, emotional situations, and independence themes.

Procedure: This intervention had four steps, the first step (concentrate, memory and comprehension) was basic exercise cognitive include the uses of dialog, suggestion and metaphor. The second step was behaviour control as condition the children ready to learning, cause they had control emotional and behaviour regulation. The third step (analize, sinthesa, evaluate) was exercise for learning strategy for modality strategic learning to reach optimal management process. The last step (creativity thinking) was flexibility thinking that application all knowledge and experience in the true world. The main goal of this intervention was increasing cognitive process of children to modality for their activity.

Participants chose themselves the story books they wanted to discuss. Participants were asked to be involved in dialog, reading, listening and writing in relation with the themes in the books. Each participant attended the therapy twice a week within eight months period. Each time, the process and the results of intervention were recorded in individual files.

Findings:

Phase 1

Participants had 11 types of cognitive distortion

Cognitive distortion causes seriously emotional impairment that block all function such cognition, emotional and behaviour functions in children. (Process journal UI)

\section{Phase 2}

Participants had eight stages cognition process as concentration, memory, comprehension, control behaviour, analyze, synthesis, evaluate, creativity thinking (Process Journal CEEPSY-I)

\section{Phase 3}

It was found that participants chose the books that representing their emotional problems. After 8 months, this intervention had proven that $80 \%$ children with learning disability had improved their self-regulation, emotional regulation, learning attitudes, motivation (make summary material school by them selves) and achievement at school (increase score up 70\%).

\section{Conclusions:}

Children with learning disability had certain types of cognitive distortion. To overcome their learning disability the therapist should restructure cognitive distortion the first time, go through improve their cognitive process with meta cognitive intervention using pictorial story books. The method metacognitive with pictorial story books were effective to attract the interest of children with learning disability to improve their attention at the same time they had learning strategy to study. This media will be easier to transform information and give a new experience to children so they can improve self awareness to restructure their cognitive distortion. In this case, the therapist must be smart to select the appropriate story books' titles, themes, words and pictures, because through pictorial books children could be easy to do metaphor, dialog, reflection, catharsis. From the therapist side, it is easier to give suggestions for the children psychological problems, and to teach children the appropriate learning process through the book themes.

\section{Keywords:}

Metacognition, suggestions, metaphore, Pictorial story book, self regulation, chatarsis, reflection, concentration, memory, comprehension, control behaviour, analyze, synthesis, evaluate, creativity thinking, self regulation, self awareness (Process Journal CEEPSY-I) 


\section{Problem Statement:}

With the approval of the Decree-Law 75/2008, the applicants to the post of director - the management and administration body of Portuguese public undergraduate schools or federation of schools- have, mandatorily, to present an intervention project for the schools to which they apply. This director's intervention project which should take into account the school's educational project needs to clarify the main lines of acting of the director during the four year period of his/her mandate.

\section{Purpose of Study:}

This study has as main objective to know some aspects of the director's intervention project. Specificaly, we intended to check the importance of this project as an instrument for the action of the director in the management and administration of the school. We wanted to ascertain if the directors did use their intervention projects for the establishment of their guidelines of educational management or if the project was used mainly as an instrument for their recruiment process.

\section{Research Methods:}

Two years after the enforcement of the Decree-Law 75/2008 and, approximately, ten months after the beginning of their tenure, we applied a questionnaire to 48 school directors. The directors we enquired are teachers with experience of school management and came from across the country.

\section{Findings:}

The kind of results we have obtained from this questionnaire does not allow us to infer some effectively supported conclusions since it is an exploratory empirical study and due to the inconclusive nature of many of the answers. Nevertheless we can posit several readings from the results that, supported by further reading and by other empirical research, can be converted into several other research hypotheses 


\section{Conclusions:}

Our data, even though not conclusive, reveal several answers of the directors that show the idea that their intervention project is consulted with relative frequency, being, therefore, a valid document in the orientation of their action facing the challenges that come by everyday. The answers may also show that the director's intervention project can be seen as an important instrument in the checking of the completion of the activities to develop through the mandate.

\section{Keywords:}

School leadership; School Management; Intervention Project; Portugal

\section{Problem Statement:}

\section{The ELO Project - Educational Leadership Observatory}

Jorge Adelino Costa

António Neto-Mendes

Patrícia Castanheira

University of Aveiro

Despite the importance that is given to school leadership, the studies on the subject in Portugal are scarce and are a measure of the limited relevance that is given to this phenomenon. Even though there has been a slow uprising of this field of study in Portugal, there is not a gathering of the research that has been done on school leadership in our country.

\section{Purpose of Study:}

The aim of this project is to create an educational leadership observatory (ELO) in order to gather the information on the research that has been done in the first ten years of this millennium on the subject of school leadership in Portugal - namely PhD and Master theses, papers in scientific journals and in proceedings of scientific congresses.

\section{Research Methods:}

This information will be theoretically characterized, using content analysis, and with the use of conceptual framework that is currently under construction. In a second stage, the research will then focus on analyzing the OCDE reports on school leadership of some countries, namely England and Canada, which have a great tradition on the study of educational leadership so that a comparative study of the similarities and differences between school leadership in those countries and Portugal can be established. The next step will be the negotiation of partnerships with centres for educational leadership of those countries in order to create the basis for a future establishment of a centre for educational leadership in Portugal.

\section{Findings:}

The goal is not to replicate the educational policies in use in those countries, but to understand the context of Portuguese school leadership and to look for the most appropriate policies to adopt. The project also involves the creation of a web page that can serve as a useful guide for national and international researchers on school leadership and that can be used as source of information for school leaders in Portugal.

\section{Conclusions:}


One of the main goals of this project, then, is the creation of a center for educational leadership in Portugal that can be used as a consultation means for the establishment of educational policies and as research support for further studies.

Keywords:

School leadership; school management; research on school leadership;

A Cross-Cultural Validation of the Technology-Rich Outcomes-Focused Learning Environment Inventory (TROFLEI)

Anita G. Welch

North Dakota State University

USA

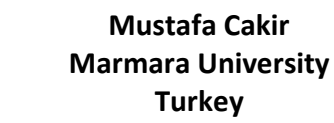

Claudette Petterson

North Dakota State University

USA

Fu-Chih Cheng

North Dakota State University

USA

Gerald Ketterling

North Dakota State University

USA

\section{Problem Statement:}

Few studies have provided a comprehensice model of classroom enviroments by including antecedents, enviroments, and outcomes in one stuy. This study is designed to provide a robust representation of the variables that influence, and which are influenced, by classroom environments.

\section{Purpose of Study:}

By using the Technology-Rich, Outcomes-Focused Learning Environment Inventory (TROFLEI), in a multilevel analysis, incorporating multiple background variables in a mixed methods design, this study hoped to identify some of the relationships surrounding classroom environment and academic efficacy. This project had four objectives: 1) investigate the cross-cultural validity of the TROFLEI when used with American and Turkish high school students; 2) to investigate associations between socioeconomic status (SES), student ethnic diversity, gender, and students' perceptions of their classroom learning environments; 3 ) to examine associations between students' perceptions of their science classroom environment and their perceptions of academic efficacy in science tasks; 4) to investigate students' perceptions of the actual and preferred science learning environment.

\section{Research Methods:}

This study was conducted in high school science classrooms in throughout the United States ( $N=131)$ and Turkey ( $N=985)$. These schools included large metropolitan areas, as well as suburban, rural, and tribal communities. Each student was asked to complete the TROFLEI survey.

Quantitative analysis was conducted in four components: multilevel confirmatory factor analysis (MCFA), scale reliability analysis, correlation and regression analyses, and MANOVA. This combination of inferential and modeling statistical analysis provided rich and robust results.

\section{Findings:}

Analysis of the data is still being conducted, but prelimary results do indicate that while internal validitey exists within the TROFLEI, differences between American and Turkish students do exist. Additional analysis is underway.

\section{Conclusions:}

The TROFLEI has a high degree of initernal consistancy with American and Turkish studnets. However, preliminary results indicate differences within their classroom environments. Additional anayalsis is being conducted and more detailed results will be presented at the conference.

Keywords: TROFLEI, cross-cultural validation, technology 


\section{Exact research on the reception of poetry}

$$
\text { Jaroslav Vala }
$$

Faculty of Education

Palacky University Olomouc

Czech Republic

\section{Problem Statement:}

Research on the reception of poetry. The key contribution of the research is a closer connection between pedagogy and experimental psychology in terms of exact research on the readers' reception and the following description of its results. 
The purpose of the study is to describe the development of a suitable research instrument and its use it in the research itself.

\title{
Research Methods:
}

The method of semantic differential (Osgood, Suci, Tannenbaum 1957) was used as the basis for the development of the suitable experimental tool for investigation of the reception of lyric poetry. This method was modified and adapted to the investigation of the reception of lyric poetry.

Findings:

Within the long-term research, we succeeded in isolating three factors which were denoted as the factors of intelligibility, evaluation and appeal. Scale factor identity was verified and the functionality of the created tool as well as sufficient saturation of separate scales by the expected factor load were proved. The split-half method and Cronbach's Alpha coefficient were used for assessing the reliability of the performed measurements. The results show that the reliability of the performed measurements is very high $(0,885-0,948)$ with both methods.

This process was used to observe the reception of selected poetry texts with various categories of respondents aged $15-19$.

\section{Conclusions:}

The performed research proved that it is possible to investigate the readers' reception of lyric poetry by an exact research method based on semantic differential.

The research proved that substantial differences exist in the reception of poems of various historical periods, and it also showed which poems are preferred by different categories of the respondents. The results can be applied in teaching literature.

At present, we started an extensive three-year research project aimed at the reception of poetry based on semantic differential and Q-methodology. One of the project parts is also longitudinal research among the students of selected school-classes on the possibilities of positive influence on their attitudes to poetry.

Keywords:

semantic differential, reception of poetry, literature didactics, literature teaching, pedagogical research

\section{The efficacy of teaching differentiation on children with Special Educational Needs (SEN) through Literature}

\author{
Gkouni Vasiliki, Postgraduate student in Department of Primary Education, University of Athens \\ Paparousi Maria, Assistant professor in Department of Primary Education, University of Thessaly \\ Andreou Eleni, Associate professor in Department of Primary Education, University of Thessaly
}

Many students present Special Educatonal Nedds (SEN) on account of learning disabilities or other problems derived from their different cultural and lingual environment. In greek reality those children are subscribed in mainstream schools without obtaining the suitable learning support in the classroom which would enable them to cope with their difficulties. On the other hand, recent research points out the importance of differentiated teaching in supporting all students participate in the learning process.

The purpose of our study is to examine the efficacy of teaching differentiation as a method for helping primary school children with SEN improve their writing skills through Children's Literature.

Our sample consisted of 16 children ranging in age from 9 to 10 years and drawn from a fourth grade of a middle-sized primary school in a suburb of Athens. Six of those children faced up with SEN. Two stories from the fourth-grade literature textbook were used for designing a variety of creative activities which were incorporated into 4 teaching hours (45 minutes each) during the lesson of literature. The writing tasks were differentiated for children with SEN. Moreover, all children completed a 7-item questionnaire before the use of differentiated teaching and immediately after, so as to assess in perspective their initial and final preferences in similar creative activities. 
The data we collected prove that most children with SEN increased the text size they produced during the differentiated writing activities but they presented variations referring to the quality of the vocabulary they used. However, there was a notable improvement in this session in some differentiated writing tasks.

In coclusion, teaching differentiation was effective on helping children with SEN of our sample increase the size of their texts in a point that they could be compared with the texts of the students without SEN. Moreover they used a superior vocabulary than usually with the prospect of improvement.

Keywords: teaching differentation, Special Educational Needs, Children's Literature

Teaching English in Algeria and Educational Reforms An overview on the Factors Entailing Students Failure in Learning Foreign Languages at University

Mrs Rezig Nadia

Maitre Assistant at the English Department

Mohamed Kheider University

Biskra-Algeria

Problem Statement:

This paper examines the factors behind the weak performance of a big number of Algerian English learners at university despite their high motivation to learn that language in reference to the educational reforms implemented at all educational levels since 2000 to the present day and the learners complex linguistic background.

Purpose of Study:The study aims basically at tracing the link between the students linguistic and educational background that had undergone successive changes in the span of 10 years and their weak achievement at university level.

Research Methods: We opted for two reseach techniques:

1-A questionnaire adressed to first year students (200/600 registered) to gather data about their attitude to learn English and their motivation.

2- A proficiency test to measure students level in English.

Students scores in proficiency test were correlated with their scores in their final exams and their

Answers to the questionnaire.

Findings:

Over 80 percent of the sample have a positive attitude towards the English culture and language.

70 percent of the students having positive attitude and failed in the entrance test, failed in the final exam.

65 percent of the students who have a negative attitude and passed the entrance test, could pass the final exam. Conclusions:

Students' learning weaknesses are result of their middle and high school weak instruction.

Keywords: Foreign language teaching, Algerian university curricula, motivation, educational reforms. 


\section{Effect of teaching of self-regulated learning strategies on self-efficacy in students}

\section{Abstract}

Author(s) Name and Affiliations Jahanshir Tavakolizadeh, PhD in Psychology, associate professor, Department of Public Health, School of Health and Social Development \& Health Promotion Research Center, Gonabad University of Medical Sciences, Gonabad, Khorasan Razavi, I.R.Iran. P.O. Box: 397 Telefax: +98 533 7229025,E-mai: jahanshir t@yahoo.com.au; Soghra Ebrahimi-Qavam,PhD in Psychology, Associate professor, School of Psychology, Allame Tabatabayi University, Tehran,I.R.Iran, E-mai: qavam2005@yahoo.com

Problem Statement: self-efficacy as a cognitive components effect on physical and psychological health condition. Low self-efficacy is related to different aspects of mental health problems. although, the studies have showed that self-efficacy play a main role on effective self regulation, but any study has done that show teaching self-regulated learning strategies can increase self-efficacy level.

Purpose of Study A research underwent with the general objective of proving the effectuality of training in selfregulated learning strategies on self-efficacy in $2^{\text {nd }}$ grade middle-school boys

Research Methods. The study is a experimental research. The sample size consisted of 30 students, 15 each in experimental and control groups, and the method used was of a random cluster multiple-stage sampling type on $2^{\text {nd }}$ grade junior-high schools of both morning and evening shifts from sector 4 of the Heptagonal Zones of the Education Office in the city of Mashhad, Iran. The measurement tools consisted of questionnaires on self-regulated learning, and self-efficacy that were executed as a pre-test in both groups. After which, only the experimental group was administered training in self-regulated learning strategies for 18 sessions of one hour each. After the training a posttest using the aforementioned questionnaires were taken from both groups. The data gathered were analyzed using SPSS software program and the independent T-test - differences between means.

Findings The results showed that there was a meaningful difference between means of self-efficacy in experimental and control groups; and that the training of self-regulated learning strategies produced a rise in self-efficacy levels in the students.

Conclusions: teaching of self-regulation strategies can increase self-efficacy level Presumably, using self-regulated learning strategies has firstly caused a boost in judgment of their abilities in the field of educational activities. These beliefs have probably later entered activities in domains outside of education and led to self-efficacy of students in various fields..

Keywords self-regulated strategies- self-efficacy - students - city of Mashhad 


\title{
the effectuality of teaching of self-regulated learning strategies on mental health in students
}

\begin{abstract}
Author(s) Name and Affiliations :Jahanshir Tavakolizadeh, PhD in Psychology, associate professor, board of basic sciences, Gonabad University of Medical Sciences, Gonabad, Khorasan Razavi, I.R.Iran.; Soghra Ebrahimi-Qavam, PhD in Psychology, Associate professor, School of Psychology, Allame Tabatabayi University, Tehran,I.R.Iran, Noor Ali Farrokhi, PhD in Psychology, Associate professor, School of Psychology, Allame Tabatabayi University, Tehran,I.R.Iran, Mahmood Golzari, PhD in Psychology, Associate professor, School of Psychology, Allame Tabatabayi University, Tehran,I.R.Iran
\end{abstract}

Problem Statement: the mental health problems produce many difficults and irrecoverable consequences for students, these problems not only on educational function, but effect on different aspects of physical, cognitive, emotional, and social development. It seems self-regulation has been positive effects on mental health.

Purpose of Study: This research has been undergone with the general objective of proving the effectuality of teaching of self-regulated learning strategies on mental health in $2^{\text {nd }}$ grade middle-school boys in the city of Mashhad.

Research Methods: The study is a experimental research. The sample size consisted of 30 students, 15 each in experimental and control groups, and a random cluster multiple-stage sampling method was used on $2^{\text {nd }}$ grade juniorhigh schools of both morning and evening shifts in sector 4 of the Heptagonal-zones of the Education Office in the city of Mashhad. The measurement tools consisted of MSLQ and GHQ-28 questionnaires that were initially executed as a pre-test in both groups. After which, only the experimental group was given teaching in self-regulated learning strategies for 18 one-hour sessions. After the teaching a post-test using the aforementioned questionnaires were taken from both groups. The data gathered were analyzed using SPSS software program and the independent T-testdifferences between means.

Findings: The results showed that there was no meaningful difference between means of mental health situation and its symptoms (physical complaints, anxiety, social dysfunction and depression) in both experimental and control groups.

Conclusions: there are any significant relationship between the teaching of self-regulated learning strategies and mental health. Although, the relationship these variables can be affected by factors such as measurement tools of mental health, the time limitation of executing the teaching of self-regulated learning strategies (the role of time factor in modifying awareness), the opportunity of more practicing and utilizig self-regulated strategies in everyday life

Keywords: teaching - self-regulated strategies - mental health - students - city of Mashhad 


\section{Factors Underlying the Reading Performance of Algerian Microbiology Students}

\section{Zahia MEBARKI Ferhat Abbas University Algeria}

\section{Problem Statement:}

In the Microbiology institute at Ferhat Abbas University at Sétif English for scientific and technical purposes has become an obligatory course. The institute receives students that have been trained in Arabic and have a low competence in the English language. This linguistic handicap in English has brought with it some problems of reading comprehension in the students' own speciality. The graduates' low-level reading proficiency in English fails to meet the requirement of their academic needs.

\section{Purpose of Study:}

The study was carried out with the aim of identifying some of the important factors that have a bearing on the reading achievement of Algerian ESP students. The general research questions addressed in the study were: (1) What are the factors which underlie the readers' reading performance? and (2) What test tasks have a bearing on the reading achievement of the test-takers?

\section{Research Methods:}

Reading comprehension test

Findings:

The findings of the first question indicate that there are three factors which underlie adequate understanding of texts: (i) lexical knowledge, (ii) coherency, and (iii) comprehension. They also revealed a significant correlation between the different factors, especially between 'lexical knowledge' and 'comprehension'. They are the main determinants of reading ability.

As for the second question, the findings indicate that the test-takers performed moderately on the 'local' reading skills which operate at the word level and involve understanding lexis and deducing meaning of lexical items as well as on 'global' reading skills and strategies which involve processing the text in order to establish an accurate comprehension as reading for main ideas, reading for details, and matching. This suggests that the lexical knowledge is tightly related with comprehension skills and strategies.

\section{Conclusions:}

Specific instruction should be integrated into the ESP reading course to prepare students become more successful readers and succeed in environments where they will have to comprehend academic texts and read an extensive amount of material in a limited amount of time. These are particularly crucial in academic fields in which most students have scientific backgrounds and scarce knowledge of linguistic notions. 


\section{Problem Statement:}

There is considerable discussion and evidence to indicate that transfer of training is a pivotal concept in learning and yet, in many training and professional development programmes, performance improvement does not occur. The solution is to use what we know about effective learning and employ a strategic transfer of training response. A key dimension is to understand the nature of professional development and transfer of training as two sides of the same coin; professional development emphasises processes and transfer of training emphasises outcomes.

Purpose of Study:

In this paper attention will be centred upon how transfer can be planned to achieve impact on-the-job and reference will be made to a teacher professional development programme in dance education. This programme will be used to demonstrate how the strategic utilisation of key principles of transfer contributed to its success.

\section{Research Methods:}

This was an action research project developed in one primary school and used experiential learning principles. Key to transferring the knowledge and skills was the use of a multilevel transfer of training approach which progressively developed staff expertise. Simple pre and post measures, observations and staff feedback were used to ascertain the success of the programme.

Findings:

The findings clearly indicated the success of the programme as all staff reported changes in their perceived competence, staff presented at conferences, the students performed dance for parents and the professional development leader's observations confirmed increased levels of competence. The ongoing programme is testimony to its success.

Conclusions:

When a professional development programme is developed it is essential that strategies be in place not only to ensure participant satisfaction and learning but also transfer of the training which can then impact upon the institution's operation.

\section{Keywords:}

Transfer of training, teacher professional development

THE IMPACT OF PERCEIVED PARENTING ON THE ACADEMIC OVERLOAD OF THE ADOLESCENTS OF KOLKATA METROPOLIS

Mitra De, Mom Asst. Professor, Department of Education, Surendranath College for Women, Kolkata. Sengupta, Debjani Professor, Department of Education, University of Calcutta, West Bengal.

Problem Statement: Our children are growing in a world where peers and media exert greater influence not ony on them but also on the parents and teachers. Indian adolescents in and around the metropolitan cities are getting more and more vulnerable to risky behaviour, falling prey to socially destructive and personally devastating ways of coping with this stress. Teenage suicides at present in India are the highest in the world with West Bengal reporting to be the highest at $11.8 \%$ in 2008 . Out of many the two most mandatory causes being environmental and psychosocial. 
The Purpose of Study was to explore the relationship between Perceived Parenting and academic Overload of the teenagers of Kolkata Metropolis, as in the long run the parent-child relationship contributes to the social support system of an adolescent, eventually affecting his/her mental health.

Research Methods: A group of 302 adolescents from Kolkata (180 boys and 152girls) aged 14-18 years participated in the study. They were selected through incidental purposive sampling thchnique. The tools used were a standerdized test of Perceived Parenting and an Academic Overload Questionnaire developed by the researchers.

Findings: Show prevalence of positive parenting with its level being above average of the entire sample under study. The level of Academic Overload was found to be within average level. There was no significant difference in relation to gender in the level of Academic Overload and Perceived Parenting.Perceived Parenting was found to have an inverse relationship with the level of Academic Overload of the adolescent.

Conclusions: The study finds solution to the two causes arising basically out of poor parent-child relationship and excess load arising in and from academics. It has a very strong implication on the family level, as it throws light as to how parents may be instrumental in shaping their child's negative thoughts.

Keywords: Academic Overload, Perceived Parenting

\section{Problem Statement:}

The role of educational psychology in teacher education has been discussed in the literature. Due to its unique contribution in the theories, research and applications of the psychological knowledge about the learner and about the learning and teaching process, educational psychology is often perceived as a necessary component in teacher preparation. Important as it appears, there is very little research about students' perception in taking educational psychology.

\section{Purpose of Study:}

The purpose of this study was to investigate students' views and needs of studying educational psychology as there was very little work to assess the value of such a course from students' perspectives.

\section{Research Methods:}

Twenty-seven undergraduates were studied. These students took Educational Psychology either as a required course or as an elective. Students' perceptions were studied through a questionnaire and students' self-reflection portfolios describing their own learning journey in the course.

Findings: 
Among 6 areas covered in the first semester in the Educational Psychology course, in terms of relevance, importance and interest, students ranked social emotional development highest, followed by personality theories, and then by theories of cognitive development. Research methodology and design was accorded the lowest ratings. The teaching methodology and characteristics of the teacher changed students' perceptions of the course. The teacher's expertise knowledge was the most crucial factor, followed by her respect for all students, her enthusiasm and her attempt to engage all students. The positive learning atmosphere, the use of a variety of active learning experiences and the teacher's presentation skills were of equal importance. Qualitative analyses of students' self-reflections showed that some students started taking the course with some negative preconceptions but changed their views as they later found that the theories learned had application value. The use of videos, in-class activities, games, discussions, project work, lecture notes, worksheets, readings, and quizzes were reported to be effective in helping students understand the course content, relate theory to practice, arouse their interest and sustain their efforts in studying the course.

\section{Conclusions:}

The present findings shed light on students' perceptions of their needs and interest in studying a course in Educational Psychology.

\section{Keywords:}

Educational Psychology, students' perception, undergraduate course, teacher education programme

Self Regulation Skills and the Post Secondary Distance Learner

Dr. Linda Chmiliar

Athabasca University

\section{Problem Statement:}

Attrition rates in distance/online courses tend to be fairly high, with drop out rates at some institutions exceeding $40 \%$. In distance/online courses, students must take initaitve and self regulate their own learning. It is important that post secondary institutions be aware of the self regulation skills of their students, as self regulation skills are strongly related to course completion and academic success.

\section{Purpose of Study:}

This study examines the self regulation skills of university students enrolled in a distance education post secondary institution, to see if they report difficulties with self regulation, as well as the specific areas in which they are experiencing difficulty. The study also examines student interest in improving self regulation skills.

\section{Research Methods:}

The study made use of an online survey for data collection. The survey was comprised of 122 questions on a Likert scale as well as several opportunities for qualitative resposnes. 3000 students who have successfully completed a course and 3000 students who had not successfuly completed a course in the last 3 years, were randomly selected.

\section{Findings:}

Data indicates that students who have difficulties completing course work do have difficulties in many areas of self regulation, and succssful students also indicate some specific areas of weakness. In addition, there is an interest in improving these skills.

\section{Conclusions:}

Self regulation skills do not develop naturally. In post secondary education, there is an assumption that students are actively involved in the learning process and utilize self regulation strategies. Unfortunately, many students do not enter post secondary education with the knowledge of appropriate strategies, and studies indicate that students report difficulties in a number of areas (Garavalia \& Gredler, 2002; Rachal, Daigle, Rachal, 2007). Therefore, students who have difficulties with self regulation need an effective learning environment that provides specific strategy instruction. Training in self regulation can lead to significant change in the self regulation and in student success (Azevdeo \& Cromley, 2004; Zimmerman, 2008). Therefore, it is imperative that institutions interested in fostering student success address student self regulation skills. 


\section{Keywords:}

distance learning, higher education, self reguatlion

\section{Leadership for Sustainable Society: a Multidisciplinary Systems Approach Brenda Bushell University of the Sacred Heart Tokyo, Japan}

Problem Statement: Notions of multi-disciplinary and responsible citizenship raise essential questions about the nature and purpose of higher education. On what basis are we preparing our graduates to become leaders in the 21st century with skills and abilities that can make a difference in terms of building a sustainable society?

Purpose of Study: Through the study of collaborative educational experiences, this research aims to identify the knowledge base and dimensions of leadership that are required to support the growth of responsible citizenship in young people today.

Research Methods: The participants of this research included 30 Japanese and 30 Nepalese university students who engaged in an experiential educational program in Nepal. The program included a series of educational leadership activities based on a multidisciplinary systems approach to sustainable education. The research employed a pre and post questionnaire using the 5-point Likert scale. A descriptive analytical method after data collection was used.

Findings: Results indicate a significant association between students' participation and the construction of knowledge around the dimensions of sustainable society. Also revealed were four prominent leadership indicators which can be incorporated into the educational pedagogy as a way to catalyse students' leadership capacities.

Conclusions: A reorientation to knowledge-building through a collaborative multidisciplinary systems approach to sustainable education, particulalry for students in more culturally traditional learning environments has the potential to nuture efficiacy and leadership in students. This study provides valuable cross-cultural data on how to interface knowlege-building and capacity-building for behavioral leadership aimed at sustainable society.

Keywords: higher education, collaborative systems approach, sustainable education, leadership indicators 


\section{Enhancing Communication Skills with PECS in Autistic Children}

Adriana S. Ginanjar, University of Indonesia

\section{Problem Statement:}

One of the main problem in autistic chidren is speech delay and communication disorder. It is not easy to teach communication skills to autistic children because they have sensory problems that result in hyperactivity, aggresive behavior and anxiety. Speech therapy as an early intervention has helped the autistic children to improve their communication skills. However, for those who are "non verbal", that is only speak a very limited words even after they reach 5 years old, it is necessary to use visual aids. PECS (Picture Exchange Communicatin Skills) is a methods using small and portable pictures to enhance communications skills.

\section{Purpose of Study:}

The purpose of this study is to apply PECS system for non verbal autistic children and find out it's effectiveness in improving the communication skills.

\section{Research Methods:}

This research is part of the education process of autistic children in a special needs school. PECS has been used for more than 5 years and evaluated through observations and quantitative measurement. The subjects are 20 autistic children beetwen the ages of 7-16 years.

\section{Findings:}

PECS has been very successful for all of the subjects to improve the communication skill in different ways:

a. expressing their needs such as foods, place to go, choosing rewards, etc

b. expressing their emotions

c. making full sentences

d. as a bridge to learn typing

\section{Conclusions:}

Many autistic children have diffciulties in verbal expression. However, it does not mean that they do not have the capacity to understand language. The application of PECS in autistic children has proved that they are able to communicate better if the tool is fit with their potentials and their way of thinking.

Keywords: communication, PECS, autistic 
Interpersonal conflicts are integral to interpersonal relationships throughout life. The way one chooses to behave during conflict can materially affect his ability to resolve the conflict and to maintain the relationship. One such relationship is created at school, between students and their teachers. It is a relationship that is potentially replete with conflict, because the teacher, as an authority figure that represents the school's doctrine, makes decisions that dictate the student's behavior in class and at school, and is therefore sometimes perceived by the latter as restricting his freedom to implement his own will, forcing him to behave according to values that are not necessarily compatible with his own. The present study is based on the assumption that an important factor affecting student perception of teacher's decisions, is the extent of fairness in the decision making process, defined in literature as "procedural justice" (Lind \& Tyler, 1988; Thibaut \& Walker 1978).

The purpose of the study is to test students' conflict management strategies during student-teacher conflict, as a function of students' perception of the extent of procedural justice in teachers' decisions. Additionally, we test to what extent the above association is mediated by students' feelings of identification, loyalty, commitment and legitimacy concerning their teachers, their class and their school. The research model is presented in the following diagram:

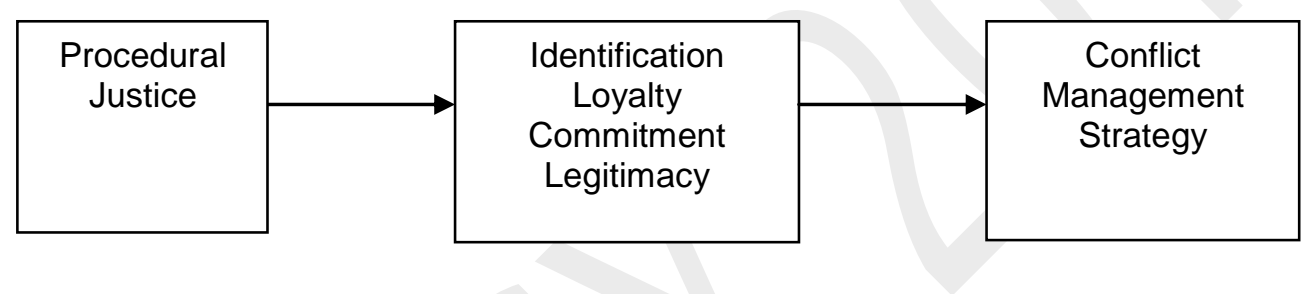

To test the model, we conducted two studies. In the first, high-school students responded to questionnaires testing the associations between perceived procedural justice and students' conflict management strategies, as well as the mediation effects of the students' feelings (identification, loyalty, commitment and legitimacy). In the second study, the four components of procedural justice were manipulated through written scenarios, and we tested their associations with students' feelings and conflict management strategies. While the first study enables to validate the proposed model of procedural justice influence, the second study illuminates the causal association between the components of procedural justice and conflict management strategies and students' feelings, while comparing the relative contribution of each of these four components to the variance in students' behavior and feelings.

The study is an innovative, interdisciplinary endeavor, connecting three fields of research: Conflict Management, Procedural Justice and Educational Psychology. It is currently at the stage of data-processing; so far, the results support the research model.

Keywords: Conflict Management, Procedural Justice, School

Gender Equity in Higher Education: Faculty Salaries, Career Development, and Academic Services

Yong-Lyun Kim

Hankuk University of Foreign Studies, South Korea

\section{Problem Statement:}

Although some professional organizations such as American Association of University Professors have annually reported the result of the national data analysis about facutly salary and provided institutions with empirical information for benchmark, individual institutions need institutionalized criteria and methods in salary analysis for gender equity. In addition, for a well-rounded research on gender equity issues, insitutions need to look into multiple aspects of faculty life including career development and workloads to diagnose potential inequity.

Purpose of Study:

The primary purpose of the study is to identify potential gender inequity in faculty poisitons in terms of salary, career development, and their workloads at a public four-year institution. 
To meet this research purpose, the study uses institutionalized research methods in the analysis. More specifically, with the faculty salary data, this study employs both descriptive and regression analysis in which gender, length of time in the institution, and discipline are included as independent variables. For the gender difference in career development, this study looks into the data about promotion and tenure evaluation records. Finally, faculty workloads including teaching and mentoring student obligations are examined to identify gender differences in academic services.

Findings:

The result from the regression analysis yielded that gender was not a significant factor affecting faculty salary variance when the study controlled the length of time (rank, length of service at the college, and prior experience) and the area of study (discipline). The analyses associated with gender difference in career development and faculty workloads found no evidence that was unfavorable to female faculty.

Conclusions:

In order to conduct a institutional study on gender equity issues, individual institutions should have specified and institutionalized research methods. Through using institutionalized methods, this study concluded that there were no obivous gender inequities in faculty salary, career development, and their workloads. Finally, this study recommends some alternative research methods that focus on qualitative approaches such as interview and climate survey to make the result more responsible and reliable.

Keywords: gender equity, higher education, salary analysis, insitutional research

\section{Preparing Items for Large Scale Computer Based Assessment: Case Study for Teachers' Certification on Basic Computer Skills}

Problem Statement: One of the main issues facing a Computer Based Assessment (CBA) system for large-scale examinations is the items' exposure due to repeated e-exams that take place in different times or places. Administrators could reduce the side effects of item's exposure (possible leaks, copying in the examination process, etc) by enriching the item bank with items that assess the same knowledge, skills and attitudes in a different way.

Purpose of Study: This paper presents the life-cycle of items used for teachers' certification in basic computer skills in the frame of a national program that is carried out in Greece since 2003 (2003-2010). A methodology for preparing items for large scale assessment is introduced. The structure of items used and the roles of people involved are described. The syllabus for basic IT skills explored (exposure, success rate etc) based on teachers' responses. A process for preparing equivalent items (families) is introduced. The teachers' behavior concerning equivalent groups of items (families) was explored based on candidates' responses.

Research Methods: Pairwise statistical tests (parametric \& non parametric) carried out on each family and family members were analyzed based on teachers' responses (respond time, success/failure rate etc). Families' items that encountered to behave different were examined side by side looking for evidences that interpret the different teachers' behavior. A set of indicators about syllabus used for teachers' certification in basic IT skills is defined (syllabus's node exposure, success rate etc). Teacher's results (pass or fail) were evaluated based on confidence intervals.

Findings: Based on teachers' responses since 2003, we can argue about a set of rules that must be taken into account when someone has to create equivalent set of questions for a large scale CBA.

Conclusions: In large scale assessment, item banks should be enriched with equivalent items. Preparing items for a large scale CBA produces knowledge and experience that can be utilized for improving an item both from educational and technical point of view. This experience should be recorded and utilized by items' authors. 


\section{Keywords:}

Teachers' certification, Computer Based Assessment on Basic Computer Skills

Problem Statement: Non- supportive family or school environments, place young people at risk for depression. However most of the studies focus only on the family environment, while the school environment is grossly neglected. The aim of this study was to investigate the predictive role of classroom environment perceptions in depression of high school students.

Purpose of Study: The purpose of present study was to investigate effect of parenting styles on academic procrastination.

Research Methods: A sample of 385 high school students (164 male, 221 female) were selected through random cluster sampling from Shiraz high schools, Iran. They completed Metacognitive Orientation of Classroom Learrning Environment scale and Children Depression Scale. To examine reliability of measures, Cronbach alpha coefficient and to determine validity, factor analysis method were used.

Findings: Results showed that there was a significant negative relationship between all dimensions of Metacognitive Orientation of Classroom Learrning Environment and children's depression, but Multiple regression analysis indicated that only "within-class discourse", "metacognitive demands", " distributed control " \& "emotional support"( 4 dimention of metacognitive Orientation of Classroom Learrning Environment) can negatively predict students' depression. In addition, independent t-test showed the significant differences between females and males in research variables

Conclusions: In sum, the results showed that classroom environment perceptions affects students' depression in school.

Keywords: Classroom environment perceptions, depression, The Metacognitive Orientation of Classroom Learrning Environment Scale, Children Depression Scale, Metacognition. 


\section{Parenting Styles and Self-esteem \\ Hamidreza zakeri, M. A $^{1}$ and Maryam Karimpour, M. A \\ ${ }^{1}$ The University of Shiraz, Shiraz, Iran \\ ${ }^{2}$ The University of Islamic Azad, Marvdasht, Iran and member of youth researchers Institute}

Problem Statement: Self-esteem is confidence in our ability to think; confidence in our ability to cope with basic challenges of life; confidence in our right to be successful and happy; feelings of being worthy, deserving, entitled to assert our needs and wants, achieve our values, and enjoy the benefits of our efforts (hooks, 2003). It is most importantly a personal judgment of self and sense of worth primarily based upon externally imposed criteria (Alford, 1997). One of the externally imposed criteria is family factors.

Purpose of Study: The purpose of present study was to investigate of the relationship between parenting styles and self-esteem.

Research Methods: Five-hundred-fourty-six Shiraz High school's students ( 240 girls and 306 boys) were participants of this study that selected by multi-stages cluster random sampling; from different high school of Shiraz. Steinberg's Parenting Styles Scale (2005) and Self-esteem Scale (Coopersmith, 1967) were used as measures of the study.

Findings: Simultaneous multiple regression of self-esteem score on the parenting styles subscales, revealed that the "psychological autonomy-granting" and "acceptance-involvement" styles were significant positive predictor of the self-esteem score. Furthermore, The result showed that the mean score of girls was greater than the mean_score of boys in the "behavioral strictness-supervision" style.

Conclusions: The parents who behave with their children based on more acceptance and less control, develop high self-esteem in their children.

Keywords: Self-esteem, Parenting Styles, Students 
Relationship Psychological wellbeing and Academic Performances, demographic Variables in University student Fariba Tabe Bordbar, Ph.D. In Psychology.Payam-e- Noor university, Shiraz, Iran Malihe Nikkar, Payam-e- Noor University, Shiraz, Iran Fatane Yazdani ,Payam-e- Noor University, Shiraz,Iran Ahmad Alipor,Payam-e- Noor university,Tehran.Iran

Problem Statement: Considerable effort has sough to extend notions of well-being and wellness as the absence of illbeing states, with psychological constructs such as self-concept, subjective well being, happiness that have been demonstrated as important components of positive well-being. Ryff (1989) operationalised a multi- dimensional model of PWB that tapped six related concepts of well-being, including autonomy, personal growth, and selfacceptance, purpose in life, environmental mastery, and positive relations with others, which are seemingly more temporally stable

Findings that identify the impact of positive psychology constructs are informing government policy on health and well-being are increased.

Purpose of Study: The purpose of this study was investigated the relationship between psychological wellbeing, academic performance and demographic variables such as sex, age, course study, marital stouts, Research Methods: For do in this study, 500 students from Payam-e-Noor University of Shiraz were asked to complete the psychological wellbeing questionnaire (Ryff, 1989).

Findings: Results indicated that psychological wellbeing related to academic performance significantly . ANOVA analyzed showed that Psychological wellbeing differs in sex, age, course study and marital status Conclusions: Given these results show university to be a time of heightened distress, there is a need to ensure that students receive the support necessary throughout their environment to enable them to successfully complete their degree course, enabling them to negotiate the transition to university and then ultimately into the workforce.In addition, results are suggested that positive psychology on improving the positive elements on university proactively is important role.

Keywords: psychological well being, Academic performances, Change ,University 


\title{
MODEL OF EVALUATION OF TEACHERS IN B-LEARNING ENVIRONMENTS
}

Dra. Karolina González Guerrero

Universidad Militar Nueva Granada

Bogotá / Colombia

Dr. José Eduardo Padilla Beltrán

Universidad Militar Nueva Granada

Bogotá / Colombia

\section{Problem Statement:}

Technological developments and inherent challenges of incorporation of "mediation, and the information and communication technologies" compel Higher Education Institutions to bet on combined training spaces or b-learning for learning orientation. Associated to this bet, there is a concern regarding the roles and functions carried out by teachers and the evaluation of their performance.

\section{Purpose of Study:}

This project is located at the intersection of the following areas: research on educational evaluation and b-learning in Higher Education. Methodologies, strategies and instruments for the evaluation of teachers are studied under this approach. The following are the purposes of this research: i) to determine the objectives of evaluation and the teachers' aspects that should be evaluated, with this, ii) to document and analyze their functions in order to iii) characterize and validate teachers' evaluation practices in b-learning contexts for Higher Education.

\section{Research Methods:}

This research takes into account data from interviews, questionnaires, forums, videoconference carried out to researchers, teachers, students, external experts from different national and international universities, research groups, virtual education centers, combining quantitative and qualitative techniques during the different stages of the project: the first, in which a database is developed with state of art information; the second, foundations and characterization of teachers' roles and functions; and the third phase will focus on socialization, diffusion and validation of the characterization of teachers' roles through a 2.0 web platform, a space built for discussion by national and international experts.

\section{Findings:}

As a result and final contribution a proposal is built to on-line develop and adapt strategies and tools which allow to evaluate the teachers' functions validated in this project.

\section{Conclusions:}

The results suggest that the implementation of an evaluation system for teachers b-learning is a desired and promising tool for quality assurance in education, a tool that will be made available to the Institutions or Higher Education.

Keywords: Education and Technology,. Assessment and Evaluation, E-learning

\author{
Learning through MOOing \\ Dr Sarah MERROUCHE-University of Oum el Bouaghi, ALGERIA
}

Problem Statement: Though many schools and universities are today connected to the Internet, its technologies are still not adequately integrated into classroom teaching and learning. Many teachers think in rather restricted ways about using online tools and resources in their profession. 
Purpose of Study: This paper attempts to shed light on the MOO (Multi-User Domain - Object Oriented) technology, which provides a flexible and rich virtual environment for synchronous communication. Focus is laid on the Da-MOO or the Educational $\mathrm{MOO}$ and the way it lends itself to collaborative learning, particularly tandem learning to support teaching in the language classroom.

Research Methods: A practical experience with a Da-MOO, "The Palace", is described. "The Palace" suggests many rooms of communication where teachers and students can meet and discuss various topics together with native speakers of the target language.

Findings: Many students find the experience appealing, motivating and useful. The MOO not only develops the users' linguistic and communicative abilities, but also their critical thinking and social interaction skills. That is why, teachers as well as learners should capitalize on this valuable tool.

Conclusions: Integrating the Internet technologies such as the MOO into the classroom curriculum is becoming an indispensable component of good teaching. In fact, they have great potential for creating active, student-centred and motivating learning environments.

\title{
Keywords:
}

MOO Technology - chat - MUD - language learning - synchronous communication - collaborative learning - tandem learning - virtual class

\section{The influence of Emotional Intelligence, Leadership Behaviour and Organizational Commitment on Organizational Readiness for Change in Higher Learning Institution}

\author{
Norshidah Nordin
}

Problem Statement: Many factors contribute to the effectiveness in implementing organizational change. However, many change effort failed due to several factors such as lack of commitment, style of leadership and emotional distress of the employees who have to implement the change. In view of the pressure expected from the internal and external environment, there is a critical need to establish a flexible and adaptive infrastructure that lead to the organization to higher levels of performance. Hence, some key managerial variables such as goals and strategies, leadership, structure, motivation and people need to be assessed in order to implement change. More importantly, failure to assess organizational readiness to change among its members may result institutional administrators dealing with resistance to change. Given this juncture, literature suggested that emotional intelligence competencies, organizational commitment and leadership behaviour could facilitate change at individual and organizational level. 
Purpose of Study: The main purpose of this study was to examine the extent of organizational readiness for change of the academic staff in the context of higher institutions and its relationship wth emotional intelligence, leadership behavior and organizational commitment.

Research Methods:This is a descriptive-correlational resarch study. It was based on conceptual framework that combined part of adapted model from organizational development and change theory. A total of 169 academic staff of University Technology MARA (UiTM) participated in this study. They were selected based on stage and cluster sampling from the main and branch campuses through Malaysia. The data were collected using a survey method and were analyzed using both descriptive and inferential statistics.

Findings: This study provided empirical evidences that the academic staff of UiTM perceived that the organization is ready for the change. The result shows that there is a significant relationship among emotional intelligence, organizational commitment and leadership behaviour on organizational readiness for change. The findings also revealed that $44.1 \%$ of the variance in readiness for change is explained by emotional intelligence, organizational commitment and transactional leadership behaviour.

Conclusions: This study implied that building emotional intelligence, organizational commitment and developing transformational and transactional leadership behaviour could contribute to formulation of organizational readiness for change and therefore to the success of a change program.

Keywords: Organizational change, commitment, transactional leadership, transformational leadership, behaviour

The Bologna Process in the Context of Teacher Education - the case of Master's Cycle in Pre-School and Primary School Education

Cristina Maria Gonçalves Pereira - PhD

Escola Superior de Educação do Instituto Politécnico de Castelo Branco

Instituto de Psicologia Cognitiva - Faculdade de Psicologia e de Ciências da Educação da Universidade de Coimbra Portugal cristina.pereira@ipcb.pt

Problem Statement: The legislation concerning Professional Qualifications for Teaching was created in the context of the Higher Education reorganization according to the Bologna Process. By situating the professional qualification of pre-school teachers and primary school teachers at the second cycle level (Master's), this law may contribute to reinforce the recognition of these actors' importance in the promotion of quality development, which is so necessary in the Portuguese society, and necessarily refers to the need of a demanding, qualitative initial teacher education. Another crucial aspect in this law relates to the possibility of extending teachers' practice into two basic education cycles.

Purpose of Study: The present communication intends to present and analyse some of the foundations of the curriculum organization for the Master's Cycle in Pre-School and Primary School Education from the Castelo Branco School of Education, giving special attention to the integration of educational research methodologies in supervised teaching practice. We conclude with the presentation and analysis of the results obtained in the experimental version of questionnaire " Concepções sobre Processos Investigativos e Prática Docente" (Conceptions on Research Processes and Teaching Practice) to the master'students.

Research Methods:

Case Study 


\section{Findings:}

The questionnaire (CRPTP) aimed at identifying the concepts about the importance of education professionals developing skills in educational research methodologies as well as of being the actors in research projects within their professional performance.

Though the CRPTP questionnaire is, at this stage, just a experimental version and its sample is not significant in order to make a more accurate and precise analysis, we believe that we may assert that it allowed us to identify the most relevant concepts according to the goals of this study.

In general the outcomes point out that the students currently attending the Master's Cycle show concepts that are close to the ones in which the curricular organization of the Cycle is based on and more precisely in the curricular units of Research Methodologies and Supervised Teaching Practices. Therefore, we can say that it reveals that there were significant changes made in the concept of teaching professionality.

\section{Keywords:}

professional qualifications for teaching; educational research methodologies; CRPTP Questionnaire

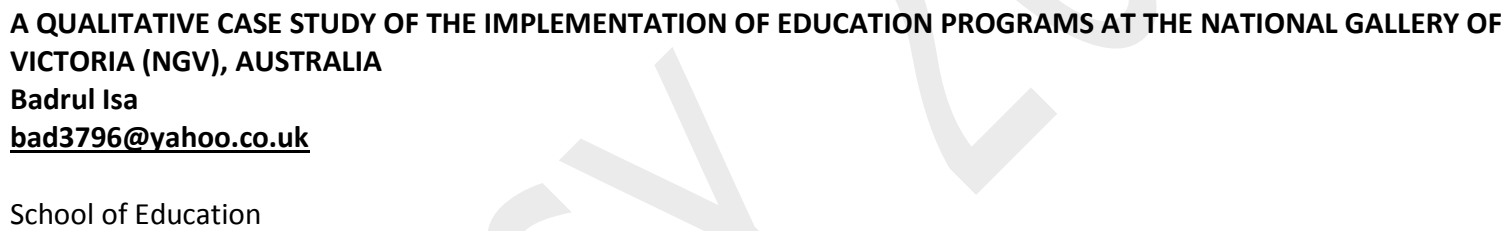

School of Education

RMIT University, Melbourne / Universiti Teknologi MARA (UiTM), Malaysia

\section{Associate Professor David Forrest david.forrest@rmit.edu.au}

School of Education

RMIT University, Melbourne

\section{Problem Statement:}

In Malaysia, cultural institutions such as museums and art galleries have long being utilised as a platform in instilling unity and tolerance among its multiracial community. And even though these institutions are striving to cater their audience from education sector more effectively, insufficient funding, the lack of expertise and trained personnel have been identified as major challenges (Khalil, Shaharuddin, Razak, Azilah, Luis, Zakaria, et al., 2000). More importantly, these institutions need a comprehensive model as a reference for the implementation of education activities. This model has to be appropriate to the unique multicultural setting that the country. For this purpose, a study looking at the education activities in the National Gallery of Victoria (NGV), Australia, is carried out, and this paper attempts to discuss the various facets that support the implementation of education activities in this institution.

\section{Purpose of Study:}

The study investigates the implementation of education programs in the NGV that target school students, with a particular attention given to the teaching process that takes place. Five main aspects are the focus of the study: its policy, organisational and managerial roles, processes involved in carrying out the programs as well as the implementation, strategies and approaches utilised. It is hoped that the study provides information about the model of effective teaching in museum and art galleries in Malaysia.

\section{Research Methods:}

The study employs qualitative case study design within pragmatic paradigm. Methods of data collection are interviews, observations and document analysis. The discussion in this paper only focuses on the data derived from the interview carried out on four NGV educators and the observations of their teaching sessions. 
Findings:

The effectiveness of the education programs in NGV can be closely associated to two main aspects. First, the quality of educational experience deliver by gallery educators; and second, efficient coordination between the management teams in organizing the programs.

\section{Conclusions:}

The succesfull implementation of education programs in NGV are driven by proper planning of its education and public program team. The findings from the study suggest that the quality of the personnel and qualified expertise are needed in order to implement effective education programs.

\section{Keywords:}

Education Programs in Art Gallery, Gallery Educators, Malaysian Museum and Art Galleries, National Gallery of Victoria (NGV) Melbourne

\section{ACADEMIC INTERNAL STAKEHOLDER CONDITION: a comparative approach Luminita Moraru, University Dunarea de Jos of Galati, Romania Head of Quality Assurance Department}

\section{Problem Statement:}

Students and academic staff are part of internal stakeholders and they participate in university governance by collective bodies such as universities senate and faculty councils. At present, often there are divergent interests between external and internal stakeholders. New trends in organization of the management structures of universities prefigure the end of the democratic decision- making tradition replacing it with management structures similar to market- based institutions or commercial companies.

\section{Purpose of Study:}

This paper seeks to analyze the various factors influencing the power of internal stakeholders in the countries that participate in the EUROAC Survey from an international comparative perspective. In the present situation, when almost all internal stakeholders in the participating countries of the EUROAC Survey are loosing their power, it becomes necessary for us to discuss the problem from an international perspective.

\section{Research Methods:}

The analysis is based on data gathered to accomplish a cross study on the academic staff conditions, perceptions and challenges in the countries involved in the EuroHESC project EUROAC - The Academic Profession in Europe: responses to societal challenges (Germany, Austria, Switzerland, Ireland, Romania, and Croatia as Principal Investigators and Finland and Poland as Associated Partners). The questionnaire was developed in consultation with our European partners.

Findings:

Junior academic staff and senior academics in many countries seem to have fewer common points with respect to influence in managing decisions, influence in academia and job security. This project gives us the opportunity to analyze the common elements or disjunction between senior and junior staff in academia. These differences refer to their access to resources, their power in the institutions and many other matters related to their status within the profession affect their employment and work situation strongly.

\section{Conclusions:}

The findings of this study demonstrate that the European academic scenario is various, complex and deeply nationally based. General demand imposed for all national educational system is to look for a more effective governance models. This analysis underlines the difficulty of cross-national comparative studies to show national differences among single institutional aspects. 


\section{Comparing response patterns of junior high school students in Japan, China, and South Korea on a language reading test developed in Japan. \\ Kazuhiro Yasunaga ${ }^{a, b}$ and Hidetoki Ishii ${ }^{a}$ \\ ${ }^{a}$ Nagoya University and ${ }^{b}$ Japan Society for the promotion of Science}

Problem Statement: In the result of PISA administered by OECD, it was reported that Japanese students have high proportion of no-response in an open-end question. However, PISA was developed in a Western culture carrying with it a Western bias. Therefore, it might not accurately assess the ability of Asian students because of unfamiliarity to the test structure and format, and to the contents of items.

Purpose of Study: The purpose of this study was to compare response patterns of Japanese, Chinese, and South Korean junior high school students on a language reading test developed in Japan.

Research Methods: Students in Japan ( $\mathrm{N}=163)$, China $(\mathrm{N}=243)$, and South Korea $(\mathrm{N}=232)$ were administered the Gunma Prefecture Achievement Test which was translated into Chinese and Korean. Students were given 50 minutes to answer, and responses were evaluated based on a scoring rubric.

Findings: Students were assigned to groups by ability (Low, Middle, High), and proportions of correct and unanswered responses of the test were analyzed by groups. Results found that Japanese students had the highest proportion of correct answers for multiple-choice items. However, they had the lowest proportion of correct answers and the highest proportion of no-response in an open-end question citing a concrete example. In contrast, South Korean students had the highest proportion of correct answers for these items, and Chinese students had the lowest proportion of no-response. It was found that there were high proportions of no-response for Japanese and Korean Low group in an open-end question which required filling in conversational sentence text. However, Korean Low group made more no-response than Japanese for this item.

Conclusions: In summary, Japanese student don't usually have a high proportion of no-response as seen in PISA. Depending on the nature of the item, Japanese and Koreans alternated in their no-response tendencies. Moreover, Chinese students were observed to have fewer no-response through all items. Furthermore, we discussed that a test must consider culture to measure ability adequately.

Keywords: reading test, proportion of correct answers, proportion of no-response 


\section{Problem Statement:}

Despite genre studies have focused on variety of writing genres and on distinct nationalities, there have been very few or no studies published on appeal letter writing as a sub-genre of official letters written by Iranian EFL students. Purpose of Study:

This paper introduces some generic characteristics of appeal letters written by EFL Iranian graduate students studying in Malaysia as it investigated if appeal letters written by Iranian students display a consistent generic structure. Research Methods:

Conducting a qualitative case-study research design, originally the main phase of this study was to explore the problems faced by the six Iranian students in the process of writing official letters, including appeal letters.

Meanwhile, the products which were the written appeal letters were rich sources of data, so they were analyzed based on the genre analysis of texts for deeper understanding of their generic features.

Findings:

Data analysis suggests that the appeal letters written by Iranian students mostly had a spoken tone, longer introduction, and discourse markers. Besides, some features of repetition were obvious in those texts. Since in some cases the students took advantage of their L1 genre experiences, findings of this study suggest that genre-awareness, whether it is in their L1 or L2, helps students in writing proficiently especially for graduate students who have to master helpful genres such as thesis writing or research article writing.

\section{Conclusions:}

My discussion is that ESL/EFL students or even native speakers of English learn more about writing through learning different genres related to their academic contexts and this genre-awareness is better to be the concern of curriculum designers and genre-based writing teachers. Another issue appears when students engage their L1 genre experiences. They can be in the line of $L 2$ genre and ease the learning process or something different which has negative impact on genre-based learning of the students. Future research can study the effect of EFL students' L1 genre experiences and their genre-awareness on genre-based writing in $\mathrm{L} 2$.

Keywords: genre analysis, appeal letters, teaching letter writing

\section{Critical Literacy Education for Children's Equal Conditions Starts in Preschool? Ulla Damber \\ Mid Sweden University}

\section{Problem Statement:}

Do preschoolteachers and teachers adjust conditions in schools' Early Literacy practices to the needs of children with diverse backgrpunds? 
The purpose was to describe and explore tentative links between Early Literacy nurtured in preschool, teacher students' ability to perform critical reading of basals, and how the findings those studies coincide with the findings of an earlier study of successful, culture-sensitive literacy practices in Elementary School. The research questions were the following: Do Swedish preschool teachers implement critial reading and foster linguistic growth when they read aloud? Are Swedsih teacher training students able to perform ctitical reading of the basals used in elementary school? How do the answers to these questions coincide with the practices of successful and empowering literacy practices in Elementary school?

\section{Research Methods:}

The study of successful practices included eight multi-cultural elementary classes students employing both statistics and in-depth teacher interviews. The preschool study included 40 preschool-teachers' read-aloud practices, based on their own observations during one week (plus narratives). The value study of commonly used basals included 20 teacher training students, employing critical discourse analyses and our analyses were based on students' narratives.

\section{Findings:}

The preschool-teachers indicated that both lack of knowledge of the importance of 'talking text' and lack of time made those occasions very scarce. The teacher students' analyses of the textbooks revealed a definite lack of competency to analyze the contents from critical perspectives, as many of the schools used more than twenty years old books, portraying a mono-cultural middle-class Sweden with rigid gender roles. Though they perceived the outdated gender roles, the mono-cultural perspectives were not often detected. Although the technical side of reading processes was not intended to be in focus, this drew attention rather than the conditions provided for meaningmaking processes embedded in the texts.

\section{Conclusions:}

The creation of a learning climate encouraging negotiations of meaning is crucial, which puts emphasis both on teacher educators ability to enhance critical awareness and on the literacy practices in preschools and schools. Meaning-making in preschool and early literacy learning definitely needs increased emphasis. Equity demands transformation of the present practices.

\section{Keywords:}

Second Language Learning, Early Literacy practices, Negotiations of Meaning, The Four Reader Role Model

The Effects of Multi Sensory Training on Dictation Problems of Gifted, Primarily School Student

Fereshte Rahim Of, Shole Amiri, Maedeh Aboutalebi, Hosein Molavi

Clinical psychology student, department of psychology, University of Isfahan

Associate professor department of psychology, University of Isfahan

M.A , child clinical psychologist

professor department of psychology, University of Isfahan

Problem Statement: Gifted and talented students who also have a specific learning disability (LD) are typically referred to as twice-exceptional and are among the most underserved students in primarily schools. Past researches showed that multi sensory training is effective treatment for children who have dictation disorder and they showed better academic performance after training. This study was designed to examine whether this training method could be used for gifted student or not.

Purpose of Study: the aim of present study is investigating effectiveness of multi sensory training on dictation problems of female, gifted, primarily school students.

Research Methods: The sample of 360 students was recruited from primarily schools and then they were screened for learning disorder and IQ score higher than 120; final sample consist of 38 female students. They were randomly assigned to the experimental and control groups. The experimental group received multi sensory training. In this study some new tools such as metronome and computer game used for training. 
Findings: : Results show that there are significant differences between two groups in dictation scores after training procedure. Students in experimental group showed higher score than students in control group $(F=40.5, p<0.001)$. Conclusions: These results are consistent with previous researches in this field. Generally, this research finding shows new ways of helping twice-exceptional students to have higher academic achievements.

Keywords:Learning disorder, Gifted student, Multi sensory training

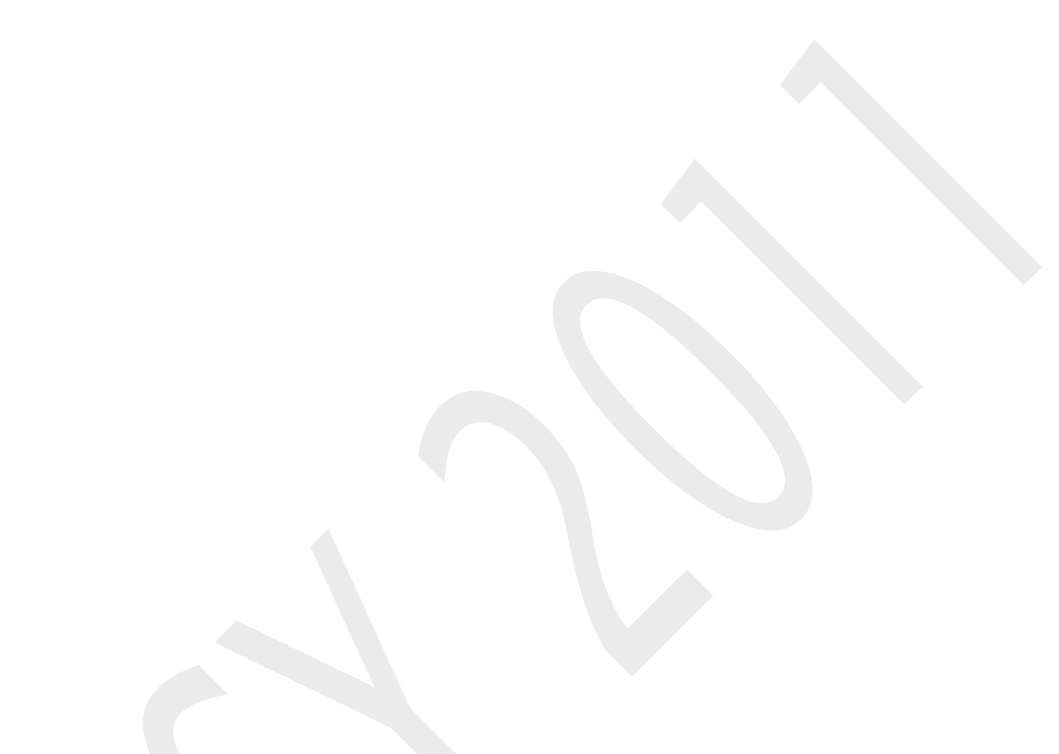

Effects of Educational Improvements on Student Social Desirability

Maedeh aboutalebi,Fereshte Rahim of

M.A.Child clinical psychologist.G,C.

Clinical psychology student,department of psychology, University of Isfahan, Iran.G,C.

Problem Statement: Students who have learning disorder show disability in three major areas of the development, these are developmental, educational, and social areas. These areas of development are interconnected. Usually Learning disorder treatments focus on developmental and educational problems. While social problems of students who have LD is as important as their developmental and educational problems. This study was designed to investigate effects of improvements in academic achievements on social desirability of students who have LD.

Purpose of Study: This study was designed to examine effects of educational improvements on students social desirability.

Research Methods: The sample of 360 students was recruited from primarily schools and then they were screened for learning disorder; final sample consist of 38 female students. They were randomly assigned to the experimental and control groups. The experimental group received multi-sensory training. Both groups were administered social desirability test before and after training.

Findings: Results show that there is significant differences between two groups in social desirability after training procedure. Students who have received treatment show higher scores in social desirability test.

Conclusions: These finding are consistent with previous researches in this field. In addition, these results prove that educational and social improvements of students who have LD are interconnected. 


\title{
ACHIEVING A SUCCESSFUL RELATIONSHIP BETWEEN NEUROSCIENCE AND EDUCATION: THE VIEWS OF PORTUGUESE
} TEACHERS

\author{
Joana Rodrigues Rato ${ }^{1}$, Ana Maria Abreu ${ }^{2}$, and Alexandre Castro-Caldas ${ }^{1}$ \\ ${ }^{1}$ Institute of the Health Sciences, Catholic University of Portugal, Portugal \\ ${ }^{2}$ Laboratory of Expertise in Sports, Faculty of Human Kinetics, Technical University of Lisbon, Portugal
}

Problem Statement: Educational Neuroscience is currently raising high attention by the educational and neuroscientific community. However, society has created too many expectations concerning what Neuroscience can bring to Education, being some of these beliefs totally unrealistic. Thus, teachers face a new dilemma: How to unify Neuroscience and educational theory and practice?

Purpose of Study: The role of Neuroscience in Education is currently under discussion in schools. With this study, we aim to identify eventual distorted expectations of the teachers and propose ways to overcome these.

Research Methods: A questionnaire was designed to understand how teachers perceive the role of Neuroscience in Education. We presented thirteen statements (about what is necessary for the success between Neuroscience and Education) to assess whether teachers agreed with them and/or if they showed distorted expectations. Some statements were based on real possibilities of success between neurocience and education and others were used as false possibilities. This study was carried out in Portugal with 30 participating schools, where 627 questionnaires were collected. These questionnaires were answered by teachers (Preschool to High School) from different areas of expertise.

Findings: The teachers' agreement with the suggested statements was widespread and our results showed that the majority of teachers acknowledged the need for further training in order to allow the interface between Neuroscience and Education to succeed. The presence of distorted expectations was also revealed.

Conclusions: The current challenge of Educational Neuroscience is to improve a scientific dialogue and a shared language in academic and neuroscientific circles. This requires professionals that may hold a shared communication across disciplines and, currently, it seems that no such professional is taking the lead at this role in Portugal. Our results show that there are still misunderstandings when teachers are questioned about the links between Neuroscience and Education. We suggest that an Educational Psychologist would be the most skilled to lead these collaborative efforts.

Keywords: Educational Neuroscience, teachers view, teacher learning 


\section{LINKING STUDENTS AND TEACHERS' PERCEPTIONS OF TEACHING AND LEARNING AT A DISCIPLINARY LEVEL: FIRST INPUT FOR QUALITY ENHANCEMENT \\ Isabel Huet, Cláudia Figueiredo, Nilza Costa, Odília Abreu \& Carla Vieira (University of Aveiro)}

\section{Problem Statement:}

Can research-based evidence foster the Quality Assurance Systems of Teaching and Learning (QAS-TL) by enriching the understanding of the data collection, the (re)design of the evaluation model, and the engagement/commitment of academia with the overall process?

\section{Purpose of Study:}

This study presents preliminary results regarding the analysis of qualitative data aiming to integrate the perspectives of students and teachers (through the analysis of open reports) so we can understand if the identified problems and cases of good practice are correlated with the views of teachers and students. This study will support the design of intervention plans with the purpose to improve the quality of teaching and learning at the University of Aveiro.

\section{Research Methods:}

For conducting this study we analysed 80 undergraduate disciplines from a representative sample of 320 at the University of Aveiro. The data analysis is being carried out using the NVivo 9 software for qualitative data analysis, and in this first stage the results follow a descriptive analysis with crosstabs between teachers and students' data coding.

\section{Findings:}

The findings point towards four main ideas: (i) students have some problems in identifying and/or describing cases of good practice, (ii) students and teachers identify similar problematic situations, (iii) teachers attribute some of these problems to students such as lack of self-regulated learning skills, and motivation, and (iv) teachers do not often self-evaluate their teaching and when they do it they reveal weak skills on assessing their practice.

\section{Conclusions:}

When addressing the arguments presented in this study, one becomes aware of the fact that it is inevitable to evaluate the quality of teaching and learning and to proceed to well-structured and supported quality assurance systems, properly grounded on theory and practice. In a globalized world, in which mass Higher Education has been replacing the former somewhat elitist systems, the need to guarantee the quality of the provided education and to continuously improve the institutional responses to the learning needs of the changing student population becomes central.

Keywords: Quality Assurance Systems, Teaching and Learning, Assessment 
Technology Enhanced Learning (TEL) in Higher Education: results from the design of a quality evaluation framework Diogo Casa Nova, António Moreira \& Nilza Costa

Problem Statement: The impact of technology in the student learning experience in Higher Education has not been evaluated on a regular basis mainly due to the lack of importance that is given to technology integration in pedagogical strategies. The increasing demands of different University stakeholders, however, suggest a more sustained evaluation of the use of technology to enhance students' learning.

Purpose of Study: This paper stems from the development of a Quality Evaluation Framework for TEL practices. Specifically we aim to present the first phase of the development of a quality evaluation framework and the design of its methodological steps. We will present several statements and linked criteria that can be used as standards for TEL quality and, therefore, capable of being used to evaluate TEL practices.

Research Methods: The research design comprises the design and development of a reference framework and the design of an evaluation model. For this communication we will present the first phase of the study, the reference framework, comprising several data collection tools such as semi-strucured individual interviews, focus group interviews and a meta-analysis study. The data collected was triangulated and validated through a literature review process.

Findings: The statements retrieved from the data collection process point out to the emerging of several criteria for evaluating the quality of TEL. These criteria were validated using the data triangulation process allowing the design of a reference framework. The criteria will be presented aligned with the corresponding statements and respective dimensions.

\section{Conclusions:}

In the development of our framework we assume that it is relevant to design an open framework that can be adapted to different contexts and objectives. This characteristic of openness is an asset of our framework since it can allow other researchers and practitioners to use the framework and design an evaluation model that is tailored to their own specific needs and contexts.*

Keywords: Technology Enhanced Learning, evaluation, quality, eLearning 
Preliminary research has shown that student academic achievement is significantly related to the level of student engagement. For example, students with higher levels of engagement tend to have higher academic achievement scores (Finn, Pannozzo, \& Voelkl, 1995; Epstein \& Sheldon, 2002; Spiegel, 2003). This result was confirmed by several studies showing this significant relationship across many different age groups (Connell, Spencer, \& Lawrence, 1994; Finn \&Rock, 1997; Skinner, Wellborn, \& Connell, 1990; Rumberger \& Larson, 1998; Ryan, 2000). Many studies have suggested that friends have a powerful influence on school adjustment, attitudes, and behaviours. However, there is a paucity of systematic investigations on the relationship between peer influence and adolescents' school engagement. Therefore, this study aimed to reveal this link by applying the longitudinal analyses as well as testing of indirect effects of peer influence via students' motivational factors such as locus of control and self-esteem.

\title{
Purpose of Study:
}

The current study investigated the longitudinal relation between peer influence and adolescents' school engagement using a Base Year, First follow up, and Second Follow-up data from the National Education Longitudinal Survey of 1988 (NELS: 88).

\section{Research Methods:}

Structural equation modeling (SEM) was used to assess the hypothesized structural relationships among latent variables. SEM was selected because it represents an appropriate analytic approach for dealing with issues of specifying directionality among variables of interest and generating flexibility with which to test causal relationships. SEM provides a causal model in which the relationships among the variables can be tested simultaneously without having to conduct multiple analyses.

\section{Findings:}

Results from this study indicated that peers have an important influence on the behaviour and development of adolescents. Students whose friends had high academic value increased in their school engagement and this fact did have a significant positive impact on the changes of adolescents' school engagement between $8^{\text {th }}$ and $12^{\text {th }}$ grades.

\section{Conclusions:}

These findings are understandable in that the child's acceptance within the peer group is one of the key measures of positive/negative school experiences. Perceived support from peers can give students a sense of trust and help students see the importance of pursuing academic success.

\section{Keywords: school engagement, peer influence, adolescents, locus of control, self-esteem}

\section{EXPERIMENTAL RESEARCH REGARDING THE DEVELOPMENT OF PSYCHOSOCIAL COMPETENCIES OF THE BEGINNING TEACHERS}

\author{
Constanta Dumitriu, "Vasile Alecsandri" University of Bacau, Romania \\ Gheorghe Dumitriu, "Vasile Alecsandri" University of Bacau, Romania
}

\section{Problem Statement:}

This study relies on the theoretical premises concerning the development of professional competencies of the beginning teachers. The starting point is the operational model that integrates seven categories of competencies: cognitive and metacognitive, methodological, communicational and relational, evaluative, psychosocial, career management, as well as ICT competencies.

\section{Purpose of Study:}

The goal of the study is to propose and validate a programme meant to improve the psychosocial competencies of the beginning teachers. In order to run the research we have established the following objectives: development and pretesting of the tools for the experimental model; initial evaluation of the psychosocial competencies, design and course of a 
programme of formative activities that lead to the improvement of the psychosocial competencies; final evaluation of the psychosocial competencies.

\title{
Research Methods:
}

As research methods we used: the formative psycho-pedagogical experiment with repeated measurements (test - post test), analysis of the products of teachers' activities (projects, competencies portfolios), psycho-pedagogical observation, and statistical methods. The stages of the psycho-pedagogical experiment are the following: initial evaluation of the level of psychosocial competencies of the beginning teachers, design and application of a programme of formative activities that leads to the improvement of the psychosocial competencies; final evaluation of this category of competencies of the beginning teachers.

\section{Findings:}

Statistical facts obtained during the research show significant differences with respect to the results obtained by the beginning teachers at the evaluation applied at the end of the formative stage, compared to those obtained at the initial evaluation.

\section{Conclusions:}

The results of this research will bring a contribution to the optimization of the initial training programmes of the beginning teachers, and support their psycho-pedagogical training for better socio-professional integration.

Keywords: psychosocial competencies, beginning teachers, formative experiment, operational model

\section{This work is supported by CNCSIS-UEFISCSU project number 834/2009 PNII - IDEI,} code 496/2008.

\section{INCREASING INDEPENDENCE VERSUS INCREASING COLLABORATION WITH ICT SUPPORT}

\author{
Elena Nechita, "Vasile Alecsandri" University of Bacau, Romania
} Iulia Cristina Timofti, "Vasile Alecsandri" University of Bacau, Romania

\section{Problem Statement:}

Over the last decade, information and communication technologies have enabled significant changes in the way people live, work, interact and learn. Some of these changes have been quite rapid in time, which is the reason why we believe that more research is needed for finding evidence on how new technologies can enhance learning. Does the use of ICT tools lead to significant improvement in independent thinking? Are motivation and enthusiasm growing when setting cooperative learning groups? Does collaboration generate new forms of communication outside the classroom, is it extended beyond school? How do we learn to learn with ICT? The paper intends to give some answers to these questions.

\section{Purpose of Study:}

We approached the above issues on students of Vasile Alecsandri University of Bacau, that graduate and become teachers. We looked for significant facts related to the effects of using ICT tools both on independence increase and collaboration increase of the subjects. We defined indicators in order to measure the two categories of competencies.

\section{Research Methods:}

In order to run the research, questionaires and interviews have been applied and work samples of students (projects, portofolios) have been studied. As well, psycho-pedagogical observation and some statistical methods have been used. 
Findings:

The study reveals the necessity to carrefully complement the tasks that lead to an improvement of independent thinking with group activities and collaboration strategies. It appears that the major factor with impact on future teachers' ICT competencies is a creative practical approach of ICT tools, that need to used in a manner which responds to their needs to personalize the learning process in a mutual environment.

\section{Conclusions:}

The findings of the study wil be applied in an operational model designated to improve the professional competencies of the beginning teachers.

Keywords: ICT tools, collaboration, networking, educational software, web 2.0

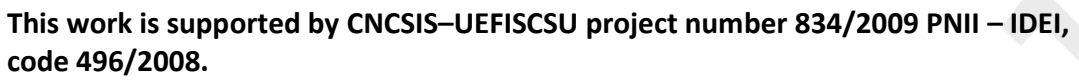

University, Education District, and Schools Collaboration in the Preparation of Local Level Educational Leaders: The Zimbabwean Experience

James D. Quarshie*, PhD, Alberta

Associate Professor and Head, Continuous Professional Development

Bahrain Teachers College, University of Bahrain, Kingdom of Bahrain

and

Victoria I. Oyedele, PhD, Awolowo

Senior Lecturer and Dean, Faculty of Education

Africa University, Zimbabwe

Problem Statement: The preparation of educational leaders has been of interest in many jurisdictions as evidenced in such works as Lunenburg \& Ornstein (2008), Hoy \& Miskel (2008), Holdaway \& Ratsoy (1991), and Quarshie (1992). In developing countries where the population usually has low level of education, and educational leaders tend to be appointed on the basis of competence in teaching, what strategies can be adopted for preparing local level educational leaders?

Purpose of Study: The purposes of this paper, which is a report of an Educational Leadership, Management and Development (ELMD) project undertaken by Africa University in collaboration with a rural Education District and selected schools in Zimbabwe, are to:

- $\quad$ share experiences in the development and implementation of the ELMD project as a strategy for preparing local level educational leaders;

- $\quad$ show how cooperation between partners in Zimbabwe and similar partners in South Africa enhanced work on the project;

- discuss the impact of the project on schools in Zimbabwe; and

- $\quad$ show implications of the project for the preparation of educational leaders in developing countries.

Research Methods: Two main methods were used to gather data for the preparation of the report. The first was experiential as demonstrated by the fact that both authors served as Directors and instructors on the project at different times. Study of documents served as the second method for gathering data for the report. Content and thematic analyses were used in analyzing the data.

Findings: The report shows that the ELMD provided participants on the project with relevant knowledge, skills, attitudes, and values needed for their leadership roles on the local school governing bodies. The ELMD was found to have empowered the local level educational leaders to become more effective as leaders not only in their schools but 
also within their local communities. There was evidence that performance of the schools involved in the project improved.

Conclusions: It is concluded that:

- $\quad$ the ELMD is an effective strategy for preparing local level educational leaders; and

- the ELMD could be adapted for preparation of educational leaders in other developing countries.

*James D Quarshie, PhD, was, until September 2008, an Associate Professor, Dean of the Faculty of Education and Director of the ELMD project at Africa University. The co-author became the Director of the project following his departure from Africa University.

Keywords:

Collaboration

Education district

Educational management

Leadership

Leadership preparation

Rural schools

School governing body

Experimental research regarding the development of methodological competences at beginning teachers

Liliana Mâţă, "Vasile Alecsandri" University of Bacău, Romania

Problem Statement:

At the foundation of this study we placed theoretical premises regarding the categories of professional competences from perspective of beginner teachers. We have foundation an operational model which integrates seven categories of competences: cognitive and metacognitive, methodological, communication and relationship, student assessment, psycho-social, technical and technological, career management.

Purpose of Study:

The purpose of this paper is to propose and validation a program for development of methodological competences at beginning teachers. In order to undertake the research there were established next objectives: elaborating, validating and pre-testing the instruments for experimental model; the final evaluation of methodological competences; establishing the formative activities for competences development and the final evaluation of methodological competences.

\section{Research Methods:}

In our research there are utilized the following research methods: the formative psycho-pedagogical experiment and statistical methods. The steps of formative experiment are: initial evaluation of methodological competences; application of formative activities for competences development and the final evaluation of methodological competences.

\section{Findings:}

The statistical data of experimental research indicate significant differences between the results obtained by beginning teachers at the evaluation tests of final stage, compared with those obtained in the initial stage.

\section{Conclusions:}

The research results contribute to highlighting the role of the training strategies on the development of methodological competences at the beginning teachers.

This work was supported by CNCSIS -UEFISCSU, project number 834/ 2009 PNII - IDEI code 496/ 2008.

\section{Keywords:}

methodological competences, beginner teachers, formative experiment, evaluation tests 


\title{
GENDER ISSUES IN EDUCATION: FACTORS INFLUENCING MALE AND FEMALE STUDENTS' ACADEMIC ACHIEVEMENT IN PUBLIC EXAMINATIONS IN MALAYSIA BASED ON HERMENEUTIC ANALYSIS
}

\author{
DR. SUPPIAH NACHIAPPAN \\ SULTAN IDRIS EDUCATION UNIVERSITY \\ MALAYSIA
}

Gender issues in the field of education has been a continuos debated issue for generations. In the present context, the gender issue is being debated heatedly based on the differences in the achievements among male and female students in public exams like UPSR, PMR, SPM and STPM. The objective of this study is to obtain views from 90 Form 4 students' (research sample) who come from three secondary schools. Hermeneutic analysis was used in order to analyse the students' written essays on the factors which contributed to the achievement of the two genders in examinations. The findings of the study clearly indicate that female students outperform male students in examinations. The sample also summed up the factors leading to the failure of male students in performing well and ways to overcome this setback.

Keywords: Gender Issues, Academic Achievement, Hermeneutic Analysis 
Prof. Dr. Susana B. Tuero

Universidad Nacional de Mar del Plata

Argentina

In English as a foreign language (EFL) learning contexts, teachers often read out while students read along a written presentation of the same text. In certain occasions, and following instructions in the textbook, students listen to a recording while reading the text. This procedure is based on the assumption that the dual-mode presentation of a text (written and spoken) helps students' text comprehension. The rational is that presenting information in two modalities allows students to choose the modality that best fits their learning style. Some research findings suggest that presenting identical spoken and written texts simultaneously have positive effects on speaking performance of college students (Borras, I., \& Lafayette, R. C., 1994; Garza, 1991; Neuman \& Koskinen, 1992).

However, recent research in cognitive theory suggests that presenting the same material in two modalities simultaneously may be detrimental, and result in less understanding. Kalyuga, Chandler and Sweller $(1998,1999)$ have used the term redundancy effect to refer to what happens in situations in which the same material is presented simultaneously in two different modes. Such dual-presentations of the same materials may not be as beneficial as expected. When the purpose is to learn the language, dual-mode presentations seems to facilitate the learning process of certain linguistic aspects, but it may reduce the effectiveness of the understanding process.

The purpose of this study was to examine the effect of simultaneous presentations (written and spoken) on EFL reading comprehension. Fifth EFL graders in a bilingual school were randomly assigned to one of two groups: the 'read only' group, and the 'read + listen' group. Students in the read-only group read a text twice while students in the read-andlisten group read and listened twice to the same text. Analysis of the data collected from a free recall task indicated that cognitive overload occurred when information was received in dual modalities, written and spoken. Results suggest that simultaneous presentation of the same material should be eliminated if the aim of the task is to improve reading comprehension and information recall in EFL learning contexts.

Keywords: EFL reading, reading comprehension, redundancy effect

Cognitive abilities and personality characteristics in reading disabled young adults

Leena Holopainen, Philosophical Faculty, University of Eastern Finland, Finland Jukka Leskinen, Department of Behavioral sciences, National Defence University, Finland

Previous studies have shown that persons with reading disabilities tend to lag behind their peers with respect to cognitive abilities this phenomenon is often called as "Matthew effect". It has also been shown that some persons who have difficulties in reading have a more negative academic self-concept than their well-achieving school mates. Relatively little is still known about the compensatory processes and mechanisms that enable the persons with reading disabilities to process information differently and role of personality characteristics in that process. 
This study examines the relationships between reading disabilities, self-concept, cognitive abilities and personality characteristics of adolescents in conscript service. Every Finnish male citizen is liable for compulsory military service, which enables to reach large amount of young adults ( $99 \%$ of males). This study is a part of a research project aimed at developing conscript training to take better into account those conscripts with reading disabilities attempting to prevent attrition from military service.

The participants (mean age 20 years, sd .61) were Finnish adolescents participating in compulsory military service at two garrisons $(\mathrm{N}=1499)$. The reading skills, cognitive abilities and self-concept were assessed at the beginning of conscript service and personality characteristics after three and six months of service. The structural equation modeling was used as analysis method. The path model was analyzed using the MPLUS program with the missing data method. Preliminary results show that reading disabilities and cognitive abilities have both direct and indirect effects on self-concept and personality characteristics. Our results shown that while reading difficulties persists at the group level into adulthood, young adults show large inter-individual variation coping with the problems.

Keywords: cognitive ability, personality characteristics, reading disability, self-concept

Social characteristics in bullying typology: digging deeper into description of bully-victim.

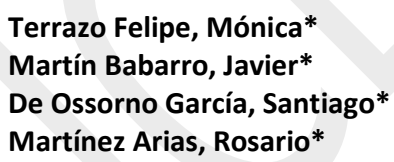

*Facultad de Psicología, Universidad Complutense, Campus de Somosaguas, 28223. Madrid. Spain.

\section{Problem Statement:}

Bullying research has established that bullies and victims often are rejected by their peers. Bully-victims have been considered as a type of victim but should be analyzed more in depth. Characteristics of those students involved in those negative social dynamics have been focused in direct aggression and its consequences.

\section{Purpose of Study:}

To clarify the aforementioned typology we used a random sample $(n=2847)$ extracted by cluster sampling of 25 secondary schools. Then, bully typology was compared with sociometric measures. In order to achieve more information about the children involved in bullying behavior, data about subjective well-being, attitude toward aggression, behavioural disorders and prosocial behavior were collected. 


\section{Research Methods:}

Sociometric measures were obtained by peer-report and three self-report questionnaires were conducted to assess the other measures, assuming good reliability and validity, adapted to the Spanish population: ESPERI (Screening Questionnaire of Behavior Disorder); C.A.D.V (Attitude Questionnaire towards Diversity and Violence); and C.E.V.E (School Violence Assessment Questionnaire), based on Olweus' Inventory. To identify roles in bullying behavior scores above eighty percentile were used: P80 in aggressive behavior for pure bullies $(n=230)$; P80 in victimization for pure victims $(n=362)$ and P80 in both for bully-victims $(n=185)$. Also these typologies were divided according with Coie and Dodge sociometric status method.

A Multifactorial MANOVA with three factors (academic level, gender and typology) was applied. Significant differences were followed with Games-Howell or Tukey's HDS post-hoc test. Pillai's Trace: $F_{3.743}=.887, P=.000$.

\section{Findings:}

Two types of bullies with different characteristics were found: those who are liked and those who are rejected by their peers. Bully-victims obtained scores with significant differentiation between both, victims and bullies, in mostly variables. With our data we could describe the traits, behavioural disorders, parental style, group climate and wellbeing related with social behavior of those above-mentioned.

\section{Conclusions:}

Finally we can clearly establish Bully-victim as a completely independent entity of bullies and victims. Traditional typologies in bullying research literature might be specified using the group influence.

\section{Keywords:}

Typology; Bully; Victim; Bully-victim; Sociometric Status

Postnatal Experiences of Urban Pakistani Men as First Time Fathers

Laila Pirani, Rozina Karmaliani, Shaneela Khowaja, Nargis Asad and Nadeem Zuberi

Aga Khan University, Karachi, Pakistan

\section{Problem Statement:}

The postnatal period is a very significant period in a man's life, especially in the case of first time fathers; this may be in the form of rewards or challenges along with the required support system. It is important to understand, that men also go thorough transition like women and experiences socio-cultural, psychological and physiological changes, therefore require support from healthcare professionals.

\section{Purpose of Study:}

The purpose of this study was to describe, and interpret the Postnatal Experiences of Urban Pakistani Men as First Time Fathers.

\section{Research Methods:}

A qualitative study, using the Van Manen's methodological approach for hermeneutic phenomenology was selected, in order to capture the meaning of this phenomenon.

\section{Findings:}

The findings formed a core notion of "Role Transition to fatherhood" and further led to three main themes; rewards, challenges and support system. Categories that emerged from themes are worldly and spiritual rewards, responsibilities, Socio-cultural concerns, relationships, psychological concerns healthcare issues, family and financial support.

\section{Conclusions:}

Participant's experiences lead to recommendations for professionals pertaining to healthcare system and for providers like nurses, doctors, researchers and community related people along with healthcare professionals involved in academia. Health care providers should take part in preparing fathers for this transition. The experiences shared by the participants could help in developing a strong knowledge base, which would provide meaning and understanding to nursing and other healthcare professionals' role in the care of the family. The knowledge gained 
could be incorporated to develop awareness literature, to help fathers for becoming equal and effective partners in the postnatal care of newborn during antenatal / birthing classes. Health care professionals in academia should incorporate father's related issues in the curriculum along with women reproductive health.

Keywords: Postnatal Experiences, Role Transition, Fatherhood

\title{
STUDENT'S POSSIBILITIES ON DEVELOPMENT A KEY COMPETENCES - ACADEMIC PREPARATIONS OF SOCIAL PEDAGOGY STUDY PROGRAM ON CZECH REPUBLIC
}

\author{
Stefan Chudy, Pavel Neumeister, Pavla Andrysova
}

Problem Statement: Education on academically board and development of key competences for praxis, in country of East Europe, is a serious problem on a process of designed study programs of social pedagogy (Chudy, 2009). In an educational field on academically board and in a development the competencies there are a great gap on a process of the solutions the open social situations. The psychosomatic preparation is one of these competencies. The second one is an exploration of a situation as a key determination of competences during university studies. The results of this research process are new study disciplines of a psychosomatic preparation, personal and social competencies (decision) development.

Purpose of Study: The present study examined how student's were associated a statements on questionnaire. After evaluations results we construct or re-construct the valid concepts of a new disciplines on psychosomatic preparations. The subjects in the study were a 150 regular student's on TBU University (in the present time we are a second group - 150 students of Palacky University). Participants were tested by non standard questionnaire. The questionnaire is processed as a 4 subtests for using a part of competencies, practice, qualifications and personal aims on a process of development key competences. Evaluations are processed by statistics software Statistica 9 and Chic. After an Analyses of Variance were performed and due a hierarchical structure of a data (student's on class, and a preferred options).

Research Methods: The subject in the study was a 150 regular student's on TBU University (in the present time we are a second group - 150 students of Palacky University). Participants were tested by non standard questionnaire. The questionnaire is processed as a 4 subtests for using a part of competencies, practice, qualifications and personal aims on a process of development key competences. Evaluations are processed by statistics software Statistica 9 and Chic. After an Analyses of Variance were performed and due hierarchical structure of a data (student's on class, and a preferred options). Findings: Results show a great impact of study preparation, creativity, personal aims and partially of a qualifications and practice experiences of students.

Conclusions: The impact of our research activities we show on preparations of Psychosomatic preparation for a practice social pedagogy on society. It also includes a comparison of two approaches concerning personal and social development of social pedagogy students.

Keywords: development a competencies, social pedagogy on Czech Republic, psychosomatic preparation 


\title{
ENHANCING CRITICAL THINKING IN FOREIGN LANGUAGE LEARNERS THROUGH ONGOING ASSESSMENT
}

\author{
Servat Shirkhani* \\ Mansour Fahim, PhD** \\ *Islamic Azad University, Khorram Abad Branch \\ ** Islamic Azad University, Science and Research Branch
}

Critical thinking refers to the individuals' ability to think and make correct decisions independently. Critical thinking has been used in first language acquisition for a long time and has been recently introduced into foreign language teaching contexts. Nowadays enhancing critical thinking in learners is considered one the tasks of foreign language teachers due to its high position in foreign language classrooms. There are various factors affecting learners' critical thinking skills, including the type of materials, the ways of teaching, the kind of activities used in the classroom, the type of feedback provided to learners as well as the way of assessing learners. The presentation is concerned with one of these factors, that is, assessment. Usually learners try to learn in way that enables them to pass the course. In other words assessment definitely influences what and how learners try to learn. Therefore, language teachers can help learners develop critical thinking skills through careful assessment practices. On such practice is ongoing assessment rather than one-shot testing so that the learners fine out that they need critical thinking skills to be successful. This presentations aims at introducing some ways in which language teachers can have such a way of assessing language learners in order to enhance the learners' critical thinking ability.

\section{Key words:}

critical thinking, language teaching, foreign language learning, and assessment. 


\title{
BARRIERS TO SELF-REGULATION OF LANGUAGE LEARNING: DRAWING ON BANDURA'S IDEAS
}

\author{
Farid Ghaemi, Ph.D* \\ Servat Shirkhani** \\ *Islamic Azad University, Karaj Branch \\ **Islamic Azad University, Science and Research Branch
}

\begin{abstract}
It is highly important for language learners to be able to control their own learning and for language teachers to develop this ability among learners since it is only through the active involvement of learners that a language can be learned and active involvement of learners requires their having control over what they learn and how they learn it. The individuals' ability to control their own behavior is referred to as self-regulation of behavior. Bandura has some interesting ideas regarding human behavior which can be easily used in educational settings. An example of these ideas is his views towards self-regulation. Bandura believes that most human behavior is self-regulated; however, this does not mean that humans have the freedom to do whatever they want. Bandura believes that freedom is defined in terms of individual's options as well as opportunities to exercise those options. Accordingly, sources of freedom can be defined and based on what defines freedom, we can determine the barriers to freedom, and thus to self-regulation. This presentation aims at elaborating on barriers to self-regulation of language learning based on Bandura's ideas. It is hoped that the discussion of constrains to self-regulation leads to more consideration of ways to eliminate such barriers and therefore to pave the way for increasing self regulation among learners.
\end{abstract}

Key words:

self-regulation, language learning, barriers, self-regulated behavior

The mediating role of academic self-efficacy in the relationship between personality traits and mathematics performance

Dr. Alireza Mooghali ${ }^{1}$, Dr. Fariba Bordbar ${ }^{1}$, Fatemeh Shams,M.A ${ }^{2}$, Nazak Soleimanpour,M.A ${ }^{2}$

${ }^{1}$ Shiraz Payam-e-Noor University(IRAN, ISLAMIC REPUBLIC OF)

${ }^{2}$ Shiraz Payam-e-Noor University(IRAN, ISLAMIC REPUBLIC OF)

${ }^{2}$ Shiraz University (IRAN, ISLAMIC REPUBLIC OF) 
Problem Statement: One of the most common approaches to the study of mathematics performance is to distinguish strong and weak students based on their mathematical outcomes or teacher perceptions and then to identify the personal characteristics that differentiate the two groups. Conception of individual differences in learning mathematics is an important issue in educational psychology.

Purpose of Study: The present research investigated the mediating role of academic self-efficacy in the relationship between the personality traits and mathematics performance.

Research Methods: Participants were 367, girls(187) and boys ( 180$)$, aged 17-18 years and selected from preuniversity of two regions in Shiraz, Iran. They completed the Goldberg's Personality traits Scale (1999) and \& Greene, Miller, Crowson, Duke, \& Akey 's Academic self-efficacy Scale ( 2004 ) and their mathematics' score was used as a criterion of mathematics performance.

Findings: The path diagram of hypothetical model was tested by simultaneous regression analysis, according to steps recommended by Baron and Kenny(1986). Results showed that.

a) Conscientiousness, openness to experience and agreeableness were positive predictors for mathematics performance. b) Openness to experience and agreeableness were positive predictors for academic self-efficacy. c) Academic self-efficacy was a mediator between personality traits and mathematics performance.

Conclusions: Students with higher level of self-efficacy can achieve better mathematics performance. Also students who are open to experience and consientiousness can organize their learning in mathematics.

Keywords : personality traits, academic self-efficacy, mathematics performance

\title{
A LONGITUDINAL STUDY REGARDING THE PSYCHOLOGISTS' PROFESSION VOCATIONAL GUIDANCE OF ROMANIAN HIGH SCHOOL STUDENTS
}

\author{
Aniţei Mihai, Chraif Mihaela \\ University of Bucharest, Faculty of Psychology and Educational Sciences
}

\section{Problem Statement:}

In psychological counseling and guidance services, the aim of appraisal service is to help the individuals know themselves better. Thus, many kinds of information such as physical features (Cakır, 2004); personality traits (Cakır, 2004; Kuzgun, 2000; Nugent, 1990) and skills (Amundson, Poehnell and Pattern, 2008) are gathered. In Romania during the economic crisis the interest of vocational guidance met the low budgets for education.

\section{Purpose of Study:}

The purposes of this study was to examine the high school students' perceptions about the counseling and guidance services in public high school from Romania and to compare the evaluation of vocational preferences of $12^{\text {th }}$ grade 
students on the psychologist profession at the Educational exhibitions from the University of Bucharest headquarter on a period of 5 years 2007-2011.

\section{Research Methods:}

Method: The participants in this longitudinal study were 558 high school students at $12^{\text {th }}$ grade, from rural and urban areas of Romania, participating at Spring Educational Exhibitions, aged between 17 and 19 years $(M=18,05$, A.S. $=0,36)$. The Instrument: the vocational guidance orientation questionnaire (Aniţei \& Chraif, 2007) evidencing the high school student perception on vocal guidance, with 4 dimensions and 25 items. The dimensions of the questionnaire are: 1) information sources; 2 ) the perceptions about the Faculty of Psychology; 3 ) the perceptions about the psychologist's development career; 4) the determinants in choosing to attend Faculty of Psychology.

\section{Findings:}

There were no statistically significant differences in the 4 year period: highlighting the advantages of being psychologist $38.5 \%$ (2010) and $36.1 \%$ (2008) from the high school students were convinced that they could have dominance in relationships; $27.6 \%$ (2010) and $29.9 \%$ (2008) would be able to know people better and $12.4 \%$ (2010) $10.1 \%$ (2008) were convinced that will help people. Furthermore they associate being psychologist with: $32.5 \%$ (2010), 28.8\% (2008) helping people; $20.4 \%$ (2010), 18.8\% (2008) working with people; $18.1 \%(2010), 17.9 \%$ (2008) counselling people and $29 \%$ (2010), $18.2 \%$ (2008) advising people.

\section{Conclusions:}

Counselling on future vocation is a process based on the knowledge of the occupation requirements and also on knowledge of details related to a specific occupation. Thus, psychological counseling and guidance services in public high schools need more involvement and strategic policies implementation.

Keywords: Counseling Psychology, Vocational Guidance, psychologist's development, strategic policies, policies implementation.

\section{ROMANIAN STUDENTS' ATTACHMENT AND INVOLVMENT TOWARDS THE ATTENDANCE TO NATIONAL AND INTERNATIONAL CONFERENCES \\ Mihai Aniţei, Mihaela Chraif University of Bucharest, Faculty of Psychology and Educationala Sciences}

\section{Problem Statement:}

The role of attachment is important because students with high university attachment should evaluate their university more positively and report enjoyment and satisfaction of the colligate experience (Astin, 1993; Light, 2001). Consequently, students who report positive evaluation of the university may demonstrate higher motivation for involvement in group activities (Bollen \& Hoyle, 1990; Chin, Salisbury, Pearson, \& Stollak, 1999). University belonging was positively related to professor caring and social acceptance (Freeman et al., 2007). Thus, Romanian students at Faculty of Psychology and Educational Sciences, University of Bucharest have been participated since 2008 at many National and International Conferences guided by their professors.

\section{Purpose of Study:}

The purposes of this study were to evidence the students' attachment and involvement towards the attendance to national and international conferences of psychology on a period of 4 years (2008-2011).

\section{Research Methods:}

The participants were 583 undergraduate students, aged between 19 and 28 years ( $M=23.65 ;$ S.D.=3.12) males and females, Faculty of Psychology and Educational Sciences, University of Bucharest on a period of 4 years. The attachment was measured by a questionnaire "Students and Attachment at the learning place" with three factors: attachment for the colleagues (5 items), attachment for the furniture and modern teaching devices and instruments (10 items) and attachment to the professors (7 items). (Aniţei, Chraif\&Bărbulescu, 2009). 
Applying the multiply regression model the predictors attachment and attitude towards scientific development had a strong predictive value for the criteria involvement and participation to national and international conferences. The $\beta$ coefficients confirmed the statistically significant correlation between the predictors and the criteria $(p<0.05)$. Also, the multivariate regression model provides a substantially reduction in error $(62.2 \%)$ and that the independent variables could predict the undergraduate students' performances in a positive and modern environment.

\section{Conclusions:}

The results of this study clearly demonstrated the important influence of attachment and scientific guidance offered by the academic staff. Students are more interested in attending conferences when a professor shows an increased interest in coordinating them. Thus, the scientific and moral support is a facilitator for the attendance of students to scientific manifestations.

Keywords: attachment, attitude towards scientific development, scientific manifestations, predictive value, for involvement in group activities.

Evaluation of children with Attention Deficit Hyperactivity Disorder and Specific Learning Disability on the WISC and Cognitive Assessment System (CAS)

Authors: Stefano Taddei (1), Bastianina Contena (1), Mariella Caria (1), Eva Venturini (2), \& Francesca Venditti (3) Affiliations: Dipartimento di Psicologia, Univ. Di Firenze (1); Dipartimento di Patol. Umana e Oncologia, Univ. di Siena (2); Facoltà di Psicologia, Univ. Di Firenze (3)

\section{Problem Statement:}

The diagnosis of the Attention Deficit Hyperactivity Disorder (ADHD) and of the Specific Learning Disabilities (SLD) are often based on instruments which have an important connection to IQ. The preponderance of the data supports the opinion that Wechsler Intelligence Scale for Children (WISC) factors, should not be relied upon for ruling in or out the diagnosis of ADHD and SLD. One of the reasons why these tests may have limited utility for detecting the types of cognitive problems that children with ADHD and SLD have is that they do not measure the cognitive attributes which are characteristic of these children. The Planning, Attention, Simultaneous, Succession Theory (PASS) redefines the concept of human intelligence through a multidimensional approach, derived from neuropsychology and cognitive psychology. The Cognitive Assessment System (CAS), based on PASS theory is an alternative to traditional IQ that takes a multidimensional view of ability based on assessment of cognitive processing rather than general intelligence. Because of the PASS-CAS potential for the assessment of children with ADHD and SLD, researchers have studied this relatively new approach and found that the PASS scales may have utility for identifying the cognitive deficits found in some children who have ADHD and SLD.

\section{Purpose of Study:}

The purpose of this study is to examine difference in cognitive performance between samples of children with diagnosed Attention Deficit Hyperactivity Disorder (ADHD), Specific Learning Disability (SLD) and the normative groups on two tests of ability.

\section{Research Methods:}

Matched samples of 10 children diagnosed with ADHD were contrasted with 10 children diagnosed with SLD. Both groups were also compared to the normative values for the WISC and CAS.

\section{Findings:}

Children with ADHD had lower Planning and Attention scores than those with SLD and than the standard sample. Children with SLD had lower Successive scores than those with ADHD and than the standardization sample. No significant difference on the WISC was found between children with ADHD, children with SLD and the matched clinical sample.

\section{Conclusions:}

The results suggest that Wechsler scores show minimal difference among the samples but CAS scores appear sensitive to the cognitive processing difficulties experienced by children with ADHD and SLD. 
Keywords: Attention Deficit Hyperactivity Disorder (ADHD),Specific Learning Disabilities (SLD), Cognitive Processes, PASS theory

Implications of Vygotsky's zone of proximal development (ZPD) in teacher education: ZPTD and self-scaffolding

Tayebeh Fani, Sama Technical and Vocational Training College, Islamic Azad University,

Tehran Branch, Iran. Farid Ghaemi, Karaj Islamic Azad university

Problem Statement: One of the major themes in Vygotsky's sociocultural theory is the zone of proximal development (ZPD). Vygotsky (1962) introduced the concept of ZPD to criticize the psychometric-based testing in Russian schools. Vygotsky's zone of proximal development was created with child development in mind and describes how cognitive growth occurs in children. Unfortunately, Vygotsky lived a short life and never proposed any specific methodology for the use of ZPD in teacher education.

Purpose of Study: Recently the idea of ZPD has been used in teacher education by scholars such as Warford (2011). In this paper, first the philosophical and historical foundation of ZPD is discussed. Then, ZPTD and different stages of developing the ZPTD are introduced. At the end of the paper, suggestions are made in how teachers can improve their ZPTD and deal with these factors

\section{Research Methods:}

This study is a descriptive study.

\section{Findings \& Conclusions:}

There are some factors which may have direct effect on the teachers' zone of proximal development and professionalism such as peers and mentors, contextual constraints, mediatory artifacts and technology. Suggestions are made in how teachers can improve their ZPTD and deal with these factors. They include diary writing, selfscaffolding, collaborating with colleagues, conducting action research, analysis of teaching practice, and having discussions with learners.

\section{Keywords:}

zone of proximal development, zone of proximal teacher development, teacher development 
ECONOMIC LITERACY AMONG MALAYSIA STUDENTS

Che Noraini Hashim

Lecturer Institute of Education, International Islamic University Malaysia

Bakare Kazeem Kayode

PhD Candidate Institute of EducationInternational Islamic University Malaysia

\section{ABSTRACT}

Economic literacy, economic awareness, and economic understanding, are terms which are synonymously, interchangeably and regularly used in the literature. Economic literacy demonstrated specified performance standards and is acquired under conditions of mastery learning and teachings about the economy, economic awareness connote "the raising of consciousness on economic affairs." The inundate Report of HMI on Economic Understanding in the School Curriculum in 1987 called for the need for pupils to have an insight into the cumulative economic wisdom of society and a sufficient understanding to apply it successfully to practical situations. This study adopted a quantitative research approach to ascertain the level of economic literacy among university students in Malaysia. In this study, the economic literacy was measured by using the America Test for Economic Literacy (TEL). The findings revealed that Malaysia students were lacking in overall economic literacy as measured by the TEL. Furthermore, the teaching of economic helps students to have some understood of economic concepts; students with economic background scored relatively higher than those without economics background, but the difference had no significant value. The findings also led to some revealing conclusion: larger percentage of Malaysian students lacked knowledge of economics and that exposure to an economics course had positive effect on the students' performance on the TEL. Findings also showed that there is low emphasis on economic education in Malaysia schools.

Keywords: Economics literacy

Case studies on School Based Support Teams in selected South African inclusive schools 


\section{Problem Statement:}

South Africa has moved from a previous special educational paradigm founded within a psycho-medical model which justified separate, exclusionary schools towards an inclusive view, legislated by Education White Paper 6 which proposed the School Based Support Team (SBST) as one of the pivotal structures for the implementation of inclusive education. Although these teams were introduced a decade ago, few schools are functioning as effectively as envisaged in the support of special needs learners who are often still excluded from the mainstream curriculum and marginalized within the school.

\section{Purpose of Study:}

Research into the functioning of these teams was done in selected inclusive and full service schools in the Gauteng province in order to establish their effectiveness in supporting special needs learners.

\section{Research Methods:}

Interpretative, descriptive case studies were used to explore the micro-world of these teams within five, purposefullyselected, primary schools. Focus group and in-depth interviews were conducted with team members. Observations of team meetings were made and documents, such as minutes of meeting and referral forms were collected. Data was analysed qualitatively, by coding into categories to arrive at themes. Trustworthiness was ensured by keeping a detailed audit trail and by member checking.

\section{Findings:}

In the one well functioning school, the SBST played a key role within the school in positively supporting learners with individualized learning programs developed. Team leadership was visionary; team members were trained in special needs; and the team regularly interacted with teachers, support personnel and outside professionals. In three schools however, the teams were less effective; team members were poorly trained; they met irregularly; there were illdefined referral and placement procedures with limited support programs developed. In the last school, the team was non-existent and represented only on paper in the schools management structure.

\section{Conclusions:}

Although the SBST is a well intentioned policy strategy, they are not functioning in the majority of schools studied due to poor leadership, inadequate training, teacher overload and limited awareness of special needs. Thus highly specific training of team members is recommended in each school to manage their special needs learners and implement the vision of inclusive education.

\section{Keywords:}

Inclusive education, Special needs education, school based support teams, teacher support teams, learning support

\section{A Qualitative Study on Personality Traits of Negative Perfectionist}

\section{Min Ma, University of Antwerp} Fei Zi, Beijing Forestry University

Problem Statement: Students from college or univeristy always come across some psychological problems, such as depression, anxiety, obsessive-compulsive neurosis. Perfectionism is closely related to the mental health of individuals. The qualitative study provides us with a new perspective to explore perfectionist personality, so we can give a comprehensive and vivid presentation about the personality traits of perfectionist, and get a deep and full understanding of possible intrinsic mechanism and outward manifestation.

Purpose of Study: By comparing the personality traits of negative perfectionist and non-negative perfectionist, the article studies the differences on cognition, emotion and motivation between the two groups.

Research Methods: A qualitative study was conducted. Four negative perfectionists and two non-negative perfectionists were interviewed by semi-structural ways. Qualitative data was analyzed. 
Findings: Cognition: Authority always makes the negative perfectionist oppressive. The self-evaluation of negative perfectionist is dominated by negative composition; to non-negative perfectionist, it involves both negative and positive composition. Both of the two groups are sensitive to the interpersonal environment. Negative perfectionist concentrates on the critics of other individuals, whereas the non-negative perfectionist converges on the acute awareness and analytical understanding of interpersonal environment. Emotion: The former is apt to be anxious and take a negative reaction, while the latter prefers to take a relatively positive reaction to cope anxious emotion. Motivation: The former pursues a comfortable life style, whereas the latter is inclined to experience various styles of life.

Conclusions: Negative perfectionist mostly experience negative feelings, motivations, and cognitions; on the contrary, the non-negative perfectionist is inclined to experience positive ones.

Keywords: Negative perfectionism, Authoritarianism, Personality traits, Qualitative analysis

\author{
THE CONCEPT OF PRESCHOOL MUSIC EDUCATION IN ESTONIAN EDUCATION SYSTEM \\ Kristi Kiilu Associate Professor, PhD \\ Music Education Department, Estonian Academy of Music and Theatre, Estonia.
}

\title{
Problem Statement:
}

Estonian people have since ancient times identified themselves through singing, the characteristics of which are the millennia-old runic song that has been recently revived, and also the tradition of song festivals, which over two centuries has imbibed its viability from the continuous music education. The timeless topicality of music education in Estonian cultural space and an increase in the importance of early childhood music education on the one hand and the absence of a systematic approach to kindergarten music education on the other gave impetus to me to investigate the factors of the development of contemporary concept of kindergarten music education from a historical perspective.

\section{Purpose of Study:}

From the above a problem arises: What changes have taken place in kindergarten music education in different historical periods? What are the factors that have influenced the formation of the concept of Estonian kindergarten music education? 
Research Methods: The methods of research included: 1) documentary analysis; 2) a questionnaire for kindergarten music teachers (183 respondents) and 3) interviews (15) with kindergarten music teachers.

Findings: The analysis revealed that although the law regulating the work of preschool educational establishments was adopted only in 1993, music education had been carried out as an independent activity since 1947 following methodological and manuscript materials and subject programmes. According to the respondents, music activity in preschool educational system has become a diverse creative process that values children and their individuality. In the process of music education attention is attached to value education and cultural traditions of Estonia.

\section{Conclusions:}

In spite of the changing political regimes music education has had a very important role in the system of Estonian preschool education and has not merely meant the acquisition of the basic truths of music but also the integration of children into the society and passing on cultural traditions. The influence of the continuity of Estonian Song and Dance Festival tradition may seem non-existent at the first sight; however, its impact on the preschool music education has been significant.

Keywords: early childhood music education, history of music education, kindergarten music education

"They have always supported my choice" Estonian and Finnish University students describing the creative aspects of their learning environmental catalysts

Adj. prof. Inkeri Ruokonen, adj. prof. Kristi Kiilu, adj. prof. Maia Muldma, prof. Maie Vikat \& prof. Heikki Ruismäki

Helsinki University, Tallinn Music Academy, Tallinn University

Problem Statement: The aim of this comparative study is to find out and describe most important learning environmental catalysts of Estonian and Finnish university students that have been or are in connection with the development of their artistic giftedness and their creative products or presentations.

Purpose of Study: The purpose of this study is to find out which are the most effective and valuable learning experiences in the learning environment. In the learning environment we focus on home, school, culture, community, hobbies, gender and chance factors.

Research Methods:The approach of this research is mainly qualitative. The data is collected from the writings of Estonian (50) and Finnish (50) university students. Research method used was a qualitative content analysis.

Findings:The results of the analysis of students' self evaluations give relevant information shows that different catalysts of learning environment have an important role in development of giftedness and couragement for creativity. In addition to home and school environment the informal learning environment or happy chances were essential for the development of artistic giftedness. There were more similarities than differenties found between two neighbour countries.

Conclusions:When developing effective learning methods and the education of children it is essential to focus both formal and informal aspects and all the environmental catalysts which may be in connection to the intrinsic motivation and to the development of giftedness and creativity.

\section{Keywords:}

Learning environment, giftedness, creativity, university students, music- and arts education 


\section{RESEARCH IN HIGHER EDUCATION: THE ROLE OF TEACHING AND STUDENT LEARNING Ana Paula Cabral \& Isabel Huet (University of Aveiro) Lewis Elton (University College of London)}

\section{Problem Statement:}

Over the past 20 years, national processes for research-quality assessment have been introduced or amended led by the United Kingdom and countries with an Anglo-Saxon influence.

Whatever the benefits of these systems might have brought to the organisation and quality of research most of them have contributed for a devaluing teaching and to a growing separation between the research worlds of the university and student learning.

\section{Purpose of Study:}

This study aims to contribute to a broader understanding of the role of research for the quality of teaching and student learning and, through the collection of good practices and recommendations, argue for the integration of these indicators in research quality assessment tools and reference frameworks.

\section{Research Methods:}

The sources of the empirical data were interviews with two members from the UK's last RAE panels (2008 - Education panel), two HE institutions' research representatives (a world-leading/ research-intensive institution with a research-led teaching approach (Education and Social Sciences) and a teaching-led/ research informed "new/post 92" institution) and two senior education researchers concerning their perceptions and experiences about the UK's research assessment system.

\section{Findings:}

The outcomes indicate the need to discuss the role of teaching and pedagogy research informed by experience and within the disciplines, the impact of research on graduate/ postgraduate student learning and staff professional development and the contribution of the different types of research and publications for the assessment criteria.

\section{Conclusions:}

Research assessment systems should value teaching and student learning through research and institutional leadership, planning and culture should support this link through the development of strategies based on a broader and context-driven conception of 'scholarship'.

Keywords: Research, Teaching, Learning, Quality, Assessment 


\section{EARLY LANGUAGE TEACHING AND SYLLABUSES Maria Stec, University of Silesia}

\section{Problem Statement:}

Language education continually surprises us, and in turn frequently offers new perspectives on learning foreign languages. The paper focuses on the most important aspects in early foreign language education. The questions are: What is the nature of English language teaching in primary schools? What are the factors that direct the process of syllabus implementation?

\section{Purpose of Study:}

The aim is to describe the process of early English education in the context of Poland. In particular, the idea is to investigate teachers' experience in teaching English to young learners $(\mathrm{YL})$ and a role of syllabuses in terms of their design, selection and implementation in a primary classroom.

Research Methods:

The first stage of the research study involves an interview with teachers and concentrates on the main tendencies in early foreign language education, teachers' qualifications for teaching YL plus tendencies in syllabus design and syllabus selection.

The second stage of the research study concentrates on syllabus implementation observed during English lessons. The observation study involves the background and detailed information: lessons' aims, time, stages, types of interactions, content, procedures plus comments on course book adaptation and teaching/learning processes.

\section{Findings:}

The findings are based on the reports from six interviews and the observation of forty-five lessons.

The results from the interview study are grouped into three categories to identify the most popular aspects in early language education. The results from the observation study are collected in four categories to examine the patterns of English syllabus implementation with YL.

\section{Conclusions:}

The results show that syllabus selection requires knowledge of other English syllabuses available and suitable for YL. A teacher's ability to reflect on a syllabus and adapt it to learners' abilities is highlighted here. The analysis of syllabus design in the context of teaching $Y L$ reveals two views. The first view is linked to the teacher's experience in teaching $Y L$, for example, understanding their needs, skills and difficulties in learning languages; as well as the teacher's knowledge of the structure of syllabuses. The second view is linked to the very process of writing and designing a syllabus document; with a group of procedures and factors important for this process. For example, these are consistency in content selection, cohesion and logical order of the structure, and linking between topics. As far as English syllabus implementation is concerned, two tendencies are observed. The first refers to the teacher's creativity and her/his preparation for teaching English lessons, which should not be based only on course books. The second tendency is linked to the teacher's good knowledge of the English syllabus and children's abilities in her/his class. 


\section{EDUCATIONAL LEVEL, GENDER AND FOREIGN LANGUAGE LEARNING SELF-REGULATION DIFFICULTY Anna Studenska, University of Silesia, Poland}

\section{Problem Statement:}

Research findings concerning age and gender differences in self-regulation of learning are inconsistent. Therefore a study was conducted to answer the following question: are there differences in subjective difficulty experienced during various stages of foreign language learning self-regulation process between male and female students from primary school, lower secondary school and upper secondary school?

\section{Purpose of Study:}

The purpose of the study was to gather the data which would be helpful in formulating guidlines for educational programmes supporting self-regulation which would address specific needs of male and female foreign language learners on various levels of education.

\section{Research Methods:}

Three hundred and eighty persons took part in the study including students from primary school ( 57 boys and 58 girls) lower secondary school ( 80 male and 89 female adolescents) and upper secondary school (49 men and 47 women). The participants completed Foreign Language Learning Self-regulation Difficulty Inventory constructed for the purpose of the research. The Inventory consists of 34 items and measures subjective difficulty experienced during choosing goals, ways and conditions of learning (alpha $=0,89)$, planning, organizing and implementing learning (alpha $=0,82)$, motivational and emotional control (alpha=0,81) and reflecting and making changes (alpha=0,86).

\section{Findings:}

The results of a two-way between groups ANOVA showed significant main effects of gender $[F(1,374)=11,964$; $\left.p=0,001 ; \eta^{2}=0,031\right]$ and educational level $\left[F(2,374)=5,956 ; p=0,003 ; \eta^{2}=0,031\right]$ in the case of difficulty in planning, organizing and implementing learning. The main effect of gender was the only one significant in the case of general foreign language learning self-regulation difficulty $\left[F(1,374)=8,487 ; p=0,004 ; \eta^{2}=0,022\right]$, difficulty in motivational and emotional control $\left[F(1,374)=11,373 ; p=0,001 ; \eta^{2}=0,030\right]$ and difficulty in reflecting and making changes $[F(1$, 374) $\left.=4,937 ; p=0,027 ; \eta^{2}=0,013\right]$.

\section{Conclusions:}

Study results showed that educational programmes aimed at supporting self-regulatory skills in foreign language learning should emphasize skills connected with planning, motivational control and reflection, especially in male upper secondary school students.

Self regulation, foreign language learning

\section{Keywords:}


Problem Statement: Starting from an idea of teaching as a complex set of practices, deep-rooted in teachers' personal "being-in-the-world", the research employs a phenomenological approach in order to gain a deep understanding of the teaching experience as it is perceived and thought of by those who are personally involved in it.

Purpose of Study: The research objectives involve both methodological reflection on and knowledge development of teachers' experience.

Research Methods: Qualitative conversational interview is the research technique we have used. This reflection originates from a two-year study of teachers' knowledge about practice: thirty-five teachers were involved each one of whom was interviewed twice.

This method is coherent with a phenomenological approach because phenomenological act of knowledge is characterized by a continuous movement between the researcher and the phenomenon investigated, which produces a deeper and closer perspective on others' lifeworld.

Findings: The analysis of the interviews has led to a complex vision of teaching practice, seen from teachers' viewpoint. The core of their descriptions concerns several different meanings, expressed by all the teachers of all school grades, drawing a composite profile of what teachers consider as essential in their practice.

The data analysis led to recognize the presence of two main areas of teachers' practice:

I. The teachers' action in the classroom

II. The conditions that facilitate teachers' action.

Each area is composed by different levels.

Conclusions: A research on the meanings teachers build about their practice can be significant on two different levels: $\mathrm{i}$. methodological; ii. About practical knowledge in schoolwork.

i. From a methodological viewpoint, during the whole process we have developed a reflection on potential and limits of a method of content analysis combining grounded theory and phenomenological approach.

ii.As for the knowledge produced through the research, we have to cope with a phenomenon - school practice - that most of the times doesn't leave traces. The research method we used it has made it possible to give voice to the teachers' practical knowledge, which is built every day at school. The teachers, dealing with different children, facing practical problems, always search adequate, creative solutions and produce concrete pedagogical perspectives.

Keywords: descriptions, teachers' experience, essence of teaching

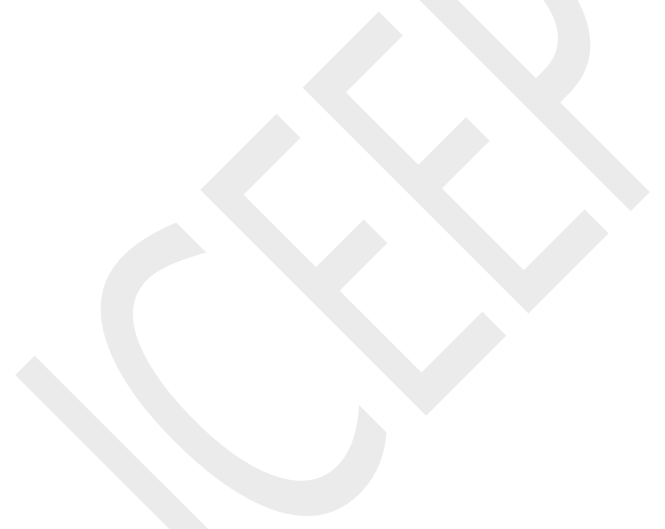

MOTIVATION TO WORK AND THE SYNDROME OF PROFESSIONAL BURN-OUT AMONG TEACHERS IN LATVIA

Valerijs Dombrovskis, Daugavpils University, Latvia

Svetlana Guseva, Daugavpils University, Latvia

Vadims Murasovs, Lärkkulla Folk Academy, Finland

Problem Statement: This study highlights and analyses the connection between peculiarities of motivation to work and professional burn-out among urban and rural school teachers in Latvia, with professional experience up to five years.

Purpose of Study: to explore the connection between Professional burn-out and motives' hierarchy in the structure of motivation to work.

Research Methods: K.Zamfir's test was applied to define the motivation of pedagogical activity. The test includes seven motives - wage, career growth opportunity, avoiding criticism from colleagues, avoiding possible penalties, need for social status and respect, satisfaction from work's process and results, opportunities to full self-realisation in one's profession. K.Maslach test was applied to detect the syndrome of Professional burn-out.

Findings: The following tendency in both groups has been discovered: (1) the motive of wage is highly important; (2) the motives of satisfaction from work's process and results and of avoiding possible penalties have appeared to be more significant for rural school teachers; (3) the motive of career growth opportunity is dominant among urban school 
teachers. The analysis of the professional burn-out syndrome components, i.e. emotional exhaustion, depersonalisation and reduction of professional achievements, has shown that levels of emotional exhaustion and reduction of professional achievements do not have any significant differences. The level of depersonalisation is higher among urban school teachers.

Conclusions: The motive of the need for social status and respect is at the bottom of the structure of motivation to work. The motive of wage dominates among the school teachers in Latvia with work experience up to five years because the teacher profession does not have a status of highly-paid one. Therefore the influx of perspective professionals into the system of education is very slow. Professional burn-out syndrome among urban and rural school teachers in Latvia is not that common. Nevertheless, the study has detected high levels of emotional exhaustion.

The quality of school education in Latvia may be decreased dramatically if the nearest decade does not allow schools experiencing the influx of young teachers and if the attitude to social status of teachers is not changed both in the society and among the teachers themselves.

Keywords: motivation, professional burn-out, rural school teacher, urban school teacher

\section{CHANGES OF HANDICAPPED AND OTHER STUDENTS'SELF-CONCEPT AND MUTUAL ATTITUDES AS A RESULT OF THEIR DIRECTED INTERACTION}

Katerina Juklova, University of Hradec Kralove, Faculty of Education, Czech Republick Monika Ulrichova, University of Hradec Kralove, Faculty of Education, Czech Republick

\section{Problem Statement:}

Academic environment represents important source of impulses of students' personal and social growth. Among students arise imformal relationships throught which they exchange experiencies. However students have to break coyness and some barriers that restrain their relating to distincion. Directed interaction may be one of the tool that can help student to break their social difficulties. The paper summarizes the results of a project focussed on the enriching the academic environment using the potential of existing differences among university students. A one semester-intervention program of personal and social growth called Sharing the experiences was created that is supposed to support the cooperation among handicapped, disadvantaged and other students.

\section{Purpose of Study:}

To identify the impact of directed interaction between handicapped and other Czech university students on their selfconcept and mutual attitudes.

\section{Research Methods:}

Set of questionaries using mainly the method of semantic differential containing Self-concept measure, Distinction tolerance and Opennes to cooperation.

Findings:

Research results confirmed the assumed changes of both common and handicapped students' who participated in the one semester-intervention program of personal and social growth Sharing the experiences. The changes related to 
students'value system, tolerance of distinction and opennes to cooperation and were found among both common and handicapped students.

\section{Conclusions:}

Regular student interaction in conjuction with sharing the experiences and cooperation results in the elevation of mutual needs respect, in the intrinsic enrichment in form of value chart movement and the changes of self-concept and of attitudes to their colleagues.

\section{Keywords:}

academic environment, student, handicap, self-concept, attitudes, directed interaction

SCHOOL: INSTITUTION WHERE CHILDREN LEARN THE ANSWERS WITHOUT ASKING QUESTIONS? Jana Marie Havigerova, University of Hradec Kralove Faculty of Education

Katerina Juklova, University of Hradec Kralove Faculty of Education Jiri Haviger, University of Hradec Kralove Faculty of Informatics and Management Iva Buresova, Masaryks University Faculty of Arts

\section{Problem Statement:}

The contemporary information society imposes new demands on its members - to cope with new technologies, to orientate in the world of informations; in other words to achieve information literacy. Information literacy fulfils by means of information behaviour (behaviour developed by the need of getting information). A significant predictor of successful information behaviour is question skill.

\section{Purpose of Study:}

To realise the analysis of verbal behaviour in primary schools in the Czech Republic in the terms of questioning and interrogation.

\section{Research Methods:}

Frequency analysis of the Czech National Corpus SCHOLA2010 (corpus contains transcript of spoken language from 204 lessons acquired in 115 different classes all over the Czech republic: 47 teachers, 2347 students, and contains 792,764 words.

Findings:

In Czech primary school there is on the average asked 41 questions in one lesson. Absolute majority of question is asked by teachers (68-88\%), the remaining percentage is divided into about 20 pupils. In other words, one teacher in one lesson puts about 33 questions, one pupil in one lesson, then, only a one third of the question! What is the role of sex? Man-teachers at the first stage asks fewer questions, at the second stage ask more questions than womenteachers. For pupils the impact of gender on the number of questions has not been established. Most of questions is asked during third and fourth lesson (before lunch).

\section{Conclusions:}

Analysis of teaching process in primary schools in the Czech Republic in terms of questioning and interrogation, suggests that Czech children in primary schools practically do not ask questions. The article discusses some of the psychological consequences of these findings. 


\section{ARE TYPES OF MEMORY CRITICAL FOR STUDENT'S SUCCESS IN TESTS OF DISCRETE MATHEMATICS? Jiri HAVIGER, Department of Informatics and Quantitative Methods, Faculty of Informatics and Management, University of Hradec Kralove}

Jana M. HAVIGEROVA, Institute of Primary and Preprimary Education, Faculty of Education, University of Hradec Kralove

\section{Problem Statement:}

The testing of mathematical knowledge (subject discrete mathematics) can be expertly distinguished into two types of tasks, depending on evoked type of memory: the semantic memory and procedural memory. We assume that there are two boundary types of students: one preferring semantic memory learning and second preferring procedural memory learning. The aim of this study was to determine whether it is possible to identify two types of tasks based on the success of students' test scores.

\section{Purpose of Study:}

Can be tasks in real exam tests divided into several clusters based only on results of this test? Do these clusters correspond with the expected types of memory used?

\section{Research Methods:}

The research was conducted under real education conditions. The basic method is the statistical analysis of test results. Method used: correlation analysis, factor analysis, analysis of variance.

\section{Findings:}

It was founded that the tasks that have been expected to evoke the same memory type, don't get similar results. Subsequent analysis revealed that the intervening variables (student's relationship to math, stress, procrastination and other) have more influence to success in tasks than the students preferred memory type.

\section{Conclusions:}

The research shows that in teaching of mathematical subjects it may be more important to improve student's relationship to the subject than to organize teaching and learning support in dependence on the activated memory type.

\section{Keywords:}

discrete mathematics, mathematical knowledge testing, semantic memory, procedural memory, statistical analysis 


\title{
SERVICE QUALITY IN A RESEARCH UNIVERSITY: A POST-GRADUATE PERSPECTIVE
}

\author{
Azizah Rajab \\ r_azie@yahoo.com \\ Siti Aishah Panatik@Abdul Rahman \\ Hamidah Abdul Rahman \\ Roziana Shaari \\ Maisarah Saat \\ Universiti Teknologi Malaysia. \\ Campus Johor Bahru \\ MALAYSIA
}

\begin{abstract}
Learners experience to higher education service in any Higher Educational Institution is intricate and multifaceted. Even though it has become a major issue in higher education worldwide, in Malaysia it has gained serious attention only in the last few years due to overwhelming applications of international learners in its local university. After spending minimum one semester or more than that in the local universities they have attended, these learners form different perception and perspective depending on situation and experience that they have gained while studying especially at a post graduate level. This paper presents the findings from a funded research project investigating the post-graduate learners perspective on education service quality based on two main criteria namely the effectiveness of managing the quality of teaching and learning and the criteria of service and facility quality. Two methods of collecting data focusing on quantitative and qualitative method are used. A simple random sampling is used among international post-graduate learners. This paper will discuss the findings and the implications of the study towards generating a good education service whilst concurrently producing qualified post-graduate learners in a highly regarded research university quality image by providing an elevated, sophisticated and acclaimed service quality towards its international learner.
\end{abstract}

Keywords: service, quality, international, education 
Siti Aisyah Binti Panatik, Azizah Rajab, Siti Khadijah Zainal Badri, Hamidah Abdul Rahman

Department of Human Resource Development

Faculty of Management \& Human Resource Development

Universiti Teknologi Malaysia

81310 UTM Johor Bahru, Malaysia

\title{
Problem Statement:
}

Work-family conflict (WFC) is an inter-role conflict arising from incompatible pressures from work and family roles (Greenhaus \& Beutell, 1985). Research has verified repeatedly the negative effects of WFC on employees' behavior, emotions and health (see Frone, 2003) underscoring the importance of helping workers reduce the conflict. To date, few authors have examined work-family conflict within school teacher in collectivistic culture such as Malaysia. There are six dimensions of conflict (time, strain, and behavior) and two directions of work-family conflict (work interference with family and family interference with work).

\section{Purpose of Study:}

This study examines the levels of work-family conflict among respondents and their differences based on demographic factors such as gender, marital status, and type of school. This study also determines the impact of work-family conflict on life satisfaction, mental health, and turnover intentions.

\section{Research Methods:}

This study utilized a survey design using questionnaires to gather the data. A total of 100 responded to the questionnaires. All the data were analyzed using the PASW 18. Means, frequencies, and percentages were used to measure the level of work-family conflict. Meanwhile, t-test and one-way analysis of variance were used to analyze differences in the levels of work-family conflict. Multiple regression analysis was performed to determine whether work-family conflict predicted life satisfaction, mental health, and turnover intentions.

\section{Findings:}

Results show that the level of work interference with family (WIF) is higher compared to the level of family interference with work (FIW) among the respondents. Time dimension is the highest level to contribute the level of work-family conflict. Work-family conflict has negative influence on mental health, life satisfaction and mental health.

\section{Conclusions:}

This study provides a discussion on the implication of this research to the development of education institutions and for future research.

Keywords: Work-Family Conflict, Life Satisfaction, Turnover Intentions, Mental Health, Teacher

\section{THE USE OF ITEM ANALYSIS FOR THE IMPROVEMENT OF OBJECTIVE EXAMINATIONS}

\author{
Anna Siri, University of Genoa
}

Michela Freddano, University of Genoa

\section{Problem Statement:}

In the standardized and objective evaluation of student performances, the item analysis is a process in which both students' answers and test questions are examined in order to assess the quality and quantity of the items and the test as a whole. 
Purpose of Study:

The aim of this study was to investigate the effect of the analysis of multiple choice student tests on the quality of the tests designed by some school teachers. Internal summative evaluation of student performances has been done by the teachers of some Genoese schools using standardized tests.

\title{
Research Methods:
}

A quasi experimental method (pre-test and post-test) was used in this study. All students from the $3^{\text {rd }}, 4^{\text {th }}$ and $5^{\text {th }}$ primary school level were selected to evaluate their performances by testing. The analysis of the students' results and items were done and reported to the teachers. The analysis was carried out including item structure, whole structure of the test, content validity, and levels of thinking skills reflected in the test questions. Moreover, the indexes of both item difficulty and item discrimination were calculated. Item distracter analysis was examined by calculating the percentage of examinees who selected incorrect alternatives. On the basis of the analysis results the tests have been re-designed.

\section{Findings:}

According to the results, there was a significant difference between before and after intervention in variables item structure, levels of thinking skills, and item analysis.

\section{Conclusions:}

The results emphasized that item analysis provides feedbacks to the teachers and offers educational tools to assist them. Moreover applying item analysis was effective on improving some qualitative and quantitative items analysis measures.

\section{Keywords:}

Item analysis; student assessment; standardized test

\section{IMPLEMENTING A RESPOSE-TO-INTERVENTION OR 'RtI' APPROACH FOR THE IDENTIFICATION AND SUPPORT FOR STUDENTS WITH DYSLEXIA - THE SINGAPORE EXPERIENCE}

\author{
Dr Mariam Aljunied (C.Psychol) \\ Lead Specialist \\ Ministry of Education, Singapore \\ Ms Ho Hil May \\ Senior Specialist \\ Ministry of Education, Singapore
}

\section{Problem Statement:}

The identification of pupils with dyslexia in Singapore had traditionally relied on the IQ-achievement discrepancy approach. That had resulted in an unsatisfactory situation where the incidence rate was only $0.6 \%$, and the mean age for dyslexia diagnosis was 9.4 years. This meant that many students with dyslexia were not identified and given early support. Limitations to the traditional discrepancy approach for dyslexia led the use of an alternative approach, i.e. 
Response to Intervention (RtI). In this approach, pupils who do not respond to interventions over time would be identified for dyslexia. A pilot project was conducted in 2007 to implement a Rtl-based identification for pupils with dyslexia in 33 primary schools in Singapore.

\section{Purpose of Study:}

The present study aims to evaluate the accuracy of Response to Intervention (Rtl)-based dyslexia screening model based on the sensitivity (i.e. true-positive rate) and specificity (true-negative rate) of the screening process.

\section{Research Methods:}

All pupils in the 2007 cohort in the 33 schools were first screened for literacy difficulties at the begininng of primary 1 to identify pupils who need additional interventions in literacy. The intervention was provided through school-based literacy programmes. Pupils' progress were closely monitored and those who show persistent literacy difficulties after 1.5 years of intervention were screened for dyslexia. From the screening, 274 pupils were identified as "at risk" for dyslexia, and confirmatory diagnoses for dyslexia were then carried out on all these "at risk" pupils. To ascertain true-negative rate, a random sample $(n=276)$ of the pupils who were screened to be "not-at-risk" underwent the full dyslexia diagnostic assessment.

\section{Findings:}

The results showed that both the sensitivity and specificity of the Rtl-based screening processes were above 0.7.

\section{Conclusions:}

Based on the present findings, about $70 \%$ of dyslexic pupils that are present among the pupils in these schools would be identified by age 7 years; a significant improvement from current local practice, where only $0.6 \%$ of pupils with dyslexia are identified for support, and many are identified only at age 9 yrs. Issues and practical implications of implementing Rtl approach to dyslexia intervention are discussed.

\section{Experimental Researches On Metacognitive Competence Development at Freshmen Students from Three Romanian} Universities

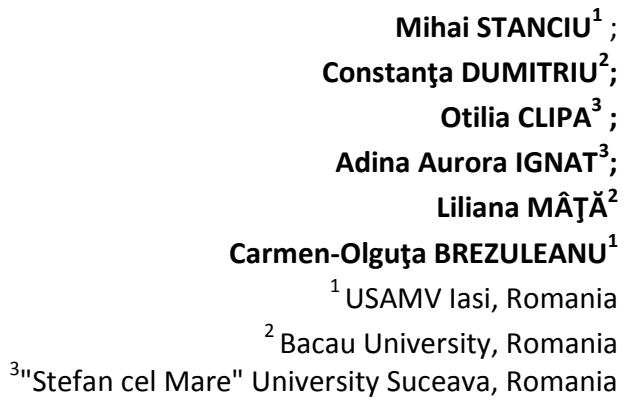

\section{Problem Statement:}

We appreciate that the educational work has to count on the profound knowledge of causes, conditions and favouring factors and especially of those that prevent the improving of university education quality. If we agree with the principle of centring the teaching -education process on the student, then the deciphering the individual mechanisms of the complex process of learning represents the basis of all researches of modernizing the teaching-learning process.

\section{Purpose of Study:}

The research was focused to identify the main difficulties encountered of freshmen students in their learning process and also to enable them with modern techniques for efficient learning (http://www.uaiasi.ro/DPPD/METACOGNITIE 92-106).

General and specific objectives of the project:

a) Raising the the students`awareness towards the learning psychological mechanisms;

b) Enabling the students with the efficient learning techniques;

c) Dissemination and generalization of the acquired experience. 


\section{Research Methods:}

Due to the instruments of psycho-pedagogical investigation, through qualitative and quantitative analyses, we will be able to offer the students, the teaching and leading staff that expertise that could lead to the improvement of education quality.

The hypothesis of the project is: if the students gain the learning techniques, then the results of the learning process will be a response to the postmodern society challenges. The university should offer to the students differentiated tasks according to their individual needs.

Findings:

The main difficulties the students meet in their learning process are linked to: the lack of learning skills, the lack of motivation and the wrong teaching style. The results emphasized the students' perceptions upon their cognitive processing during their preparation for an exam and upon their own learning style. The read-in of the individual mechanism of the complex learning process is the basic prerequisite for all searching for modernisation of the teaching process in order to contribute to the better quality of education.

\section{Conclusions:}

The results pointed out that the students have gained abilities of different techniques of intellectual work, which are so useful during the university years, as well as to their preparing for the long term learning.

Keywords: competences, meta-cognition, learning, students, quality.

Individual and group factors of curricular innovations in the domain of Language didactics

Andreia Irina Suciu, Liliana Mâţă, "Vasile Alecsandri" University of Bacău, Romania

Roxana Ghiațău, "Al. I. Cuza” University of lasi

\section{Problem Statement:}

At the foundation of this study we placed theoretical premises regarding the factors of curricular innovations in the domain of Language didactics. The curriculum change and teacher competence development occur in a three-level context of school organization: the individual level, the group/ programme level, and the whole school/ organizational level.

\section{Purpose of Study:}

We present in this study a pedagogical approach to understanding curriculum change in school from the perspective of individual and group factors in the domain of Language didactics. The purpose of our study is that of determining the level of importance of these factors for the disciplines in the Language and Communication curricular area from the point of view of their applicability, viability and other similar variables.

\section{Research Methods:}

The main categories of individual and group factors from the perspective of curricular innovations are part of the questionnaire. This instrument was applied to 102 teachers from pre-academic education with specialization in the Language and communication curricular area.

Findings:

The research results outline a hierarchy of categories of individual and group factors in the process of curriculum innovation in the domain of Language didactics.

\section{Conclusions:}

The study highlights the importance of the wide gamut of variables that have to be taken into consideration when developing an innovative curricular programme starting with the individual (the student, the teacher, the headmaster) and finishing with the organization (the school or the government).

The study was performed within the CNCSIS PNII -TE 282/July 2010 project "INOVACOM - Curricular innovations for the development of the pedagogical competencies of teachers of Romanian language and communication through initial training programmes for teachers". 


\title{
Keywords:
}

methodological competences, beginner teachers, formative experiment, evaluation tests

\section{Expectations and Experiences of Pupil Teachers during Teaching Practice: Theoretical and Practical Implications}

\author{
Dr. Muhammad Saeed Shahid \\ Department of Elementary Education \\ Institute of Education and Research \\ University of the Punjab, Lahore-Pakistan \\ Dr. Muhammad Athar Hussain \\ Department of Elementary Education \\ Institute of Education and Research \\ University of the Punjab, Lahore-Pakistan
}

\begin{abstract}
The purpose of the study was to explore expectations and experiences of pupil-teachers during their teaching practice session. The paper examines how the theoretical coursework of pupil teachers support them and bother them during their teaching practice. What are the practical considerations that they need and what issues they face. For this purpose a sample of 45 pupil-teachers of M.A. Early childhood Education program was randomly selected. An observation schedule was prepared to observe them during their teacher practice. An interview protocol was also designed to get their views on theoretical and practical implications of their teaching experiences. Collected data were analyzed qualitatively to get deeper understanding of the problem. Results showed that there was a mismatch between theoretical coursework and practical teaching work. The pupil-teachers' expectations were very high and they had passion to work but they experienced non-professional attitude of cooperating teachers. Data also showed that the pupil teachers' training during coursework was professional weak and demanded more focus on practical side of training rather than theoretical. The pupil-teachers could not observe full freedom for employing teaching methodology which affected teaching-learning process in the respective classrooms. It was suggested that there might be more practical and activity oriented material and training sessions during their coursework along with proper supervision and guidance.
\end{abstract}

Keywords: Teaching Practice, Pupil-Teachers, Teaching methodology, Professional Skills 


\section{Challenge of the empty space. Group factors as a part of drama education Tapio Toivanen \\ Anu Pyykkö \\ Heikki Ruismäki}

\section{Problem Statement:}

1) How do structural factors of a group appear in drama teaching?

2) How do structural factors of a group influence the progression and functionality of a drama lesson?

\section{Purpose of Study:}

The aim of this preliminary case study is to build a model that could help teacher students to increase their theoretical knowledge of the structural factors that influence drama lessons. Group's structural factors were chosen as the target of the theoretical study due to the social nature of drama teaching.

\section{Research Methods:}

In this study the research material contained two of ten videotaped drama lessons held by class teacher trainees in Viikki's Teacher Training School of Helsinki University in Finland. The set of data used in this study was collected from March 2011 to April 2011. The material used in this article included one lesson from $1^{\text {st }}$ and $2^{\text {nd }}$ grades. The research team coded the video recordings which formed the basis of the analysis.

Findings:

Based on the findings from the video analysis students' group roles and their infraction have a crucial impact on the success of the lesson. The considering of group roles seem to have a straight connection to all the other structural factors of the group, trainee teacher communication and the success of the lesson. In this study the success of the lesson means pupils active participation in drama action. Teachers remedial actions during drama lessons were aligned with the consideration of group roles.

\section{Conclusions:}

Drama requires the physical and mental involvement of the pupils and the teacher but at the same time the pupils are also physically and mentally involved in the social group of the class. The teacher using drama needs to be able to facilitate the working dynamics of both kinds of groups in empty space. There has to be recognition and facilitation at the same time. Becoming a teacher using drama in education requires skills and knowledge of drama and group dynamics.

Keywords: Drama education, group factors, teacher education, trainee teacher, finnish teacher education

Anxiety and attitude of secondary school students towards foreign language learning

Dr. Muhammad Athar Hussain

Department of Elementary Education

Institute of Education and Research

University of the Punjab, Lahore-Pakistan 


\author{
Dr. Muhammad Saeed Shahid \\ Professor of Education \\ Department of Elementary Education \\ Institute of Education and Research \\ University of the Punjab, Lahore-Pakistan \\ Dr. Amir Zaman \\ Department of Education \\ International Islamic University, Islamabad
}

Multiple methodologies are being used for teaching and learning of foreign language. In countries where English is taught as a foreign language, learners suffer various levels of being anxious and develop a specific attitude towards English. The paper examined foreign language anxiety of $10^{\text {th }}$ grade students and their attitude towards foreign language learning. Sample of the study was $72010^{\text {th }}$ grade students of public sector secondary schools from six districts of the Punjab Province of Pakistan. Data were analyzed statistically using SPSS. Level of anxiety and level of attitude were determined through percentage. t-test was used to find out gender and location-wise differences. Pearson correlation was also used to find out relationship of anxiety with attitude of the students. Results showed that there was significant gender difference in foreign language anxiety and attitude towards foreign language. Significant negative correlation was found between foreign language anxiety and students' attitude towards foreign language learning. Results also revealed that girls were less anxious in English language class and had more positive attitude towards English. Rural students were more anxious in English and had less positive attitude towards English. It was suggested that training might be given to English language teachers on modern pedagogical patterns. Curriculum might be redesigned keeping the context of the learners in mind.

Keywords: Foreign language anxiety, Attitude towards English, Gender differences, Language learning.

Preschool and Primary School Teachers' Attitudes Towards Inclusive Education in Egypt: The Role of Experience and SelfEfficacy

\author{
Mahmoud M. Emam; College of Education, Sultan Qaboos University, Oman \& Assiut University, Egypt \\ Ahmed H. Mohamed; Assiut University, Faculty of Education, Egypt
}

\title{
Problem Statement:
}

Inclusive Education in Egypt has recently received a momentum by the reauthorization of the Child Act in 2008 and the issuing of the Inclusion Mandate in 2009. The purpose of this study is to examine the relationship between teacher self-efficacy and teacher attitudes toward the inclusive classroom. Research studies have demonstrated that teachers' sense of self-efficacy directly impacts student performance.

Purpose of Study: 
The current study investigates the association between teachers' perception of self-efficacy and their attitudes towards the inclusion of pupils with special educational needs (SEN) in at preschool and primary settings. In addition, we explore whether experience plays a role in the relationship between teachers' self-efficacy and attitudes towards inclusion.

\section{Research Methods:}

The Opinions Relevant to Integration of Students with Disabilities (ORI) and Teacher Self-Efficacy Scale were administered to 95 primary school teachers and 71 preschool teachers. The participants were selected randomly from eight different schools in Assiut, the Capital of Upper Egypt.

\section{Findings:}

Results show that scores on the teacher Self Efficacy Scale predict scores on the ORI for both preschool and primary school teachers. Experience is shown to play no role on the relationship between teachers' self efficacy and their attitudes. No differences were found between preschool and primary school teachers attitudes, whereas primary school teachers showed a higher sense of self-efficacy than do preschool teachers regarding the inclusion of pupils with SEN.

\section{Conclusions:}

The results of the study are discussed in relation to international literature on inclusive education. Finally the implications of the study are discussed in relation to the policies and inclusive education in Egypt

\section{Keywords:}

\section{The School Counsellor and the Gifted Children Education}

\section{Aurora - Adina Ignat, "Stefan cel Mare" University, Suceava, Romania}

\section{Problem Statement:}

The counselling for gifted children requires some answers to the questions like the following: Are the experiences of the gifted children different from those of regularly children? The social-emotional development of the gifted differs from the one of normal children? Besides these questions, it is important to take into account the personality of the counsellor as the agent who involves into the developmental counselling process of the gifted. We have tested the impact of the counsellor into the mind of the teachers and parents in order to see what are the attitudes towards the counselling services. The paper intends to present the extent of the involvement of the school counsellor in the gifted children education. The theoretical framework is based on a study of the recognized perceptions of the counsellor role within the different counselling models for gifted.

Purpose of Study: The research intends to figure out the role of the counsellor within the educational team of gifted children from the teachers` and parents` point of view.

Research Methods: The research, based on a survey, was done on a sample of 641 subjects, 556 teachers and 85 parents of the gifted children and it tries to emphasize the counsellor role expectations. The hypothesis of the study was that the counsellor is part of the collaborators team of the teachers and parents in the gifted child education. Findings: The results showed a positive perception about the counsellor as an important agent in gifted education. Conclusions: This means that it is necessary the development of the psycho-pedagogical assistance services specialized for gifted children and also the specialized trained counsellors are needed.

Keywords: gifted education; gifted counselling; counsellor 
Multivariate differential analyses of adolescents' experiences of aggression in families

Chris Myburgh (prof), Marie Poggenpoel (prof) and Dorothey Du Plessis (Dr). University of Johannesburg, South Africa

Problem Statement:

Aggression is part of the South African society and is having implications for the mental health of persons living in South Africa. From research cited in the literature it is clear that aggression can be negative, depending on the intentions behind an individual's behaviour. However, it can also contribute toward the mental health of those involved. Thus aggression can either be constructive or destructive. Constructive aggression may lead to the experience of energy, motivation, challenges and excitement.

\section{Purpose of Study:}

In this paper the nature and extend of adolescents' experiences, assessments and management of aggression and aggressive behaviour in the family is investigated.

\section{Research Methods:}

A deductive explorative approach is followed in which aggression is reasoned to be dependent on aspects such as self-concept, moral reasoning, communication, frustration tolerance and relationships in the family. To analyse the data from questionnaires of 100 families (95 adolescents, 95 mothers \& 91 fathers) from affluent SES circumstances Cronach Alpha, various consecutive first and second order factor analyses, correlations, multiple regression, MANOVA, ANOVA and Scheffè/ Dunnett tests was used.

\section{Findings:}

It was found that aggression (dependent variable) correlate negative with the independent variables; and the correlations between adolescents and their parents on each of the variables are high. The regression analyses indicated that different predictors are relevant in predicting levels of aggression. The differences between adolescents and their mothers; and adolescents and their fathers concerning aggression and the independent variables are therefore merely differences of degree rather than substantive differences. Further, the significant differences are between adolescents and their mothers. By inspecting the sizes of the differences between the means, it is clear that the differences are not substantial. This paper focuses on differences from the perspective of the adolescent.

\section{Conclusions:}

Overall it seems as if the experienced levels of aggression between adolescents and their parents are small and indicate a fairly healthy situation in the family. The observation is based on the fact that the means of aggression are fairly low and the sizes of the means on the independent variables are relatively high. Educational implications are indicated.

\section{Keywords:}

Adolescents

Experience of aggression

Families

Multivariate differential analyses

Internal Evaluation:Appropriate Strategic for Quality Evaluation and Improvement of Management in Departments at Universities(The Case of Iran)

Reza Mohammadi 1, Fakhteh Eshaghi 2, Mahbobeh Arefi 3

1. National Organization of Educational Testing(IRAN, ISLAMIC REPUBLIC OF)

2. National Organization of Educational Testing(IRAN, ISLAMIC REPUBLIC OF) 
During the last two decades, the higher education management has faced different challenges; on one side the increasing growth in social demand for entering higher education, quantitative extension, decrease or stagnation in allocated financial resources and the increase in demand for responsibility, accountability and transparency of the academic affairs and on the other side quality maintenance, improvement and assurance. So that it forced the academic management to evaluate its performance toward the quality promotion and assurance. In line with this issue, the international studies and national experiences shows that due to the nature of higher education, the internal evaluation approach which is the basis of quality assurance systems at universities of the world is appropriate to evaluate all the main factors of academic system namely its management and organization and it also has an important role in quality improvement of management at all Iran's academic system levels (amongst them is the educational department which is one of the main and operational levels) that its outcome is obtaining the maximum efficiency and effectiveness of the department performance.

So alongside introducing the concept and theoretical and practical principles of internal evaluation in higher education, this paper attempts to present the application of internal evaluation for quality improvement of management in departments at universities. The research design applied in this study is meta-analysis and the statistical population includes 296 reports of departments' internal evaluation and 90 samples are selected and analyzed based on the purposeful sampling method. The meta-analysis of the results of the management process evaluation in the internal evaluation reports of departments at universities is based on 8 main factors including development plans, functions, regulations and internal laws, meeting schedules and the presence of the faculty members, head of department, extra-group activities, funding and coordination of human resource and facilities. The results indicate that management process quality of departments at universities is rather desirable and requires planning for its improvement. Therefore, based on the results of the analysis, recommendations are presented for management improvement in departments at universities.

Keywords: Management at University, Internal Evaluation, Quality Improvement.

Subject: The examination of effective factors of knowledge sharing(case study: an research organization) Dr khodayar abili

Department of Psychology and Education

University of Tehran

Fatemeh narenji thani

PHD student of Tehran university

Faranak mokhtarian

PHD student of Tehran university

Mohammad mehdi rashidi

PHD student of Tehran university

\section{Problem Statement:}

Today the majority of experts believe that organizations should seek effective methods for the distribution and division of organizational knowledge between the different levels of Human Resources within the organization. Bailey and Clarke (2001) believe that "the goal of management, in utilizing knowledge management in organizations is improving share of knowledge between individuals in the organization, and between individuals and organizations for the purpose of creating competitive advantage." Therefore, the necessity of identifying and utilizing effective 
methods for sharing and transferring knowledge throughout the organization, and the need for knowledge management in the organization have become more apparent.

Purpose of Study:

The aim of this study is the examination of effective factors in knowledge sharing in a research organization .

\section{Research Methods:}

Utilizing the correlation research method, 50 experts were selected randomly.

\section{Findings:}

Research data after collection, were analyzed using the Spearman correlation method, Mann- Whitney, Wilcoxon, and Friedman test. Research results show that in the studied organization: (1) The knowledge sharing condition of the organizations' employees is relatively desirable; (2) Age, work experience, educational field of study, level of study and organizational position has not resulted in significant differences in knowledge sharing; (3) Knowledge sharing is positively related to human factors (commitment and trust), and negatively related to structure factors (formalization, centralization, and complexity); (4) Positive relation was observed between knowledge sharing and creative and innovative culture (which are components of cultural factors), and negative relation was seen between knowledge management and bureaucratic culture (which is considered as another cultural factor). Deterrent factors in knowledge sharing (bureaucratic culture and structure factors) do not show a meaningful difference in terms of ranking, while amongst facilitative factors (human factors, creative, innovative and supportive cultures) creative and innovative cultures have achieved the most rankings respectively, and after that, trust, supportive culture and commitment are ranked respectively.

\section{Conclusions:}

Trust , commitment among units are important for facilitating knowledge sharing among units, and creative and innovative organizational culture are beneficial for the implementation of knowledge sharing activities.

Key words: knowledge sharing, learning organization, research organization

The examination of the role of transformational leadership in organizational learning: A SAIPA Company case study Fatemeh narenji Thani

$\mathrm{PhD}$ candidate of Tehran university

Seyed mohammad Mirkamali

Professor of Tehran university

Farnoosh alami

PhD candidate of Allameh Tabataba'i university

Abstract

\section{Problem Statement:}

The prerequisite for continuum organizational change and evolution in today's dynamic and ever changing environments is the presence of intuitive, strategic or in a more clear sense, transformational leaders. Because of the increasing attention to the leadership factor in creating organizational evolution in the world, and considering its role in organizational learning, this research attempts to examine the mutual relation between transformational leadership and organizational learning through correlation research method.

\section{Purpose of Study:}

This research aims at investigating of the role of transformational leadership in organizational learning between SAIPA Co. expert staff

\section{Research Methods:}

Using correlation research method 120 SAIPA Co. expert staff were randomly selected. Research data after collection using the research questionnaire were analyzed using Pearson Correlation method, T Test for independent groups, one way variance analysis and step-by-step regression

\section{Findings:}

Obtained results show that based on SAIPA experts' opinions, the current condition of transformational leadership and organizational learning is relatively desirable in the aforementioned company. On the other hand, work experience does not create and difference in organizational learning, but gender and education create difference in (risk receptivity, exploring reasons for mistake) and (taking advantage of experiences, risk receptivity) components respectively. In addition, a positive and meaningful relation exists between the components of transformational 
leadership and organizational learning. Finally, idealized influence (behavior) as one of the dimensions of transformational leadership is considered the most important anticipator in organizational learning.

\title{
Conclusions:
}

Transformational leadership has a critical role in stimulating learning,creativity, innovation,craetion and implication of knowledge.this kind of leadership can facilats organizational learning throgh directing, making structures,facilating actins and relations between groups.

Keywords: Organizational learning, transformational leadership, learning organization

\section{Teacher perceptions on teacher evaluation: The purposes and the assessors within assessment process}

\author{
Otilia Clipa, "Stefan cel Mare" University, Suceava, Romania*
}

Problem Statement: We have approached the main line of the theoretical and investigative characteristics for teacher evaluation such as they appear within scientific literature in the science of education area.

Purpose of Study: The main goal of the paper is to investigate the purposes of teacher evaluation from the perspective of the teachers and the ideal portrait of the assessors for this assessment process.

Research Methods: The investigative part is done through the survey about some aspects of the evaluation process on teacher evaluation. The sample comprises teachers from primary and preschool level.

Findings: The teacher considers the assessment purpose is depending on some factors (educational level, degree and years of experience). The positive corelation was between age, years of experience and the portrait of assessors. In terms of the gained results we have described the perceived assessor portrait from the teachers' point of view. Conclusions: The results obtained after the quantitative and qualitative analysis help to figure out more clearly the goals and the desired assessor from the teachers' perspective. The final data helps to build a better system of evaluation for teacher in in-service teacher training and for the optimizing the quality of the teaching and assessment process.

The gained data were correlated with the data derived other research with a same topic.

Keywords: teachers evaluation, goals of evaluation, assessors

\section{A Study on the Quality of Work Life(QWL) among the Faculty Members of the Universities of Tehran and Sharif}

\author{
Seyed Mohammad Mirkamali \\ Professor \\ Department of Psychology and Education \\ University of Tehran \\ Fatemeh Narenji Sani \\ PHD student of Administration \\ University of Tehra
}

\section{Problem Statement:}

Faculty members as one of the greatest resources of any society and, also, one of the most crucial of educational system's factors plays a critical role in training specialized forces and, finally, result of their effort is social development and growth in human societies. the researchers had intentioned to the problems arising from the complex human factor as QWL, which examine the actual conditions related to work and work environment in a given organization. members 'dissatisfaction of QWL is a problem that harms all of the employees -without consider to rank and situation. The aim of many organizations is increasing theirs members 's satisfaction in all levels. however 
,this is a complex problem; because the separation and determination that what factors relate to QWL is a difficult action.

\title{
Purpose of Study:
}

This study aims at the investigation into the Quality of Work Life (QWL) among the faculty members of the Universities of Tehran and Sharif.

\section{Research Methods:}

Using correlation research method, 144 faculties were selected based on classifying and relative method according to their academic ranks.

\section{Findings:}

The collected data were analyze by using, T Test. The findings indicate: a) The faculty member of both UT and USh are in relative unfavorable QWL condition ,b) There is not a significant difference in the level of QWL among the faculty members of two universities; but ,however, there is a small difference in social integrity and cohesiveness between two populations. Put differently, the members of USh hold an upper level of social integration and cohesiveness in comparison with the members of UT

\section{Conclusions:}

For improving faculties' Q.W.L universities - more than every things - need fundamental transformations that there are some suggestions in this article.

Keywords: Quality of Work Life, Faculty Members, and Universities.

\section{Adolescents' perception of rape}

\author{
Dr. Prem J. H. Heeralal \\ Lecturer \\ University of Fort Hare, \\ Faculty of Education, \\ School for Initial Teacher Education, \\ P. Bag X9083 \\ East London \\ South Africa \\ 5200 \\ e-mail: PHeeralal@ufh.ac.za \\ Cell: +27 (0)83797 1029
}

In order to study adolescents' perception of rape, relevant literature pertaining to rape and adolescence as a stage in the development of an individual was reviewed. The descriptive method of research was used to collect data with regard to adolescents' perception of rape. Grade eleven learners at selected schools, completed an empirical survey comprising a structured questionnaire. The data that was collected was analysed using inferential statistics. From the information gathered the following are the most important findings of the research regarding adolescents' perception of rape: adolescents are aware that rape is unlawful, adolescents believe that effective law enforcement can curb rape, adolescents do not believe that a culture of violence contributes to rape, women are reluctant to report being raped, adolescents' perception is that rape victims have difficulty in coping with relationships with other people, the study reveals that it is vital for rape victims to talk about the rape, adolescents perceive rape as a crime of aggression, adolescents do not want parents to support a child that has been raped, rape is an action that decreases the self-esteem of women, they do not believe that there is any relationship between rape and family violence, they are uncertain if there is a relationship between women abuse and rape within marriage. 
The study also reveals that there is a significant difference statistically between the responses of males and females regarding responses to question that deal with rape whereas there is no significant difference between the responses of males and females - regarding questions based on adolescence as a developmental stage.

Based on the findings, the study makes the following recommendations: adolescents must lobby support to ensure more effective law enforcement, speak out against rape and must not be put under pressure by peers to engage in sex, parents need to communicate more effectively with adolescents, law enforcement must be stepped up to curb rape, programs must be put in place to educate adolescents regarding rape.

CHALLENGING THE BRAIN TO READ BETTER

Zvia Breznitz PhD, Merav Amiel, Itamar Sela PhD

The Edmond J. Safra Brain Research Center for the Study of Learning Disabilities, University of Haifa, Israel

\section{Problem Statement:}

Reading is an essential skill for functioning in the literate society. Approximately $10-15 \%$ of the population suffers from reading difficulties to disabilities; therefore it is important to develop effective interventions.

\section{Purpose of Study:}

The purpose of this study was to test the ability to improve reading and brain activity in reading among students at varying reading levels as a result of a training program. The Reading Acceleration Program (RAP) is a computerized training program developed based on the principles of the Acceleration Phenomenon (Breznitz, 2006).

\section{Research Methods:}

30 readers diagnosed with developmental dyslexia (S.D. -1.5) and 30 skilled readers from grades 4 and 5 participated in the study. Participants were tested with behavioral measures related to reading abilities and brain-imaging measures (EEG) pre-training and post-training, as well as 6 months after training.

Participants trained over the course of 24 sessions, 20 minutes each session, 4 times a week. The training program included training of word retrieval and sentence and paragraph reading. Training was based on presentation of stimuli at an accelerated rate that changed according to the reading pace and comprehension of every participant.

\section{Findings:}

Comparisons between the reading abilities pre- and post-training revealed that both groups improved in their reading fluency and comprehension. The dyslexic group also significantly improved on decoding measures. Gains among readers in the dyslexic group were more pronounced. At the end of the training the brain activity of the dyslexic readers, as was expressed in the N170 component, had become more similar to that of the skilled readers. In addition, after training, motivation measures had increased in both groups.

\section{Conclusions:}

The human brain must be challenged in order to change. The results of the current study indicate that all readers, especially dyslexic readers, can be trained to read better. It is important to note that the acceleration training was individually adapted to the abilities and performance of each subject. Reading abilities improved and were retained to a certain degree after 6 months. This improvement was also expressed in the brain. 


\section{Study of Emotional Intelligence and Learning Strategies}

Ramezan Hasanzadeh, Fatema Shahmohamadi

Associate prof. of Psychology Department, Islamic Azad University- Sari Branch, Iran

Faculty member of English Department, Islamic Azad University- Ayatollah Amoli Branch, Iran

The present study investigates the relationship between Emotional Intelligence and Learning Strategies, which are essential for the success of an average cognitively intelligent person in his/ her academic life. The statistical sample of the study involves a random selection of 100 university students from different fields of study in Iran. For the purpose of data collection, the researchers administered two questionnaires: Bar-On questionnaire and Learning and Study Strategies Inventory ( Lassi). The results show 1 . There is a significant relationship between students' total emotional intelligence and learning strategies both in females and males. 2. There isn't a meaningful difference between students' Emotional Intelligence and their fields of study. 3. There isn't a meaningful difference between students' learning strategies and their fields of study. 4. There is a meaningful difference between males and females in learning strategies. The study suggests academies screen the students on their arrival and if needed offer some requisite courses on learning and study strategies. It also suggests instructors be encouraged to intertwine emotional intelligence components with the subject of the course to boost students ' academic achievement.

Keywords- Cognitive Intelligence; Emotional Intelligence; Learning Strategies; Bar-On questionnaire; Lassi 


\section{MUSIC SUBJECT IN ESTONIAN BASIC EDUCATION: THE REFLECTIONS OF STATE CURRICULUM IN MUSIC TEACHERS' PEDAGOGICAL THINKING}

doctoral student Anu Sepp, adj. prof.Inkeri Ruokonen, prof.Heikki Ruismäki

\section{Problem Statement:}

Teacher's pedagogical thinking is actually decision making and has influence on the whole teaching process. In music teaching the objectives of the curriculum are gained through different musical activities.

Research questions:

1. How does the Estonian music teachers' pedagogical thinking reflect in their teaching process?

2. What are the teaching practices used to gain the objectives of the music curriculum?

3. How do music teachers think about their teaching practices?

Purpose of Study:

The aim of the study is to find out the Estonian music teachers' pedagogical thinking according to the three level model of teachers' pedagogical thinking (Kansanen 1999).The purpose is to find out to what extent the decision the teachers are making are being influenced by the state curriculum, what music teaching practices are mostly used and what music education views can be found in the background of those practices.

\section{Research Methods:}

The data was collected using questionnaires and the results of 107 Estonian music teachers answers were analysed using both qualitative and quantitative methods.

\section{Findings:}

The findings show that the music teachers' pedagogical thinking stays mainly on the 1st and 2 nd level. The music teaching practices used are good at gaining the curriculum objectives. Teachers are more involved with everyday practical problems and they reflect upon their teaching very seldom.

\section{Conclusions:}

The use and implementation of different methods and musical activities is giving good results in Estonia and is worth introducing and spreading. More attention should be paid to reflection and discussions about values and visions of music education.

Keywords: music education, musical activities, pedagogical thinking, Estonian music teaching 


\section{Problem Statement:}

The subject of this paper is the relationship between teachers' style of classroom management, classroom climate, and pupil's school achievement. The research problem is thus defined as it is konown that the way of classroom management can affect the academic success.

\section{Purpose of Study:}

Classroom management is related to all teachers actions aimed to establish the stimulative learning environment. According to Martin and Boldwin (1993), three teachers' classroom management styles could be distinguished: interventionist, non-interventionist and interactionist. The purpose of study is to examine the relations between teachers' classroom management styles, satisfaction with classroom climate and pupils' school achievement. The study is also aimed to determine which classroom management style is favored by Serbian teachers in elementary schools.

\section{Research Methods:}

The sample consisted of 273 school teachers. Two observers independently evaluated teacher's behaviour for two school classes, using the Protocol for teachers' classrom management styles assessment, developed for research purposes. Teachers and pupils administered the quesionnaires to evaluate classroom climate also. Instruments used demonstrated satisfactory reliability.

\section{Findings:}

It is found that $59,5 \%$ of observed teachers are interactionists, $24,2 \%$ are interventionists and $16,4 \%$ of them are noninterventionists. Analysis of variance shows that both teachers and pupils are the most satisfied with the classroom climate which is created by the teacher-interactionist. Pupils are less satisfied with the classroom climate if teacher is interventionist and non-interventionist $(p<.05)$. Teachers-interventionists are the less satisfied with the classroom climate $(p<.05)$. Pupils achieved the best school success whne the teacher practiced interactionist style (average grade 4,12 ), and the lowest when the teacher were interventionists (average grade 3,80 , the mean difference significant at $p<0,01)$.

\section{Conclusions:}

The research findings show that the interactioning teacher's classroom management style is the most appropriate for creating good classroom climate, which in turn has stimulating effect on pupils' school achievement. Results are discussed from the standpoint of the most desirable conditions for learning and pupils' abilities development. The results suggest that teachers should continuosly improve their proffessional competences, specially their communication skills and skills in active teaching and learning methods practicing.

Keywords: classroom management styles, classroom climate, school achievement

The Relationship between Iranian EFL Learners' Perceptual Learning Styles and Their Multiple Intelligences

Zohreh Seifoori, (Ph.D.)

Islamic Azad University-Tabriz Branch

Maryam Zarei, (M.A.)

Islamic Azad University-Tabriz Branch

In the present century, two important theories, that is, the Learning Styles theory and the Multiple Intelligences theory have been put forward in order to explain the individual differences, and to arrange learning environments according to these individual differences. Accordingly, the present study was conducted to investigate the mostly preferred perceptual learning styles and intelligences among Iranian English as a foreign language (EFL) learners and to explore any probable relationship between each of 6 types of learning styles (i.e., visual, auditory, tactile, kinesthetic, individual, \& group) and 7 types of intelligences (i.e., linguistic, mathematical, spatial, bodily, musical, interpersonal,\& intrapersonal). The participants included 94 male and female English major sophomores aged between 19 and 30 at Islamic Azad University- Tabriz Branch. They were selected from among 110 students based on 
their scores on a Preliminary English Test (PET). Three other instruments were used to obtain research data: a modified version of Perceptual learning style preference questionnaire (Reid, 1987), a semi-structured interview which was used to help the researchers better understand the quantitative data gathered from the learning style questionnaire, and a multiple intelligence inventory (Christison, 1996). Statistical analysis and correlation of the data indicated that kinesthetic learning style and spatial intelligence were the most dominant among Iranian English major sophomores. The correlation analysis also revealed significant positive relations between tactile learning style and mathematical intelligence; kinesthetic learning style and mathematical intelligence; tactile learning style and spatial intelligence; tactile learning style and bodily intelligence; and kinesthetic learning style and bodily intelligence. The findings can have practical implications for learners, teachers, and material developers.

Keywords: Perceptual Learning Styles, Multiple Intelligences

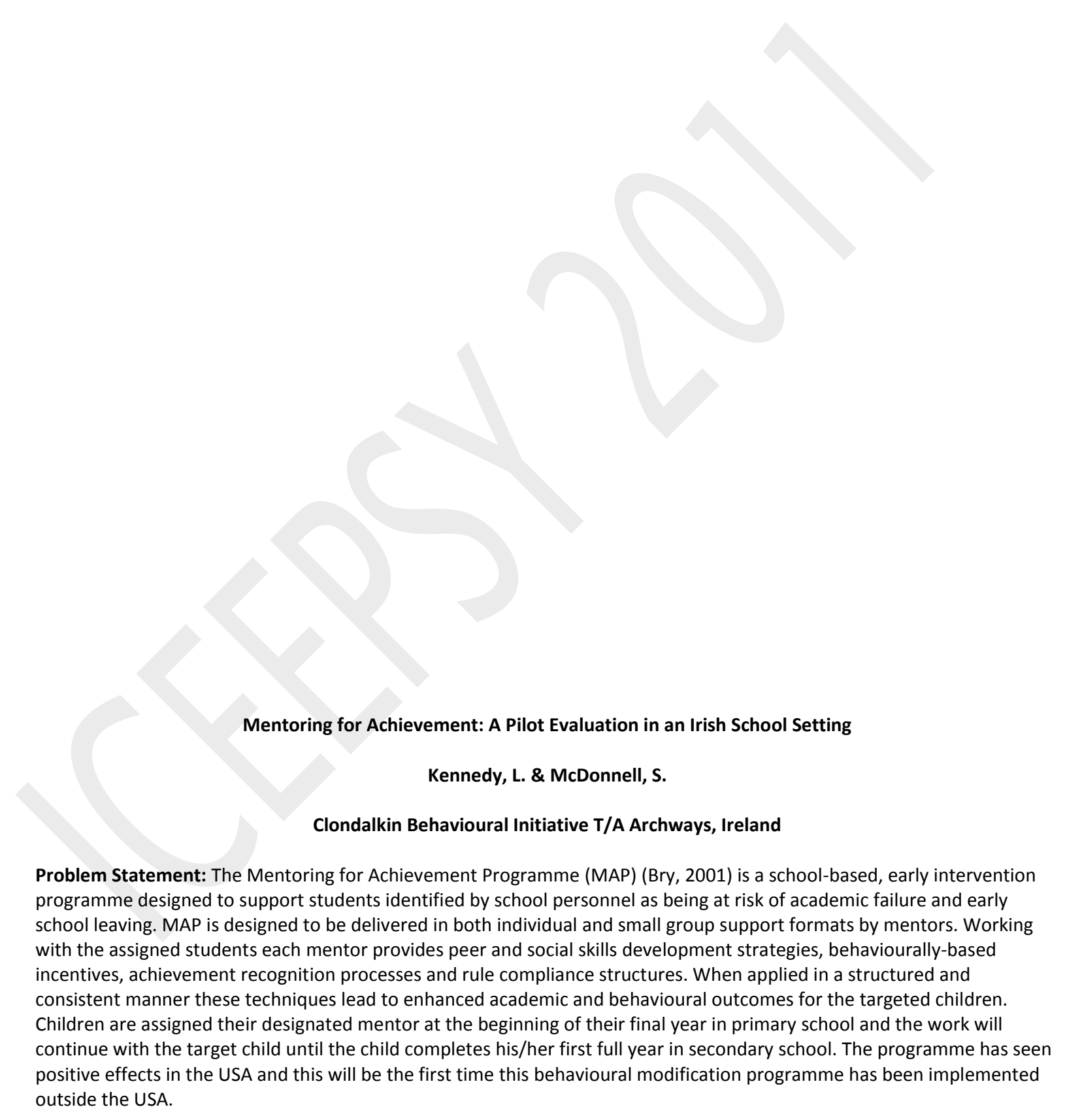

Aim: The current study is part of a series of evaluations which will be carried out on the pilot MAP intervention in Ireland.

Method: Thirty eight primary school students are currently participating in the programme. This study will utilize both quantitative and qualitative methods. The Strengths and Difficulties Questionnaire (SDQ) (Goodman, 1998) will be collected from both the parents and the teachers of the students involved at two initial time points. Attendance records will be collected from the schools involved. Focus groups will be carried out with the children at the end of their school 
year to ascertain their experience of the programme to date. Interviews will be conducted with the teachers, professionals involved and managers to evaluate the programme's effectiveness to date.

Findings: The current study will focus on the results from the first phase of the programme. Findings will draw on both the children's and professional's experience of the MAP programme to date. SDQ results will add baseline and time one data for the next stage of evaluation.

Conclusions: Results will be discussed in relation to future directions for the programme and experiences of students and professionals involved so far.

Keywords: School Based, Early Intervention, Mentoring, Behaviour Modification

MORAL REASONING AND EMPATHY IN SERBIAN TEACHERS

Snežana Stojiljković, University of Niš, Faculty of Philosophy - Department of Psychology

Andjelija Stojanovic, Zvonimir Doskovic

\section{Problem Statement:}

The study is aimed to examine moral judgment and empathy of Serbian teachers from cognitivistic standpoint. Teacher has great responsibility at all levels of education, not only as a transmitter of knowledge, but also as a person who has an important educational role. Teacher is also a model for emulation of their students, so it's important to research system of moral values of teachers. The object of interest has been teachers' empathy too, due to the fact that it represents one of the preconditions of moral development and an important factor in classroom management.

\section{Purpose of Study:}

- determine the level of teachers' moral judgment and empathy and to find out if there are any differences between teachers employed in elementary, secondary and higher education institutions;

- examine if there are any differences in teachers' moral judgment and empathy connected to gender, age, formal education.

\section{Research Methods:}

The research sample consists of 120 teachers $(40+40$ of them are teachers in elementary at secondary school, and 40 are professors at University of Nish and University of Belgrade). Both genders are included (53 males and 67 females), aged 24 to 64 years.

Rest's DIT (Defining Issues Test), adapted serbian version, is used for the assessment of moral judgment (preconventional, conventional and postconventional moral reasoning, according to Kohlberg's theory). Davis' IRI (Index of Interpersonal Reactivity) is used for the assessment of empathy.

\section{Findings:}

The results show that teachers have highest score at conventional moral thinking, as it is expected to be. The postconventional type of moral reasoning is second frequent level of moral reasoning. Teachers employed in elementary and secondary schools more often practise preconventional and conventional forms of morality than university professors do. Elementary school teachers are more empathic than college and university teachers; they 
have developed higher emotional aspects of empathy than cognitive ones. Women more often than men practise stage 3 of moral reasoning which is associated with empathy.

\title{
Conclusions:
}

Findings are discussed from the perspective of the educational role of teachers. The results suggest it is desirable to undertake activities that encourage the development of moral thinking and empathic abilities of teachers too.

Keywords: moral reasoning; empathy; teachers; educational role of schooling

\author{
University teaching: didactic expertise reflected by metacognitive abilities and emotional control \\ Dana Opre, Mirela Calbaza-Ormenisan, Adrian Opre \\ Babes Bolyai University, Romania
}

For the last decades we can notice a major shifting in educational research domain. The behaviorist approach on teaching and learning is replaced by cognitive and social cognitive approaches. Practically, the interest on teaching moves beyond the teacher's observable behaviors, and target the exploration of the way teacher thinks (knowledge, beliefs and personal theories) and the way he/she develops didactic competencies. Based on this new perspective, the present study aims to make a multidimensional analysis of the university didactic expertise. In this sense, our research has been guided by three major goals: 1. the identification of cognitive, behavioral, emotional and personality factors that can influence the university didactic activity. 2. the evaluation of the impact of cognitive (rationality and reflexivity) and emotional factors on didactic performance. 3. the development of a university didactic expertise model. Selecting experts and veterans from university teachers and considering the variety of methods and instruments, the quantitative and qualitative analysis have been made. For quantitative approach we have conducted two experiments: a. $2 \times 3$ factorial design (didactic expertise $x$ metacognitive abilities); b. $2 \times 2$ factorial design (didactic expertise $x$ emotional control). For qualitative approach we have assessed the content of faculty reflection about teaching by using stimulated recall method. ANOVA two way was applied for quantitative collected data and we have found significant differences between expert and veteran teachers. More exactly, our results revealed that the didactic expertise is clearly dependent upon the frequency of efficient teaching strategies $(F=7,24, p<.01)$ teachers' emotional control competencies $(F=4,7, p<.05)$, metacognitive abilities and reflexive practices $(F=6,45, p<.01)$. Taking together with their personality profile and knowledge about general pedagogy $(F=6$, $12, p<.01)$ the findings can sustain a pertinent model of didactic expertise. In conclusion, we consider that our outcomes are very useful for teaching staff professional development departments, helping them to design professional programs and, implicitly to train university teachers in order to became didactic experts.

KEYWORDS: didactic expertise in higher education, metacognition and emotional control in teaching, training programs for faculty professional development 


\title{
SELF KIT Program: Strategies for improving children' socio-emotional competencies
}

\author{
Adrian Opre \\ Ramona Buzgar \\ Oana Ghimbulut \\ Mirela Calbaza-Ormenisan \\ Babes-Bolyai University, Cluj Napoca, Romania
}

In the last years we have noticed a worrying increase of unhealthy emotions and behaviors in educational setting. It is obvious that children who display such conduct represent a real challenge for teachers, parents and especially for school and clinical psychologists. The long-term consequences upon the school performance, psycho-somatic health and social integration of these students are alarming. Looking for the pertinent solutions and based on our 10 years experience with cognitive-behavioral interventions (CBT counseling programs), we developed the SELF KIT program. "SELF KIT" (SocialEmotional Learning Facilitator) is a psychological and educational counseling program, elaborated on the principles of rational-emotive and behavioral theory. Its main aim is the development of socio-emotional competences in pre-school and school-aged children. Due to its structure, content and implementation strategies, the SELF-KIT can be easily adapted to diverse socio-cultural and educational (curricular) contexts. Additionally, the typology and difficulty level of activities are selected based on the cognitive and socio-emotional profile of children at different ages.

We already started to demonstrate that SELF KIT is efficient in developing social and emotional competencies in children aged 4 to 11 years old. In order to do that, we have implemented SELF KIT program in two target group samples. For pre- and post-intervention assessment we have used (for children 4-6 years old) PedA (Platform of Child Development Evaluation) and (for children $7-11$ years old) ASEBA (Achenbach System of Empirically Based Assessment)). Our preliminary data analyzed by ANOVA, showed that cognitive and social-emotional competencies significantly improve after the program implementation $(F=4,7, p<0.05)$; also the frequency and severity of conduct disorders decreased $(F=4,3$, $\mathrm{p}<0.05$ ). We consider that the data collected in this pilot studies, represent pertinent arguments in supporting the viability and ecological validity of SELF KIT program. The two version of SELF Kit program will be presented.

Keywords: SELF KIT program, Rational-emotive and behavioral education, psychological counseling, social - emotional competencies. 
The Relationship between Iranian EFL Learners' Perceptual Learning Styles and Their Multiple Intelligences Zohreh Seifoori, (Ph.D.)

Islamic Azad University-Tabriz Branch

Maryam Zarei, (M.A.)

Islamic Azad University-Tabriz Branch

In the present century, two important theories, that is, the Learning Styles theory and the Multiple Intelligences theory have been put forward in order to explain the individual differences, and to arrange learning environments according to these individual differences. Accordingly, the present study was conducted to investigate the mostly preferred perceptual learning styles and intelligences among Iranian English as a foreign language (EFL) learners and to explore any probable relationship between each of 6 types of learning styles (i.e., visual, auditory, tactile, kinesthetic, individual, \& group) and 7 types of intelligences (i.e., linguistic, mathematical, spatial, bodily, musical, interpersonal,\& intrapersonal). The participants included 94 male and female English major sophomores aged between 19 and 30 at Islamic Azad University- Tabriz Branch. They were selected from among 110 students based on their scores on a Preliminary English Test (PET). Three other instruments were used to obtain research data: a modified version of Perceptual learning style preference questionnaire (Reid, 1987), a semi-structured interview which was used to help the researchers better understand the quantitative data gathered from the learning style questionnaire, and a multiple intelligence inventory (Christison, 1996). Statistical analysis and correlation of the data indicated that kinesthetic learning style and spatial intelligence were the most dominant among Iranian English major sophomores. The correlation analysis also revealed significant positive relations between tactile learning style and mathematical intelligence; kinesthetic learning style and mathematical intelligence; tactile learning style and spatial intelligence; tactile learning style and bodily intelligence; and kinesthetic learning style and bodily intelligence. The findings can have practical implications for learners, teachers, and material developers.

Keywords: Perceptual Learning Styles, Multiple Intelligences

To learn and not to learn - that is the question

Ellinor Silius-Ahonen \& Maria Gustavson

Arcada University of Applied Sciences

Problem Statement: Forms of examination in a Higher Educational setting where learning outcomes are manifested. Existing practice often lacks the connection between learning processes that are deeper and reflective to their character. It is also usually focused on the individual and therefore fails to meet collaborative learning practice. Written exams, as the academic setting seems to favour, might even fall into a pit of formalistic and mechnical rituals. 
Further more the personal meaning making process is disconnected if the exam is only regarded a product, not a learning process itself, concerning the whole, person.

Purpose of Study: Our purpose is to create an authentic arena for knowledge production where the current setting of the University becomes both the stage in a Vygotskijan (1978) sense and the mirror of societal settings (Goffman 2004).

Research Methods: Our chosen approach is action research. The material was collected through interviews, participative observation, learning diaries and the course evaluation. The students in a case study are as professionals going to be placed in highly complex and sociodynamic working conditions. Reading scientific articles on health promotion and preparing a drama where the core findings in the articles are articulated and expressed in class for an audience of other student and the teacher team

Findings: The student feedback and the form of examination showed how acting give meaning in different aspects concerning the actors themselves, co- actors, the audience, the text as content of articles and the situation as the learning arena.

Conclusions: We find that drama is a good example as a form of learning as well as a resource of creating setting where learning outcomes are appropriated. Further research on different forms of examination is aquired.

\section{Keywords:}

Forms of examination, drama, contextual and situated learning

\section{"They have always supported my choice" Estonian and Finnish University students describing the creative aspects of their learning environmental catalysts}

Adj. prof. Inkeri Ruokonen, adj. prof. Kristi Kiilu, adj. prof. Maia Muldma, prof. Maie Vikat \& prof. Heikki Ruismäki

Helsinki University, Tallinn Music Academy, Tallinn University

Problem Statement: The aim of this comparative study is to find out and describe most important learning environmental catalysts of Estonian and Finnish university students that have been or are in connection with the development of their artistic giftedness and their creative products or presentations.

Purpose of Study: The purpose of this study is to find out which are the most effective and valuable learning experiences in the learning environment. In the learning environment we focus on home, school, culture, community, hobbies, gender and chance factors.

Research Methods:The approach of this research is mainly qualitative. The data is collected from the writings of Estonian (50) and Finnish (50) university students. Research method used was a qualitative content analysis.

Findings:The results of the analysis of students' self evaluations give relevant information shows that different catalysts of learning environment have an important role in development of giftedness and couragement for 
creativity. In addition to home and school environment the informal learning environment or happy chances were essential for the development of artistic giftedness. There were more similarities than differenties found between two neighbour countries.

Conclusions:When developing effective learning methods and the education of children it is essential to focus both formal and informal aspects and all the environmental catalysts which may be in connection to the intrinsic motivation and to the development of giftedness and creativity.

\section{Keywords:}

Learning environment, giftedness, creativity, university students, music- and arts education

\section{Gender differences in Citizenship Behavior among the Iranian Elementary School Students}

A. Navehebrahim, Associate Professor Dean, School of Education and Psychology Tarbiat Moallem University, Tehran, Iran navehebrahim@tmu.ac.ir Somayeh Masoudi

M.A. in Educational Administration

Islamic Azad University, Science \& Research Branch, Tehran, IRAN somaye.masoudi@yahoo.com

Problem Statement: Citizen education has become an important component of school curriculum. Schools have taken close responsibility to provide citizens getting involved in the democratic values of the society.

Purpose of Study: The present study was conducted to investigate the degree of citizenship behavior among the Iranian elementary school students.

Research Methods: Population for the study were all 5500 male and females students in 104 elementary schools in District No. 8, East of Tehran, IRAN. A sample population of 385 for each gender group, a total of 770, based on Morgan Table were randomly selected and a researcher designed questionnaire with 50 iems was used to determine citizenship behavior among students in the study. According to literature, citizenship behavior was defined in terms of social, cognitive, democratic and creative behavior of students. 
Findings: The binominal test showed that students do believe and practice civics education. Yet, there was found a significant difference between male and female students. Male students stand much higher in citizenship behaviour compare to female students.

Conclusions: The study recommends a more detailed inspection of curricula regarding the competencies required to be a good citizen.

Keywords:

citizenship education; elementary schools; IRAN

DESIGNING A MODEL FOR MANAGING TALENTS OF STUDENTS IN ELEMENTARY SCHOOLS: A QUALITATIVE STUDY BASED ON GROUNDED THEORY

Fahimeh Veladat, M.A. in Educational Administration Young Researchers Club, Islamshahr Branch Islamic Azad University

(Tehran, IRAN, ISLAMIC REPUBLIC OF) fahimeh_veladat@yahoo.com

\section{Abdolrahim Navehebrahim, Associate Professor \\ School of Education and Psychology Tarbiat Moallem University. (Tehran, IRAN, ISLAMIC REPUBLIC OF) naveh1954@yahoo.com}

Problem Statement: Management is the key to organizational achievements. It will increase productivity. Talent, too, like all other phenomena, requires to be managed. Many programs are designed to manage manpower talents in business and service sectors, but not a clear program exists for managing students talents in schools.

Purpose of Study: The purpose of this qualitative study was to design a model for managing students talents in Iranian elementary schools from the perspectives of education Experts

Research Methods: Following a review of literature, a group of experts in school management were purposefully selected to respond an open-answer researcher designed questionnaire. Grounded theory approach was, therefore, taken to collect data needed. The experts in school administration were asked about the impediments and opportunities available to perform talent management in elementary schools. Adequacy of data was shown when 20 experts in education expressed their views. The data was categorized and then assessed by use of factor analysis.

Findings: Four major categories were conceptualized in this respect, namely: identifying, maintaining, and improving. flourishing. Therefore, according to the grounded theory applied, the experts interviewed believe that the above categories should be considered in managing students talents. The interviewees also expressed their views for the components of each category.

Conclusions: The conceptual model found in the study is in harmony with the models in the literature for business and service sectors, yet different components were found for each category based on school environment. Further study is suggested to examine the degree to which these categories are implemented in Iranian elementary schools. 
Happiness for our kids in schools: A conceptual model

Fatemeh Talebzadeh, Ph.D. Student in Educational Administration

Young Researchers Club, Islamshahr Branch ,Islamic Azad University

(Tehran, IRAN, ISLAMIC REPUBLIC OF)

Bahar1979@yahoo.com

Mahmoud samkan, Electrical Engineering Faculty, Air-University

(Tehran, IRAN, ISLAMIC REPUBLIC OF)

msamkan@yahoo.com

Problem Statement: Since we know happiness, motivates individual activities, raises awareness, strengthens creativity and facilitates social relationships. Regardless of how it can acquire, physical health also improve. People, who are happy, feel more secure, easier to decide, also have a more achievements and collaborative spirit. So happiness is the important key in educational system, but not a clear program exists for creating happiness for the students in schools.

Purpose of Study: The purpose of this study was try to present a conceptual model for creating happiness in Iranian elementary schools.

Research Methods: Through review of literature and previous studies, a conceptual model for creating happiness was presented.

Findings: Four major categories were defined in this respect, namely: phisical, social-emotional, individual and instructional factors. Therefore, according to this factors, a conceptual model for creating happiness in iranian elementary schools was presented.

Conclusions: The main issue to discuss in this paper was lack of considration of happiness of our kids in schools. Thus a conceptual model with four major areas, based on the litrature review was designed. Further study is suggested to examine the degree to which these categories are implemented in Iranian elementary schools.

Keywords: Happiness; Elementary Schools; Students. 


\title{
ELICITING MANAGEMENT EDUCATION MODEL OF TEACHING (MEMT) FROM A DECADE STUDIES IN IRAN AND ITS USE FOR TEACHING
}

\author{
Behrangi Mohammadreza, karimi nazila \\ Professor on educational administration, chaiman of educational administration department, University of Tarbiat \\ Moallem,Tehran-Iran. \\ Postgraduate student of educationl administration, Islamic Azad University Branch of Sciences and \\ Researches,Tehran-Iran
}

Problem Statement: Considering the legacy and studying the past decade research, there found to be no study in which the compatibility of teaching academic subject on World Art History with its content and its nurturing and instruction effects be considered.

Purpose of Study: This article is to justify the use of modern model (MEMT) that fits teaching science, focusing on its implication on teaching World Art History as an academic subject in a professional and technical institute in Tehran, Iran. The goal is to introduce MEMT through delving into existing teaching models, and eliciting the most applicable models in MENT.

Research Methods: The experiences of the past decade in relation to the different models implied in all levels of schools were studied by use of library references. More than 100 research papers and postgraduate theses were reviewed. Teaching models and their findings were analyzed descriptively and a conceptual model was designed to show the strengths and weaknesses of the methods.

Findings: The most popular methods of teaching during the last decade in Iran discovered to be: Active; interactive using media and technology; participation and cooperation; discovery and group investigation; problem solving. Whereas, the four families of models of teaching i.e. information processing, social, personal, and behavioural models were in use the nurturing effects such as scientific thinking skills, cognitive, meta cognitive, creativity and innovation where considered. Three parts and 7 steps of MEMT:

$1^{\text {st }}$ part is preparation which includes: 1- advance organizer; 2- formative evaluation; 3- mastery learning; 4- peer group self-evaluation; 5- jigsaw participation. In the second part is process of teaching: 6- selection of compatible teaching model and technology and its implementation; and the third part contains the $7^{\text {th }}$ step summative evaluation and feedbacks revitalize MEMT use.

Conclusions: Findings secure the use of MEMT with its instruction and nurturing effects promises.

Keywords: MEMT, nurturing effect, models of teaching 


\title{
A feasibility study on the development of a Learner Organization in Tehran Islamic Azad University- Science and
} Research Branch

\author{
Leili Abdoli \\ Member of Faculty, Educational Administration Department, Gheshm Branch ,Islamic Azad University \\ (Tehran, IRAN, ISLAMIC REPUBLIC OF) \\ Lili_abdoli@yahoo.co.uk
}

Problem Statement: The organizations in modern world are in the state of everlasting change as new situations arise all the time in the course of their life cycle. The adaptability and flexibility is the essential features of the organizations that survive in the long run through on-going development and upgrading the scientific know-how of their members. In other words modern institutions need to turn to a "Learner Organization".

Purpose of Study: The present paper is a feasibility study on the development of a learner organization within the Faculty of Management and Economics in Tehran Islamic Azad University Science and Research Branch.

Research Methods: The collected data was interpreted by applying analytical method. The statistical population included 269 faculty teaching staff and office workers and witness group consisted of 74 randomly selected subjects. The data was analysed through the application of SPSS software $X^{2}$ test.

Findings: The findings of this study indicated that the Faculty of Management and Economics does not have the characteristics of a "Learner Organization".

Conclusions: The main issue to discuss in this paper was development of a Learner Organization in the universities. Although still there is a gap between current and desired situation but learner organization characteristic in the faculty of management and economics in Tehran Islamic Azad University Science and Research Branch is at a below the average.

Keywords: Learner Organization; Group Learning; Systematic Thinking

A Model for application of ICT in the process of teaching and learning

Shabnam Bidarian, Ph.D Student. in Educational Administration

Sciences and Research Branch, Islamic Azad University

(Tehran, IRAN, ISLAMIC REPUBLIC OF)

Shabnam.bidarian@yahoo.com

Soheila Bidarian, M.A. Social Sciences and Psychology Faculty

Central Tehran Branch, Islamic Azad University

(Tehran, IRAN, ISLAMIC REPUBLIC OF) 


\section{Soheila.bidarian@yahoo.com}

Problem Statement: Information and Communication Technology plays a crucial role in the educational system of many countries in our world and is regarded as a strategic tool. The ICT has enabled the educators to plan and control the learning processes. It has also changed the function of eductors and facilitated equal opportunity in the educational settings.

Purpose of Study: The present study aims at introducing a model for optimization of teaching and learning processes through the application of the ICT.

Research Methods: The descriptive method is used in the study and a model is purposed for the application of ICT after reviewing the previous literature on the subject.

Findings: The application of the ICT modifies the existing teaching methods as it ensures a higher level of cultural openness and cooperative learning in the educational interactions. The virtual education will also serve as a teaching aid as well as a distant education provider.

Conclusions: The most important issue in the present study is the application students-centred strategies in the educational programmes and the purposed model is based on this concept.

Keywords: The Information and Communication Technology; Student-Centre education; Teaching and Learning

School Brands Engaged in Cost-Benefit Analysis: Schooling Market

Fahimeh Veladat, M.A. in Educational Administration

Young Researchers Club, Islamshahr Branch Islamic Azad University

(Tehran, IRAN, ISLAMIC REPUBLIC OF)

fahimeh_veladat@yahoo.com

Fatemeh Yazdani,Full time Instructor in

University of applied science and technology

(Tehran, IRAN, ISLAMIC REPUBLIC OF)

f.yazdani48@gmail.com

Problem Statement: Schools as social organizations need to be in competitive market for survival. Question is whether the smart and branded schools are engaged in learning and teaching process for a higher profit or for higher quality. How far is the schools' brand helping them to achieve their goals.

Purpose of Study: This study is to consider perspectives of brand elementry school principals in terms of how they use their brands to enter into the market. 
Research Methods: This applied research is using a qualitative method. To collect data from sample population of 10 elemetry school distinguished principals, an open-ended questionnaire was designed based on literature reviewed. The instrument was to find out the importance of school brand, parents views on school brand, students reflection on schools brands, how students choose brand school, how they use their views on cost-benefit analysis of brand schools. NVIVO software was used for the qualitative analysis of the data.

Findings: The study revealed that school principals use brands as an advantage in order to be able to sustain in the competitive market. They also use brands for further benefits.

Conclusions: Parents and students as the main school customers have a deep and comprehensive analysis of school. School providers on the other hand are looking for futher competition in the market. The conceptual model found in this study shows the relationship between parents, students choice and school brand, school environment and competitive market.

Keywords: Schooling market; Brands; cost-benefit market

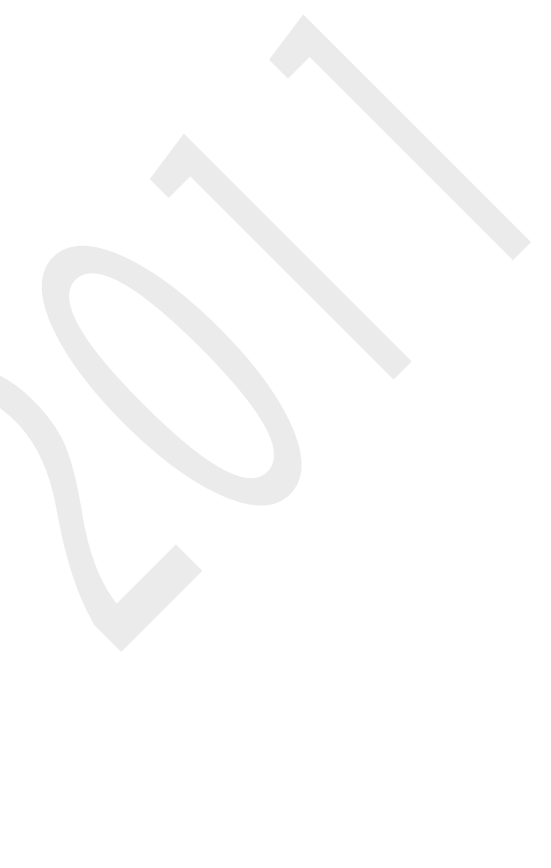

The effect of meta-cognitive education on the mathematics achievement of students as a sample of basic sciences subjects in comparison with traditional method of math teaching at first grade of guidance course of study in Tehran (2009-2010)

MirMoftakhari ,M.A.in Educational Administration,Islamic Azad University Mitra (Tehran ,IRAN ISLAMIC REPUBLIC OF)

Mirmoftakharimm@yahoo.com

Afsane Zamani Moghadam,Associate Professor School Of Management

(Tehran ,IRAN ISLAMIC REPUBLIC OF

Afz810@gmail.com

Problem Statement: Today, one of the main goals of education in the 21st century is to learn how to learn. This means compiling and developing a set of thinking process that can be used in problem- solving. Here, it assists one's meta-cognitive behavior in solving complicated problems and situations.

Purpose of study: For this reason, we have dealt with surveying the students' awareness of prerequisite in mathematics, their self-regulating in learning, the amount of their control and monitoring on learning, and their scheduling in learning mathematics. In this study, a pretest-posttest plan was used along with a witness group. Research Methods: In this plan, the subjects were selected quite randomly and placed in experimental and witness $(n=15)$ groups. The tool to collect data, in this study, included math test/examination, a questionnaire based on indexes table. In order to determine the validity and reliability of tools of study, a test-retest method was used. The Pearson correlation coefficient of 0.72 was determined between them. Statistical population in this research consisted of girl students studied in the first grade of guidance course of study in the $5^{\text {th }}$ educational district of Tehran. Descriptive statistics includes frequencies, percentages and means were used to describe the data of each question. An inferential statistics of t-test was used to compare the scores acquired through math test by both groups. And in order to review the attitudes of students toward meta-cognitive teaching method and the acquired experiences by them in contract with control group, a covariance analysis was used. Obtained results are presented using diagrams, charts and tables.

Findins: results revealed that metacognitive training increase not only the mean score in Self-regulated Learning, evaluating and planning in mathematics but also in mathematics scores. 
Conclusions: In order to develop meta-cognitive knowledge, it requires authorities to plan and compile activities and contents, and determine objectives in the field of assignments and strategies required in the curriculum. In addition, self-regulating learning has to be accounted for and meta-cognitive skills should be taught

Keywords: Thinking Process; Meta-cognitive Behavior; Meta-cognitive Teaching Method; Learning;

Scheduling; Self-regulating; Learning Monitoring

The study of effective factors on the teachers' work commitment in High Schools

Niloufar Mohammadtaheri: Ph.d scholar ,Department of Education, Roudehen Branch ,Islamic Azad University,

Roudehen,Iran

Problem statement : These days teachers are one of the most important foundations in education and many factors influence teachers' performance. The role of teachers is so sensitive. Researcher intent to identify what factors influence teachers' work commitment.

Purpose of study:The purpose of present study is to investigate the effective factors on teachers' work commitment in Tehran city in year of 2009 .

Research Methods: The research method was descriptive. The population of this study includes 2800 teachers' high schools of 4 th region of Tehran city. The samples were chosen by the use of Morgan table and it comprised about 340 subjects. The sampling method was simple random sampling. The research tool is a researcher-made multiple choice questionnaire that included 25 questions by Likert five-degree range. The validity of the instrument was examined by 30 experts, and its reliability was calculated by Cronbach Alpha method proved 0.89 . And six assumptions were made to investigate relationship between some main factors on high school teachers' commitment. The gathered data were analyzed by using of descriptive statistics including graph, frequency distribution and inferential statistics including $\mathrm{X}^{2}$ Test and Spearman Correlation.

Findings: There was positive and significant correlation between economic factors, human relationship, teacher's knowledge, in-school factors, values systems, Teacher' personality traits and teachers' work commitment.

Conclusions: Work commitment is one of the aspects of teachers operation but officials and principals of schools have to pay attention to all aspects of this sensitive profession to improve learning process. Also education is development substructure.

Key Words: Commitment, Work Commitment, Teachers' Knowledge, Economic factors, Human relationship, In-school factor, Values systems, Teacher's personality traits

The purpose of present study is to investigate the effective factors on teacher's work commitment in Tehran in year of 2009. The research method was descriptive. The population of this study includes 2800 teachers' high school of 4 th region of Tehran city. The samples were chosen by the use of Morgan table and it comprised about 340 subjects. The sampling method was simple random sampling. The research tool is a researcher-made multiple choice questionnaire that included 25 questions by Likert five-degree range. The validity of the instrument was examined by 30 experts, and its reliability was calculated by Cronbach Alpha method proved to be 0.89 . And six assumptions were made to investigate relationship between some main factors on high school teachers' commitment. The gathered data were analyzed by using of descriptive statistics including graph, frequency distribution and inferential statistics including $\mathrm{X}^{2}$ Test and Spearman correlation. The results of research showed that : There was positive and significant correlation between economic factors, human relationship, teacher's knowledge, in-school factors, values systems, Teacher' personality traits and teachers' commitment. 
Key words: Commitment, Work Commitment, Teachers' Knowledge, Economic factors, Human relationship, In-school factors, Values systems, Teacher's personality traits

The relationship between principals' creativity and schools' happiness at secondary schools in Semnan city

Nader Soleimani -Department of Educational Administration, Islamic Azad University, Garmsar Branch, Iran Elaheh Tebyanian - Islamic Azad University, Garmsar Branch

\section{Problem Statement:}

Having schools with lack of happiness is one of major problems of education system. This issue has been rarely considered. There are many students with little stimulus, and elusive from school. This illusiveness is often hidden. The evidence shows that students' lack of happiness will lead to deficiency in flourishing of intelligence, of creativity, and education achievements. Main question of the present research was how school principals would be able to create a happy school environment.

Purpose of Study: The purpose of the study was to explore the relationship between principals' creative behaviour and school happiness

Research Methods: The study used the descriptive (correlation) method of data collection. The participants in this study were 170 teachers at secondary schools in Semnan city. Two instruments were used to collect data. Both creativity of principals and school happiness were measured by a self-designed questionnaire. The data was analyzed by using the Pearson product-moment correlation technique, T-test, ANOVA and multiple regressions.

Findings: A significant positive relationship was found between each of the four dimensions of creativity (Initiating, Flexibility, Motivation, Endure) and schools' happiness. Multiple regression analysis indicated that dimensions of creativity are significant predictors of schools' happiness.

Conclusions: Happy schools present students a happy life. Creating such a happy environment is but possible by school principals' creativity. Creative, flexible, motivated and suffering principals are able to provide happy environment in schools. Increasing lights in the classrooms, a well designed and applicable heating and cooling system, applying happy and light colours on the yard walls and classroom doors and windows, light colours for students and teachers desk, and a fresh green area will all improve happiness and will make schools attractive. Providing happiness in school will lead to better motivations among students and will indirectly influence their effectiveness 
Relationship between anaemia caused from the iron deficiency with academic achievement among third grade high school female students

\author{
Nader Soleimani \\ Department of Educational Administration, Garmsar Branch, Islamic Azad University, Garmsar,Iran
}

Nasrin partovi

Islamic Azad University, Garmsar Branch

Problem Statement: Anaemia caused from Iron deficiency is one of most wide-spread diseases in the world. Children in school age and specially in the age of adolescence will come to experience the danger of anaemia based on iron deficiency. It is the age anaemia wil have a fast gowth. Adolescents need to different foods, particularly iron, will increase but the need is much higher among females. Students with iron deficiency will get infected with microbes due to decrease of body strength. Intelligence $Q$ will be lower. Learning abilities will then decrease during this condition and so will be with achievement.

Purpose of Study: The purpose of the study was to explore the relationship between the anaemia, accrued from the iron deficiency anaemia, with academic achievement of girls third grade high school students in mathematics and physics course.

Research Methods: The study used descriptive (correlation) method of data collection. The participants in this study were 46 girl students at secondary schools in Garmsar city. Data from performing test of anaemia was collected. The data was analyzed by using the Pearson product-moment correlation technique and T-test.

Findings: A significantly positive relationship was found between the six factors of blood (FERITIN, SERUM IRON, MCV, $\mathrm{MCH}, \mathrm{HCT}, \mathrm{HB}$ ) and academic achievement.

A significant negative relationship was found between the three factors of blood deficiency (IRON BONDING, RDV,RETIC) and academic achievement

Results from $\mathrm{T}$ test revealed that achievement scores of students with anaemia were much lower than healthy students.

Conclusions: Anaemia caused from Iron deficiency is wide-spread among Iraninan female students. This physiological problem will negatively affect learning and educational achievement. Iron deficiency is a mal-nutrition problem among students. Education experts should look for solutions.

Keywords: anaemia; iron deficiency; students; Garmsar schools

Collegial management to improve the effectiveness of managers' organizational behaviour in educational institutions 


\section{(Tehran, IRAN, ISLAMIC REPUBLIC OF)}

E-mail:La_sharifian@yahoo.com

Problem statement: These days, there are many problems in educational institutions, one of them is lack of participation in a decision-making process. The researcher intends to investigate ways to enhance participation of teachers and other stakeholders in high schools.

Purpose of study: The purpose of study is to present a collegial management method to increasing effectiveness of managers' organizational behaviour in high schools.

Research Methods: The research method was descriptive. An independent variable was collegial management and the effectiveness was a dependent variable. Population of this study includes 1400 teachers' high schools in Tehran. A sample was chosen by the use of Morgan table and it comprised about 305 subjects. The sampling method was simple random sampling. The research tool is a researcher-made multiple choice questionnaire. Collected data were analyzed by using of descriptive statistics including graph, frequency distribution and inferential statistics including Pearson Correlation and multi variant regression Correlation.

Findings: The study has realized that there is deep correlation between collegial management and effectiveness of the managers and the minor hypothesis is: There are deep and positive relations between collegial management and managers' human relations. And also there are relations between the collegial management and group working and flexibility and using the new methods in education.

Conclusions: Managers have to take new methods of management to enhance participation of teachers which lead to increase motivation, innovation, self-discovery, self controlling, job satisfaction, and finally effectiveness.

Keywords: Collegial Management, effectiveness, Managers' human relations, Group Working, Flexibility, New methods

The study of effective factors on the teachers' work commitment in High Schools

Niloufar Mohammadtaheri : Ph.d scholar, Department of Education, Roudehen Branch, Islamic Azad University, Roudehen, Iran

E-mail:nmohammadtaheri@yahoo.com

Tel : 00989121962346

Problem statement : These days teachers are one of the most important foundations in education and many factors influence teachers, performance. The role of teachers is so sensitive.Researcher intent to identify what factors influence teachers, work commitment.

Purpose of study:The purpose of present study is to investigate the effective factors on teachers' work commitment in Tehran city.

Research Methods: The research method was descriptive. The population of this study includes 2800 teachers, high schools of 4th region of Tehran city. The samples were chosen by the use of Morgan table and it comprised about 340 
subjects. The sampling method was simple random sampling. The research tool is a researcher-made multiple choice questionnaire that included 25 questions by Likert five-degree range. The validity of the instrument was examined by 30 experts, and its reliability was calculated by Cronbach Alpha method proved 0.89 . And six assumptions were made to investigate relationship between some main factors on high school teachers, commitment. The gathered data were analyzed by using of descriptive statistics including graph, frequency distribution and inferential statistics including Spearman Correlation Test.

Findings: There was positive and significant correlation between economic factors, human relationship, teacher's knowledge, in-school factors, values systems, Teacher' personality traits and teachers' work commitment. Conclusions: Work commitment is one of the aspects of teachers' operation but officials and principals of schools have to pay attention to all aspects of this sensitive profession to improve learning process. Also education is development substructure.

Key Words: Commitment, Work Commitment, Teachers' Knowledge, Economic factors, Human relationship, In-school factor, Values systems, Teacher's personality traits

Study of some effective aspects and factors on empowerment of the experts in educational institutions.

Asefeh Mostajeran Gortani :M.A graduated of Educational Management,Islamic Azad University,Tehran Centre,Iran

Problem Statement:Todays empowerment is essential needs of educational institutions that their staff responses to clients and stakeholders effectively. The researcher tries to find which psychological aspects and managerial factors lead them to be more empowerment.

Purpose of Study: This study aims to responses two key themes according to the managerial and psychological views.

Research Methods: The research method is descriptive. Tools of research are two questionnaires : one is Whetten \& Cameron questionnaire and the other is researcher-made multiple choice questionnaire. Pupulation of the study was 1500 experts of educational institutions in Tehran.Sample was selected by Morgan table and it included 312 subjects (both male and female). Method of sampling was stratified random sampling . In order to determine psychological aspects, the Freedman test was applied and the pearson correlation was used to recognize managerial factors. To analyze colleted data both descriptive and inferential statistics were applied. 
Findings: Based on colleted data, there are direct and significant relationships between all psychological aspects and mangerial factors. However, there are deep relationships between a psychological aspect of meaningfulfeeling and empowerment. Also, applying participative management can make staff more empowerment.

Conclusions: In educational institutions paying more attention to psychological aspects and empowerment factors lead to creat inner power that can transfer to the system in turn cause the whole organization to be more empowement.

Keywords: Empowerment, Self-effectivness, Meaning fulfeeling, Self-determination, Trust, Participative management , Rewards based on performance, Job enrichment

\author{
Professional competencies of elementary teachers and descriptive evaluation \\ Maryam Ilanlou, M.A. in Educational Planning-Tehran University Branch \\ (Tehran, IRAN, ISLAMIC REPUBLIC OF) \\ Maryam Zand, M.A. in Educational Administration \\ Young Researchers Club, Islamshahr Branch Islamic Azad University \\ (Tehran, IRAN, ISLAMIC REPUBLIC OF)
}

Problem Statement: Previous studies in education has shown that many factors such as curriculum, instruction, instruments and evaluation affect teaching-learning process and education achievement of students. In recent years, Iranian education system has applied a descriptive evaluation method moving from quantity-based achievement toward quality-orientation that is developing creative students (Hasani, 2005) Achieving the goals in this trend requires a strong infrastructure to support the change. And innovation Professional competencies of teachers need to be known as an influential factor in this process.

Purpose of Study:This study is to find out the degree of influence of teachers' professional competencies in effectiveness of descriptive evaluation.

Research Methods:A survey method was applied for this study. Population for the study was all teachers of elementary schools of Paakdasht, in Tehran province. Through simple random sampling a number of 300 teachers were selected as statistical population for the study. Instrument for data collection was a researcher designed questionnaire and observation as well. Reliability of the instrument was calculated 0.92 for professional competencies and 0.97 for elements of descriptive evaluation. by use of alph Cronbach.

Findings:The study revealed that there was a meaningful positive and strong relationship between professional competencies of teachers and descriptive evaluation. 
Conclusions:The higher the degree of general and professional competencies of teachers, the better the use of instruments of descriptive evaluation will be as the study showed. Teachers will then be more enable to achieve the goals of the new evaluation system.Providing equal training for teachers this trend will help equal gains and a generalization of the system. This study has provided some recommendation for better use of the descriptive evaluation in elementary schools.

Keywords: professional competencies; descriptive evaluation; elementary schools; Iran.

\section{The presentation of the suitable model for creating knowlgde management in the educational organizations (highter education)}

Authors Name : Seyeed Farhad Eftekharzade,Ph.D.Associat Professor School Of Social Siences In Tehran Central Branch Islamic Azad University.

Batool Mohammadi ,M.A. educational Administration In Tehran Central Branch Islamic Azad University.

Problem Statement:The institutions Universities and educational bodies for achieving sustainable competitive advantage and for creation of strategic knowledge have benefitted from innovations, strategies and techniques applied in private and commercial sectors. One of these innovations is application of management of Knowledge in educational environment.

Purpose of Study: The aim of this article is assessment of educational situation for establishment of knowledge management and presentation of the suitable model for creating knowledge management in highter education.

Research Methods: Present study using descriptive method of preparatory type, investigates situation of Islamic Azad University for establishment of a suitable model of knowledge management.

The statistical society in this research includes all members of the scientific board and employees of Islamic Azad University of Tehran central Branch. For analysis of research's questions, descriptive and inferential statistics are used. Statistical universe of research is composed of all Faculty Members and staff of Islamic Azad University, Tehran Central Branch. The research tool was a forty seven-question questionnaire performed in Likert scale and its permissibility is accounted using lecturers' and experts' opinion and its reliability is accounted by trial implementation and its reliability is accounted by coefficient of Kronbach Alpha. In order to analyze the data resulted by implementation of questionnaire, we used T, K-S statistical methods, analysis of variance and LSD pursuit test.

Findings: Results of the research show that at this university human force is in good condition, organizational structure and culture is at average level, and condition of information technology for application of knowledge management is not suitable. .

Conclusions: In the end, based on results of the research, suggestions for paving the road for establishment of knowledge management, executing model and stages for implimentation of Knowledge management in the university are provided.

Keywords: : Knowledge, knowledge management, Organizational culture, Human recorces, Information technology, education institute, University. 


\section{The study of high schools managers' problems in Tehran city}

Azita Joibari : Ph.d scholar ,Department of education, Roudehen Branch, Islamic Azad University, Roudehen ,Iran. The member of young researchers club, Islamic Azad University, Roudehen Branch, Iran

Problem Statement: : Now a days education must be considered to solve social problems, because education is basic matter in many societies .Managers are most important person in schools, But sometimes their problems were ignored.

Purpose of Study: The aim of the present research is study about obstacles and existing problems of high schools managers in the city of Tehran and determining problems in female and male schools and also existing obstacles according to the levels of education and gender.

Research Methods: The method of this research is descriptive. Population in this research is managers of high schools in Tehran's include 1261. The samples were 297 according to Morgan table. Sampling method was stratified sampling. The tool of research is a researcher-made questionnaire. To determine the reliability and validity of questionnaire after implementation of the experimental test by 30 managers, Cronbach's Alpha was 0.91. Questionnaire has made by Likert scale. The data collected from the execution of questionnaire made by researcher, by using the descriptive statistics (frequency distribution tables,) and inferential statistics ( $\chi^{2}$ test, T-student Test) were analyzed.

Findings: The results showed that : 1.components of evaluation, cooperative decision - making good human relations, educational facilities and equipment, communications and information technology and innovation and creativity are important obstacles of educational managers.2. Managers with any degree are faced educational problems in their schools.

Conclusions: : Managers face many problems in school that it may be influence managers' operation, educational authorities have to pay attention to their problems that they work with more motivation .It leads to more effectiveness.

Keywords: Educational Managers, Managers' Problem, Evaluation, Cooperative Decision-making 


\author{
A framework for Professional citizenship education based on knowledge management principles \\ Leila safaei fakhri, Educational Administration Department \\ Shahr-e-rey Branch ,Islamic Azad University \\ (Tehran, IRAN, ISLAMIC REPUBLIC OF) \\ Leila.safaee@gmail.com \\ Fatemeh Talebzadeh, Ph.D. Student in Educational Administration \\ Young Researchers Club, Islamshahr Branch ,Islamic Azad University \\ (Tehran, IRAN, ISLAMIC REPUBLIC OF) \\ Bahar1979@yahoo.com
}

Problem Statement: Educational systems are responsible for sociability and prepare new generations for playing the role of citizenship in the local, national and global community. The basic question is how the new generation would be ready for the role of citizenship and which education approach can lead to citizenship educational in knowledge age.

Purpose of Study: The aim of this paper is to demonstrate the dimensions of professional citizenship education considering the knowledge management principles towards promoting social, human and intellectual capitals in educational system in Iran.

Research Methods: Through review of literature and previous studies, the paper has been discussed the basic features and components of professional citizenship education based on knowledge management principles.

Findings: The interactions among educational system makes mutual trust, commitment to values, norms and eventually are bound to the scientific culture. Because of human capital (knowledge and skills), social capital (trust and commitment) and intellectual capital in the field of schools goal and mission are equipped and they complement each other.

Conclusions: It is necessary that the educational systems make changes in educational curricula for educating professional citizens in order to respond to global challenges and transformations, development and promoting their human, social and intellectual capital.

Keywords: professional citizenship education; knowledge management principles

Improve faculty effectiveness by sabbatical leave

Ali Taghipoor zahir, Educational Administration Department

Science and research Branch ,Islamic Azad University

(Tehran, IRAN, ISLAMIC REPUBLIC OF)

Taghipoor2@yahoo.com

Leila safaeifakhri, Ph.D. Student in Educational Administration

Science and research Branch ,Islamic Azad University 


\title{
(Tehran, IRAN, ISLAMIC REPUBLIC OF)
}

\author{
Leila.safaee@gmail.com
}

Problem Statement: Changes in expectations about the quality of higher education have dramatically increased the need for effectiveness and creative faculty development programs. Improving faculty as an institutional process is, trying to reform knowledge, skills and attitudes of faculty toward the usability and performance to revitalizing, rebuilding and recreating the structure and contents. One of the forms of support for professional development and empowerment of faculty is, providing sabbatical leave by the study, synergistic knowledge, and update information, familiarity with scientific and technological advances by other countries.

Purpose of Study: The purpose of this study was try to present a conceptual framework for effectiveness of sabbatical leave in Islamic Azad University of Iran.

Research Methods: Through review of literature and previous studies, a conceptual framework for effectiveness of sabbatical leave was presented.

Findings: Three major factors were defined in this respect, namely: organizational, proffesional development and individual factors. Therefore, according to this factors, a conceptual framework for effectiveness of sabbatical leave in Islamic Azad University of Iran was presented.

Conclusions: The main issue to discuss in this paper was lack of effectiveness conceptual framework of sabbatical leave in Islamic Azad uvinersitiy. Also these findings could be used by University leaders to affecting the quality improvement to gain skills and knowledge required of faculty members should plan.

Keywords: sabbatical leave, effectiveness, faculty

\section{Qualities of knowledge management at Departments of Education - Case of Semnan Province}

\author{
A. Navehebrahim, Associate Professor, \\ Dean, School of Education and Psychology \\ Tarbiat Moallem University, Tehran, IRAN \\ naveh1954@yahoo.com
}

Problem Statement: Knowledge management is a way of making organizational development and organizational survival.

Purpose of Study: The present research was conducted with the purpose of evaluating knowledge management in the Department of Education of Semnan Province and its sub offices in four major cities of the province, namely Shahrood Damghan, Semnan and Garmsar.

Research Methods: Lawson's Knowledge management questionnaire (2003), including 28 items for gathering data, with a reliability of $94 \%$, was used to collect data. The questionnaire measured such components as : generating, acquiring, 
organizing, maintaining, propagating and applying the knowledge. The population for the sutudy, then, included all 250 executive staff members holding B.A or higher university Degrees. Based on Morgan Table, a sample of 150 personnel were selected randomly. Two methods of descriptive and inferential statistics were applied in order to analyze the data collected.

Findings: Results revealed that "Knowledge management Components" were in pre- intermediate level. However, among them, generating the knowledge had the highest MEAN and maintaining the knowledge had the lowest MEAN.

Conclusions: Educational settings are to provide developments of schools as their counterparts. Knowledge management could help a higher productivity of educational organizations. The findings of the present study could be used in similar organizations to ensure institutional effectiveness and more productive schools as a result.

Keywords: Knowledge management; Evaluation; Department of Education; Semnan Province; IRAN;

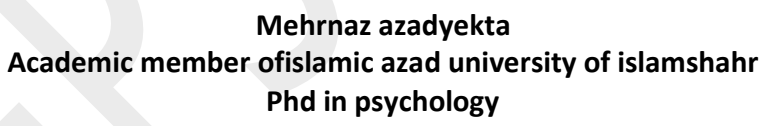

Prevalence of Conduct Disorder among Elementary Students in Tehran City

Problem Statement:Conduct disorder is serious psychopathological disorder, in terms of both the severity and adverse outcome.A child or youth who has conduct disorder exhibits a persistence pattern of antisocial behavior that significantly impairs every day functioning at home or school or leads conclude that the child is unmanageable .

Purpose of Study:The aim of this study was to investigate the prevalence of conduct disorder among elementary students in tehran city.

Research Methods:The sample size consisted of 2016 elementary students (1102 boys and 914 girls ) which were selected utilizing multistage stratified random method. Children symptom inventory (4 -edition (CSI-4), and demographics inventory were used to diagnose students with conduct disorder .Frequency, percentage, and chi square test were used for data analysis .

Findings:The results indicated that 10.5 percent of students had conduct disorder. Prevalence of condut disorder was more in boys than girls. Fourth grade students had maximum rate of conduct disorder. There existed a significant relationship between sex, Parenting style . mother education, parental divorce, and fathers job with conduct disorder. There is no significant relationship between parental death and father scholastic with conduct disorder .

Conclusions: According to the finding, conduct disorder is considerably high, and familial variables, especially parenting styles is associated with conduct disorder. This reasearch suggest that Children must receive serious attention and supports. 
Keywords:Prevalence, conduct disorder, elementary students , tehran city

\section{The effect of learning by ICT on Educational Advances among the Students of payam-e Noor University (PNU)}

Eisa Samari, PhD student in higher education planning in university of shahid beheshty, Iran, Tehran Mohammad Atashak, Ph.D Student in Educational Management in Shahid Beheshti University, Iran, Tehran

\section{Problem Statement:}

It is for sometime that anew challenge named "making use of Information and Communication Technology" has come face to face with policy makers and authorities of learning status of the country. Several studies have emphasized on ability to make use of information technology in teaching-learning process.

\section{Purpose of Study:}

Purpose the present study took place to study the effect of Information and Communication Technology on educational advances among the students of Peyam-e-Noor University, Astara- branch.

\section{Research Methods:}

The present research is a semi-experimental study, of the type of pre-test and post-test with the two experimental and controlled groups that was done about 300 students by selecting the relative classified sampling. Experimental group students (150 students) engaged in learning using the information and communication technology, while in educating the controlled group, the usual method (traditional method) was used. The research place was Peyam-eNoor University, Astara- branch.

Findings:

The study showed that the average of educational progress variables, self-regulated learning, and educational stimulation among the students who engaged in learning through ICT was by far greater than that of students who learned through traditional method.

\section{Conclusions:}

This research has practiced the comparison between the amount of effect of education based on ICT and traditional way on educational stimulation among the students; so that results from the research showed that the amount of educational stimulation among the students educated based on ICT was by far more than that of those.

Keywords:Information and communication technology(ICT),strategies for independent learning, strategies of stimulation for learning 


\section{Identifying Corruption among Teachers of Tehran}

Mohammad Atashak, Ph.D Student in Educational Management in Shahid Beheshti University, Iran, Tehran

\section{Problem Statement:}

Due to its nature and various functions, the institution of education has been considered very important among the people and statesmen, all along the history. Nevertheless, the existence and prevalence of corruption prevents optimal efficiency and effectiveness of educational Institutions. As the teachers are the most important and influential elements of educational system, they are always prone to more risk than others. Therefore, it is necessary to identify the cases of corruption among teachers with the aim of reaching education organizational health, improving learning processes, and extending moral values.

\section{Purpose of Study:}

This paper tries to identify corruption among teachers of Tehran.

\section{Research Methods:}

The paper is of qualitative Method in which the data is gathered through Documental Analysis and semi-structured interviews with subject matter expert.

\section{Findings:}

The results of the paper indicate that cases of corruption among the teachers are in the fields of recruitment, appointment, promotion, payment, relationship with students and parents, teaching, and finally evaluation of the students.

\section{Conclusions:}

The following measures should be taken in order to prevent and decrease the cases of corruption among teachers: recruit the teachers with higher ethical qualifications, formulate teachers' ethical code of conduct, supporting internal and external auditory institutes, and more crucial than others, investigating the factors leading to corruption among teachers.

Keywords: corruption, Education, teacher. 
The study of effectiveness of descriptive evaluation in primary schools Ensieh Pouladi,Afsaneh Zamani Moghadam,Science and research branch,Islamic Azad university,Tehran,Iran

Purpose of Study: Basic purpose of this study is investigating effects of evaluation on educational performance of primary school student

\section{Research Methods:}

This study is applicable purposely and in "Descriptive" method is navigating.

\section{Conclusions:}

-Descriptive evaluation decreases students' stress.

-There isn't significant difference between female and male teacher's attitude toward the effects of descriptive evaluation on stress.

-Descriptive evaluation increases educational performance.

-There isn't significant difference between female and male teacher's attitude about the effects of descriptive evaluation on educational performance.

-Descriptive evaluation increases teacher's satisfaction.

-There isn't significant difference between female and male teacher's attitude toward the effects of descriptive evaluation on teacher's satisfaction.

Keywords:Descriptive evaluation ,educational performance, stress, Descriptive, teacher's satisfaction 


\title{
Yingbin Su, Sun Yat-sen University, China
}

Liu Liu, Sun Yat-sen University, China

\section{Problem Statement:}

Students are faced with a variety of challenges when searching online for academic purposes. Theoretically, they monitor and control their search behaviour throughout the process. Initial attempts to examine this process take the form of students' responses to questionnaire items, interview probes, or content revealed in think aloud protocols. However, the content of thoughts reported in self-reports only describes what students perceive about themselves in the context of remembered task conditions, which are quite likely to be incomplete, distorted, or reconstructed. Hence, we seek new technology-based methods that can compensate for these limitations.

\section{Purpose of Study:}

The purpose of this study is to present a computer tracking tool which traces students' online search behaviour so that we can understand the way they search accurately and validly.

\section{Research Methods:}

We invented a web-browser add-on application which can easily installed to Firefox web browser. As students start search, each mouse behavior (hyperlink-click/highlight/comment) and keyboard entry (search terms/comments) are timestamped and logged on-the-fly. These records support grounded interpretations about how a student constructs knowledge. A pilot study was conducted with 14 university students who were assigned a searching task.

\section{Findings:}

Two users' data were lost due to their faliure to activate our tracking tool. 12 users' reports showed that their search activities were not affected by the tool at any level (they were not told that their search process was being tracked). The computer logs successfully captured the whole searching process. Preliminary analyses revealed that time spent on the writing task per se did not necessarily guarantee better quality of work, yet time spent on searching, reading and selecting information was more critical.

\section{Conclusions:}

This research tool we developed shows great promise by filling the gap between what students think how they learn and how they actually learn. Trace data reflect what students do in ways that reveal more accurately, although not perfectly, whether, when, and how they access prior knowledge to process new information. With sufficient samples of trace data, it is possible to identify online search patterns and seek ways to improve it.

Keywords: Online Search Tool, Tracking, Traces

\author{
Social-Emotional Loneliness and Life Satisfaction in University Students \\ Azimeh Salimi, M. A \\ The University of Shiraz, Shiraz, Iran
}

Problem Statement: Loneliness is a common and distressing psychological experience that reflects discrepancies between one's desired and one's actual relationships. numerous studies, have proved that there are relations between loneliness and psychological well-being or life satisfaction, but the distinction between social and emotional loneliness and the separate effects of them on life satisfaction have been ignored.

Purpose of Study: The purpose of present study was to examine effects of social and emotional loneliness on life satisfaction and response to this question that which dimension of loneliness is undesirable or has more effect on life satisfaction? 
Research Methods: A sample of 396 (172 male , 224 female) university students were selected through random cluster sampling from Shiraz University (medicine, engineering and human sciences), Iran. data was gathered by administering short version of the Social and Emotional Loneliness Scale for Adults and the Satisfaction with Life Scale, and Demographic Information such as gender, major, grade and average.To examine reliability of measures, Cronbach alpha coefficient and to determine validity, factor analysis method were used.

Findings: Results showed that gender had an effect on loneliness levels of the students. Thus, male students reported significantly greater loneliness than female students. In addition, findings indicated that loneliness was a significant negative predictor of life satisfaction, but emotional loneliness was a stronger predictor of life satisfaction, rather than social loneliness.

Conclusions: In sum, the results showed that the effect of emotional loneliness on life satisfaction is stronger than social loneliness.

Keywords: Social Loneliness, Emotional Loneliness, Life Satisfaction, Social and Emotional Loneliness Scale, the Satisfaction with Life Scale

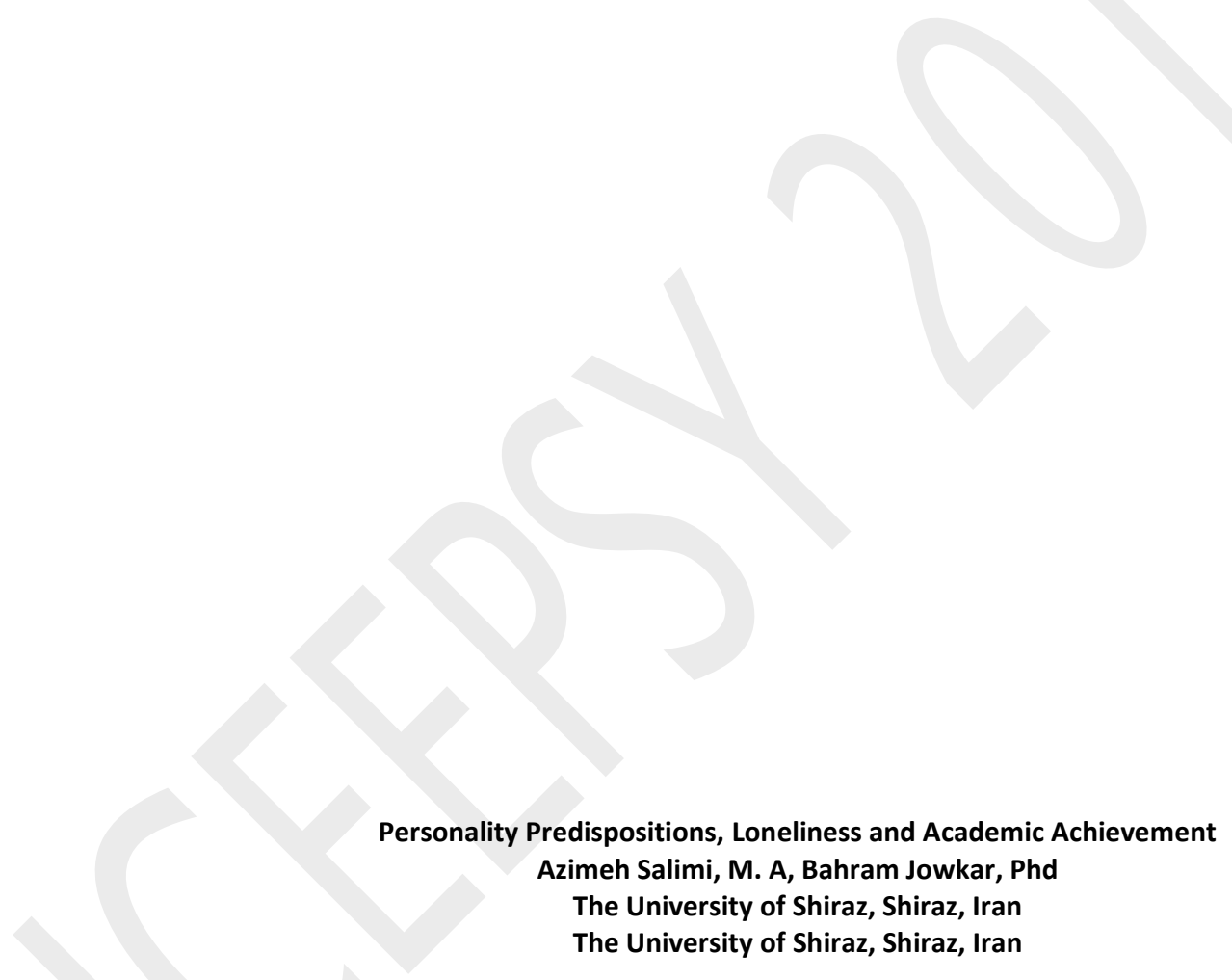

Problem Statement: Studies about personality and loneliness is an issue of a great interest in many researches. But most of them have focused on eysenck's personality theory. while the

framework of Blatt's model of personality has considered Depressive Personality Styles, and loneliness. On the other hand effects of these variables on academic achievement have been ignored.

Purpose of Study: This study is an attempt to understand the relationship between Blatt's personality predispositions (self-criticism, dependency and efficacy) with loneliness and academic achievement in late adolescents.

Research Methods: Participants were 426 (204 boys and 222 girls) late adolescents were selected through random cluster sampling from Shiraz high schools, Iran. They completed Depressive Experiences Questionnaire and Short form of Social and Emotional Loneliness Scale. Students' GPA was an index of academic achievement. To examine reliability of measures Cronbach alpha coefficient and to determine the validity factor analysis method were applied.

Findings: Results showed that all of personality variables were significant predictors of loneliness: self-criticism was positive but dependency and efficacy were negetive predictors of loneliness. Whereas previous researches had been 
indicated that dependency is a positive predictor of depression and loneliness. Moreover results showed self-criticism was negative and efficacy was positive predictor of academic achievement.

Conclusions: Blatt's personality predispositions have significant effect on loneliness and academic achievement.

Keywords: Personality, Self-Criticism, Dependency, Efficacy, Social-Emotional Loneliness, Academic Achievement

Exploring the Teachers' Use of Spoken Corrective Feedback in Teaching Iranian EFL learners at Different levels of Proficiency

Saeideh Ahangari, ph.D

Somayeh Amirzadeh, MA

Department of English Language, Tabriz branch, Islamic Azad University,

Tabriz, Iran

Problem Statement:

Over the past few decades the role of corrective feedback in the process of learning a foreign language has been much debated in the field of classroom second language learning. Handling students' grammatical accuracy is one of the most demanding tasks confronted by second and foreign language teachers. In all teaching situations and particularly in EFL contexts when teachers decide to correct learners' errors, their aim is to use correction beneficially to support and enhance learning. Almost all EFL teachers agree with this fact but there might be disagreements on whether or not there should be differences between feedback types provided at different levels of proficiency and how.

Purpose of Study:

Finely tuned and pertinent corrective feedback is an important tool for teachers to prevent their learners' errors from fossilization and help them progress along their interlanguage continuum. There are different factors contributing to efficacy of corrective feedback among them is taking into consideration the proficiency level of learners in choosing corrective feedback techniques. Hence inspired by this challenge, and realizing that no such researches have been undertaken thus far to address this problem, the researcher intends to explore and observe oral corrective feedback types that teachers provide for learners at different levels of proficiency.

\section{Research Methods:}

This research was a survey study done in one of the language institutes of Tabriz, Iran. In this study the researcher used a database of 360 corrective feedback moves which two EFL teachers provided to their learners at three levels of proficiency(elementary, intermediate, advanced). Eight types of corrective feedbacks were identified and their distribution in relation to proficiency levels of learners was determined

\section{Findings:}

As was anticipated, statistical calculations revealed that recast was the most frequently used type of corrective feedback by teachers at all three levels of proficiency. However, as learners became more proficient teachers reduced recasts and incorporated other explicit and self correction techniques.

\section{Conclusions:}


The present study builds on previous studies by focusing on the fact that even though a great deal of L2 learning takes place through exposure to comprehensible input, learners may require corrective feedback, when mere exposure cannot help them and depending on different levels of proficiency the type of corrective feedback may vary.

The results of this study may be helpful in EFL domain. Sometimes provision of corrective feedback which is not proportionate with the learners' proficiency level may have a hindering effect in their language learning development.

\section{Keywords:}

Clarification Request, Corrective Feedback, Elicitation, Error, Explicit Correction ,Focus -on-Form , Feedback, Metalinguistic Feedback, Proficiency level, Recast

\section{The Effect of Oral Output on Accuracy and Fluency of Iranian EFL Learners' Task-based Oral Performance}

Zohreh Seifoori (Ph.D.), Islamic Azad University- Tabriz Branch

Soghra Goudarzi (MA.), Islamic Azad University- Tabriz Branch

\section{Abstract}

Helping foreign language learners to produce accurate and fluent speech is a major concern for many teachers of English as a foreign language (EFL). Research findings have underscored the effect of oral output on English learners' oral performance in terms of accuracy and fluency in EFL situations. It is believed that the output produced by the learners promotes noticing of formal elements in the target language ( $T L$ ) input and affects subsequent learning of the form. Therefore, this study set out to investigate the probability of enhancing both accuracy and fluency of Iranian EFL learners' task-based oral speech via an output-oriented program. Fifty Iranian English sophomores at Islamic Azad University-Tabriz Branch participated in the study and were randomly assigned to output experimental group and non-output control group. Initial homogeneity of the groups was verified using a general proficiency test and an oral pre-test. Both groups received instruction for six sessions and were taught how to use different fluency and accuracy strategies to produce more fluent and accurate speech. The only difference between the two groups was that at the end of each session the experimental output group participants narrated a picture strip while the non-output group participants didn't have any output. The results from the ANCOVA analysis of the oral post-test data revealed significant differences between the two groups. The output group did produce more accurate and fluent speech on the post -test compared to the non-output group. The findings have significant pedagogical implications for EFL learners in highly exposure-limited contexts.

Keywords: Fluency, accuracy, output, task-based speech 
A Study on the Effect of the Numbers of Options on the Parameters and the Question's Goodness of Fit, and its Effect on Information Function of the Question in Different Levels of Ability in Multiple Choice Tests

\author{
Gholamreza Golmohammad-Nazhad Bahrami (Ph.D.), Islamic Azad University- Tabriz Branch
}

\title{
Abstract
}

In behavioral science experts are always look for studies which increase the human knowledge about the humanistic problems and make suggestion about the application of these findings. In order to deal with these sort of problems and obtaining the objectives, collection of valid evidence, reliable information and careful measurement of individual's mental and behavioral characteristics is required. Therefore, the aim of the present study is to investigate the effect of the number of options in multiple choice items which is used as the measurement and information collection instrument, so that the best form which is more accurate and suitable among the others can be determined. This study compares the

discrimination parameter $\left(a_{j}\right)$, difficulty parameter $\left(b_{j}\right)$, and the chance among questions with four and six options. It also compares the information function at different levels of ability and the goodness of fit items with four and six options. The statistical population was 985 students from different fields of study at Islamic Azad University- Tabriz Branch in Iran. They have been selected by random sampling. Parallel form ( A \& B) R.B. Cattell intelligence test was implemented without chronological interval. A form has 36 items with six options and B form has 36 items with four options. The research questions and their results are as follow: The first question deals with the difference of $\left(a_{j}\right)$ between items with four and six options, the result showed no difference in discrimination parameter between them, i.e. there is no effect based on the number of options in discrimination parameter item. The second question explores the difference of the difficulty degree of items between the two tests. The results showed that the level of difficulty in items with six options is higher than that of four options, and it seems quite logical. The third question investigates the difference of the number of wrong answers between the different levels of ability and the results showed that there is significant difference between various levels of ability. The fourth question examines whether the number of wrong answers among different levels of ability will change equally. The result showed that with the change in the number of item options, there will also be a change in the number of wrong answers, but this change among the different levels of ability is not equal. The fifth question investigates whether the change in the number of options will lead to the change in information function items, and if this change is equal in different levels of ability. The result showed that with the change in the number of options, the information function items will also change and the more the number of the options the more difficult the items will become. Consequently in the higher level, the information function will be higher and it will be lower at lower levels of ability. The sixth question explores the effect of the number of options in the goodness of fit items (i.e. the fit of item to the measurement model). The result showed no considerable effect of the number of options on the goodness of fit item. This investigation was implemented both in two parametric and three parametric IRT model.

Keywords: Chance, Choice, Difficulty Parameter, Discrimination Parameter, Goodness of Fit, Guess, Information Function, Item, Option, Item Response Theory (IRT).

Assessing quality of international joint higher education programs in Iran

Khodayar Abili, PhD

Associate Professor of Higher Education

University of Tehran, Iran

Abili hrm@yahoo.com abili@ut.ac.ir 
Problem statement: Iran is a developing country which strives to maintain a higher standard when it comes to educational matters and concerns. To develop productive human resources, various educational reforms have been passed in recent decades. However, despite the establishment of private universities and admitting second shift students in public universities in recent years, higher education system has not been able to satisfy the high demand in the market. As a result, many started to move abroad for getting higher and advanced education. Therefore, a new type of higher education program started to make it possible for young graduates to get further higher education without leaving the country - the emergence of various international joint programs between Iranian universities and foreign institutions. Although these programs have been carried out between Iranian universities and higher education institutions of other mainly developed countries during the last 10-15 years, unfortunately, most of these programs are facing with quality-related issues in meeting their students' expectations. Therefore, the question to be addressed in this study is: What are the quality-related issues with these programs in Iranian universities and how they should be dealt with?

Purpose of study: This is a multiple-case study conducted on existing joint higher education programs offered in Iran in order to explore quality-related challenges with these programs to make suggestions for their improvement as well as to make recommendations for future joint programs with foreign higher education institutions.

Research methods: To collect data, a survey was conducted with a sample of students who are participating in these programs. This survey was followed by unstructured interviews with a selected number of faculty members who have taught in these programs and some managerial staff who are running and supporting these programs in selected Iranian universities in order to find out their views on the subject and their recommendations for improvement.

Findings: Findings indicated that international joint programs in Iran are facing with some quality-related challenges related to content and implementation of these programs.

Conclusions: These programs offer valuable opportunities for both Iranian universities and foreign partners. However, quality of these programs is what matters to their students. Therefore, both Iranian and foreign partners should do their best in order to provide unique and world-class learning experiences to their students.

Keywords: Assessment, quality, international joint higher education program, university, Iran

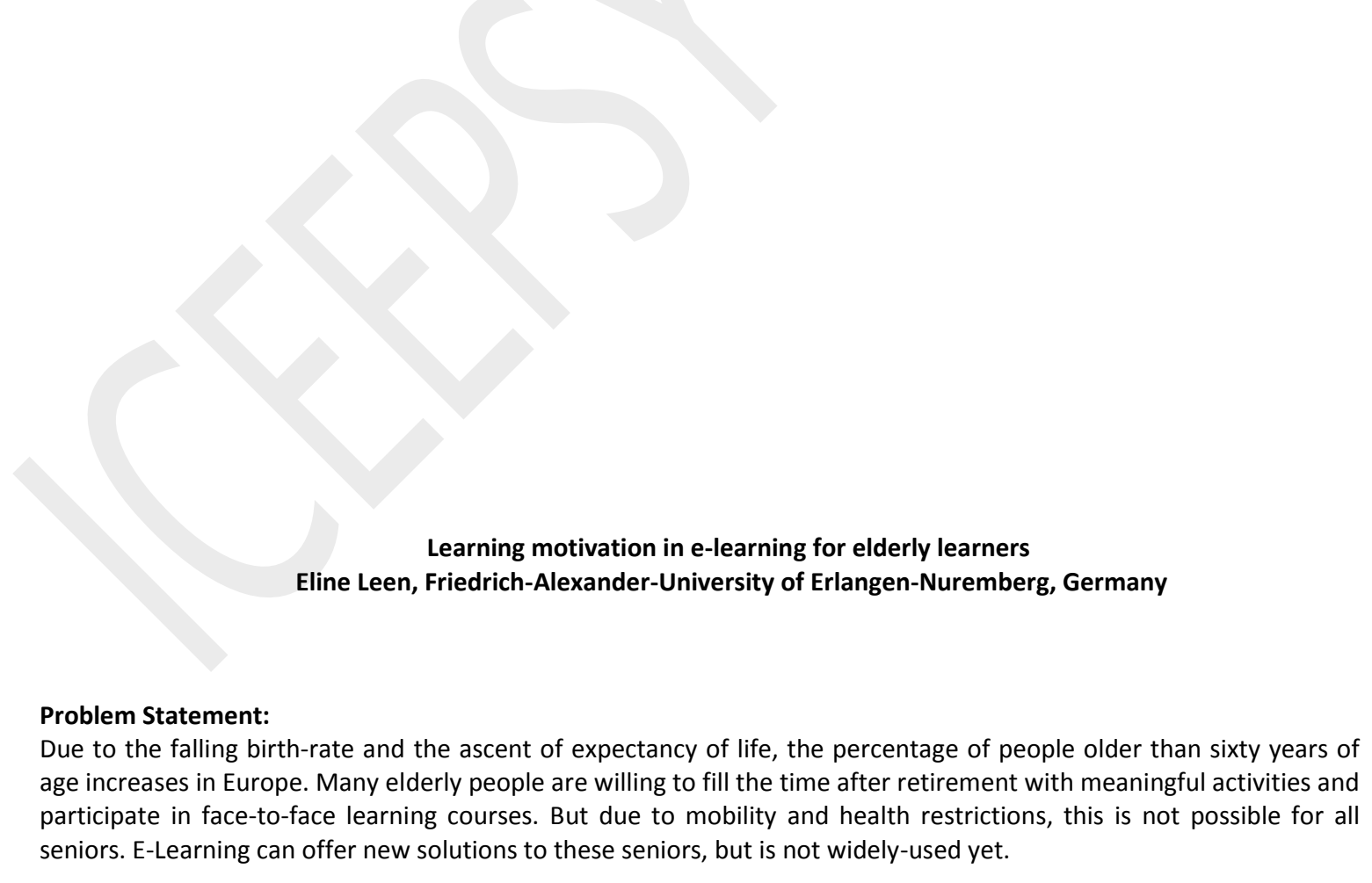

Purpose of Study:

Studies about learning motivation in e-learning usually focus on young learners. Therefore not much is known about the intentions and motivation of elderly learners who are participating in online learning courses. To motivate and 
facilitate this group of learners in the future, motivation, personality traits and life satisfaction were tested in this study and motivational differences between elderly and young adult learners were tested.

\section{Research Methods:}

Elderly learners and young adult learners $(N=119)$ who participated in e-learning courses filled in an online questionnaire about their motivation for e-learning, questions about life-satisfaction and a personality questionnaire (NEO-FFI). They also completed an implicit memory test (IMT) to study implicit learning motivation.

\section{Findings:}

Through factor analysis four motivational dimensions were found: target-oriented and experience-oriented motivation, content motivation and achievement motivation.

Elderly and young adult learners significantly differ between all four dimensions: high motivation scores for targetoriented and achievement motivation were found in young adult learners, whereas in elderly learners experienceoriented and content motivation were high. Elderly and young learners also differ on the IMT and on some personality traits but not on life satisfaction. Seniors who decide to participate in e-learning are less neurotic, more agreeable and more open to experience than a reference sample of seniors.

\section{Conclusions:}

Learning motivation is different between young adult and elderly learners. This should be taken into account when elearning material is developed. Because experience-oriented motivation is high in seniors, social interactions and content that is important to their current living situation should be included in learning materials, whereas material for young adult learners should focus more on achievement and on future challenges.

Keywords: e-learning, elderly learners, learning motivation

\section{The connections among anxiety, academic achievement and general intelligence Birutė Balsevičienė, Garliava secondary school, Kaunas district, Lithuania Liuda Šinkariova, Vytautas Magnus university, Lithuania}

Problem Statement: There are many research analysing academic achievement problems and results and their connections with intelligence, but findings are controversial. It's possible that there are more phenomena which influence both - academic achievement and intelligence.

Purpose of Study: The aim of this study was to analyse the connections among anxiety (trait and state), academic achievement and general intelligence.

Research Methods: Students ( $n=170 ; 41$ male and 129 female) completed State - Trait Anxiety inventor (STAl, Spielberger et.al., 1970), Ravens progressive matrices (Raven, 1938). Academic achievement was assessed by mean of two last year's grades mean.

Findings: Trait anxiety and academic achievement are not connected in the group of subjects with deeper trait anxiety despite their intelligence. Trait anxiety is connected with academic achievement in the group of subjects with less trait anxiety and higher intelligence (the deeper trait anxiety is the better achievements are). Trait anxiety and academic achievements are not connected in the group of subjects with less trait anxiety and average or low intelligence. Scores of state anxiety were lower after the testing intelligence than before the test in the group of subjects with more trait anxiety.

Conclusions: Trait anxiety is connected with academic achievement just in the group of subjects with less trait anxiety and higher intelligence (the deeper trait anxiety is the better achievements are).

Keywords: general intelligence, academic achievement, anxiety (trait and state) 


\section{IMPLEMENTATION OF A COMPREHENSIVE STUDENT-CENTRED APPROACH TO EDUCATION: A CASE STUDY Dr Ben van der Merwe, Central University of Technology, Free State, South Africa}

The term student-centred learning - as in the outcomes-based education paradigm - is widely used in the teaching and learning literature and many terms such as flexible learning, experiential learning and self-directed learning have been linked with student-centred learning. The exhausted term "student-centred learning" can also hold different meanings to different people.

In practice student-centred learning is described by a range of terminology and this can led to confusion surrounding its implementation. The paradigm shift from a lecturer-centred to a more student-centred approach to education places the student in the centre of the educational process. The lecturer-focused knowledge transfer, such as lecturing, has begun to be increasingly criticised and this has paved the way for a widespread growth of student-centred learning as an alternative approach to education. The key factor is to focus on the student, on his or her learning experiences and development, wellbeing and retention so that institutional learning programmes are delivered in ways that are demonstrably in the student's best interests.

However, the author is of the opinion that the implementation of a comprehensive student-centred approach to education requires that all role-players in the educational process (academic and support services) must be focused on student success, because it is the responsibility of a whole university community to educate a single student. The argument is that the implementation of a comprehensive student-centred approach could also enhance the success and student throughput rates. The viewpoint should be to develop a comprehensive student support system to provide the intellectual, social, emotional and physical support that individual students may need to succeed in the higher education environment.

The purpose of this paper is to introduce a comprehensive student-centred approach to education to enhance teaching and learning practices, with specific reference to the Central University of Technology, Free State. 
Keywords: Student-centred approach, Comprehensive educational approach, Paradigm shift.

\author{
CHILDHOOD DEPRESSION IN THE SCHOOL CONTEXT \\ Elena Bernaras, Joana Jaureguizar, Marian Soroa, Izaskun Ibabe \& Carmen Cuevas \\ University of the Basque Country (Spain)
}

\begin{abstract}
Depression is the leading cause of disability in the world today (Murray and Lopez, 1996). Although depressive symptoms increase over time, research has found that the first symptoms of major depression emerge around age 11-12, especially in girls (Essau et al., 2010), and that less severe symptoms can be observed in children as young as 7-8 (Kovacs et al., 1984). However, childhood depression is one of the most undertreated and debilitating psychological disorders (Cichetti and Toth, 1998). Therefore, early assessment of depressive symptoms is essential for the prevention of future symptoms, and school can be a strategic context for their detection.

The aims of this study are to analyze depression rates in 8-12 year olds in the Basque Country (Spain) in relation to age and sex, and to study the relationship between depressive symptoms and school adjustment. Teachers' competence in detecting early symptoms is also studied.

The sample comprised 814 students ( 414 girls and 404 boys) aged 8 to 12 . They filled out two questionnaires: the Behaviour Assessment System for Children (BASC) (Reynolds and Kamphaus, 1992), and the Children's Depression Scale (CDS) (Lang and Tisher, 1997). Their teachers completed the Teacher's Report Form (TRF) (Achenbach and Rescorla, 2001). The results show that about $4 \%$ of the sample presented clinically significant depressive symptoms, with a significant interaction between sex and age: at the age of 8-9 there are no significant differences between girls and boys; at the age of 10-11 boys present more depressive symptoms, but by the age of 12 there is a reversal in the rates, with girls showing considerably more depressive symptoms. The findings also show that depressive symptoms and school maladjustment are related. Finally, teachers' assessments did not match students' reports about their depressive symptoms. It appears that teachers are used to detecting behaviour problems but not depressive symptoms.

The implications for school detection and prevention programmes are discussed in detail.
\end{abstract}

Keywords: depression, school, children, adjustment, teacher 


\title{
The effect of pre-task planning on the accuracy and complexity of Iranian EFL learners' oral performance
}

\author{
Saeideh Ahangari, ph.D \\ Islamic Azad University-Tabriz Branch \\ Mortaza Abdi, MA \\ Islamic Azad University-Ardabil Branch
}

Problem Statement: It is assumed that learners possess limited capacities of attention; that the various language production and comprehension elements compete for such limited capacities; and attention to one area may be at the expense of other areas. In this regard, the choice between attention to form and attention to meaning plays a central role (Foster \& Skehan, 1999).

Purpose of Study: This study was designed to examine the effect of pre-task planning (strategic planning) on the complexity and accuracy of task-based oral performance with the decision-making task type among 40 Iranian EFL learners majoring in Teaching English as a Foreign Language (TEFL) at Islamic Azad University-Maragheh Branch.

Research Methods: The design of this study was quasi-experimental, with experimental and control groups. Performing the same task type, the experimental group was provided with a 10-minute planning time before task performance whereas the control group was given a zero-planning time. To measure the complexity and accuracy of the participants' oral production, their performance was transcribed. Later, the collected data were coded for the two dimensions of oral production based on the established criteria.

Findings: Two independent samples t-tests were run to compare the participants' oral performance. The findings reveal that pre-task planning has a positive effect on complexity whereas no positive effect is evident in the accuracy of learners' oral performance.

Conclusions: The findings of the present study provided support for the close link between pre-task planning as a metacognitive strategy and complex oral performance. Planning prior to task performance seems to predispose learners to attend to propositional content and its organization and this results in enhanced complexity.

Keywords: pre-task planning, oral performance, decision making task, accuracy, complexity

The role of personal values in enhancing student experience and satisfaction: A cross cultural study of international postgraduate students

Rodney Arambewela, Deakin University, Australia John Hall, Deakin University, Australia

Problem Statement: Universities are faced with the challenging task of educating an increasingly diverse and mobile student community. An understanding of the backgrounds of students and their expectations is central to ensure effective delivery of educational and support services to enhance student experience and satisfaction. The study of student personal values is able to provide better understanding of student demands and aspirations and to assist universities to target educational and support services to meet the differential needs of students. 
Purpose of Study: To examine the differences in personal values among Asian international postgraduate students studying in Australian universities and to discuss the strategic implications of these differences in relation to enhancing student experience and satisfaction.

Research Methods: Data collected from a sample of 371 postgraduate students from China, India, Indonesia and Thailand studying in five universities in Victoria, Australia. Personal values were measured using Kahle's (1983) List Of Values (LOV). Factor analysis was undertaken to determine the underlying personal value domains and Structural Equation Modelling (SEM) to analyse the relationship of the value constructs to student satisfaction. ANOVA and MANOVA tests employed to examine the differences of personal values between the nationalities, gender and age.

Findings: Factor Analysis resulted in a two factor solution and labelled as Self-efficacy and Hedonism which explained 73.5 percent of the variance. MANOVA and ANOVA results indicated significant differences (.001) across the values constructs of Self-efficacy and Hedonism and the individual variables between nationalities, gender and age.

SEM results indicated a link between student satisfaction and the value domains of Self-efficacy and Hedonism.

Conclusions: The study highlighed the opportunities for universities to recognise that Asia is a differentiated market place and the development of segmented approach in designing educational programs as part of the strategy to enhance student experience and satisfaction. The inclusion of cultural aspects in educational programs, promotional material that fits in with different cultural backgrounds of students, self-paced learning approaches, promotion of cross cultural understanding among university staff are among the recommended strategies.

Keywords: International students, Personal values, Cultural diversity, Student experience and satisfaction Using assistive technologies in the development of a dialogic and cooperative approach to feedback: An exploration of
trainee teachers' views.

By

Nikki Sowe and Gordon Ade-Ojo

This study is driven by two separate but interrelated issues. First, it is driven by the desire to explore the effectiveness of assistive technologies in the structure of professional development of trainee teachers. Second, it seeks to explore the extent to which such technologies, as reflected in the use of digital recordings in the process of self-reflection by trainee teachers, can contribute to the promotion of a dialogic (Alexander, 2008) and cooperative (Edge1992, 2002 and 2006) approaches in the use of feedback for the development of trainee teachers with a focus on problem solving. The anchor for this exploration is the desire to move away from the teacher (educator) -centred role (Copland 2010) that is prevalent in the use of feedback in contemporary teacher training programmes.

The study surveyed the views of trainee teachers in two colleges through the use of a questionnaire and through a focus group discussion in consonance with the integrative approach to action research which acknowledges the importance of the voice of the third person (Coghlan and Brannick, 2010). The findings were subjected to both qualitative and quantitative analysis, the former through the use of the SPSS statistical analysis tool and the latter through an ethnolinguistic approach (Copland 2010). The study found that in the views of trainee teachers (third person), the use of assistive technologies can significantly facilitate the promotion of the dialogic/cooperative approaches to giving and using feedback in the professional development of trainee teachers if certain conditions were met. The study concluded that while these approaches are highly desired by trainee teachers who see them as more helpful than the prevalent teacher-centred approach, there is the need to develop a conceptual framework for its implementation. 


\section{SCHOOL CONTEXT: FAMILY SATISFACTION AND SOCIAL COMPETENCE OF CHILDREN WITH ATTENTION DEFICIT} HYPERACTIVITY DISORDER "ADHD" *

Rosa García, Pilar Jara y Desiree Sánchez

Department of Developmental Psychology, Educational, Social and Methodology

Universidad Jaume I, Facultad de Ciencias Humanas y Sociales, Av. de Vicent Sos Baynat, s/n

12071 Castellón de la Plana (ESPAÑA)

* Work done under the project frame PSI2008 06121/PSIC. Funding agency Ministry of Science and Innovation.Spain

Problem Statement: A high percentage of children with Attention Deficit Hyperactivity Disorder (ADHD) have low school performance which affects their educational attainment as well as their academic performance and persists into adolescence. Therefore, it is important the relationship between the families of children with ADHD and educators, as these children need more psychoeducational attention (Jensen, 2004). Children with ADHD, not only show academic problems, they also have difficulties in relationships with peers, which persist until adulthood.

Purpose of Study: The present study is to analyze on the one hand, the perception and relationship of families of children with ADHD, with professional services and educators. On the other hand examines the perceptions of teachers on social competence of children with ADHD is examined.

Research Methods:To carry out the objectives the subscale of Family Satisfaction was applied with the Services and Professional Educators of the assessment instrument of families needs with children with developmental difficulties, Family Opinions (FAOP; Robledo \& Garcia, 2007) to parents and prosocial behavior subscales and problems with peers from Strengths and Difficulties Questionnaire "SDQ" CAS "(Goodman, 2001) to teachers. The tests were given to parents and teachers of 21 with ADHD and to 28 children without ADHD.

Findings: Considering the first objective, the results show significant differences in the assessment and satisfaction of families of children with ADHD compared to families of children without ADHD in relation to professional educators. The results of the second objective, indicate that teachers perceive significant differences in social skills among children with ADHD and children without ADHD. 
Conclusions: The analysis of the relationship between the family and school and teachers' perception on the social functioning of children with ADHD, it provides important information about academic and social life of children with ADHD showing the need to extend treatment beyond the attention on the core symptoms of ADHD.

\section{Keywords:}

Attention Deficit Hyperactivity Disorder (ADHD), family perception, social skills, prosocial behavior, peer problems.

Communication and Discursive Strategies. Theory and Practice in Training Pre-School and Primary School Teachers Angelica HOBJILĂ, Faculty of Psychology and Education Sciences, "Alexandru Ioan Cuza” University, lasi, Romania

Problem Statement: What is the role of communication, in general, and of discursive strategies, in particular, in the theoretical and practical training of pre-school and primary school teachers (in Romania)?

Purpose of Study: In exploring this problem, I aim to: (1) pinpoint the role occupied by communication and by discursive strategies in the curricula and course syllabi pertaining to the initial training of pre-primary and primary school teachers; (2) analyse the ways in which teaching practice tutors, on the one hand, and students engaged in practical training, on the other, relate to the issue of communicating with children of pre-school and primary school age.

Research Methods: The study draws on the qualitative analysis of the following elements: (a) the current curricula and syllabi pertaining to courses in Pedagogy of Pre-School and Primary School Education (as taught in Romanian universities); (b) data gathered by interviewing teaching practice tutors and $2^{\text {nd }}$ and $3^{\text {rd }}$-year students - majors in Pedagogy of Pre-School and Primary School Education (lasi).

Findings: The analysis yielded the following findings: the curricula and course syllabi exhibit a predominantly theoretical orientation in actualising the issues related to communication; this reality is reflected by the opinions of teacher trainers and students, who believe that, during practical activities, discursive strategies are either not consciously actualised or, if actualised, they are not properly adapted to the particular characteristics of children and to the dimensions of the educational context respectively; one may notice the emphasis placed on locutionary acts to the detriment of illocutionary and perlocutionary acts.

Conclusions: In order to optimise the relationship between theory and practice in the area of communication and of actualisation of discursive strategies in activities conducted in kindergarten and in primary school, it is necessary to focus on the applied component of initial teacher training. In this respect, potential avenues for subsequent development in this area include: adjusting certain components of the course syllabi, conducting activities that shift the emphasis from the locutionary to the illocutionary and the perlocutionary, proposing compulsory and/or optional disciplines that would explore and implement discursive strategies in various educational contexts.

Keywords: communication, discursive strategies, initial teacher training, curriculum, teaching practice. 


\title{
CHILDHOOD DEPRESSION IN THE SCHOOL CONTEXT
}

Elena Bernaras, Joana Jaureguizar, Marian Soroa, Izaskun Ibabe \& Carmen Cuevas University of the Basque Country (Spain)

\begin{abstract}
Depression is the leading cause of disability in the world today (Murray and Lopez, 1996). Although depressive symptoms increase over time, research has found that the first symptoms of major depression emerge around age 11-12, especially in girls (Essau et al., 2010), and that less severe symptoms can be observed in children as young as 7-8 (Kovacs et al., 1984). However, childhood depression is one of the most undertreated and debilitating psychological disorders (Cichetti and Toth, 1998). Therefore, early assessment of depressive symptoms is essential for the prevention of future symptoms, and school can be a strategic context for their detection.

The aims of this study are to analyze depression rates in 8-12 year olds in the Basque Country (Spain) in relation to age and sex, and to study the relationship between depressive symptoms and school adjustment. Teachers' competence in detecting early symptoms is also studied.

The sample comprised 814 students (414 girls and 404 boys) aged 8 to 12 . They filled out two questionnaires: the Behaviour Assessment System for Children (BASC) (Reynolds and Kamphaus, 1992), and the Children's Depression Scale (CDS) (Lang and Tisher, 1997). Their teachers completed the Teacher's Report Form (TRF) (Achenbach and Rescorla, 2001). The results show that about $4 \%$ of the sample presented clinically significant depressive symptoms, with a significant interaction between sex and age: at the age of 8-9 there are no significant differences between girls and boys; at the age of 10-11 boys present more depressive symptoms, but by the age of 12 there is a reversal in the rates, with girls showing considerably more depressive symptoms. The findings also show that depressive symptoms and school maladjustment are related. Finally, teachers' assessments did not match students' reports about their depressive symptoms. It appears that teachers are used to detecting behaviour problems but not depressive symptoms.

The implications for school detection and prevention programmes are discussed in detail.
\end{abstract}

Keywords: depression, school, children, adjustment, teacher

Value And Resource Management Strategies Among Students Of Arabic As A Third Language Course

GHAZALI YUSRI

Academy of Language Studies

Universiti Teknologi MARA

ghazaliy@salam.uitm.edu.my

NIK MOHD RAHIMI

Faculty of Education 


\author{
Universiti Kebangsaan Malaysia \\ nrahimi@ukm.my \\ WAN HASLINA WAH \\ Faculty of Medicine \\ Universiti Kebangsaan Malaysia \\ afifiyad@yahoo.co.uk
}

\title{
Problem Statement:
}

This study investigated the value level in learning oral Arabic among students at Universiti Teknologi MARA (UiTM) Malaysia and its correlation with the use of resource management strategies. The concept of value and resource management strategies was derived from the self-regulated learning framework. Value consists of three main components, namely intrinsic motivation, extrinsic motivation and task value. Meanwhile, resource management strategies consist of four components, namely time and study management, effort regulation, peer learning and help seeking. This study was carried out due to some previous studies which showed that value and resource management strategies contributed significantly on students' learning and achievement including in learning languages.

\section{Purpose of Study:}

The purposes of this study were to investigate (1) the value level among overall students, (2) the correlation between students' value and their use of resource management strategies, and (3) the differences in the use of resource management strategies between students with different level of value.

\section{Research Methods:}

The sample of this quantitative study comprised of 455 students which were selected using a disproportionate stratified random sampling. The data were also collected through a questionnaire adapted from a self-regulated learning strategies instrument which is The Motivated Strategies for Learning Questionnaire (MSLQ).

\section{Findings:}

The study revealed that (1) the value level of overall students was high; (2) there were significant correlations between value and the use of resource management strategies among students; and (3) the high value group of students used significantly higher in all components of resource management strategies than the moderate group.

\section{Conclusions:}

This study has some classroom implications. It suggested that value components should be nurtured among students by selecting appropriate learning activities and implementing proficiency tests rather than achievement tests. Collaborative learning activities should also involve students of mixed value level which can be assessed through their prior learning experience and gender.

\section{Keywords}

Course value; Resource management strategies; Oral Arabic learning; Self-regulated learning; MSLQ 
Gender different between Imaginary Audience and Personal Fable with Resilience among Male and Female

Bahram Jowkar, Phd and Leaila Noorafshan, M. A

${ }^{1}$ The University of Shiraz, Shiraz, Iran

${ }^{2}$ The University of Shiraz, Shiraz, Iran

Problem Statement: The theoretical context for adolescent egocentrism with Resilience in male and female .

Purpose of Study: This study investigated gender different between Imaginary Audience and Personal fable with Resilience in male and female.

Research Methods: Participants were 700girls(350)and boys (350) students, selected from high schools Shiraz(one of the great city of Iran) ,via random cluster sampling method.The subjects completed the New Personal Fable Scale (NPFS) with three subscales (Omnipotence, Personal Uniqueness, Invulnerability ), Imaginary Audience Scale, and Adult Resilience Scale (ARS) with five subscales (Personal competence, social competence, Family coherence, Social support, Personal structure)

Findings: Results showed that Imaginary Audience was significant positive predictor of the social competence and Family coherence among male and there is not a significant difference among girl and boy

Conclusions: The results of present study provided good evidence to support Lapsly's model .

Keywords: Resilience, Personal fable, Imaginary audience 
School Environment and Locus of control in relation to job satisfaction among School Teachers - A Study from Indian Perspective

Rituparna Basak \& Anjali Ghosh

Psychology Research Unit

Indian Statistical Institute, Kolkata, India

Problem Statement: In the present scenario with the rapid pace of changes in the society schools also have to adjust with these changes. These adjustments are only possible because of the teachers of the schools who play these crucial roles to help schools. Fulfilment of these crucial roles depends on how perfectly and satisfactorily they do their jobs. This satisfaction is influenced by the environment where the teacher works or teaches i.e. school environment and along with this teacher's belief about his/her work i.e. their locus of control.

Purpose of Study: The purpose of this study is to explore different patterns of relationship of job satisfaction with school environment and locus of control in different groups of school teachers selected from different school of Kolkata, India. And another objective is also to see whether there is any demographic variable play any major role on the job satisfaction of the teachers or not.

Research Methods: 160 data were obtained from the school teachers of Kolkata. Revised School-Level Environment Questionnaire developed by Johnson, Stevens \& Zvoch (2007), Rotter Locus of control scale (1966) and Paula Lester's Teacher job satisfaction questionnaire (1982) were used in this study.

Findings: Results showed that job satisfaction is significantly and positively correlated with different domains of school environment and significantly and negatively correlated with locus of control. Stepwise regression analysis indicated that job satisfaction can be significantly predicted by locus of control and maximum domains of school environment.

Conclusions: This study highlighted a vital impact of school environment and locus of control on job satisfaction. Teachers who have high internal locus of control (belief that outcomes are related to their behaviour or personal investment) are highly satisfied with their job. 


\section{Problem Statement:}

Teachers as major players in a school need to respond to challenges posed by the society in which they live, work or develop professionally. Literature argues that in order to embrace the pedagogical practices that they need to learn in order to become competent teachers, they have to bring their beliefs about teaching to a conscious level and accommodate them with new knowledge acquired during the training. By means of answering questions focused on particular issues they can articulate and examine their beliefs which may contribute to a better understanding of the phenomena involved and the solutions they seek for.

\section{Purpose of Study:}

This paper discusses the importance of teaching the capacity to be reflective at earlier points of the professional development, so that individuals can be more receptive to change. Adapting to change requires not only adapting to new situations, but also understanding, accepting and implementing into practice of new ideas, concepts or approaches. Therefore developing such abilities in teachers becomes highly relevant on long term for TE.

\section{Research Methods:}

The study has a qualitative approach. It presents the case study of 14 subjects investigates by means of questionnaires, interviews, observation reports their awareness level of reflective processes in relation to their understanding of professional identity and growth, after the implementation of reflective enquiry method. This approach of change in a systematic manner represents a method of helping adults to identify needs and adapt to change by means of questions.

\section{Findings:}

The model used was developed from an extensive research study in the business field, whose findings lead to the conclusion that successful change in opinion was made by asking smart questions in a particular sequence. The present study argues that a systematic approach to enquiry can facilitate in-depth reflection and lead to an autonomous learner that can make sense of the way old beliefs interfere with new theories and that is able to make the right decisions for changing professional practice.

\section{Conclusions:}

Being able to develop the capacity to be reflective and analyse, understand and adapt easily to new conditions has implications at systemic level, as it can enable a work force in education that shows readiness for change. At the same time there is required a new curriculum approach within the training programmes. This research applied a method used previously in the business field to teacher education. If developed appropriately, it could become a relevant learning method for continuous teacher education. 
Keywords:

reflection, systematic enquiry, continuous education, professional development

Arts-based pedagogy as a means of fostering creative and critical thinking

Dr Briege Casey

School of Nursing, Dublin City University, Dublin Ireland

\section{Problem Statement:}

For students in contemporary nurse education, learning is a complex yet taken-for-granted process. Student nurses are encouraged to adopt traditional, unquestioned perspectives and practices while simultaneously encountering and engaging with the multiplicity of cognitive and emotional stimuli inherent in modern day nursing contexts. Thus, students need to be able to think creatively and critically and to develop more pluralistic ways of noticing, interpreting and understanding their dynamic environments. Many researchers claim that arts-based approaches in education offer ways of calling forth inner creative forces and developing possibilities for new or different ways constructing experience and knowledge.

\section{Purpose of Study:}

To examine the processes, methods and experiences of using arts-based inquiry among a group of twenty second year undergraduate students as they participated in a Nursing Humanities option module. To evaluate the capacities of arts-based inquiry as a transformative pedagogy, as a means of exploring and dialoguing complex experiences and perceptions and as a method of fostering creative and critical thinking.

\section{Research Methods:}

The ethnographic study involved participant observation while working with students in the role of facilitator. Arts-based approaches included creative writing, art-marking, dance and drama. The capacities of arts-based approaches to foster creative and critical thinking were explored through analysis of student artwork/artmaking processes, contextual discussions and researcher fieldnotes.

\section{Findings:}

My work with these students has deepened my appreciation that learning is a multi-dimensional process and that facilitating humanities study/arts-based inquiry among student nurses challenges habituated positions of both teachers and students. Inquiry and knowledge development seemed to occur among the students through three arts-inspired processes, namely:

- Re-enactment of lived experience through the creation of artwork

- Contemplation/ representation of health care issues through art-making

- Interrogating and responding to created art (own and others)

\section{Conclusions:}

Arts-based approaches evoke and invite engagement with both the particular and the universal in pluralistic, non doctrinal and collaborative ways. Pedagogical practices that model and encourage this plurality have the potential to widen personal and professional boundaries concerning conceptions of knowledge and learning and to foster confidence in asking different and interesting questions. 


\section{RELIGIUS THERAPY AS ONE OF AN ALTERNATIVE WAYS IN GETTING EDUCATIONAL BETTERMENT FOR CHILDREN WITH AUTISM SPECTRUM DISORDER (ASD)}

Husni Fithri, Ahmad Dahlan University, Indonesia

Data from Autism and Developmental Disabilities Monitoring (ADDM) Network in multiple communities throughout the U.S. in 2006 shows an average of 1 in 110 children have an autism spectrum disorder (ASD). Moreover Yayasan Autisme Indonesia (YAI) stated that there is an increasing number of children with ASD in Indonesia based on the data from doctor's medical check up.

This condition requires a big concern mainly in the topic of educational system for children with ASD. Some cases in Indonesia show that children with ASD could not get a good educational service at school whereas education is important to make them develop well. This probably happens due to lack of human resources, facilities, and others. Scientists have already find a lot of therapies like speech therapy, music therapy, secretin therapy, and etc. Those therapies have its own lacks thus need to be complemented with others.

The purpose of this study examined whether Religius therapy could give an improvement behavior for children with ASD. Method of this study used ex post facto method in which the data are collected after the event happened. Researcher interviewed and observed students, teacher, parents, and other significant persons. Then researcher traced the time, found out the causes, the relation and got to know the meaning.

Researcher found that there were a lot of differences before and after the children got a treatment with religius therapy. Emotionally, children are more calm and easier to be controlled. It helps teacher and parents to start the class or give other therapies.

Religius therapy could be used in educational system for children with ASD. This therapy helps teacher and parents to controll the children.

Keywords: Religius Therapy, Education, ASD

Improving teaching practices to promote the integration of newcomers

Marie J. Myers, Queen's University, Canada

Problem Statement: In Canada, immigration is ever-increasing. To accommodate the very diverse student population change has to be fast paced. The Ministry of Education of Ontario undertakes constant reviews and implements new policies and guidelines through the publication and regular dissemination of documents based on province-wide 
consultations and specific research projects. As a follow-up to a project subsidized by the Ministry of Education (Myers, 2006) a number of documents were published to correct identified shortcomings and also implement suggested recommendations for change.

Purpose of Study: The purpose was to identify first, how the Myers' research report impacted future practice recommendations, second, the extent of the effectiveness of the recommended changes in the new documents for teaching practice as regards the newcomers as well as third, language accommodations made to support them.

Research Methods: For the first study needs analysis was used as a method to analyze data obtained through a questionnaire administered to all French speaking school councils in the province. Document and semiotic analyses of related subsequent publications by the Ministry of Education of Ontario (2009a, 2009b, 2009c, 2010a, 2010b and 2010c) were carried out to identify respective recommended changes in policy and practices following the results of the first study. Using contrastive analysis we compared the earlier recommendations and follow-up documents Findings: Findings include overall measures such as, relevant directions on admission policies, mandated welcoming and follow-through strategies; for teaching effectiveness, a more holistic approach to grammar teaching, modified teaching outcomes for newcomers, and pedagogical orientation and intervention around a cultural approach; language development guides include steps for the accommodation of newcomers as regards language expectations Conclusions: In conclusion, relevant information is provided throughout, with in addition, a stand alone document listing adaptations for teaching contents in a special support course, the lack of which had been identified by Myers as being the biggest gap in support offered by the Ministry. The implementations of such measures will not only place French speaking newcomers at par with their English speaking counterparts, but the thoughtfulness evident in all the recent documents might explain the slight increase in French school pupils compared to a decrease in English school numbers.

\author{
AN INVESTIGATION OF THE ROLE OF INSTRUCTION IN SECOND LANGUAGE PRODUCTION: A CASE OF $3^{\text {RD }}$ PERSON \\ SINGULAR -S \\ AmirAli Mohammadkhani \\ Samaneh Eslamdoost \\ Sepide Gholamreza'i \\ ALLAME TABATABAI UNIVERSITY
}

Problem Statement:

It has been observed that many learners are taught the third person singular $-s$ in very low levels of learning English. However, they usually do not use it correctly even when they achieve high levels of proficiency. Some researchers (Pienemann 1998, 2003; Pica 1983) claim that some forms are acquired later than some other forms. They have shown that a definite accuracy order exists in learning forms and that this order remains more or less the 
same no matter what first language learners speak. Based on their ideas, learners irrespective of being instructed or not, cannot use third person -s until they pass a series of levels.

A good explanation for these ideas could be the claim made by Pienemann $(1998,2003)$ about processing constraints and the claim by Pica (1983) that if the structure is formally simple and expresses a form-function relationship that is uncomplicated instruction may lead to improved accuracy. If the structure's form lacks complexity and it is salient but is functionally complex instruction may help learners to learn the form but learners end up making a lot of errors because they do not know how to use it. If a structure is functionally very complex instruction has no effect at all.

Purpose of Study:

Based on these claims the researchers in this study want to investigate the systematicities and regularities on the use of $3^{\text {rd }}$ person -s by learners in different proficiency levels in order to find experimental support for the claim that if a form is not salient and functionally complex the instruction will have no impact on the emergence of this morpheme.

In order to find the support for this claim, learners from three different proficiency levels were given a writing task and a grammaticality judgment task in order to find the accuracy of their use of this morpheme and their proficiency level.

Research Methods:

For the purpose of this study, researchers chose Pallotti's (2007) emergence criterion. The participants of this study were 151 male and female students studying English as a foreign language. 45 of them (male and female, intermediate level), studying in Urmia, took part in the preparatory part of the study. The remaining 106 students were the main participants of the study, studying English at Marefat and Shokuh Language Institutes.

The proficiency level of main participants ranged from elementary to advance (50 female elementary students, 47 male and female intermediate students, and 9 male and female advanced students).

At the first stage of the study all participants were asked to complete a free writing task, describing a typical day of one of their family members. A grammaticality judgment task was also designed and used in this study.

In the first phase of the study, learners in Urmia were asked to complete a writing task. The purpose of such writing was to detect the most frequently made mistakes by students. Based on these errors the grammatical judgment task was designed and administered to the main participants.

In the next step, the main participants were also asked to complete the same task whose aim was to identify the productive aspect of their interlanguage. They also completed the grammaticality judgment task which was assumed to be representative of receptive aspect of their interlanguage. The data gathered by these two tasks were analyzed and the results are reported.

Findings:

The results showed that Elementary learners had an average accuracy level of $51 \%$ in writing task and $48 \%$ in GJT. Intermediate students' average accuracy level was $73 \%$ in writing task and it was $78 \%$ in GJT. Advanced students showed $96 \%$ of average accuracy in writing task and 98\% in GJT. Analysis of data showed that elementary learners are less developed in their interlanguage and are in lower levels of development based on Processability theory $(1998,2003)$. Advanced and intermediate learners are in fact in higher levels of processing capacity and can provide grammatical structures systematically.

Conclusions:

The study concludes that learners in higher levels are more accurate in the productive use and also recognition of structures since they have a more developed interlanguage system. These findings and interpretations clearly show that instruction does not have a significant impact on the order of acquisition and learners use of their language. And as it is mentioned in processability theory and multidimensional model learners are only able to provide the grammatical structures if they are at the right level of interlanguage development $(1998,2003)$. 


\title{
The neglected aspects of test method: Channels of input and expected response
}

\author{
Mohsen Ghaffari \\ Samaneh Eslamdoost \\ Ali Asghar Ghasemi
}

Allameh Tabataba'i University

Problem Statement:

Different authors worked on the effect of facets of test method proposed by Bachman (1990). What seems to have been neglected in the literature is the effect of channels, written vs. spoken, of input and expected response on the test performance of language learners.

\section{Purpose of Study:}

This study was an attempt to investigate the possible effect of different channels on test performance of young language learners.

\section{Research Methods:}

29 Iranian learners of English as foreign language (EFL) participated in this study. The participants were all female, and their average age was 10 . Four tests, developed by the author, were administered to the participants with a one-day interval. What distinguished these tests from one another was the variation in channels of their input and expected response. The learners were interviewed after all the tests were administered to see which test they preferred and why. The analysis of variance (ANOVA) and the Scheffe Test were used to help the author with statistics.

\section{Findings:}

As the results reveal, participants performed the best when the channel of both the input and the expected response was oral (aural). One of the reasons for this outperformance can be, as the participants themselves said, that this test was like their ordinary classroom activity and they were familiar with it. 
This study was an attemp to shed light on the effectiveness of considering the channels of input and expected response on the test performance of young Iranian learners of English as a foreign language (EFL). As the results indicate, the participants performed much better on the test whose channels of input and expected response were oral. Similar studies should be done, on adults and with extended discourse, in order to be able to generalize the findings of this study.

\section{Keywords:}

Young learners, Test method, Channel, Input, Expected response

Integration or separation? Explore the nature of creativity through creative writing from elementary school students in Taiwan

Tsai-Ling Chu

National Taiwan Normal University
Wei-Wen Lin

National Taipei University of Education

Abstract

Although many creative thinking tests have seen creativity as integration of fluency, flexibility, and originality, the nature of creativity still have left a lot of unsolved questions. The most important one have been that whether we can combine different mental ability to represent individual's creativity. Thus, the paramount aim in this study was to unveil whether creativity is integrative or separate ability. In our study, 37 elementary school students had finished Imagination Test which involved two verbal activities and a creative composition, and then consensual assessment was conducted by two raters. In Imagination Test, there were three norm-referenced indices which were rated, respectively, fluency, flexibility, and originality, and five criterion-referenced indices also scored. Indices of consensual assessment were creativeness of product and quality of product. The main results indicated that individual's creativity on creative composition correlated positively and significantly with originality in Imagination Test, and it was also found to positively correlated with humour -concept's uniqueness. Besides, other indices had low or no correlation with scores of consensual assessment. To conclude, our study primary validated that creativity include separate components, rather than an integration of different indexes. Some suggestions and discussions were proposed for future study and assessment of creativity.

Keywords: creativity, consensual assessment, Imagination Test 


\title{
Exploration on the Correlation between Cognitive Load and Performances of Reading Comprehension according to the
}

Influence of Arrangements of Contents of the Social Studies Textbook for Sixth-grade students in Taiwan

\author{
Tsai-Wen, Lin National Taiwan Normal University
}

Textbooks are essential for both teachers' instruction and students' efficient learning; on the other hand, more and more researches concerning textbooks has been made with the perspectives of cognitive psychology. Hence, the arrangements of textbooks could be qualified for students' learning. The main purpose of this study aims to explore how students' cognitive load and reading comprehension are affected by the arrangements of contents of the social studies textbook, particularly with reference to cognitive load theory. Based on the consequences of this study, concrete and beneficial suggestions for both arrangements of textbooks and further studies can be developed in the foreseeable future.

The method of this study was quasi-experimental study with a" post-test of experimental group and control group". The subjects of this research were 357 sixth-grade students from the elementary school in Kaohsiung. Chinese Achievement Test for Junior High and Elementary School Students", "Adaptation (I)", and "Adaptation(II)" were manipulated as the instruments for this study.

The results of this study were proposed as follows. Students' cognitive load as well as their performances of reading comprehension were affected by different arrangements of contents with different levels of inner element interactivities. Furthermore, via the addition of the appendixes of effective reading resources, students' cognitive load was decreased, but with the increase of reading comprehension, when they reading. Hence, suggestions of the arrangement for social textbooks could be contended based on the discoveries of the study.

Keywords:

cognitive load, reading comprehension, social studies textbook, arrangements of contents of the textbook, element interactivity 


\title{
Problem Statement:
}

Motivation and attitude have been widely accepted by both teachers and researchers as key factors that influence the rate and success of second/foreign (L2) learning. They provide the primary impetus to initiate learning the L2 and later the driving force to sustain the long and often tedious learning process; indeed all the other factors involved in L2 acquisition presuppose motivation and attitude to some extent. Without sufficient motivation and good attitude, even the individuals with the most remarkable abilities cannot accomplish long-term goals, and neither are appropriate curricula and good teaching enough on their own to ensure student achievement. So lack of attention to these factors can lead to inefficiencies in learning L2. The research question lying behind this study is: Is there any effective and efficient relationship between language learning and motivation and attitude?

\section{Purpose of Study:}

This article intends to achieve a main purpose: to provide an overview of recent advances in research on motivation and attitude to learn a foreign or second language (L2). The paper illustrates that through raising the consciousness of the teachers toward the importance of motivation and attitude in language learning and teaching we can enhance the language learning abilities of the students- it provides some implications for better language learning.

Research Methods:

In this paper authors have concentrated on descriptive and analytical approaches in order to clarify the role of attitude and motivation in language learning - which are deeply rooted in Educational Psychology. For doing this, authors have focused on relevant webs, books, journals research papers, etc.

Findings:

In this paper, authors have achieved practical and tangible findings and some of them include: 1 . There is a direct relationship between language learning and motivation and attitude. 2. Appropriate changes in teaching methods, teaching strategies, class courses, and learning strategies can positively motivate students. 3 . Designing and implementation of various techniques can change students attitude positively toward L2 learning. And there are some other findings that are mentioned in paper.

Conclusions:

Motivation and attitude, seminal issues in Educational Psychology, play important role in foreign and second language (L2) learning. Systematic and academic application of "motivation and attitude" issues in language learning classes is very important and can make language courses more interesting and motivate students to embrace the language readily while studying the courses.

\section{Keywords: Motivation, Attitude and Language Learning}

\author{
A Study of the relationship between senior line and staff managers' development in Ministry of Education and \\ organizational effectiveness in the Educational System of Iran \\ Dr.Gholamreza Rahimi \\ Islamic Azad University of Kalybar, I.R.of IRAN
}

\section{Dr. Majid Vahedi}

Payame Noor University, 19395-4697 Tehran, I.R.of IRAN

Problem Statement: Educational organization, as the greatest administrative system of the country, is one of the organizations that is experiencing sudden changes and needs to adjust itself to the great stream of the changes. During the 21st century, some organizations will emerge that will know how to promote management potentials to improve the administration system continually (Hajipoor, 2002; p. 44).Therefore, a study of the development of the managers as Jonson 
and Vander (2004) state provides the educational opportunities for managers to improve their own potential abilities and instruct the staff for it in the further varying conditions.

Purpose of Study:

The purpose of this research is to investigate the relationship between the top executives in different provinces and the managers' development of Education Ministry with the effectiveness of educational organizations

Research Methods:

The present research describes the phenomenons under investigation, it is a descriptive research. The sample includes 70 participants that 30 of them are the top executives of all provinces and 40 are the executives of the Education Ministry. Due to the limited number of participants, no sampling was carried out. Among all top executives of the provinces and the managers of education ministry, i.e. $\mathrm{N}=70$, only 34 of them filled the questionnaires completely, 17 of top executives \& 17 the ministry managers. In fact, the data was given to the computer based on the 34 questionnaires and were used as the based for statistical and managerial analysis.

Findings: the findings of the regression can be summarized as follow:

Pearson's correlation coefficient showed no significant relationship between knowledge, skill and ability and organizational effectiveness. While correlation coefficient of Pearson and the linear relationship with multiple regression relationship showed a signification relationship between the 3 variables; the t-test findings showed no significant differences between the view points of the managers out of the ministry and those of ministry about the dimensions and factors of development of the managers. However, theory shows the fact that these 3 variables showed a close relationship with philosophical mentality of the managers and the philosophical mentality had a direct relationship with organizational effectiveness.

Conclusions:

1- Instructing management knowledge increases skills and abilities of the managers.2- Great emphasis must be put on communicative management knowledge and decision- making to increase management skills.3- Great emphasis must be put on human knowledge and decision- making to increase management skills.4- The presence of decision- making knowledge among dichotomies of the discussion emphasizes the managers' development in education system. Considering these points helps us to design a successful education system and managers' development.

Keywords: Managers Development, Managers' ability, managers' skills, managers' knowledge, organizational effectiveness.

Causal relationship between sexual reality and experiences: A two-wave panel study of Japanese high school students Megumi KASHIBUCHI ${ }^{1}$, Reiko ANDO ${ }^{2}$, Kanae SUZUKI $I^{1}$, Rui KATSURA ${ }^{3}$, Ayuchi KUMAZAKI ${ }^{3}$, Akira SAKAMOTO ${ }^{3}$, 1 University of Tsukuba 2 Kinjo University 2 Ochanomizu University

Problem Statement: Kashibuchi et al. (2010) has shown that Japanese adolescents underestimate first sexual intercourse average age and overestimate sexual intercourse experience rate (\%) of their peers. Perceived sexual reality, which is shown as those estimates, can induce adolescents to accept and to motivate sexual activities at a young age, and then it could promote their own sexual experiences. On the other hand, according to the idea of a false consensus effect (Ross, Greene, \& House, 1977) which is the tendency to estimate one's own attitudes and behaviors as common, it is thought that the adolescents perceive their peers' active sexual experiences by having own sexual experience. Thus, there could be effects of both sexual reality on experiences and sexual experiences on reality. But few studies have examined the causal relationship between them.

Purpose of Study: This study examined the causal relationship between adolescents' sexual reality and experiences by a two-wave panel study.

Research Methods: A two-wave panel study was conducted of 892 Japanese high school students (349 male and 543 female) at half-year intervals. The participants were asked to estimate first sexual intercourse average age (years old) and sexual intercourse experience rate (\%) of their male or female peers. They were also asked whether they had ever had any experiences of their date, kiss, petting and sexual intercourse (with/without condoms).

Findings: The false consensus effect was confirmed in both male and female participants, and the effect was larger in estimates of the same-sex peers than of the opposite-sex. In contrast, the effect of sexual reality on experiences was 
confirmed consistently only in female participants. Sexual reality may not directly influence their own sexual experiences among male participants.

Conclusions: This study suggested that sexual experiences could have the effects on sexual reality, and that sexual reality could have the effects on sexual experiences in female adolescents.

Keywords: a false consensus effect, rate estimation, peer pressure, social norms, gender differences

Recipient's responses in daily counselling and helping situation Mieko Takahira (Chubu University)

Problem Statement:

In daily life, people sometime consult professionals such as physicians, counsellors, teachers, and lawyers about their troubles or worries. In many case, people consult non-professionals such as their friends. But, there are fewer studies of non-professional recipient's responses than professional ones. In particular, it is necessary to investigate recipient's responses when they are consulted on serious troubles or worries.

Purpose of Study:

How do people respond when their close friend consulted about serious troubles or worries? The primary aim of this study was to investigate non-professional recipient's affects, cognitions, and behaviours in daily counselling and helping situation.

Research Methods:

One hundred and eighty undergraduates (88 men, and 92 women) were showed the story that their close friend consulted them about serious troubles in daily situation. They read the story and answered a following questionnaire. Data were analysed by structural equation modelling.

Findings:

The results indicated that irritation decrease active listening and remarks aimed at solving the problem. Helplessness decrease remarks aimed at solving the problem and affirmation. Pleasure led to active listening, remarks aimed at solving the problem, and affirmation. Anxiety led to active listening and cheer. Sadness led to cheer and affirmation.

Conclusions:

When non-professional people were consulted serious troubles, both negative and positive affects were evoked. Negative affects decreased active and future-oriented responses, and increase passive and temporary ones. Positive affects increased active and future-oriented responses. 


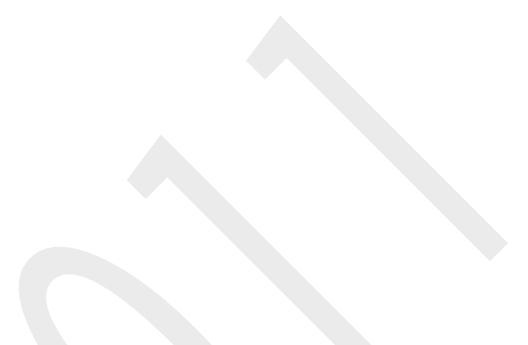

The effects of online etiquettes and ICT skills on school-bullying and cyber-bullying: The two-wave panel study of Japanese elementary, secondary, and high school students

Ayuchi KUMAZAKI ${ }^{1}$, Kanae SUZUKI ${ }^{2}$, Rui KATSURA ${ }^{1}$, AKira SAKAMOTO ${ }^{1}$, Megumi KASHIBUCHI ${ }^{2}$

1 Ochanomizu University 2 University of Tsukuba

Problem Statement: Recent years, as children's use of the Internet increases, there is occurring the cyber-bullying problem all around the world. But there have been few studies about the factors that restrain cyber-bullying. And most studies are correlation-based, so there are few studies examined causal relationships.

Purpose of Study: This study examined the causal relationship between cyber-bullying and the two factors that were expected to influence cyber-bullying by a two-wave panel study. The one was ICT skills, skills of making full use of media and Internet. Another one was online etiquette, understanding right from wrong about computer mediated communication (CMC). Furthermore, if ICT skills had negative effects on cyber-bullying, we examined whether online etiquettes would have reduce that effect.

Research Methods: We conducted a two-wave panel questionnaire survey on Japanese 885 elementary students (11 years old and in the 5th grade at the first time), 2,407 secondary school students (13 years old and in the 7th grade at the first time), and 1,016 high school students (16 years old and in the 10th grade at the first time). We asked them about ICT skills; online etiquettes, cyber-bullying and bullying experiences. ICT skills are how well the one can make use of media and Internet. Online etiquettes are to judge the how wrong the CMC actions are. Cyber-bullying and bullying experiences are whether cyber-bullied (and bullied) or not someone who was in the same school in a month.

Findings: Having proficient ICT skills significantly increased cyber-bullying in junior high school students. Having good online etiquette did not significantly affect on cyber-bullying, but in elementary and secondary school students, it significantly decreased bullying. We also examined whether having good online etiquette moderates the effects of ICT skills on cyber-bullying. We found the interaction effect only in male secondary school students. For boys in secondary school, having a good online etiquette diminished the negative effects of ICT skills.

Conclusions: This study suggested that it is important to develop understanding right from wrong to prevent bullying and cyber-bullying.

Keywords:cyber-bullying, school-bullying, online etiquettes, ICT skills, 2 wave panel survey 


\section{The Importance of Level of Consciousness and Mindfulness Training in Predicting Problem Solving Ability} Dr. Jules A. Troyer, Valdosta State University. Valdosta, GA

Problem Statement: Intelligence and motivation are not the only predictors of good problem solving ability. This study analyzed the effectiveness of mindfulness training on problem solving ability and the ability of the Troyer Level of Consciousness Inventory to predict problem solving ability in undergraduate university students.

Purpose of Study: This study analyzed the effectiveness of mindfulness training on problem solving ability and the ability of the Troyer Level of Consciousness Inventory to predict problem solving ability in undergraduate university students.

Research Methods: First, participants in both the treatment and control groups completed a short demographics questionnaire. Second, both the treatment group and control group participants took the 23 item Troyer Level of Consciousness Inventory (TLOCI). The TLOCI has already been focus group tested at Northern Arizona University in Fall 2007, validated in a large scale national study, and cleared through the Delta State IRB. The entire survey took approximately 10-25 minutes to complete. Third, a baseline measure of problem solving ability was taken from both the control and treatment groups. Participants completed problems in multiple problem solving categories. Fourth, participants from the treatment group were taught a simple 10 minute mindfulness training exercise, involving focused meditation on breath and body relaxation.

Findings: The results of this research indicated statistical significance in the effectiveness of minfulness training to improve problem solving ability in a diverse set of problems in undergraduate students. Additionally, the Troyer Level of Consciousness Inventory was revealed to have strong predictive ability for high and low level problem solvers..

Conclusions: This experiment assists in substantiating the connection between consciousness level and ability to solve diverse problems and the effectiveness of mindfulness training as an educational intervention to improve problem solving in undergraduate university students. 
The factors influencing class teacher students`evaluations relating to the quality of initial teacher education in Tallinn University

Anne Uusen (PhD, Associated Professor)

Tallinn University

Institute of Educational Sciences

Department of Primary Education

Estonia

Problem Statement: Over the past few decades Estonian society has been facing social, cultural, economic and technological changes and challenges. Education and teaching are the key-elements in the light of understanding and coping with the changes in the society. Therefore the professionalism of teachers and the high quality teacher education are the most highlighted issues in discussions connected with educational reform in Estonia. Due to the many new and rapidly changing tasks and roles teachers are expected to fulfill, substantial improvements and reforms of teacher education are seen as imperative.

Purpose of Study: Fostering the dialogue between all the parties involved in teacher education and its reform, it's important to know, how student teachers themselves evaluate the initial teacher education. The current presentation introduces the results of a research the aim of which was to get information about student teachers' opinions about the quality of initial class teacher education in the Tallinn University in order to overlook the class teacher curriculum.

Research Methods: The qualitative research method in the form of free writing was used for getting empirical research data. The main questions that researcher-teacher trainer wanted to get answer to, were: which factors influence student class teachers' opinions towards quality of their education the most? What are they or are not satisfied with?

Findings: More than half of the students said that one of the indicators of quality of teacher education is the lectures' professionalism. Next frequent issues named in the students' writings were connected with general and didactic subjects. Almost all the statements about didactic subjects expressed satisfaction. Statements connected with general subject mostly expressed dissatisfaction. The percentage of students satisfied with more general subject is connected with the year of studies.

Conclusions: The results of the research showed that the most visible factor of evaluating the quality of education seems to be lecturers' professionalism, devotion, communication skills and attractiveness. The next important aspect is the amount and the place of practical subjects and the balance between didactic and general subjects. It seems to be necessary to re-look the class teacher curricula and initial teacher education from this viewpoint.

Keywords:

Initial teacher education, quality of initial teacher education, indicators of the quality of education

\section{VALORIZATION OF THE NURSE TUTOR CHARACTERISTICS': ENHANCING THE TEACHING LEARNING PROCESS Sandra Sílvia Silva Monteiro Santos Cruz, Escola Superior de Enfermagem do Porto - Portugal}

Problem Statement: In the existing literature, we find studies which related clinical supervision and training in nursing. Jerlock \& Falk \& Severinsson (2003) refer that the clinical supervision aims to influence positively the process of student learning, it can support the students decision making' in the clinical practice. Holm \& Lantz \& Severinsson (1998) suggest that there is an association between the group supervision effects and development of the 
professional identity by the nursing students. The figure of the nurse tutor is so relevant in the teaching learning process that we decided to carry out a study that took the following problem as a core: What are the nurse tutor caractheristics' that enhance the teaching learning process?

Purpose of Study: The aim of this study was to identify the valorization of the characteritics of the student nurse tutor with the use of the Clinical Instructor Ranking Scale (CICRS) by Rauen (1974) and translated into Portuguese by Antunes (1998).

Research Methods: This study is placed within the paradigm of quantitative research. Content analysis has been used with the purpose to know the participants' opinion about the trainning that the nurse tutor should have to perform. This research was made in several health care institutions in the metropolitan area of Oporto - Portugal. 513 filled out questionnaires were obtained from nurse students, nursing teachers and nurses.

Findings: We pointed out differences of opinion among the groups and inside each group about the valorization of the nurse tutors characteristics'.

Conclusions: Specific trainning such as attending clinical supervision courses must be a part of the personal curriculum of the nurse tutor. It is necessary to celebrate institucional written agreement between nursing schools and health institutions in which, key aspects must be stated in the document constructed by both.

\section{Keywords: Nurse Tutor, Valorization of Characteristics, Clinical Supervision}

\section{References:}

- ANTUNES, M. (1998). Será a representação do enfermeiro docente ideal semelhante para docentes e para alunos?. Dissertação apresentada à Escola Superior de Enfermagem Maria Fernanda Resende no âmbito do Curso de Pedagogia Aplicada à Enfermagem. Lisboa. S.Ed.

口 JERLOCK, M; FALK, K; SEVERINSSON, E. (2003). Academic nursing education guidelines: tool for bridging the gap between theory, research and practice. Nursing and Health Sciences, 5, $219-228$.

- RAUEN, K. (1974). The clinical instructor as a role model. Journal of Nursing Education, 3, 33-40.

- JERLOCK, M; FALK, K; SEVERINSSON, E. (2003). Academic nursing education guidelines: tool for bridging the gap between theory, research and practice. Nursing and Health Sciences, 5, 219-228.

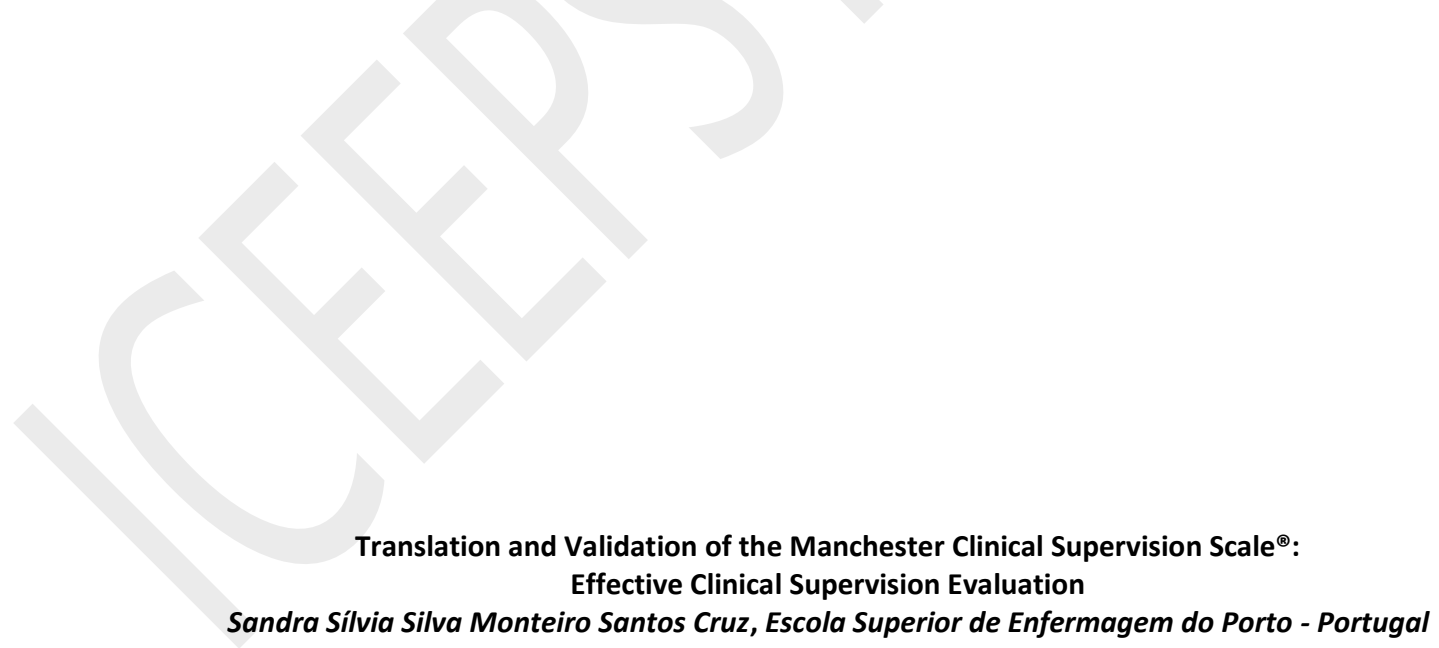

Problem Statement: The relevance of the nurses' decisions as far as their patients are concerned is so huge that ignoring/hiding the positive clinical supervision effects is a serious mistake that cannot be made. In Portugal as we are at the beggining of clinical supervision we don't have any instrument to assess the process of clinical supervision.

Purpose of Study: We carried out a research which the aim was to translate and validate the Manchester Clinical Supervision Scale ${ }^{\circledR}$ (MCSS) into Portuguese. It comprises 7 sub - scales: Trust/rapport, supervisor advice/support; improved care/skills, importance/value of clinical supervision, finding time, personal issues and reflection. 
Research Methods: The translation process was conducted by applying the methods of translation and back translation.The translations were compared and analysed by three experts in clinical supervision in nursing ( 2 Coordinators of the Post Graduation in Clinical Supervision in Nursing at the Escola Superior de Enfermagem do Porto (Oporto Nursing College), and the Coordinator of the College Research Unit, who is an invited professor of several International Universities with several publications on clinical supervision and member of the scientific committee of the doctoral program at the Lisbon University. The MCSS $^{\circledR}$ and the back translation were compared by the research, the experts, the translator and by the author of the Scale. An empirical study using a test - retest design was made to estimate cross cultural relevance. The study was placed within the paradigme of quantitative research and grew in 21 care units at the Matosinhos Local Health Unit between July - August 2008. A paired sample with 230 filled out questionnaires were obtained. We used the Statistical Package for Social Sciences ${ }^{\circledR}$ program version 17.0 for data analysis.

Findings: Cronbach's alpha value for the total score was 0,923 in both periods and in the sub-scales at the first time was 0,413 (personal issues) - 0,893 (supervisor advice/support), and in the second time was 0,453 (personal issues) 0,910 (supervisor advice/support).

Conclusions: The Portuguese version of the $\mathrm{MCSS}^{\circledR}$ is culturally acceptable and consistent with the original. The Scale ${ }^{\circledR}$ evaluates effectivelly aspects of the clinical supervision process therefore supervisors and supervisees can adjust strategies to improve outcomes.

\section{Keywords: Manchester Clinical Supervision Scale ${ }^{\circledR}$ Translation; Validation}

\section{SUPERVISING SIGN LANGUAGE INTERPRETERS STUDENTS}

Cátia Marlene Silva Monteiro Santos, Universidade Lusófona do Porto - Portugal

Problem Statement: The challenge for the supervisor is to prepare the sign language interpreters students for flexibility and adaptability to demanding situations that will emerge in their life course. The concern about the quality of these students is the result of another concern felt; that is the quality of their supervisors who assist the students in their teaching - learning process.

Purpose of Study and Research Method: Through a literature review this paper aims to reflect on the supervisor profile of the sign language interpreters' students and to understand how he/she can improve and develop the student's knowledge and skills in sign language.

Findings: A lot of professionals recognizes that many of the interpreters do not dominate some of the issues that they have to interpret and that may create confusion in the broadcast content (Guarinello et al, 2008,). And it is also recognized that there is a considerable gap between thinking and acting, between theory and practice, especially when it comes to evaluate the students. School is still seen as "a battlefield where what counts is the classification, more than the know-how "(Perrenoud, 1999, p.120)

Conclusions: The sign language interpreter acts as a liaison between the deaf and the listener communities. Therefore the supervisor shall have qualifications, ethics, knowledge of deaf culture and performance in sign language, so he/she can break down communication barriers and be successful in the teaching-learning process (Souza e Boruchovitch, 2009). School programs must develop a significant set of skills enabling the student to be ready for professional 
practice. (Perrenoud, 1997) Therefore the evaluation's main target is the student transformation in several dimensions like the personal, professional, intellectual and social level.

Keywords:Supervisor; Sign language interpreter student; Profile.

References:

- Souza, N., \& Boruchovitch, E. (2009). Avaliação da aprendizagem e motivação para aprender: tramas e entrelaços na formação de professores. Educação Temática Digital. 10, 204-227.

- Guarinello, A., Santana, A., Figueiredo, L., \& Massi, G. (2008). O intérprete universitário da língua brasileira de sinais na cidade de Curitiba. Revista Brasileira de Educação Especial , pp. 63-74.

- Perrenoud, P. (1997) - Construire des compétences dès l'école. Paris. ESE

- Perrenoud, P (1999). Construir competências desde a escola. Porto Alegre: Artmed.

The Role of Topic Familiarity and Rhetorical Organization of Texts in L2 Incidental Vocabulary Acquisition Author: Babak Mahdavy Affiliation: Islamic Azad University, Qaemshahr branch

Problem Statement:

Theories of incidental learning suggest that much of human learning happens when individuals do not attend to what they learn. In L1 and L2 learning literature the role of different factors contributing to this type of learning has been discussed (e.g. Pulido, 2004a). However, although both topic familiarity and rhetorical organization of texts contribute to text comprehensibility, the role of these two factors and their combined effects have not been investigated.

Purpose of Study:

The present study aims to show the extent to which the competition between meaning and form of texts contribute to the incidental acquisition of new words.

\section{Research Methods:}

The participants included 64 intermediate EFL learners who were divided into four different groups. Each group was assigned to read either the rhetorically organized or disorganized version of a narrative with a familiar content or a similar narrative with an unfamiliar content. The texts consisted of approximately the same number of clauses (3537) and T-Units (18-23). The two versions of the narratives contained around 255 words. As learners were reading the texts for meaning, they chose the correct meaning of the four new words. Each of the new words was glossed in the learners' mother tongue and appeared twice in the narratives. Decision on the number of the new words was made on the basis of the results of previous studies. They indicated optimal density for inferring the meaning of new words is two to five new words in 100 words. And two exposures have been shown to be enough for prompt but measureable gains in vocabulary knowledge (e.g. Liu and Nation, 1985; Rott, 1999). After the learners read the texts, their acquired knowledge of the four new words was measured using an unexpected Wesche and Paribakht's (1996) Vocabulary Knowledge Scale (VKS). 
Findings:

Results of ANOVA and Tukey HSD test showed that topic familiarity in the first place and then rhetorical organization are related to the incidental acquisition of new words.

\section{Conclusions:}

Therefore, it can be concluded that content familiarity plays a more important role in the meaning-making process needed for the incidental acquisition of new vocabulary. Implications of the findings will be discussed.

\section{Keywords:}

Incidental vocabulary acquisition, topic familiarity, rhetorical organization, Vocabulary Knowledge Scale (VKS)

Metacognition education and moral reasoning : a case report of high school girls in Iran

The majority of metacognition education studies in Iran are focused on academic achievement (Ebrahimi ghavam 1998). As result the effects of this education on the promotion of moral reasoning and ethical behavior is not fully understood. Regarding the finding of Swanson and hill (1993) stemming on this hint that the people who have learned more strategies in various features, including moral activities and have saved these matters in their long term memory, are more probable of using knowledge in their own moral reasoning functions. The present study is to investigate the relationship between these two variables.

Aims: Determining the effects of metacognitive education, moral reasoning and behavior in first grade high school girls. Methodology: The design of study is based on a two group experimental study with pre-test and post-test The sample population was consisted of 32 first grade randomly selected high school girls. Which of them consisted the case group and the other 16 students were in control group. The mean age was 15 year \pm 4 months. The survey tools were 3 sets of questionnaires of metaconitive knowledge (Swanson and Hill1993), ethical behavior rating scale and moral reasoning .The intervention plan consisted of 8 ninety minutes sessions. The data analyses methods was variance analysis.

Results :Metacognition education in both moral reasoning and metacognitive knowledge (person- task - strategy) showed a significant difference between two groups. But in the case of ethical behavior, although a significant difference was not obtained between two groups, a significant difference between pre-test and post-test was observed in the experiment group.

Conclusions: metacognition education was found to be effective in development of metaconitive knowledge and its related variables(person-task-strategy) and also reasoning. In order to obtain better results, it is suggested that a longer period of educational sessions be used and also the contents of the educational materials should be revised so that more reliable outcomes would be achieved.

Key words: metaconitive knowledge, ethical behavior, metacognition education 
Factors Affecting Accounting Students' Performance : The Case of Students at the Islamic Azad University

\author{
Mansour Garkaz \\ Accounting dept; Islamic Azad UniversityBahman banimahad \\ Accounting dept; Islamic Azad University
}

Hadis smaili

Every year number of accounting students are disqualified so they leave the course or their studies cold not finished timely. Decreased academic performance of students from satisfactory level to unsatisfactory levels is an important problem is the educational system. With the wastage in current cost, frustration and loss of confidence in learners, prevent the blossoming of talents and abilities of individual, create large losses to students its family, the university and the community.

This study aims to consider whether there is a significant relationship between individual factors such as gender, interest in the desired degree, diploma type, marital status, employment status, family role in course selection and academic performance are accounting students?

Quantitative research methods, through research and from the survey questionnaire, the study population included 5070 students of bachelor degree in accounting, Islamic Azad University in Tehran has been the academic year 1389-90. 450 subjects using stratified random sampling were selected according to statistical community. Statistical methods used to analyze data independent $\mathbf{T}$ test was. The results show that academic achievement between men and women a significant level alpha 0.05 , there are significant differences.

So the average academic achievement has been more in women than men. Average academic achievement has been more in mathematics Diploma students in compare to non-math diploma students as well as average academic achievement has been more in unemployed students than employed students. Students interested in accounting also had better academic performance in compare to non interested students in accounting.

But between student employment and family roles in course selection and academic performance accounting students academic progress, significant level alpha 0.05 there is no significant difference.

Key word: Performance, gender, interest in the desired degree, diploma type, marital status, employment status

Learning Styles of Language Learners in an EFL Writing Class

Aranya Srijongjai

Department of Western Languages, Faculty of Humanities, Srinakharinwirot University, Thailand 
As EFL sholars have widely discussed how to manage a class to suit students' learning approaches, a number of studies have investigated learning styles and their influences on students' academic achievement. In the context of EFL writing, learning styles can be discussed as well. This paper presents results from a study of learnng styles of Thai English majors in an EFL writing class. The objectives of the study were to identify the learning styles of these students and to see whether there were significant differences of their learning styles based on their achievement levels in their English writing course. The participants of this study were 88 second-year English majors in the B.A. program at the Faculty of Humanities, Srinakharinwirot University in the 2009 academic year. The instruments used in the study were the Memletics Learning Styles Inventory and a semi-structured interview. The Cronbach's alpha reliability of the inventory was $\mathbf{0 . 7 5 2}$. The data were analyzed using means and one-way analysis of variance (ANOVA). From data analysis, the findings showed that the average primary and secondary learning styles of the students were social and verbal and there were no significant differences of the students' learning styles based on their achievement levels in the writing class.

Keywords: academic achievement, EFL writing, learning styles

The relationship between socio-demographic characteristics and the establishment of close relationships among university students

Claudia Balula Chaves - Study Center in Education, Technology and Health (CI\&DETS), Polytechnic Institute of Viseu, Portugal

João Carvalho Duarte - Study Center in Education, Technology and Health (CI\&DETS), Polytechnic Institute of Viseu, Portugal

Paula Baptista Nelas - Study Center in Education, Technology and Health (CI\&DETS), Polytechnic Institute of Viseu, Portugal

Emília Carvalho Coutinho - Study Center in Education, Technology and Health (CI\&DETS), Polytechnic Institute of Viseu, Portugal

Rui Tavares Dionisio - Public Health Unit of Dão-Lafões II, Portugal

Rosa Carvalho Martins - Study Center in Education, Technology and Health (CI\&DETS), Polytechnic Institute of Viseu, Portugal

Madalena Cunha - Study Center in Education, Technology and Health (CI\&DETS), Polytechnic Institute of Viseu, Portugal

Problem Statement: when transitioning from secondary education to university the student is confronted with various experiences such as establishing close relationships, becoming more autonomous from their family, managing time and money, disconnecting from pre-university relationships, as well as being exposed to broader social contact. The university student does not undergo significant physical changes as they do during their teens however, they do undergo social and emotional experiences.

Purpose of Study: Researching the association between the socio-demographic characteristics and the intimate relationships in a sample of university students.

Research Methods: A quantitative, descriptive and correlational study with a sample of 2001 students $(60.7 \%$ females, age $M=21.76 \pm 4.43$ ), from universities in the Northern and Central areas of Portugal. The protocol for gathering information includes the characterisation of the epidemiological profile and patterns of intimate relationships among students.

Findings: The dominant profile for the students was: young female, average age was 21.76, single, residing in an urban area, living with parents, a sibling and other family members, the majority of their parents only have the $4^{\text {th }}$ grade, their father is a blue collar worker and their mother is an unskilled worker. They practice a religion and are not employed. The majority are doing a degree in Nursing and Medicine; 7 in 10 students were in their first year. $60.5 \%$ had sexual intercourse in the previous month and $81.4 \%$ had already been sexually active. $80 \%$ of those who were sexually active were in monogamous relationships. As for the frequency of sexual intercourse within the past month, $40.5 \%$ reported having vaginal sex with only one partner; however what was alarming was that the percentage of those who never used a condom was $59.5 \%$.

Conclusions: The relationship between socio-demographic characteristics and the establishment of intimate relationships supports the creation of programmes that promote the prevention of starting or continuing to have unprotected sexual intercourse. 
Dialogue between generations, generativity, and ego integrity - results of intervention projects in post-soviet societies

\section{Problem Statement:}

Realization of generativity and ego integrity in old age does not simply reflect individual aspirations, resources and competences but also cultural demand and expectations, social roles, and intergenerational relationships. Long-term dominant ideologies and rapid social change can be hypothesized to exacerbate dealing successfully with these developmental tasks in post-soviet societies since members of older and younger generations may have particularly different perspectives on subjectively important aspects of history and society. In a cooperation between the Institute of Gerontology and the Foundation "Remembrance, Responsibility and Future" a total of 40 local projects in Belarus, Russia, and Ukraine have been implemented and continuously supported to stimulate and increase informal learning in dialogue between generations. 13 of these projects are evaluated in a longitudinal research design consisting of 4 measurement points during a period of 2 years.

\section{Purpose of Study:}

1.) Analysis of generativity and ego-integrity in a sample of 404 older people from Belarus, Russia, and Ukraine

2.) Analysis of generativity scores and perceptions of old age generativity in a sample of 194 younger people from the aforementioned countries

3.) Analysis of development of generativity and ego-integrity between the first three points of measurement

4.) Analysis of predictors of changes in generativity and ego integrity

\section{Research Methods:}

Semi-structured biographical interviews and psychometric scales for assessment of generativity (LGS, McAdams; SOCSubscale Meaningfulness, Antonovsky)

\section{Findings:}

Scores for generativity and meaningfulness improved, particularly in Ukraine, whereas in Belarus there were only marginal changes. Younger people perceived generativity in older people to be higher than generativity in their own generation. Socio-demographic variables (age, sex, marital status, parenthood) cannot explain for differences between countries. 
Conclusions:

Findings suggest that establishing dialogues between generations in the context of local projects is a promising measure to stimulate informal learning, to enhance generativity and ego integrity in older people and to improve perceptions of older people in younger generations.

Keywords: generativity; ego integrity; post soviet society; gerontology

\section{Designing learning environments in assembly lines through self-determination}

Alexandra Nukta, Daimler AG

Modern assembly lines in automotive industry have to deal with increasingly growing complexity of assembly tasks, tremendous speed and number of process changes as well as an exploding degree of product customization. Learning skills of assembly workers are foundation for developing their professional as well as social competences in such an environment. Learning skills of assembly workers are therefore key factor to successfully assure competitiveness of modern assembly line.

Factors that impact job satisfaction, organizational citizenship behaviour (OCB) and performance of blue collar workers were not yet investigated in detail. Up to date, research on “Lifelong Learning” and „Learning Organization“ lack empirical analysis of impacting factors to improve the effectiveness of learning environments. Showing influences of learning parameters on job satisfaction for blue collar workers would greatly support the future assembly process design.

This work shows a novel approach by using self-determination theory to specifically explore relations between basic psychological needs (short BPN) such as fulfilling competence, relatedness, autonomy and job satisfaction, performance and OCB of blue collar workers. Based on self-determination theory an industrial learning model was developed where BPN and external parameters for autonomy support and communication were considered. Furthermore, a field experiment was conducted in automotive industry. Modified learning environments addressed basic needs differently, so that their impact on job satisfaction, performance and OCB could be measured. The experiment also indicates that designing an industrial learning environment using BPN principles improves satisfaction, performance and OCB of blue collar workers.

\section{Keywords:}

Self Determination Theory, job satisfaction, blue collar, organizational citizenship behaviour, autonomy, work performance 


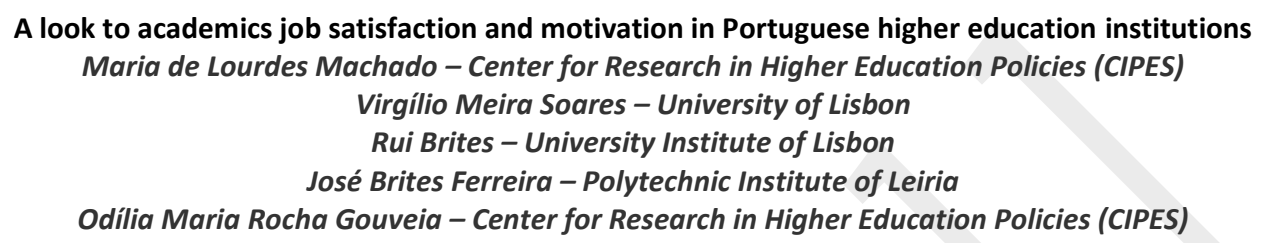

Problem Statement:

The academic staff is a key resource within higher education institutions and therefore it has a major role in achieving the objectives of the institution. Moreover the performance of academic staff determines much of the student success and has an impact on student learning. Thus, motivation and satisfaction of the academic staff is crucial for the academics 'performance and, consequently, for the quality of higher education institutions.

Purpose of Study:

We will present and discuss a study on academic satisfaction and motivation within the Portuguese higher education institutions - An Examination of Academic Job Satisfaction and Motivation in Portuguese Higher Education (PTDC/ESC/67784/2006), financed by the Foundation for Science and Technology. The main purpose of the research project is:

-To identify factors and their interactions affecting the dimensions associated with job satisfaction and motivation of academic staff.

Research Methods:

An eclectic quantitative and qualitative approach is being adopted for this project: 1) quantitative survey data gathering, 2) qualitative interview data gathering and 3) qualitative document examination.

The sample is all universe of faculty members including all sub-groups (professor, researcher, part-time, full-time, etc.), and institutional types of Portuguese higher education institutions (public-private, university-polytechnic, etc.).

Other findings will yield qualitative results relating to human resources management policies, practices and related factors affecting the development of careers.

Findings:

From a practical point of view, the findings from this project should heighten awareness, sensitivity and dialogue regarding the important issues that need to be addressed to promote and maintain job satisfaction and motivation within the ranks of the academic staff.

Conclusions:

A diverse range of information on multiple dimensions of the faculty job in higher education, in particular dimensions of satisfaction and motivation within academia will be presented. Moreover the results about academic satisfaction in Portuguese higher education institutions may have relevance to other countries. 
The relationship between personality traits and academic achievement in university of tehran's students

Soraya Hakimia , Elaheh Hejazia , Masoud Gholamali Lavasania

a Department of Educational Psychology \& Counseling, University of Tehran; Tehran, Iran

Problem Statement: as we know , education quality improvement and investment on human and aterial resources are effective factors in comprehensive development's countries. In the same way, academic achievement of students also is the basic objectives of teaching programs; and attention to learners's individual differences in academic achievement has great importance.These differences may be included spectrum of available; such as personality differences, cognitive differences and perceptual differences.

Purpose of Study: The current research studies the relation between personality traits with academic achievement among the students.

Research Methods: This research had been examined on 285 students at college of economics and college of management (including 191 female, 94 male). The NEO-Five Factor Inventory (NEO-FFI) (Paul T. Costa, Jr. and Robert R. McCrae., 1985) and average of scores's students had been applied for collecting data. Data collected from sophomores and juniors of the aforesaid colleges. Stepwise regression had been applied for study of the relations and predictive quantity of aforementioned variables, meanwhile for comparing males and females in research variables; Multivariate analysis of variance (MANOVA) and T-tests had been used.

Findings: Results of using stepwise regression showed that personality traits can predict $48 \%$ changes in academic achievement. The most powerful predictor in academic achievement is Conscientiousness that can predict $39 \%$ variance of educational development

Conclusions: Analysis of the results showed that personality traits (except "openness to experience" factor) are in direct / meaningful relation with academic achievement; and Conscientiousness is strongest personality traits to predict acadeic achievement. there is no meaningful discrepancy among personality traits, and academic achievement between two genders.

Keywords: personality traits- academic achievement

\author{
Mentoring - an useful tool for teacher training \\ Elena Seghedin, PhD, \\ Livia Ostafe, PhD student \\ Al.I.Cuza University, Iasi, Romania
}

Problem Statement: 
The continues training of teachers has been widely debated. What should teacher know today to convey the contents, to use appropriate methods, learning strategies? How can we find these things if not from the teachers themselves? This study suggests that professional development plans are useful because they bring real perception regarding the need for teacher training.

Starting from the idea that the professionalization of teaching is very important we wanted demonstrate that mentoring is a vital tool in the continuing education of teachers.

Purpose of Study:

The main purpose of this study was to demonstrate the need for internship mentoring new teachers' professional development. Another purpose of this study is that to motivate the need of a specific training for became a teacher mentor. We tried also to identify the training needs of students, beginners teachers, principals and mentor teachers.

Research Methods:

For the last ten years Al.I.Cuza university - in an educational partnership with EuroEd Foundation - has developed a strategic project for mentor training so we started an comparative study between the level of the perceptions about the need of training, recorded in different times and different categories of teachers. The methods we used were inquires based on surveys, Focus Group and individual interviews. It was a longitudinal study held for 10 years. The first investigation was conducted in 2001-2004, the second in 2007-2008, and the last one in March 2011. Categories of respondents: students, teachers, principals and mentor teachers.

Findings:

We identified the need for a training program on probation for mentors. For teaching career $69 \%$ in the group of subjects showed mentoring as the easiest and most effective form of support for the beginner. Also it was proved that beginning teachers have registered high scores on items that measure the interest in learning new teaching strategies.

Conclusions:

We highlighted the teacher's concerning over the practical aspects of teaching, the need for working class tools, techniques and resources to help teachers to understand their students and to establish best teaching and learning approaches. It was show also the opportunity for mentoring internship and also the need for specific skills training teachers.

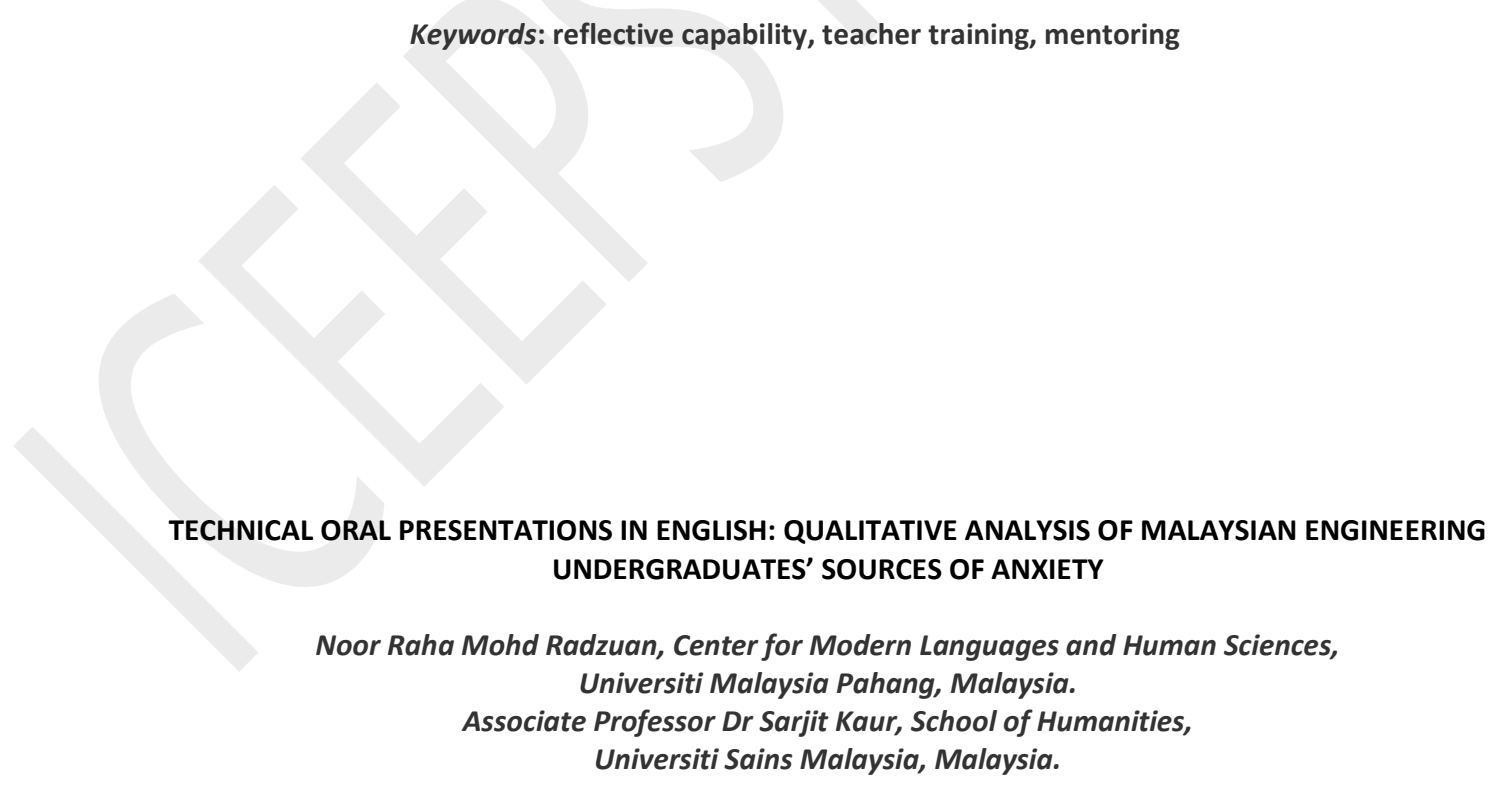

Technical oral presentations are an integral component of engineering courses, but it is no doubt an anxiety-inducing experience for most engineering students. This paper presents an in-depth qualitative analysis of the sources for anxiety experienced by engineering students in delivering Undergraduate Research Project (URP) oral presentations. The URP oral presentations which are required to be delivered in English are part of faculty graduation requirements. Utilizing a qualitative method of enquiry, focus group interviews were conducted with 6 groups of students, comprising 44 final year engineering students from the Faculty of Chemical and Natural Resources Engineering at Universiti Malaysia Pahang, Malaysia. The interviews were conducted after they had completed URP oral presentations in the $7^{\text {th }}$ semester of their course of study. The results of the study reveal several main sources of anxiety that exist among the students in delivering 
the presentations, namely demanding and provocative evaluation panels, limited technical knowledge and barriers in students' English language proficiency. The current findings add substantially to our understanding of contributory factors for anxiety feelings experienced by engineering students in delivering technical oral presentations in English. In addition, the findings have a number of important implications for future practice especially in the decision of the appropriate approach in managing anxiety in students' presentations towards enhancing their presentation performance. The implications of this study point to the fact that providing for effective technical oral presentations in academic settings is an integral task for students' preparation for future work-related tasks in their professional setting in today's globalised work environments.

Keywords: technical oral presentation; engineering; presentation anxiety; English as a second language

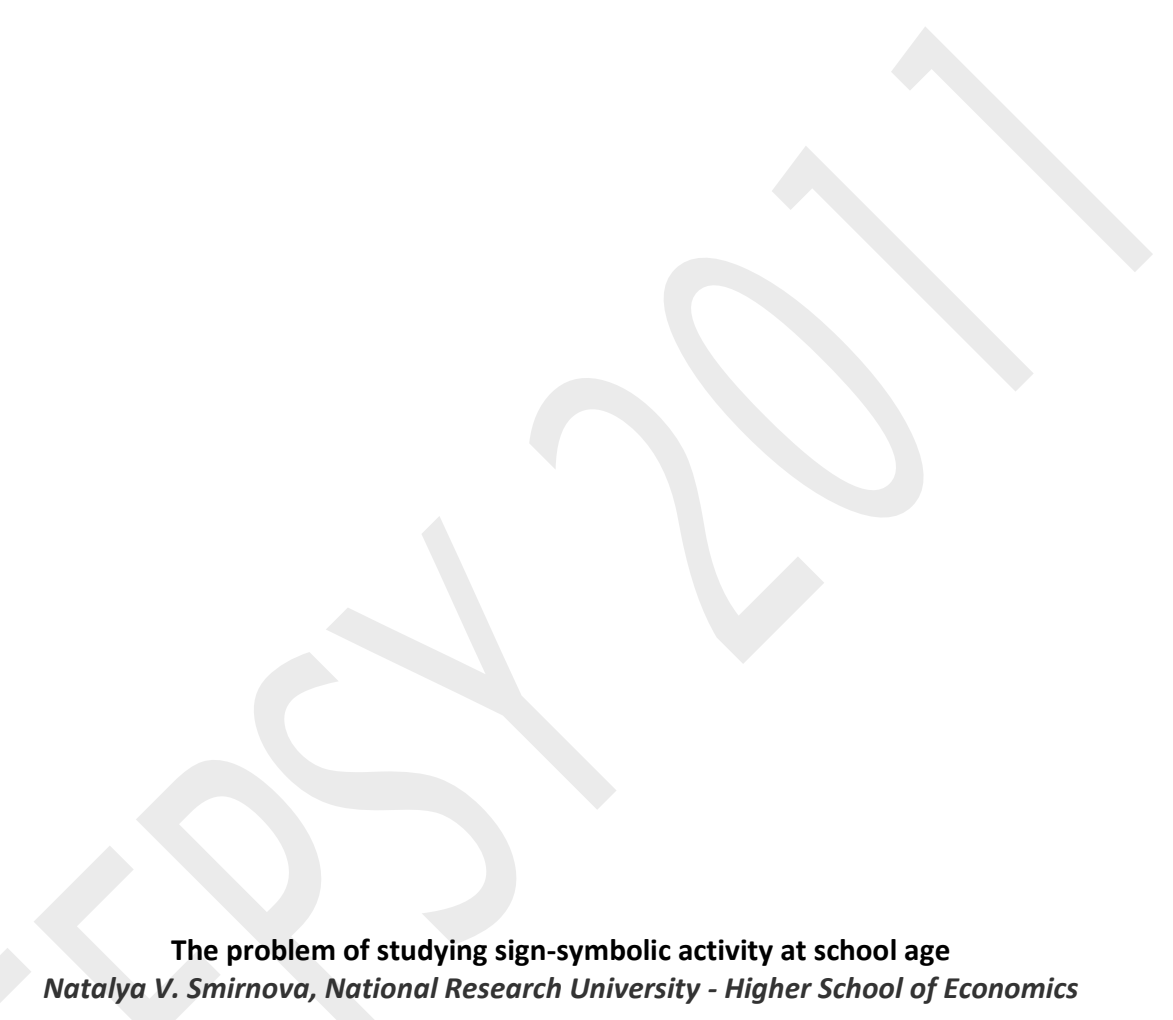

Problem Statement:

The problem of studying sign-symbolic activity (SSA) is defined. SSA is analyzed as a system of mediation, representation and relation aiming at reflection and transformation of reality. At the same time it is considered as an action and belongs to higher psychic functions and is an essential condition for the human development and life at all ages. However little research has been done in the field of sign-symbolic representation based on age factor and individual personal characteristics. Most SSA studies refer to the field of pedagogical psychology and empirical research shows that in most cases SSA does not reach any substantial level of development.

Purpose of Study:

The main aim of this study is to explore and analyze the nature of SSA (structure, types, and functions) and its dynamics. SSA is studied within 3 school age groups $\left(2^{\text {nd }}, 7^{\text {th }}\right.$ and $11^{\text {th }}$ grades) with the aim to identify at what age each of the main 4 SSA types (modeling, schematization, coding, substitution) reaches some definite level of its development. SSA dynamics is studied irrespectively of any external conditions and without creating any special environment for its development.

Research Methods:

Studying and analysis of literature and research papers in the field of psychology and developmental psychology Development of a set of original experimental exercises in order to study SSA dynamics and a set of parameters to measure SSA level

Findings and conclusions:

The importance of studying SSA in the age context has been proved. There has been created an original methodology to evaluate and assess SSA dynamics according to some parameters. In the course of the psychological research we have developed a set of criteria to measure SSA level taking into account the child's age, general cognitive level and gender. The 
results of the pilot experimental research show the following features of SSA dynamics at school age: SSA type connection with age characteristics, nature of development of SSA types (4 types), SSA chaotic nature as school curriculum does not have systematic approach to SSA development.

Keywords: sign-symbolic activity, SSA dynamics, school age, gender, cognitive level

Teachers' Intentions and Learners' Perceptions about Recasts, Prompts, and Models Asghar Salimi (Ph.D Candidate), English department, Maragheh University, Maragheh, Iran Asgharsalimi356@gmail.com Tel: +989143802607

Nahid Delju, M.A in TEFL, Islamic Azad University, Science and Research Branch, Urmia, Iran

Problem Statement:

Hassan Asadollahfam (Ph.D), Islamic Azad University, Bonab Branch, Iran Asadollahfam@yahoo.com

Long's Interaction Hypothesis (1996) suggests that interaction facilitates second language development because during interaction learners may receive feedback or the reactive information that they receive regarding the linguistic and communicative success or failure of their utterances. A number of SLA researchers have investigated the effectiveness of recasts, models, and prompts as widely used types of corrective feedbacks in second language classrooms ignoring the roles of teachers' intentions and learners' perceptions. Some researchers in the field argue the ambiguity of such interactional feedbacks to the learners.

Purpose of Study:

The main purpose of this experimental study is to investigate teachers' intentions materialized in prosodic features on diminishing the ambiguity of linguistic recasts, prompts, and models when they are used frequently as focus on form techniques.

Research Methods:

For this purpose 45 learners of English with intermediate level of proficiency were randomly assigned into three groups as the participants of the study. The data were collected using 12 sessions of video tape of task-based interactions in teacher initiated focus on form episodes. Chi-square was employed as the statistical means of analysis.

Findings:

The results proved significant relationship between teachers' intentions and learners' perceptions in recasts and prompts but not in models.

Conclusions:

The study carries significant implications for SLA researchers and language teachers in EFL contexts.

Thematic Section is Effective Language Teaching and Second Language Practice

Keywords:

Recasts, Prompts, Models, Teachers' Intentions, Learners' Perceptions, Corrective Feedback 


\section{Spiral teaching method: Stair stepped to promote learning}

Fahimeh Veladat, M.A. in Educational Administration

Young Researchers Club, Islamshahr Branch Islamic Azad University

(Tehran, IRAN, ISLAMIC REPUBLIC OF)

fahimeh_veladat@yahoo.com

Fatemeh Mohammadi, M.A. in Educational Administration

Islamic Azad University

(Tehran, IRAN, ISLAMIC REPUBLIC OF)

fmohammadi61@gmail.com

\section{Problem Statement:}

many teaching models has been stated yet that are known as active teaching patterns and Each one relies on a new dimension of learning that can cover one or more skills. But did the models pay attention to the use of hearing and vision (together) that theorists believe that can cover 75 percent of learning? Spiral teaching model- that is known with this name , because of it's steps- is one of the active teaching models with 11 steps and 15 goals and use these two senses as well as writing for better learning on children.

\section{Purpose of Study:}

This article tries to show the effect of Spiral teaching method in comparison with traditional methods. Samples are students of grade two of prep school that are examined at biology course.

\section{Research Methods:}

Type this research is application oriented and Research Methodology is semi experimental we choose two classes each one have 15 students and .one of them is examination group and the other one would be control group. We used T test and SPSS soft ware to compare the difference of grades between these two groups.

\section{Findings:}

Results showed that scores of these groups had sensible differences.

\section{Conclusions:}

Spiral teaching method is not separate from other methods of teaching. We can count it as a new look or a combination of other methods .every single course needs specific method of teaching or a combination of methods. As much more senses involved in learning, we'll get better results .operational area of Spiral teaching method is using both hearing and vision and make students to writ the learned lessons. Results show the effectiveness this teaching method for confirmation of learned lessons.

\section{Keywords:}

Teaching methods, spiral learning, learning, effective teaching 


\title{
Descriptive Assessment in the Education System of Iran: Challenges and Drawbacks
}

\author{
Maryam Zand, M.A. in Educational Administration \\ Young Researchers Club, Islamshahr Branch Islamic Azad University \\ (Tehran, IRAN, ISLAMIC REPUBLIC OF) \\ mzand2009@yahoo.com \\ Maryam Ilanlou, M.A. in Educational Planning-Tehran University Branch \\ (Tehran, IRAN, ISLAMIC REPUBLIC OF) \\ m.ilaanlu@gmail.com
}

Problem Statement: In the past three decades the quantative approach has replaced the qualitative assessment measures in the education system of developed countries. While the educational system of Iran has adopted some of these new measures, the descriptive assessment is not fully implemented. At the moment the only type of assessment in Iranian schools is end of the year achievement tests which are in fact qualitative measures. In recent years some attempts are done towards implementing a quantative approach to the assessment of students mainly in primary schools. All school staff received on the job training before any further change in the schools routines, but a number of drawbacks and challenges turned up in practice. The problem posed in the present paper concerns the reason behind this failure.

Purpose of the Study: The study aims at pinpointing the challenges and drawbacks the educators faced in the process of adopting the new assessment measures.

Research Method: The study is done based on qualitative method; data collocation is done through interviewing the subjects. The statistical population consisted of teachers who were involved in implementing the project.

Findings: The findings of the study indicated that there are a number of factors that affect successful implantation of the new measures in the education system of Iran. To name a few one can refer to the followings:

- The number of students in crowded classes

- The lack of understanding among families

- The lack of a unified approach to instruction and assessment

- The lack of information among teachers

- Principals' negative viewpoints

- $\quad$ Red taping

- The lack of resources

- Weak team work among school staff and teachers

Conclusion: It can be said as the conclusion to the study that different infrastructures have affected the successful implementation of the new assessment measures in Iran and can be taken as the major reason behind the failure of the project. The study also sets forward a number of recommendations and analyse the required infrastructures in some details.

Key words:

Descriptive Assessment, Education System, Challenges and Drawbacks, Iran 


\title{
The Assessment of the Educational Quality in E-citizenship Group of Tehran Technical Complex and Devising
} Optimization Strategies

\author{
Shahroz Farjad, Educational Administration Department \\ Islamshahr Branch ,Islamic Azad University \\ (Tehran, IRAN, ISLAMIC REPUBLIC OF) \\ Farjad.edu@gmail.com
}

Nader Barzegar, Educational Administration Department

Islamshahr Branch ,Islamic Azad University

(Tehran, IRAN, ISLAMIC REPUBLIC OF)

Naderyasin@yahoo.com

Nahid Hosseiny, M.A. in educational technology

(Tehran, IRAN, ISLAMIC REPUBLIC OF)

hosseiny.edu@gmail.com

Problem Statement: The quality of educational services has been a matter of major concern to the educators. The education quality index is used as an assessment measure all over the world in this respect. The present paper focuses on the educational quality indices of E-citizenship Group of Tehran Technical Complex in form of the input and output of the education system.

Purpose of Study: The study aims at pinpointing both strong and weak points of the above named educational body in order to facilitate the process of decision-making in such like institutions.

Research Methods: The study is an applied one and the data collection method has been descriptive. The statistical population consisted of students, teachers and graduates of the selected centre. The data was collected through the application of sampling, questionnaires, interviews, and checklists. The analysis is done considering 10 factors, 43 standard measures and 84 indicators.

Findings: The input index $(=2.32)$ is almost acceptable, process index $(=3.29)$ is in acceptable level, while output index $(=2.32)$ falls below the standard level.

Conclusions: The study showed that the educational quality in the subject centre needed to be improved through implementation of optimizing measures and practical strategies.

Keywords: Assessment; educational quality; quality index; E-citizenship Group 


\author{
Islamshahr Branch ,Islamic Azad University \\ (Tehran, IRAN, ISLAMIC REPUBLIC OF) \\ Nader_yasin@yahoo.com \\ Shahrooz Farjad, Educational Administration Department \\ Islamshahr Branch ,Islamic Azad University \\ (Tehran, IRAN, ISLAMIC REPUBLIC OF) \\ Farjad.edu@gmail.com
}

Problem Statement: Nowadays, for development employees to achieve new knowledge and technology, culture building and improvement of staff performance, organizations hold a different job-training courses. Therefore, measurement training effectiveness and it's impact on employee performance has a lot of importance.

Purpose of Study: The present paper aims at determining the impact of on-the-job training courses on the performance of the employees at the Organization for Martyrs' Affairs.

Research Methods: The statistical population consisted of the managers and staff in 5 provinces; they were selected among those employees who had taken part in at least 2 courses since $2010(N=2700)$. The witness group $(n=480)$ were selected through "improbable accessible sampling" method based on Morgan, Cohen and Krejcie tables. The data collection was done by the used of valid questionnaire and interviews. The Alpha index $(=0.95)$ was used to measure item reliability. This applied study is done on the basis of descriptive survey method. Data analysis is done through application of both descriptive and interpretative statistics.

Findings: The findings of the study indicated that these courses affect staff performance to some extent, but the level of changes fall below the desired standard. The study questions found their proper answers and a number of optimization strategies were set forward that can be the area of the further studies.

Conclusions: Besides that, we mentioned some recommendations for performance improving of the Foundation's Training department that can be a Basis for next researches.

Keywords: Specialized Training Courses; Performance, on the job training

Navigation structural equation model of creativity in educational administrators Sistan and Baluchistan Maryam Najafi mogadamnejad*

The purpose of this research, design and evaluation of causal models of creativity training managers in departments and Islamic Azad university has been. .The study community, all the managers and training departments of universities in Sistan-Baluchistan province in 2011 with the management side have been training. To select the sample, the stratified random sampling was used in compliance with the ratio between the total of 231 educational administration, 85 (44 male and 41 female director manager), were selected. This research is correlation descriptive and especially structural equation modelling is seeking. Measuring instruments, questionnaires, creativity Torrance (1959), organizational innovation questionnaire Omid et al (2002), organizational culture questionnaire Dennison (2000), organizational climate questionnaire and Benjamin Bartlett (1974), a questionnaire - the organizational learning Nyf (2001) and knowledge 
management Questionnaire Ralf (1999) is. Data analysis - descriptive statistics of indicators and inferential statistics methods Friedman test, $\mathrm{t}$ and one-way ANOVA was used. particularly finding confirmatory path analysis, structural equation modes. The results showed that: A) The status of creativity in management education is moderate. B) state variables of organizational culture, organizational climate, organizational learning and knowledge management as factors affecting the creativity and innovation in management education is moderate. C) organizational culture, knowledge management, organizational learning and organizational climate were most common to least impact on innovation and creativity are the managers. D) variables of organizational culture, organizational climate, organizational learning and knowledge management and relationship with direct effect, positive and significant variable in the management of creativity training. E) creativity variables, organizational culture, organizational climate, organizational learning and knowledge management and relationship with direct effects, with variable positive and significant innovation in management training. F) Model A. creativity training managers are fitted. Therefore, it can be said to enhance creativity and innovation in the State service education should pay strengthen the organizational culture variables, organizational climate, organizational learning and knowledge management.

Keywords:

Creativity, innovation, organizational culture, knowledge management, organizational learning and organizational climate, training managers

*Educational researcher\& Head department of Teachers training college in Islamic azad University, Iranshahr

Teacher's role in the development of learning opportunities

\section{AlirezaAraghieh}

Narges borzabadi farahani

Fatemeh Behjati Ardakani

\section{GholamrezaNaderizadeh}

\section{Problem Statement:}

One of the most essential developments in education system is progress in attitudes and methods of teaching. Furthermore, the old methods cannot train today's learners for future.

\section{Purpose of Study:}

The purpose of this article is the study of importance of "education quality". The research is aimed to consider methods of increasing education quality. A statistic sample of the study has included 60 staff of faculty members of Islamic Azad university area 8 and 12.

\section{Research Methods:}

The method of research is Delphi technique and based on that the faculty members were asked to provide a list of methods of increasing education quality and then the preliminary list has been provided through collected lists. Then the preliminary list was sent to the faculty members in order to do any necessary improvements. Finally, a new list has been offered according to suggestions and improvements; similarly the list was presented to poll. 
Based on findings, there is consensus among faculty members that the most influential factors on increasing education quality in classrooms are: proficiency of teachers on materials, presentation methods, being an active teacher, generate motivation on students and classroom management.

Conclusions:

Teachers with Methods of increasing education quality can enhance learning opportunities for more students and provide bacground to facilitate student Success. Teachers in this area are very important role.

Keywords:

Teachers ,curriculum, Learning, Delphi

Cheating Behaviors in Academic Context: Does Academic Moral Disengagement Matter?

Maria Luisa Farnese, Department of Psychology, Sapienza University of Rome, Italy

Carlo Tramontano, National Institute for the Educational Evaluation of Instruction and Training (INVALSI), Italy Roberta Fida, Department of Psychology, Sapienza University of Rome, Italy

Marinella Paciello, International Telematic University Uninettuno

\section{Problem Statement:}

Cheating behaviors are becoming more and more pervasive and frequent in academic context (McCabe, 2001; McCabe \& Trevino, 1997), with grave repercussions on the main mission of any educational institution: to promote the acquisition of actual knowledge and competences in students (Whitley \& Keith-Spiegel, 2001). Hence, academic cheating behaviors can be considered as transgressive conducts (Bandura, 1996), and in this line they need to be investigated.

\section{Purpose of Study:}

The aim of the present study is to translate in the academic context a model proposed by Bandura and his colleagues in studying transgressive behaviors (Bandura, Barbaranelli, Caprara, Pastorelli, Regalia, 2001), to investigate the role of domain specific self efficacy beliefs and intellectual moral disengagement in influencing students' cheating behaviors and, in turn, academic performance.

\section{Research Methods:}

We implemented a structural equation model on data obtained by a questionnaire administered to a sample of 416 Italian college students (61\% females; mean age 24 years, s.d. 2.51 year). The main self reported measures included were: self efficacy in managing negative emotion, regulatory self-efficacy, self-efficacy for self-regulated learning, intellectual moral disengagement, and academic performance. Finally, in order to evaluate the permeability of cheating behaviors in academic context, participants were asked to indicate how frequently these conducts are acted both by them directly and by their colleagues.

\section{Findings:}

Self-efficacy beliefs and colleagues' cheating behaviors strongly influenced individual cheating behaviors both directly and indirectly, through the mediation of intellectual moral disengagement $\left(R^{2}=.50\right)$. Academic performance is mainly influenced by self-efficacy for self-regulated learning, in line with previous findings (Caprara, Fida, Vecchione, Del Bove, Vecchio et al., 2008), yet also intellectual moral disengagement and self efficacy in managing negative emotions showed significant paths $\left(R^{2}=.14\right)$. Cheating behaviors did not influence performance. The fit of the model resulted excellent.

Conclusions: 
Our finding highlight the pivotal role of intellectual moral disengagement and perceived peers behaviors in facilitating academic cheating behaviors, above and beyond the impact of self-efficacy beliefs. Future studies should deeply investigate the interaction of individual and contextual dimensions in order to identify the most efficacious strategies to discourage these dysfunctional and unproductive conducts.

Keywords:

Cheating Behavior, Academic Performance, Moral Disengagement, Self-efficacy believes

The relationship between gender, perception of classroom structure, achievement goals, perceived instrumentality and academic achievement in English course third grad middle school students (English as second language)

Maryam Rostami a , Elaheh Hejazia , Masoud Gholamali Lavasani ${ }^{a}$

a Department of Educational Psychology \& Counseling, University of Tehran; Tehran, Iran

Problem Statement:Academic achievement is a complex phenomenon, several research are discussed some of the factors and variables affecting academic achievement. Recently research focused on motivational and cognitive factors interact with some of the lessons. This study wants to answer the question how much cognitivemotivational factors is related to the development course in English (second language).

Purpose of Study:This study focuses on the relationship between gender,perception of classroom structure, achievement goals, perceived instrumentality and achievement in English course.

Research Methods:For this study 336 third grade middle school students from area 12 of tehran have been selected through a multi-stage sampling.

For data analysis of descriptive statistics and to answer the questions from being used hierarchical regression analysis also for finding two gender differences was used analysis of variance (ANOVA) and T- tests. Academic achievement of the students was assessed and valued through the final exam grades.

Findings:Results of using hierarchical regression showed that variables perception of classroom structure ,achievement goals , perceived instrumentality can predict $17.1 \%$ changes in academic achievement. The results tow gender differences in perception of classroom structure and performance avoidance goals showed that girls earn higher grades than boys, but there is no difference between the other variables in boys and girls.

Conclusions:These founds can be concluded that academic achievement in English is not depend on gender variable and variables perception of classroom structure, achievement goals and perceived instrumentality are the important roles in the academic Achievement in English language.

Keywords:perception of classroom structure, achievement goals, perceived instrumentality and academic achievement in English language 


\section{THE ATTITUDES OF MEDICAL, NURSING AND PHARMACY STUDENTS TO INTER-PROFESSIONAL LEARNING \\ Aziz, Z, Lim CT, Phang YY \\ Department of Pharmacy, Faculty of Medicine, University Malaya, 50603 Kuala Lumpur, Malaysia}

Problem Statement:

Inter-professional learning (IPL) has the potential to promote collaboration among health care professionals in the delivery of quality health care. For the IPL to have a positive influence on inter-professional collaboration the health care students must be willing to learn together. Attitudinal factors have been identified as major influences on the implementation of IPL. Relatively little is known about attitudes of healthcare students in Malaysia towards IPL.

Purpose of Study:

The aim of the study was to examine the attitudes of undergraduate medical, pharmacy and nursing students towards inter-professional learning.

Research Methods:

The medical, pharmacy, and nursing students at the University of Malaya, Malaysia self-administered the Readiness for Inter-Professional Learning Scale (RIPLS). The RIPLS is a 19-item questionnaire that uses a five-point Likert-type scale to measure attitudes toward IPL on three subscales: team-work and collaboration; professional identity; roles and responsibilities. All 19 items in the RIPLS were summed to provide an overall score. Attitudinal differences between the three groups were analysed based on RIPLS score.

\section{Findings:}

Out of 850 undergraduate students approached, 836 agreed to participate giving a response rate of $98 \%$. The internal reliability of RIPLS was acceptable $(\alpha=0.84)$. Overall, the majority of the students from all groups had a favourable responses towards IPL on the subscale "teamwork and colloboration" and was willing to be involved in IPL. A one-way between groups analysis of variance conducted to explore the difference between the three groups on the RIPLS scores showed there was a statistically significant difference for the three groups $\left(F_{2,828}=11.36, P<0.01\right)$. Post-hoc comparisons with Tukey test indicated the mean score for medical students $(M=72.45, S D=8.80$ ) was significantly different from pharmacy students $(M=75.49, S D=7.200)$. Nursing students $(M=74.43, S D=8.02)$ did not differ significantly from either medical or pharmacy students. The findings showed that pharmacy students were significantly more willing to be engaged in IPL compared to medical students.

\section{Conclusions:}

The findings suggests that a favourable attitude towards IPL exists among the medical, nursing and pharmacy students and this provides support for the introduction of IPL in their undergraduate curriculum.

Keywords:

questionnaires, perceptions, team-work, colloboration, curriculum, Malaysia

In the right placement at the right time? An investigation of the psychological outcomes of placement learning.

Tina McAdie, Fiona Purdie, Nigel King, Lisa Ward University of Huddersfield

Problem Statement: 
The development of higher order employment skills in undergraduates is a matter of growing concern and an area of increasing research interest. As a result of record number of graduates (Browne, 2010) and increasing difficulty in securing a job post-graduation, universities are challenged to design courses that are better equipped to enable students acquire the skills, knowledge, competence, and experience that increase employability and lead to more satisfying careers (Bates, 2008). Does work integrated learning (placements, sandwich education, professional training and internships) provide a plausible mechanism to develop these crucial skills?

\section{Purpose of Study:}

In this emerging area of research interest, this study will investigate the relationship between work integrated learning and the psychological variables believed to play an important role for graduate success in the subsequent transition to the labour market. Specifically, whether there are significant psychological outcome differences in self-concept, self-efficacy, hope, procrastination, and study skills/work ethic between students who pursue work integrated learning and students who pursue a more traditional degree programme.

\section{Research Methods:}

A large sample of undergraduate students at the University of Huddersfield, UK, was used. Undergraduates in all years of study, pursuing both traditional and WIL degrees, from all schools, were invited to participate in the study at the end of their academic year. Demographic information including information regarding educational attainment, work related activity and subject area was collected. In addition the following psychological measures were utilised:

- $\quad$ Trait Hope Scale (THS: Snyder et al., 1991).

- $\quad$ Procrastination Assessment Scale - Students (PASS: Solomon \& Rothblum, 1984).

- Self-Description Questionnaire III (SDQ-III: Marsh \& O'Neill, 1984).

- $\quad$ College Academic Self-Efficacy Scale (CASES: Owen \& Froman, 1988).

- Motivated Strategies for Learning Questionnaire (MSLQ: Pintrich, Smith, Garcia, \& McKeachie, 1993).

All scales are valid and reliable and have been extensively piloted at partner institutions.

Data will be analysed using statistical methods with work integrated learning/non-work integrated learning as the independent variable.

\section{Findings \& Conclusions:}

As this study is a work-in-progress, results and conclusions will be disseminated at the conference and will be available in our full paper.

\section{Keywords:}

Employability, psychological factors, work integrated learning, placements, sandwich education 


\title{
DOMAIN-SPECIFIC CONTEXT OF STUDENTS' SELF-REGULATED LEARNING IN THE FIELD OF HELPING PROFESSIONS PREPARATION
}

\author{
Karla Hrbáčková, Jakub Hladík
}

Department of Pedagogical Science, Faculty of Humanities, Tomas Bata University in Zlín, Czech Republic

\section{Abstract:}

The current research on self-regulated learning has stressed the important role of cognitive and noncognitive components in achieving academic success. Many of these studies has examined cognitive, metacognitive and motivational components of self-regulated learning without the consideration of contextual differences. Using within-subject research design, the present study assessed differences in students' self-regulated learning process across the subject areas. The participants were university students (future social pedagogy profession) in Zlín region who responded to a self-report questionnaire. Cluster analysis was used to identify self-regulated learning profile groups within the domains of scientific subject (social research) and profiling subject (social works) in the field of helping professions preparation. Subject-domain analyses suggested a tendency for students to be relatively unconsistent in the metacognitive component across domains. Findings are discussed in terms of their importance for understanding the contextual nature of students' self-regulated learning.

\section{Keywords:}

Self-regulated learning; domain specific; cognitive, metacognitive and motivational components; university students; helping professions 


\section{Bullying at School: The role of family}

Maria Papanikolaou ${ }^{1}$, Thomai Chatzikosma ${ }^{2}$, Koutra Kleio ${ }^{3}$

Tecnological Educational Institute of Crete, Heraklio, Greece, Social Work Department

${ }^{1}$ Bachelor degree. Contact: ma7pa@yahoo.gr

${ }^{2}$ Bachelor degree. Contact: mimi@inbox.com

${ }^{3}$ Phd(c) Social Medicine, MPH, Social Worker, Department of Social Work, Technological Educational Institute of Crete, Heraklion, Crete, Greece. Contact: kkoutra@staff.teicrete.gr

Problem Statement:

Recent decades, bullying seems to increasingly concern the scientific community, because of the alarming dimensions that takes in many countries of the world. Researches' data report that approximately 3 out of 10 children involve in bullying as victims, as perpetrators or as both. Bullying is an occurrence which affected by different factors; family, however, considered to be the most important, since it has the longest influence on its members.

Purpose of Study:

This study examines the extend of bullying at schools and, the family impact on the demonstration of intimidating behaviors among students.

\section{Research Methods:}

This is a field research on students who attend at public secondary institutions at the urban area of Heraklion, Crete, Greece. A random sampling in clusters was held and the amount of the sample was 460 students with a mean of age 14,5 years. For data collection, self - administered questionnaires were used (Revised Olweus Bully/Victim questionnaire \& HBSC /WHO). The non - parametric Spearman's co-efficient and the non - parametric analysis of Kruskal - Wallis were used for the data analysis.

Findings:

A percentage of $17,5 \%$ of the students of the sample were victimized and a $16,5 \%$ have participated in bullying others. Furthermore, the majority of students, $(40 \%)$ in the sample, assess teachers' counteraction to bullying as "little or nothing" while, only the $\mathbf{2 , 6 1 \%}$ of students feel it as "very". Students' involvement in bullying incidents increases when there is no punishment, despite the child's misbehave, or when parents enforce the discipline methods without justification. Moreover, bullying is related with parents' reluctance to provide assistance on issues towards school. Finally, some parenting behaviors which reflect children's upbringing are connected with bullying. 
Conclusions:

Apparently, school life constitutes a harsh reality for many adolescents. Even though the term "bullying" is obscure, the actions that reflect it are recognizable. School is the place where the majority of incidents occurs and, must be the context in which to develop and focus interventions; of which family shouldn't be overlooked, since it seems to be indissoluble linked to various forms of aggressiveness, where a person learns to manifest or encouraged to develop.

Keyword : bullying, family, school, parenting, students

\author{
CREATING OF NEW POSSIBILITIES FOR THE EMPLOYABILITY IN ROMANIA \\ BY IMPLEMENTING THE TEC-TONIQ 2 PROJECT \\ Suditu Mihaela, University Petroleum-Gas of Ploiesti, Romania \\ Stan Emil, University Petroleum-Gas of Ploiesti, Romania \\ Safta Cristina Georgiana, University Petroleum-Gas of Ploiesti, Romania
}

Problem Statement:

Today we live in a context in which work's precarity and an increase in unemployment rate have become alarming (more than 5 mil. unemployed per year in Europe) and the ways of organizing workforce have evolved. New priorities and strategies have been defined by European policies in matters of professional training, starting with the Bordeaux Communique (2008) and Louvain Communique (2009).

In the contrext of the current gloal crisis, we approach the issue of securing the professional route of youths with poor economic status and/or having a temporary employment by transfering procedures of acknowledgement and valorization of experince obtained thriough other means than the formal ones.

Our target public is represented by youth under 30, workers with part time contracts, seasonal workers, workers with fixed term contracts, employees working in several companies in order to cover a full time schedule, low-skilled young people

Purpose of Study:

We aim to present a study which is part of the Tec-Toniq 2, project that is financed through the Leonardo da Vinci European funds. The fundamental principle of the project is securing the professional routes by means of setting up a specialist network to develop practices of acknowledgement and valorizatoin of experiences; these networks include Temporary work Agencies, companies, social partners, universities, professional training centres, orientation structures, structures dealing with social and professional insertion devices for the public with a precarious situation

\title{
Research Methods:
}

The methods used to carry on the research are: experiment - within which we apply an instrument for psichological selfanalysis and for knowledge assessment - and the analysis of official public documents in view of delineating the current Romanian legal framework.

Findings:

We aim, through the proposed practices, to answer to the qualification needs of the workers and to promote concepts as acknowledgement, valorization and validation of competences. At the same time we envisage the transformation of the target public in actors of professional training process, capable to anticipate disruptions, to make informed decisions and to benefit from opportunities.

Conclusions:

For Romania, the Tec-Toniq 2 project brings a plus of value in the field of professional training and employment by the transfer of experiences and good practices. The results may be best observed at individual level by the increase of self esteem and the capacity to value one's own professional skills.

Keywords: professional insertion, portfolio, training, skills, counseling 


\section{A REFLECTION OF INTEGRATED MULTI-DISCIPLINARY COURSE IN BUILT ENVIRONMENT Fadzidah Abdullah (Dr.)}

Problem Statement:

Purpose of Study:

The traditionally accepted way of working in the design studio in architectural education does not always address collaborative efforts required by the architectural profession. In fact, architectural education encourages the "primacy of the autonomous designer by focusing all its attention on the student's experience as an individual" (Cuff, 1991). This phenomenon is unlike the real situation in an architectural practice environment, where architects collaborate with structural, electrical and mechanical consultants, landscape and interior designers, contractors, clients, end-users etc. The need to instil collaborative capability among architectural students is essential because the success of architects is dependent upon the application of knowledge from multiple disciplines.

This paper aims to investigate the effectiveness of the Integrated Multi-disciplinary course in instilling leadership and teamwork skills among architecture students. The specific objectives of the research are:

a. to examine if the multi-disciplinary course enhance students understanding of architects' and other related professions' roles in built environment;

b. to evaluate if the course effectively develop students' leadership skills; to assess if the course instils teamwork skills among students;

c. to identify measure of improvement possible for the course based on the reflection done.

Research Methods:

This research uses combination of qualitative and quantitative methods to achieve its objectives. Literature review will be done to analyses the current scenarios of architectural education that leads to criticism, and investigate on subject of collaborative working environment among students. In addition, survey will be conducted to get generalization of ideas in the effectiveness of the Integrated Multi-disciplinary course in enhancing students' collaborative and leadership skills.

Findings:

This study would outline the fundamental issues causing lack of professional competency among architectural graduates, focusing specifically on how contemporary architectural education train students to have proficient collaborative skills. Development of new instructional design that includes multi-disciplinary concept for teaching and learning architecture might be recommended.

Conclusions:

This research may have significant impact in improving the quality of contemporary architectural education. It provides direction and mode of actions to be incorporated in the development of instructional design of architecture education.

Keywords:

Multi-disciplinary Project, Architectural Education, Teamwork Skill, Leadership skill, Design Studio, Built Environment.

ENHANCING CRITICAL LITERACY IN WRITING BY EMPLOYING MEDIA IN EXPLICIT INSTRUCTIONAL APPROACHES Julie S C Chuah

Universiti Sains Malaysia;

Manjet Kaur Mehar Singh

Universiti Sains Malaysia

TITLE OF PAPER (11 pts, Arial, Centered)

Author(s) Name and Affiliations 


\section{Problem Statement:}

The lack of critical literacy among undergraduates is a worrying trend as even though a host of information is now easily obtainable, with the Internet acting as one of its main receptacle and dispenser, there seems to be a disconnection between the two parameters. Further to this, prior assumptions cannot be made on students having any basic competencies in critical literacy at all. Imbedded instructions with critical thinking skills woven into the content matter may not ensure that students are empowered to transfer their critical literacy from one discipline to another. Failure of students to think critically will significantly affect their intellectual competence, ranging from their methodical reasoning and logical deduction to the students' aptitude for writing in any discipline.

Purpose of Study:

The purpose of this study is to gauge the efficacy and effectiveness in using media to enhance the level of critical literacy among students particularly in their EFL argumentative writing. This study also seeks to compare the degree of students' critical literacy as a result of being exposed to explicit methods of critical thinking instruction in contrast to imbedded instruction. From this study, it will suggest that more could be done in improving the curriculum to enhance students' critical literacy not only in EFL but in any other discipline.

\section{Research Methods:}

Using media with explicit instructions of critical thinking skills over a period of 14 weeks, this pretest and posttest experimental design involved a total of 46 undergraduates enrolled in a compulsory upper intermediate English language proficiency course. The treatment group and the control group had an equal number of 23 participants each. The material for this course, designed with imbedded instruction of critical thinking skills, was used as a tool to gauge the participants' critical literacy skills. Focus group interviews were also conducted to further substantiate the study.

Findings:

Results for the treatment group demonstrated higher scores in the posttest compared to the pretest writing assignments. There was a significant increase $(p<0.05)$ in the participants' critical literacy in their posttest writing scores compared to the pretest. From the interviews, the majority of the participants supported the use of media as it helps them to write more effectively while the explicit methods in teaching critical thinking skills helps them to analyze information more critically and expand their creativity.

Conclusions:

The findings from this study suggest that the use of media and employment of explicit approach in instructions had invariably enhanced students' writing performance to a great extent. Students can be taught explicitly to develop their critical thinking ability to interpret the content of media, analyze its social impact as well as explore the purpose, audience and ownership of the media. Critical literacy should be given emphasis not only in second language learning but across all disciplines.

Keywords: 


\section{MALAYSIAN MOTHERS' BELIEFS IN DEVELOPING EMERGENT LITERACY THROUGH READING}

Fauzilah Md Husain

Universiti Sains Malaysia

Julie S C Chuah

Universiti Sains Malaysia

Manjet Kaur Mehar Singh

Universiti Sains Malaysia

TITLE OF PAPER (11 pts, Arial, Centered)

Author(s) Name and Affiliations

Problem Statement:

Mothers play an integral role in fostering children's reading habits as it has been found that if mothers begin reading to their children at an early age, children's interest in books and literacy is likely to be sustained as they develop. Mothers' beliefs in reading to their children is crucial in ensuring their children's reading success. However, not much research has been done on Malaysian mothers' beliefs in the aspect of developing emergent literacy skills of their preschool age children \& the relationships of those beliefs with mothers' education level, ethnic background and family socioeconomic status.

Purpose of Study:

The purpose of this study was to investigate Malaysian mothers' beliefs in reading to their preschool children. Another purpose of this study was to discover whether mothers' reading beliefs vary by maternal education, ethnic background and family socioeconomic status.

Research Methods: 
Both quantitative and qualitative methods were employed in this study. Mothers' beliefs about reading were measured on the Parental Reading Belief Inventory (PRBI) adapted from Debaryshe \& Binder, 1994. The qualitative method consisted of a semi-structured interview which allowed for some flexibility on the part of the respondents. The completed inventories were obtained from 72 mothers of preschool children between the ages of $4-6$.

Findings:

There was a significant correlation $(p<.05)$ between maternal education, ethnic background and family socioeconomic status and mothers' beliefs in reading. The results also show that most mothers felt reading to their children is a beneficial activity although they did not recall being read to as a child.

Conclusions:

The findings of this study revealed that Malaysian mothers provided considerable support to help their preschool children to become competent readers. The mothers also consider reading and writing skills as readiness skills that their children should possess before formal school even though some mothers report challenges in engaging their children in reading. The findings also suggest that mothers beliefs may impact literacy development and therefore, mothers should continue to provide frequent modeling opportunities to ensure their childrens' reading success.

Keywords:

Emergent literacy, mothers' beliefs, reading, preschool children

Occupational stress

Gangi Leila, Soghra Ebrahimi Ghavam

Problem Statement:

Teacher, unlike the structural, textural, and superfacial changes and developments in educational system in many countries, still is one of the major components of eduction procecess. Therefor, one important sterategy for dealing with instructional and educational challengs is studying and considering of teachers conditions and wellfar.

Purpose of Study:

The purpose of this study is identification of factors related with teachers occupational stress and developing a model for predicting and estimating teachers occupational stress to promoting the instructional quality in schools.

\section{Research Methods:}

A sample of 600 teachers ( 247 male and 353 female) were randomly chosen from elementary, secondary, and high schools. Four questionnairs were used as a data collection instrument: 1) Features and facilities of classroom and school; 2) Van Der Doef Occupational Strees Questionnaire; 3) Organizatonal climate Description Questionnaire, and 4) Ohaio State Teacher Efficacy Scale. To determine relationships and importance of every related components with teachers occupational stress, Structural Equation Modeling (SEM) as well as variance-covariance matrix analysis were usesd.

Findings:

Data analysis and consideration of the pattern of the casual relationships between variables indicated that number of students, directive management style, efficacy in classroom management, efficacy in student engagement have positive and significanct relationship with teacher stress, and factors such as teacher experience, facilities, supportive management style, efficacy in instructional strategies, and problems about students have negative effect on teachers stress. In general, presented model of relationships between variables can predict $70 \%$ of teachers stress.

\section{Conclusions:}

These findings indicate that teachers occupational stress could be reduced through controlling factors that effect on it, and help them for doing their tasks about delivering educational services to students. 
Keywords:

occupational stressors, teacher efficacy, management style

\section{HIGHER EDUCATION IN LIBYA, SYSTEM UNDER STRESS}

Abdalmonem Tamtam ${ }^{1}$, Abdul. G. Olabi ${ }^{2}$, Sumsun Naher ${ }^{3}$ and Fiona Gallagher ${ }^{4}$ School of Mechanical and Manufacturing Engineering ${ }^{1,2,3}$, Dublin City University. Ireland School of Applied Language and Intercultural Studies ${ }^{4}$, Dublin City University. Ireland

Problem Statement: The researcher's knowledge, there has been few studies conducted on the problems facing higher education system in Libya. recent research show there is a significant gap in higher education levels. This means, there is an urgent need to address this by filling this gap. Research developing around the problem show that, the gap can be blamed on changes of systems and policies in the country. Lack of materials and resources necessary for maintaining existing educational programs and services as culpable. However much of the burden emanates from the rapid growth of learning institutions. University colleges have spread across Libya and a ban of foreign language in Libya have played a central role in stressing the higher education learning in the country.

Purpose of Study: Our paper aims to present a comprehensive insight with reference to the higher education system in libya and how policy and administration backed by political nuances have caused a currant situation that has affected the quality of the education.

Research Methods: The methods used in the paper include: literature review, policy document content analysis, quality assurance policies analysis.

Findings: Research shows that there is a significant gap in higher education levels. This means, there is an urgent need to address this by filling this gap.

Conclusions: The paper draws from a wide range research ideal recommendations and possible solutions for problems. 
Problem Statement: Nursing process is a systematic and dynamic method which promotes individualized nursing care; assists nurse to respond the clients needs and consists manner to improve or maintain the clients level of health. It directs nurse and patient to accomplish the following process; assessment, nursing diagnosis, Planning, Implementation and evaluation which enables nurse to organize and deliver appropriate nursing care to a client. For all nursing students in medical-surgical nursing fields this process is teaching in Iran; however research showed that students have no enough knowledge and skill to apply it after graduation.

Purpose of Study: This study aimed to assess the effect of a workshop presentation in learning nursing process on nursing students. Furthermore, was to compare this method with traditional teaching scheme in development of knowledge and skill in applying nursing process.

Research Methods: In this interventional study,18 female nursing students participated. A pilot study was conducted among nursing staffs of hospitals in workshop framework which leaded to apply among nursing students. Teaching time was organized in four 2 hours sessions. Two first sessions were specified to describe the process, goals, steps, benefits; and the nursing assessment steps. In third session after illustrating NANDA format, students were divided into 3 groups and applied nursing diagnosis in presumptive equal patients. Nursing diagnosis for patient was listed in 45 minute by groups and then following a group discussion was corrected. This process was applied in forth session to plan goals and nursing interventions. Finally, all of the participants were encouraged to organize nursing care plan for an actual patient as assignment. Participants were marked according to the assignment and a final exam. Mark was considered in a scale of 0 to 20.

Findings: Compare with students of last two semesters which had this course with traditional teaching method, students mark was increased significantly $(P=0.0001)$. Overall students had a good feeling regarding the workshop teaching; however time deficit for the groups presentation and discussion was mentioned.

Conclusions: As a conclusion, teaching nursing process by workshop presentation could be effective and incentive for student. However, some issues need more concern; a more comprehensive strategy is recommended.

Keywords: Nursing process, teaching methods, workshop, learning

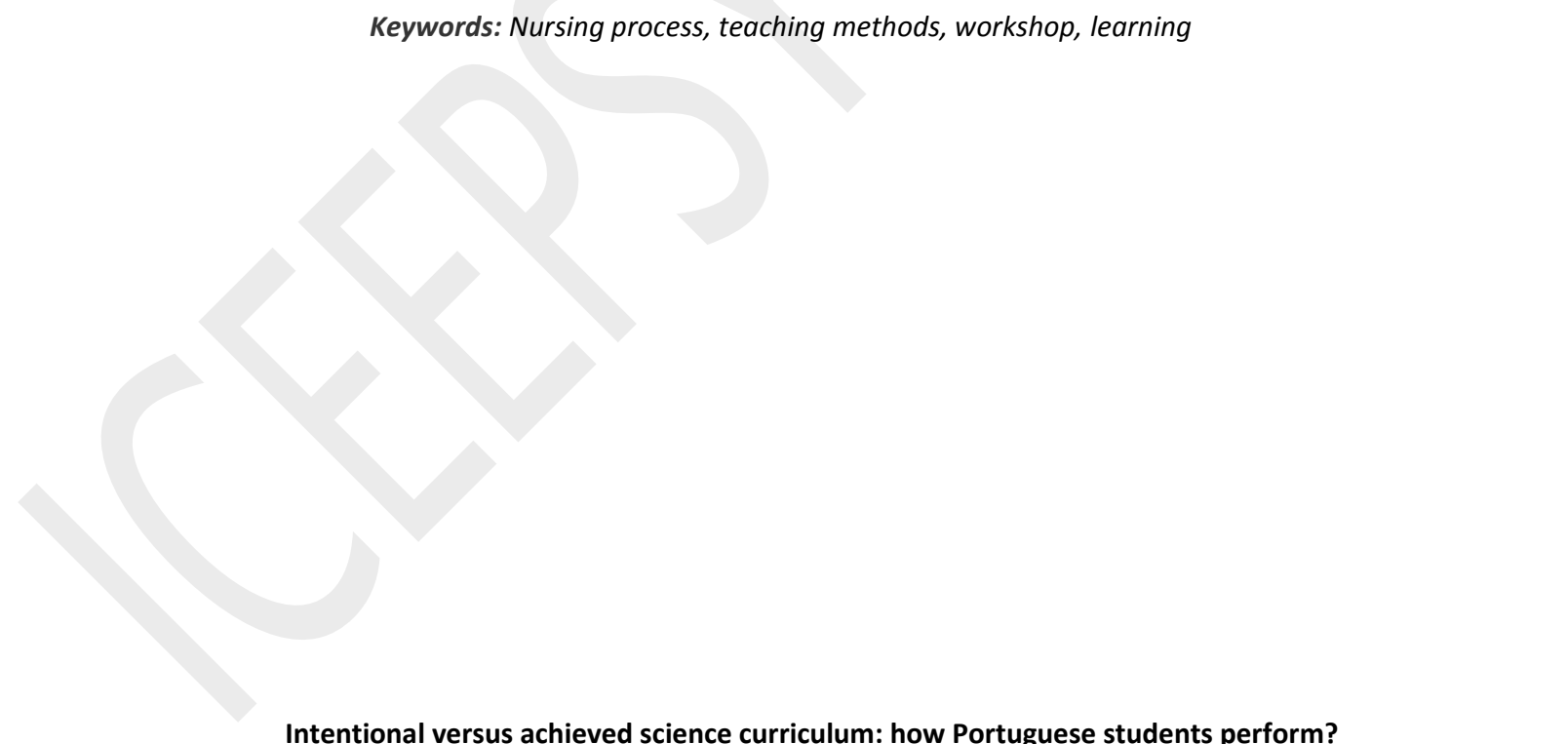

Intentional versus achieved science curriculum: how Portuguese students perform?

Submission to Oral Participation

Thematic session: Basic education - Basic skills

Freire, S.; Faria, C.; Galvão, C.; Baptista, M.; Figueiredo, O. \& Almeida, P.

Institute of Education, University of Lisbon

Taking into account the characteristics of contemporary societies, science curricula have been reconsidered. Nowadays developing students' substantive, procedural and epistemological knowledge, along with reasoning, communication and 
argumentation competencies are recognized as important goals of science education. These are central goals of the Portuguese science curriculum. However, studies reveal that teachers emphasize the substantive knowledge to the detriment of other competencies. The present study emerges in the context of assessing the Portuguese science curriculum for the 3rd cycle of basic education. It aims at understanding how teachers interpret curriculum documents, how they implement the recommendations and curriculum guidelines and how students experience it. In this presentation, we will present data related to the students. In order to analyze the type of competencies that students are actually developing in science classes, we applied two types of tests, one to be answered individually, and another in group. These tests were adapted to the Portuguese reality, from PISA and NAEP. Their primary aim was to examine how students: (a) interpret phenomena and evidences; (b) analyze graphs and charts and; (c) mobilize scientific concepts to explain and solve problems of everyday life. Participants were 27 students from $10^{\text {th }}$ grade science class. This class can be considered as being representative of Portuguese students. They come from three different elementary schools, and are very heterogeneous concerning their parents' socio-educational level. Additionally, students performed differently in science classes in the first term, with grades varying between 9 to 17 points (in a scale of 0 to 20). The results indicate that the questions related with substantive knowledge had higher \% of correct answers when compared to questions related to other competencies. Apparently, in spite of presenting some basic scientific knowledge, students did not mobilize it adequately for explaining and solving the problems presented. The explanations given were based on students' common sense knowledge. Given these results, it is important to understand the significance of this lack of scientific knowledge mobilization. Is it a question of lacking complex scientific knowledge? Is it a question of not having developed other competencies besides substantive knowledge in science classes?

\title{
Self-Concept and Task Values in mathematics: testing measurement invariance on TIMSS 2007 data
}

\begin{abstract}
Carlo Tramontano, National Institute for the Educational Evaluation of Instruction and Training (INVALSI), Italy Stefania Codella, National Institute for the Educational Evaluation of Instruction and Training (INVALSI), Italy Elisa Caponera, National Institute for the Educational Evaluation of Instruction and Training (INVALSI), Italy Emanuela Vinci, National Institute for the Educational Evaluation of Instruction and Training (INVALSI), Italy Roberta Fida, Department of Psychology, Sapienza University of Rome, Italy
\end{abstract}

\section{Problem Statement:}

International studies on academic achievement make available a considerable amount of data and a highly informative picture of national educational systems (Miller, Sen, Malley, \& Burns, 2009; OECD, 2010). One of the most relevant international surveys is Trends in International Mathematics and Science Study (TIMSS), that measures trends in mathematics and science attainment at the fourth and eighth grades in approximately 60 countries worldwide (Mullis, Martin, Ruddock, O'Sullivan, \& Preuschoff, C., 2009). Yet, some authors (Eklöf, 2007; House, 2006) claim attention on the necessity of secondary analysis aimed at attesting measurement invariance for background scales included in the survey.

Purpose of Study:

All items used in TIMSS 2007 were developed in English, and then translated adopting a translation-back translation procedure. This procedure guarantees semantic equivalence. Nonetheless, to allow a correct confrontation of the scores on a specific scale, it is fundamental to demonstrate measurement equivalence (Reise, Widaman, \& Pugh, 1993).The aim of this study is to test measurement invariance of mathematics intrinsic and utility values, and mathematics self concept scales included in TIMSS 2007, comparing Italian and US sample.

\section{Research Methods:}

American ( $\mathrm{N}=7377)$ and Italian $(\mathrm{N}=4408)$ 8th grade students participating to TIMSS 2007 were considered. We adopted a cross-validation processes. For each sample we randomly selected a sub-sample (about $20 \%$ ) to implement an Exploratory Factor Analysis to investigate the dimensionality and the reliability of the measures. On the remaining $80 \%$ of the samples we run a Multi-group Confirmatory Factor Analysis to investigate the structural invariance across samples, testing three nested models: configural, metric, and scalar invariance (Steenkamp, Baumgartner, 1998). To compare nested models we used the difference in Comparative Fit Index, following Cheung and Rensvold (2002) suggestions. 
The configural invariance model confirmed the three factor oblique model in both countries. Moreover data attest the tenability of a partial scalar invariance model for each of the three scale.

Conclusions:

Our findings confirmed the importance of secondary analysis developed through adequate methodological procedures that can highlight both differences and analogies in measures included in international studies. Overall our results attest a good generalizability of the measures under study.

\title{
Keywords:
}

Measurement invariance, TIMSS 2007, Mathematic Self-concept, Mathematic Task Values

\section{Cognitive Load Effects of Multiple Modalities in Listening Instruction and the Gains in Listening Comprehension}

\author{
Kaine Gulozer \\ Yildiz Technical University
}

Problem Statement: The effectiveness of instructional design for developing listening comprehension in English as a second language (L2) is of prime concern to language teachers. Several technology based instructional designs with the emphasis on distinct presentation of listening tasks are highlighted in literature. However, there is a lack of empirical studies to clarify issues concerning modality differences for foreign language (FL) learners and their effect on comprehension. Moreover, learners' listening performance may be affected by the modality in which the tasks are presented (extraneous cognitive load) or the amount of cognitive resources that learners invest in schema construction and automation (germane cognitive load).

Purpose of Study: Based on cognitive load theory, this study examines whether the subjects' listening performance varied when the instructional formats of listening tasks were presented in four different modalities. Listening with auditory materials only (LO), narrow listening (NL), listening with a full written script (LFS) and listening with synchronous subtitled text (LSS) were employed to evaluate the subjects' listening performance.

Research Methods: This study employed a mixed method design utilizing qualitative and quantitative tools including semi- structured interviews with test takers to assess the best facilitating modality for listening comprehension as well as post test scores to determine student performance. Fifty-four intermediate and advanced level pre-service teacher candidates of English whose L1 was Turkish completed four tests through different representations that required them to listen to dialogues and to complete a number of multiple choice comprehension questions.

Findings: The results indicated that different type of instructional format did have a significant effect on subjects' comprehension. Subjects performed best on NL test for both language levels, followed by LFS and LFS. They scored lowest on LO test. In addition, significant differences in comprehension were found between intermediate and advanced level of teacher candidates in LO modality. A post test survey revealed that $93 \%$ of the subjects preferred NL format because the given the chance of repeated listening facilitated comprehension of spoken stimuli and higher degree of comprehension.

Conclusions: From a pedagogical perspective, the findings offer English language teachers information about the instructional efficiency of incorporating different modalities in listening comprehension tasks that enable learners to promote meaningful listening comprehension.

\section{Keywords:}

Cognitive Load Theory, instructional design, extraneous cognitive load, germane cognitive load, listening comprehension 


\section{Bullying during adolescence and social networks analysis}

Mirko Antino, Javier Martín Babarro, Monica Terrazo Felipe, Santiago De Ossorno García \& Lorena Paredes Becerra

\section{Problem Statement:}

During adolescence issues of acceptance and reject among peer become increasingly important and groups of students become larger and stratified. Cliques formed by adolescents show structures, leaderships and hierarchies. Students without friends and social support among peers have a risk of victimization. Group variables should be analyzed to understand peer group influence in negative social dynamics like bullying.

Purpose of Study:

In a classroom from a Spanish secondary school, students spend between 5 and 6 hours a day together. Friendship networks inside these classrooms can show different levels of cohesion and reciprocity. Our hypotheses aim to demonstrate that a cohesive group will focus on a small number of isolated or rejected students to display aggressive behaviours on them. Otherwise, a non cohesive group will share aggressive behaviours among a higher number of students.

Research Methods: The hypotheses were tested with data from a sociometric questionnaire (IESOCIO) conducted in 134 classrooms from 25 secondary schools ( $N=2857$ students; $M$ age = 14.1 years). Data were explored using social network analysis with UCINET 6 software.

\section{Findings:}

The findings revealed that cohesive groups showed a higher level of bullying, and less average violence inside the group of the classroom. Non cohesive groups showed a lower level of bullying and an increase of the average violence.

\section{Conclusions:}

This is a staring point of a model that permit explain bullying cases involving the group characteristics. Understanding peer group influence in bullying, let us propose a method of intervention based on peer helpers and group information.

\section{The effect of motivational self-talk on reaction time}

Shahzad Tahmasebi Boroujeni *, Banafsheh Ghaheri

Faculty of physical education and sport sciences, University of Tehran, Tehran, Iran

\section{Purpose of Study:}

The primary purpose of this study was to investigate the effect of motivational self-talk on the auditory whole body, simple and choice reaction time. Secondly, we aimed to examine the relationship between participants' belief in selftalk and performance. 


\section{Research Methods:}

Thirty-four female university students voluntarily participated in the study who accomplished three reaction time tasks on two occasions. At the first day whole body, simple and choice reaction times were assessed separately in five trials. One week later participants engaged in motivational self-talk before each trial and then filled out the belief in self-talk questionnaire (BSQ). Paired sample t-test was conducted to compare pre-test and post-test means.

\section{Findings:}

Results indicated that motivational self-talk lead to a significant decrease in choice reaction time $(p=0.001)$. Although, there were no significant differences between pre-test and post-test in whole body and simple reaction times. Furthermore, bivariate correlation showed no significant correlation between belief in self-talk and performance.

Conclusions:

The results suggest that using motivational self-talk can help to react remarkably fast in choice reaction time tasks.

\section{Keywords:}

Motivational self-talk, Belief in self-talk, whole body RT, Simple RT, Choice RT

Bridging Brain and Educational Sciences: An Optical Brain Imaging Study of Math Problem Solving

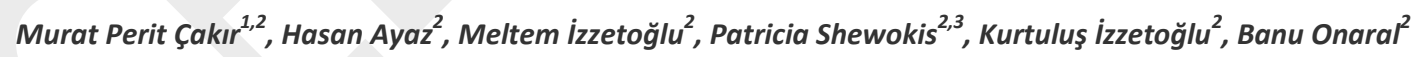

${ }^{1}$ Department of Cognitive Science, Informatics Institute, Middle East Technical Univ., Ankara, Turkey

${ }^{2}$ CONQUER Collaborative, School of Biomedical Engineering, Science \& Health Systems, Drexel University, Philadelphia, PA, USA

${ }^{3}$ College of Nursing and Health Professions, Drexel University, Philadelphia, PA, USA

Recent advances in neuro-imaging technology has opened up exciting possibilities for collaboration between neuroscience and educational research, which may help us develop a better understanding of the nature of learning. Neural foundations of problem solving and mathematical thinking are important areas of research in cognitive neuroscience and the newly emerging field of Mind, Brain and Education. Recent brain imaging studies that employ EEG, fMRI, and PET techniques have implicated that the prefrontal and parietal cortices are involved during higher order cognitive processes related to learning such as attention, decision making, planning and problem solving.

In this paper we present a case study where we investigate neural correlates of math problem solving in a computer-based environment by bringing insights from educational research and cognitive neuroscience. We used functional near-infrared spectroscopy (fNIRS) technology to measure changes in blood oxygenation in the dorsolateral prefrontal cortex while subjects attempt to solve tangram puzzles. fNIRS has been successfully used to monitor neural activity related to cognitive processes by measuring changes in relative levels of oxygenated and deoxygenated hemoglobin in various experimental settings. Moreover, fNIRS offers a portable imaging modality 
that allows non-invasive monitoring of brain activity in more realistic settings as compared to conventional imaging modalities like fMRI and PET where subjects are placed in confined positions.

In this study we aim to observe if the fNIR signal is responsive to changes in cognitive workload due to variations in task difficulty and problem types, and whether better problem solvers exhibit different brain activation patterns as compared to novices. As part of our experimental study subjects went through a number of tangram puzzles that differ in difficulty. The problem solving moves performed by the subjects are recorded through screen capture software. Our preliminary results indicate that there's higher level of activation during experimental tasks compared to control tasks for all 8 participants. By the time of the conference we will expand this analysis further by observing if activation patterns will differ during critical moments in problem solving and in response to different problem types (e.g. completing geometric versus animal shapes).

Keywords: Optical brain imaging, fNIR, problem solving

Virtual role play via Instant Messaging (IM) in language classroom Noor Azlinda Zainal Abidin , Universiti Malaysia Pahang, Malaysia

Abstract: The use of Instant Messaging in language learning is not something new for language educators. Some have started using IM as a tool in teaching and learning to attract their students in language classroom through communication activities. In this study, IM is used as a medium for students to do role plays in language classroom. It was observed that in face to face role playing, some students tend to be shy or afraid when they were asked to act out in front of their friends. Some were too shy of making mistakes and chose to be passive and refused to talk or participated actively instead remained quiet in the role play. Therefore the study was carried out to see how effective was a virtual role play in replacing the traditional role play by incorporating the use of technology in the classroom. In this study, IM was used as a tool for students to do role plays. A situation was given to 32 Diploma students and they were asked to prepare an impromptu role play with their pair. In performing the session, the students were asked to add their friend in their buddy list and acted within the time given. A questionnaire was then distributed to them to ask for their perception in using IM as a new way of role playing in language classroom. The data were then analyzed using SPPS package to see the frequency of the results. The results have shown that students feel more comfortable in doing role play via IM. They do not feel afraid or shy in communicating with their partner. They tried to use the target language though they made mistakes. The virtual role play is seen as a better option for educators to allow all students to participate in role play. Incorporating technology in the classroom has also promoted the students to get involved actively in communication especially in using the target language. It is hoped that the new dimension of language learning is created by introducing virtual role play via IM in language classroom.

Keywords: Instant messaging (IM), role play, language classroom, virtual 
The use of Instant Messaging (IM) in Group discussion in Language Learning Environment

Noor Azlinda Zainal Abidin, Universiti Malaysia Pahang

The use of Instant Messaging (IM) in language learning is seen as an alternative way for educators to attract students in learning as well sustaining their interest in acquiring the target language. In teaching the second language learners the target language, teachers would usually have problems in ensuring all students to use the target language in all discussions conducted in groups. Therefore it is crucial for the study to be carried out. In this study, IM was introduced to students and used as a medium for them to communicate with their group members to complete a group work assigned. A mixed method study was carried out to examine the effect of Instant Messaging (IM) on ESL students' performance in group discussion for university students. A quasi experimental study was carried out to a group of 27 first year students who are pursuing Engineering Degree program in a Technical English course. Students were assigned a final assignment which was on product innovation. The Instant Messaging (IM) treatment took about 7 consecutive weeks for 15 minute meeting twice a week. Students were asked to work in groups to discuss topics assigned on their final project by their lecturer using Yahoo Messenger (YM). Data were collected from close ended questionnaire and interviews done to see the effectiveness of using IM in completing task in language learning environment. Results of the study have shown that students perform better in completing task and prefer to communicate using Instant Messaging (IM) in academic discussions. Feedback from students' responses has also proven the effectiveness of Instant Messaging (IM) in language learning environment.

Keywords: Instant Messaging (IM), group work, ESL, task completion 


\section{HOW LEARNERS COPE WITH ENGLISH TENSES: EVIDENCE FROM THINK-ALOUD PROTOCOLS \\ Shahin Vaezi \\ Iran University of Science and Technology \\ Mehrasa Alizadeh \\ Allameh Tabatabai University}

Problem Statement:

Mastering the temporal system of a second language and being able to correctly implement this knowledge especially in spontaneous production is a challenging task to accomplish. That is why most learners often have problems using appropriate tenses in oral and written production.

Purpose of Study:

The present study attempts to shed light on the way Iranian learners cope with a tense task and how they come up with responses.

Research Methods:

The participants, 26 engineering students who were taking an EAP course at Iran University of Science and Technology, were given a tense task in the form of a cloze and were asked to think aloud as they were completing the task. Data were analyzed initially through fully transcribing the participants' think-aloud audio files. Next, the researchers attempted to extract the processes the participants went through as well as the strategies they employed while completing the task and also the reasons they provided for their choices.

Findings:

It was found that learners with lower language abilities attended to the tense of verbs more than their aspects while completing the task. Yet among learners with higher knowledge of English, both tense and aspect were paid attention to. The data also reveal that where learners had a time signal available in the immediate context, they successfully recognized it in most cases and responded more easily. They were, however, in most cases negligent of other elements in a sentence such as verbs and nouns that could help them come up with correct responses. Moreover, they frequently made negative transfer from their L1, Persian, which caused them to provide incorrect answers.

Conclusions:

The findings indicate that learners have gone through a variety of processes while accomplishing the assigned task. The findings of this study can help language teachers improve their approaches to teaching grammar and raising students' consciousness toward probable sources of errors in using English tenses and aspects. The researchers suggest replications with other groups of language learners in different settings with different tasks or in spoken mode to come up with more comprehensive, more generalizable results.

Keywords:

Tense, Aspect, Tense Task, Think-Aloud Protocols 
Problem Statement:

Teachers are facing now the influences of the information society and the problems of teaching the so called "netgeneration". The institutions try to adapt to these challenges by developing of digital learning modules, and adequate infrastructure. However, these attempts are often unsuccessful.

Purpose of Study:

Comparing results of two investigations (in 2006 and 2010) we try two highlight differences in two student groups. Research Methods:

Sample

The students' attitude toward e-learning was measured in two phases. In the first phase: in $2006, \mathrm{~N}=362,53 \%$ with elearning experience, $64 \%$ female, average age 23,5 years. In the second phase: in $2010, \mathrm{~N}=412,18 \%$ with e-learning experience, $51 \%$ female, average age 19,6 years.

Research instruments

Computer Anxiety Rating Scale (Heissen et al, 1987 q. Sam et al, 2005) for measuring anxiety during working with computers.

Computer Attitude Scale (Bandalos and Benson, 1990 revised form of CAS by Loyd \& Gesard, 1985). This Scale measures Computer confidence and Computer liking and Computer achievement.

Findings:

There was difference $(p<0.05)$ between the students' attitude (liking, confidence and achievement) in the two periods. The 'net-generation' has a less favourable attitude toward computers, than students of the year 2006.

Gender difference also occurred, we found that men show better attitude toward computers in both samples. Both men' and women' results on Computer confidence subscale were the highest.

There was difference $(p<0.05)$ in the age groups' attitude components. 20-30 year-old student in the 2006 sample showed the most unfavourable, while 31-40 year-old student attitude is the most favourable.

We found difference $(p<0.01)$ in students' computer attitude depending on e-learning experience. The more the students experience is the more favourable their computer attitude is.

The computer anxiety is significantly ( $p=0,007)$ higher in the 2010 sample, women' anxiety is also higher and in both sample the anxiety is decreases with e-learning experience. We find difference in the 2006 sample the 20-30 year-old group showed the highest level of anxiety, and the 31-40 year-old group anxiety was the lowest.

Conclusions:

Possible reason of unfavourable reactions of "netgeneration" is their higher anxiety in task situation.

Keywords: computer attitude, computer anxiety, net-generation

Shared-Learning Experience During a Clinical Pharmacy Practice Experience

S. F. ZAKARIA, M.Clin.Pharm, B.Pharm, ${ }^{1}$ and A. AWAISU, Ph.D, B.Pharm ${ }^{2}$

${ }^{1}$ Kulliyyah of Pharmacy, International Islamic University Malaysia, Pahang, Malaysia.

${ }^{2}$ College of Pharmacy, Qatar University, Doha.

Purpose of Study:

To implement a shared learning approach through fourth-year students' mentorship of third-year students and to assess the perception of the mentored students on the value of their shared learning experience. 


\section{Research Methods:}

We introduced shared learning experience in clinical pharmacy and pharmacotherapeutic practice experiences involving 87 third-year and 51 fourth-year students. Both student groups undertook the practice experiences together, with third-year students working in smaller groups mentored by fourth-year students.

Findings:

A majority of the students ( $>75 \%$ ) believed that they learned to work as a team during their practice experiences and that the shared learning approach provided an opportunity to practice their communication skills. Similarly, most respondents (> 70\%) agreed that the new approach would help them become effective members of the healthcare team and would facilitate their professional relationships in future practice. Almost two-thirds of the students believed that the shared learning enhanced their ability to understand clinical problems. However, about $31 \%$ of the pharmacy students felt that they couldhave learned clinical problem-solving skills equally well working only with peers from their own student group.

\section{Conclusions:}

The pharmacy students in the current study generally believed that the shared-learning approach enhanced their ability to understand clinical problems and improved their communication and teamwork skills. Both groups of students were positive that they had acquired some skills through the shared learning approach.

Keywords: shared learning, pharmacy education, pharmacy practice experience, patient assessment, therapeutics

Learners' Learning Style Classification related to IQ and Personality Traits based on EEG dataset Nazre Abdul Rashid, Mohd. Nasir Taib, Sahrim Lias \& Norizam Sulaiman

${ }^{1}$ Faculty of Arts, Computing and Creative Industry, Universiti Pendidikan Sultan Idris, 35900 Perak, Malaysia

${ }^{2}$ Faculty of Electrical Engineering, Universiti Teknologi MARA, 40450, Shah Alam, Malaysia.

${ }^{3}$ Nondestructive Biomedical \& Pharmaceutical Research Centre, Universiti Teknologi MARA, 40450 Shah Alam, Malaysia.

${ }^{4}$ Faculty of Electrical \& Electronic Engineering, Universiti Malaysia Pahang, 26000 Kuantan, Pahang, Malaysia.

nazre.rashid@gmail.com,dr.nasir@ieee.org

\section{Problem Statement:}

The effort of using bio-related characteristic to understand learners' attributes in Education field is still relatively low. Nevertheless, to achieve a best session of teaching and learning, students way of Learning aka Learning Style should be put under focus scrutiny. Their related IQ and personality traits should be also given attention as for the educators to understand the students better. 
To understand the learners' Learning Style and its relationship to IQ and personality traits using Electroenchephalogram (EEG) dataset and Kolb's Learning Style Inventory (LSI)

Research Methods:

EEG technology, Kolb's LSI, Statistical Package Analysis and Literature Review

Findings:

1. Learners' Learning style could be obtained and classify using EEG dataset and Kolb's LSI

2. The LS could be related to learners' IQ

3. The LS could be related to personality traits

Conclusions:

Learners' LS, IQ and personality traits could lead educators to understand their students in a more proper way hence giving the best hint for effective teaching and learning session.

\section{Keywords:}

Learning Style, EEG, IQ, Personality traits, Classification

\section{THE NEED FOR COMPETENT WORK READY ENGLISH LANGUAGE LEARNERS}

Ezihaslinda Ngah, Noor Raha Mohd Radzuan,

Noor Azlinda Zainal Abidin, and Wan Jumani Fauzi

Universiti Malaysia Pahang, Lebuhraya Tun Razak 26300 Kuantan, Pahang, Malaysia

\section{Abstract}

In Malaysia, Malaysian University English Test (MUET) is a test of English language proficiency used in Malaysian public higher educational institutions for the purpose of undergraduates' admission. However, in preparing students for the workplace, proficiency test alone is not enough. They also need to be competent in applying the four language skills in work related tasks which cover listening, speaking, reading and writing. Therefore, the aim of this paper is to share the authors' experience in using thematic approach in developing English proficiency test paper at a technical university in the east coast of Malaysia. The test paper developed encompasses four language skills which share a similar theme. The input from listening and reading texts will be used as the output in speaking (in the form of presentation) and writing assessment. Should this assessment be successful to measure our engineering students' ability to apply the four skills in work related tasks, this test will show how successful the students are in applying what they have learnt throughout their course of studies at the university. The industries may as well benefit from the assessment as not only it could serve as an indicator to gauge the English language proficiency level of newly-employed staff but also as an instrument to measure their competency on work-related skills where English is concerned. It also holds a potential to be used as an entrance requirement for new employees 
Cluster Analysis of Student Stiles of Living-Together in Classroom

Veronica Rosa, CIRMPA, Interuniversity Centre of Research in the Genesis and Development of Prosocial and Antisocial Motivations, Sapienza University of Rome, Italy

Roberta Fida, Department of Psychology, Sapienza University of Rome, Italy

Francesco Avallone, Department of Psychology, Sapienza University of Rome, Italy

Problem Statement:

Youth adolescents spend much of their time in school, especially in class. Hance, students' experience of the life in class has pivotal role in their well-being and in building their future (Cohen, 2006). In this line, it is capital to investigate the different ways in which students live and perceive the classroom, in terms of their classmates and their teachers.

Purpose of Study:

The general purpose of this study is identify homogeneous groups of students who have different feelings and perception about their class and their "living-togeter".

Research Methods:

On a sample of 1,917 Italian students attending $10^{\text {th }}$ grade ( $52 \%$ females; mean age=15 years; s.d.=.7 year) a self report questionnaire was administred. İ particular it included PYC ("How Do You Perceive Your Classroom?") inventory to measure ten dimensions of student perception of "living-together" (student loyalty, support, tolerance, cooperation, cohesion, assertiveness, power and rule orientation, teacher support and equity, Fida, Rosa, Avallone, in press), three student satisfaction items, a ten items values scale (Schwartz, 1992) and sociodemographic variables. To identify homogeneous groups who shared similar patterns we implemented cluster analysis (Bergman \& El-Khouri, 2001). Then Anovas and chi-squared analysis were performed to validate and describe the profiles identified.

Findings:

Cluster analyses revealed four Styles of Living-Together in Classroom: cooperative/proactive/loyal living-together (students showed a positive vision of what happens in class), respectful/tolerant living-together (the classroom is a place with little support and loyalty and lots of respect for rules, and tolerance), comradely/intolerant/relationally accomplice living-together (the classroom is a place with little respect for rules, tolerance and loyalty, but with good peer support), passive/individualist/hostile living-together (students showed a negative vision of what happens in class).

Conclusions:

Our study showed that students have different stiles of "living-together" that affect in different ways student wellbeing. Moreover, our findings indicate the pivotal role of teachers in creating a classroom environment that promote well-being. Future studies could include samples of older children (mean age 18 years) to verify if there are groups with the same stiles of living-together in class for different students' age of high school. 
Keywords: $10^{\text {th }}$ Italian students, Cluster analysis, Well-being, “Living-together”.

\author{
An evaluation of art education in primary and secondary school: the Danish case \\ Ulf Hjelmar, research programme director, Institute of Governmental research, \\ Copenhagen, Denmark
}

Problem Statement: It is widely acknowledged that Danish education is creative and supportive of arts outcomes. At the same time international evaluations have shown that Denmark has slipped behind neighboring countries in terms of arts education provisions. Following this, it has been suggested that a number of improvements are needed to enhance the quality of arts education in Denmark.

Purpose of Study: The paper will analyse the current Danish arts education in primary and secondary school. What are the strengths and weaknesses of the arts education? Does the arts education live up to the ideals outlined in the legislation in the area? Finally, which initiatives and strategies can be applied to improve arts education?

Research Methods: The evaluation is based on multiple sources of data. A nationwide survey among schools are carried out, secondary data from ministries are used (available statistics), qualitative data from 27 site-visits on schools are included, and results from two workshops with stakeholders in the area are also included.

Findings: The evaluation will be finally reported in August/September 2011. It is expected that the evaluation will find that arts matter and that arts are viewed as a valued part of education. It is also expected that the evaluation will show that the strengths of the arts education are matters such as flexible structures and integrated learning. The weaknesses of arts education are expected to be found around resource issues (lack of facilities), teachers' training and lack of evaluation/reflection.

Conclusions and recommendations: Denmark could be a front runner in creative education. The Danish educational system is well-equipped for the future and has the potential to produce young people with the necessary creative and innovative skills. In order to fulfill this potential the evaluation report will point to a number of initiatives in the area (e.g. compulsory arts education in all grades).

Keywords: Evaluation, arts education, primary school, secondary school, educational system, Denmark 


\section{Promoting Relational Competences in Early Intervention (EI) through Video Home Training / Video Interaction Guidance (VHT/VIG) Method}

Paula Santos (first author), Fátima Feliciano, Carlos Silva, Gabriela Portugal, Leonor Carvalho, Rosa Tavares, Adelaide Bicho, Orlanda Simões, Cláudia Rodrigues and Sandra Agra

University of Aveiro, Portugal - psantos@ua.pt

Problem Statement: Literature and the Portuguese law point to the need of developing an Early Intervention (EI) model that addresses the needs of $0-6$ children at risk of development delay and their families, through the development of a family centered and relationships focused approach, applied through community agencies working in an articulated model, in transdisciplinary teams. To guarantee the quality of the intervention, reflexive supervision facilitates mutual understanding in parent-professional relationship and, indirectly, in parent-child interactions. Assuming that in VHT/VIG the video feedback allows for discussion and demonstration of how to enrich and develop basic communication, reinforcing them on professionals, parents and children, and that their core values - partnership with families, intervention in home context, focusing on existing relational competences and respect for cultural and social diversity - are common to El, the method presents itself as a path of excellence for promoting El competences.

Purpose of Study: to promote competences in El professionals and families of children at risk of developmental delay through VHT/VIG.

\section{Research Methods:}

The study involves an intervention group (Aveiro's El structure): one specialist in VHT/VIG strengthens El supervisors and professionals, who strengthen parents, who strengthen their children; and two control groups (El structures of Coimbra and Portalegre). In the intervention group, by comparison to control's, supervisors are expected to exhibit higher supervision and reflective leadership competences, and lower stress vulnerability; professionals are expected to exhibit higher El competences and lower stress vulnerability; families are expected to evidence higher competences to identify needs and resources relevant to their projects, as families, and lower levels of depression symptoms; we expect that children attain higher growth values and development levels. The project will be held for 3 years more, after a pilot-study period of preparing and testing procedures and organization matrix; it will involve 3 moments of gathering data, T0, T1 and T2. It's funded by Science and Technology Foundation (COMPETE: FCOMP-01-0124-FEDER-014395).

Findings: after data from pilot-study, we're now collecting data on T0; by October 2011, we'll have them statistically treated and analyzed, by using SPSS software.

Conclusions: Not applicable.

Keywords: Early Intervention, VHT/VIG, family support, supervision

The effect of self-regulation training strategies on the academic motivation and self-efficacy

Masoud Gholamali Lavasania*, ,Fatemeh Sadat Mirhosseini a,,Maryam Davoodi a

aDepartment of Educational Psychology and Counselling, University of Tehran, Tehran, Iran

Problem Statement: With considering the importance of academic motivation and self-efficacy of students in educational environments, and relationships between student use of self-regulation strategies and motivational beliefs, as well as 
enhancing the skills required of early years education, the present study was conducted the impact of self-regulation learning strategies on academic motivation and self-efficacy elementary school fifth grade students.

Purpose of Study: The purpose of this study was to determine the effects of self-regulation training strategies on the academic motivation and self-efficacy of students.

Research Methods: The design of research was quasi-experimental method with pretest-posttest. subjects were 46 elementary-school girls that selected from the fifth grade school and were put at two groups(23 experimental group and 23 control group).At first the students were tested with motivated strategies for learning questionnaire (MSLQ),academic motivation scale and self-efficacy scale. The experimental group were trained with self-regulation training strategies in 10 sessions of 60 minutes duration, and then scores of the two groups were compared in post tests.

Findings: Data was analyzed using analysis of covariance (ANCOVA). At academic motivation and self-efficacy, experimental group was significantly $(p<0.05)$ higher than control group.

Conclusions: The result indicated that self-regulation program strategies led to increased academic motivation and self-efficacy and the implications for future research and self-regulation learning programs for elementary students are discussed and proposed.

Keywords: self-regulation training; academic motivation; academic self-efficacy

Dr. J. Roberts (PhD) \& Ms. Cheryl Whiting (M.A.)

University of Victoria

Victoria, British Columbia, CANADA

\section{Problem Statement:}

Children with epilepsy comprise a large percentage of the chronic health population and many of these children struggle with learning and social relationships. It is therefore crucial that educators understand the special educational needs of these children so that they can create optimal learning experiences for them. 
This oral presentation will present data from a study investigating the QOL of children with epilepsy and their families. The specific objectives of the study were to: (a) Identify the perceptions and psycho-social experiences of the primary caregivers of children with epilepsy regarding their interaction with the schools which impact both the child and family's quality of life, and (b) clarify how families think schools can best support, accommodate, and prepare for these children and families. This oral presentation will focus primarily on the special educational needs of these children.

\title{
Research Methods:
}

To meet these objectives, this study adopts a qualitative (phenomenological) methodology. Interviews were conducted with seven families of children diagnosed with epilepsy and who were between the ages of 5 and 12. Each interview was recorded, transcribed and carefully analyzed to identify patterns/themes that created a deep understanding of the family's school and QOL experiences.

\section{Findings:}

Five themative categories were elicited from the interviews: (1) Health-Related Issues (2) Family Coping, (3) Acadmic Experiences, (4) Social Belonging, and 5) Awareness.

Conclusions:

These findings offer special educators important information about how to better prepare, support, and accommodate children with epilepsy. With the movement toward inclusive educational practices understanding how to best support and accommodate children with health-related challenges is crucial.

Keywords:

Special education; epilepsy; medically fragile school children

\section{Language, technology and culture: Interrogating research data in the Hong Kong higher-education context}

\author{
Carmel McNaught \\ Director of the Centre for Learning Enhancement And Research (CLEAR) \\ The Chinese University of Hong Kong
}

Problem Statement:

Hong Kong society is Cantonese in language and culture. While the universities in Hong Kong are well-connected internationally and academics in Hong Kong regard themselves as being as belonging to a global higher-education community, there are subtle nuances in how educational relationships are negotiated that broadly relate to the Chinese concept of 'face' but have particular characteristics that relate to Hong Kong and the desire to preserve Cantonese language and culture within a greater (and somewhat overwhelming?) national Chinese identity. Interrogating and interpreting research data in the Hong Kong higher-education context requires an understanding of these subtleties.

Purpose of Study:

This paper has been written in order to articulate and explore the implications of these complex and subtle linguistic and cultural nuances for educational research.

\section{Research Methods:}

Staff in the Centre for Learning Enhancement And Research (CLEAR) at The Chinese University of Hong Kong (CUHK) have conducted a number of research projects focusing on several aspects of learning design, with a particular focus 
on the incorporation of interactive learning activities and technology-enhanced teaching and learning. In this paper I will present a qualitative meta-analysis across a number of these projects, seeking to show how the Chinese concept of 'face' is instantiated in a Hong Kong context.

\section{Findings:}

Each teacher needs to establish a 'mutual comfort zone' in her/his class in order to engage students in debate, and foster honest interchange and active exploration of ideas. There are a number of tensions that need to be negotiated in this process. Two examples are:

- The need for individual rewards through grades versus designing for learning that focuses on group responsibility in order to protect each person's 'face'.

- The need for careful record-keeping and accountability for quality-assurance purposes versus the 'hidden rules' that operate in Hong Kong.

\section{Conclusions:}

The findings from this paper are (subtly) incorporated into the professional-development programmes that CLEAR runs for teaching staff at CUHK. Feedback indicates that this is an important aspect of CLEAR's work.

\section{Second Language Learning: Using ePortfolios and mobile devices to address student learning outcomes}

\section{Problem Statement:}

$$
\text { David M. Kennedy }
$$

Director of the Teaching and Learning Centre (TLC) Lingnan University, Hong Kong

Lingnan University is unique amongst the universities in Hong Kong. It espouses a Liberal Arts philosophy within an Outcomes-based Approach to Teaching and Learning (OBATL). English and Putonghua are key elements of a Lingnan experience. The need to provide evidence of learning outcomes, within a culture that does not always value English as a second language, is challenging for both teachers and the University.

\section{Purpose of Study:}

This paper describes recent work that has been undertaken to broaden the basis for assessment of student Englishlanguage competencies and student approaches to learning using an open-source ePortfolio (Mahara), while simultaneously addressing staff workload. The changes were initiated by the change to an OBATL, evidence of excessive staff workloads, and the need to engage students in more reflective practice as part of the broader Liberal Arts experience.

\section{Research Methods:}

The TLC and the Head of the Centre for English and Additional Languages (CEAL) have collaborated to create a more student-centred learning environment. Data include assessment evidence of English-language competencies and skills, survey data on student approaches to learning, and staff assessment of changes in workload. Both qualitative and quantitative data have been gathered and analysed, leading to curriculum and instructional changes that are evidence-based.

Findings:

The most significant findings are derived from the analysis of student approaches to learning using the Student Process Questionnaire (SPQ), before and after the course, and the Course Teaching and Learning Evaluation (CTLE) data. We found that while some students' expectations have been met, it is clear from the data that many students have an 
instrumental view of learning English, radically different from the expectations of teachers. Teachers believed that students would be more intrinsically motivated to learn English, and more understanding of the need for independent learning. This results in a disjuncture between students' and teachers' expectations.

Conclusions:

The findings have informed the curriculum design of the course for the coming semester, and highlighted the need for teachers to receive further staff development.

Keywords: Hong Kong; English; second language; ePortfolios; outcomes

SEX EDUCATION AMONG PORTUGUESE ADOLESCENT STUDENTS

Lúcia Ramiro (1,2,3,4), Marta Reis (1,2,3,5), Margarida Gaspar de Matos $(1,2,5,6)$ \& José Alves Dinis $(1,2,6)$

1- $\quad$ Projecto Aventura Social - Faculdade de Motricidade Humana, Technical University of Lisbon, Portugal

2- Investigator CMDT/Instituto de Higiene e Medicina Tropical/UNL, Lisbon, Portugal

3- $\quad$ PhD student - Fundação para a Ciência e a Tecnologia - SFRH/BD/43388/2008; SFRH/BD/37583/2007

4- $\quad$ Teacher

5- Psychologist

6- Professor

Problem Statement: Sexual and reproductive health is fundamental to the development of society. Adolescents need skills and information in order to avoid getting involved in risky behaviors. They spend a significant part of their time at school, where there are all necessary resources for education, hence the importance of sex education in school context.

Purpose of Study: Sex education is becoming a regular practice in Portuguese schools. The aim of this research was to deepen knowledge of sexual behavior in Portuguese adolescents, as well as their opinion on sex education.

Research Methods: Data were collected through a self-administered questionnaire from the Portuguese sample of the Health Behavior in School-aged Children (HBSC), a collaborative WHO study. The study provides national representative data of students attending $6^{\text {th }}, 8^{\text {th }}$ and $10^{\text {th }}$ grades. The 2010 sample is constituted by 5050 participants $(52.3 \%$ female and $47.7 \%$ male), with an average age of 14 years old. A subset of participants attending $8^{\text {th }}$ and $10^{\text {th }}$ grades was constituted in order to study sexual behavior.

Findings: The findings show that $21.8 \%$ of adolescents are sexually active and had their first sexual intercourse at fourteen or more. Considering those who are sexually active, $82.5 \%$ referred having used condom and 53.5 the contraceptive pill during last sexual intercourse. Results showed that, in general, adolescents consider sex education will help them have better knowledge, $65,9 \%$ stated they had already had sex education lessons, which was recognized as very useful by the majority. Nevertheless, they prefer to talk about it with friends and colleagues than to parents and teachers. Regarding the sources of information, $65.8 \%$ chose the internet.

Conclusions: Sex education may have been responsible for the positive evolution in adolescents' sexual risk behaviors. Nevertheless, there's still a long way to go since there are still adolescents that get involved in risk behaviors and overall they do not feel comfortable addressing those themes with teachers. Programs have to take into account these results so that they can be better suited for adolescents.

Keywords: sexual education, school, programs 
Problem Statement:

The motivation should be seen as a very important factor in the learning process. The motivated student has the inner strength to learn, to discover and capitalize capabilities, improve academic performance and adapt to the demands of the school context. The interpersonal environment in which they develop the teaching / learning process should enable the student to feel supported, respected as a person and able to guide and direct their own action. An atmosphere of optimism increases motivation. Given this problematic we question how the sense of belonging to school and intrinsic motivation for the course influences the perception of learning in the course.

\title{
Purpose of Study:
}

Motivation is seen as an essential element in resource utilization of the subject to achieve a goal, with particular emphasis on school learning. So with our study we intend to examine how the sense of belonging to school and intrinsic motivation for the course influences the perception of learning in the course.

\section{Research Methods:}

This is a quantitative research intended to analyse the relationship between constructs like academic achievement, learning performance, teacher-student interaction, student-student interaction and self-esteem. Lisrel software was used to develop the Structured Equation Model of academic achievement determinants.

Findings:

The research carried out involved administering a set of educational scales to a sample of 1986 high students. The sample includes $38,5 \%$ male and $61,5 \%$ female students, with ages between 14 and 22 years old, of the different levels of secondary education; $78 \%$ of the students failed at least one time, $36 \%$ study less than an hour per day whereas $45 \%$ study one to two hours, and $8 \%$ study between three and five hours.

\section{Conclusions:}

A structural model reveals that the negative sense of belonging to school has negative impact on the intrinsic motivation and perceived learning the course. Intrinsic motivation for the course positively influences the perception of learning in the course.

Keywords: Perception of learning, motivation, sense of belonging to school

\author{
Risk Behaviour: Substance Use among Portuguese Adolescents \\ Mafalda Ferreira, Faculty of Human Kinetics \\ Margarida Gaspar de Matos, Faculty of Human Kinetics
}

Problem Statement: To better understand substance use during adolescence, it is critical to assess the differences in personal characteristics, as well as social, cultural and environmental factors and the interaction between these factors. The school context and the social environment in which the adolescent is integrated have been identified as the most consistent predictors of substance use in adolescence, thus the need to explore behaviors associated with these specific contexts, and therefore improving prevention of this harmful behavior.

Purpose of Study: The purpose of this study was to understand the evolution of substance use, namely tobacco, alcohol and drugs, as well as the relationship with other risk behaviors among Portuguese adolescents. 
Research Methods: The data in the study derives from a collaborative study with the World Health Organization, integral part of the HBSC study - Health Behavior in School-aged Children - developed by the Portuguese team. The sample consists of over 17000 adolescents in the 6th, 8th and 10th grades of the public school system with an average of 14 years old $(\mathrm{SD}=1.81)$. The measure, on which this study is based on is a self-administration questionnaire, applied in school by teachers and in which some questions regard substance abuse (tobacco, alcohol and drugs).

Findings: The results show a decrease in substance use from the 2002 study to the 2010 one. Regarding differences according to gender, age and social economic status, it shows a bigger user on part of boys in classes of the 10th grade and in lower social economic status, therefore, agreeing with the theoretical results of literature.

Conclusions: In the present study, we sought to establish a pattern of evolution at the level of substance use, including tobacco consumption, frequency of drunkenness, ever having tried cannabis and consumption of illicit substances in the last 30 days. The HBSC survey results in the construction of a coherent set of indicators that, taken together, provide a valid representation of health and lifestyles of adolescents and its temporal evolution, enabling a careful assessment of health policy systems and intervention in order to promote health and prevention of risk behaviors, specifically the use and abuse of substances during adolescence.

\section{THE EFFECTS OF SEX EDUCATION IN PROMOTING SEXUAL AND REPRODUCTIVE HEALTH IN PORTUGUESE UNIVERSITY STUDENTS}

Marta Reis (1,2,3,4), Lúcia Ramiro (1,2,3,5), Margarida Gaspar de Matos $(1,2,4,6)$ \& José Alves Diniz $(1,2,6)$

7- Projecto Aventura Social - Faculdade de Motricidade Humana, /Universidade Técnica de Lisboa, Estrada da Costa, 1495688 Cruz Quebrada, Portugal

8- Investigator CMDT-LA/UNL - Centro da Malária e Doenças Tropicais, Laboratório Associado. Instituto de Higiene e Medicina Tropical, Universidade Nova de Lisboa, Rua da Junqueira, 96, 1349-008 Lisboa, Portugal

9- PhD student - This study was supported by a FCT grant (SFRH/BD/37583/2007;SFRH/BD/43388/2008)/ CNLCS/ACS/CMDT - La/UNL.

10- Psychologist

11- Teacher

12- Professor

Problem Statement: Sexuality continues to be, in many countries, an area that requires urgent interventions. In recent years, it has been observed an evolution in terms of sexual and reproductive health in Portuguese youngsters, but not all claim to have a preventive sexual behaviour yet, and not having preventive sexual behaviours, can have serious consequences in terms of public health. For this reason, most research emphasizes the importance of sex education from the earliest school years and identify young people as an important target group for prevention.

Purpose of Study: The goal of this research was to analyze the significance of sex education in schools and what are its effects in promoting healthy sexual behaviour of university students.

Research Methods: The Health Behaviour in School-aged Children (HBSC) is a collaborative WHO study, developed by 44 countries in order to study health and risk behaviours in adolescence. This particular study - the Sexual and 
Reproductive Health in College Students (HBSC / SRHCS) - is an extension of the HBSC in college students. This study has the approval of a scientific committee, an ethical national committee and the national commission for data protection and followed strictly all the guidelines for human rights protection. The study provides national representative data of 3278 Portuguese college students, between 18 and 35 years old. The sample included $70 \%$ women and $30 \%$ men, whose mean age was 21 years. The majorities of students are of Portuguese nationality (97.3\%), single (95.5\%), catholic (71.9\%) and heterosexual (96.4\%).

Findings: College students who had sex education in high school mentioned more often having had fewer sexual risk behaviours (less occasional partners, less sex associated to alcohol and drugs, less STIs, less unwanted pregnancies and abortions) than those who had not.

Conclusions: It was found that sex education, as a continuous process of learning and socialization that includes, not only transmitting information, but also the development of attitudes and skills related with human sexuality, is the most important way to prevent problems related to sexual and reproductive health of young people.

Keywords: sexual education, promoting sexual and reproductive health, college students

Learning Outcomes and the European Qualifications Framework in Higher Education - Awareness and attitudes of stakeholders across different European countries

Eline Leen, Friedrich-Alexander-University of Erlangen-Nuremberg, Germany

Thomas Kretschmer, Maria Begoña Arenas Romero, SCIENTER, Spain

\section{Problem Statement:}

The shift towards an authentic "Learning Outcomes" approach in Higher Education (assessing outcomes rather than effort) is a challenging endeavour which requires a change in mind-set and practice at all levels (programs and course design; teaching and assessment practices; quality assurance approaches; dialogue with the other learning systems and society). However, when intended as more than a "cosmetic" exercise, the Learning Outcomes approach has the potential of building reliable and systematic bridges between the "Ivory Towers" of higher education and society, thanks to the use of an agreed common language. The UNILO project aims exactly at promoting this understanding of the learning outcomes approach in European higher education systems, to make them more effective and increasingly oriented towards lifelong and life-wide learning.

\section{Purpose of Study:}

The research project UNILO thus intends to explore the Learning Outcomes approach in the frame of EQF/EHEA contributing to its full understanding and application by promoting the active involvement of the Career services of the Universities helping the huge target group of European University students and holders of professional qualifications to better understand its potential.

\section{Research Methods:}

An online survey was set up, consisting of questions on personal data, 10 questions on knowledge about the basic concepts of Learning Outcomes and the Bologna process for all respondents and 30 questions for the more experienced respondents.

3,534 data sets from 32 European countries were analysed, and 187 participants also completed the second part for the more experienced respondents. 
Findings:

The survey showed that the majority of the respondents has a very limited knowledge about the Bologna Process or the Europeans Qualifications Framework. Most of them have never heard of these terms. Those who have experience with the approach have a rather positive attitude towards LOs and EQF.

Conclusions:

The results indicate that there's a huge diversity with respect to the awareness about LOs and EQF/NQF in Europe. Surprisingly, even many HE professionals are unaware of the concepts. Well-informed respondents have a rather positive attitude towards LOs and EQF. Most HE institutions show at least some activity to promote the approach(es).

Keywords: Bolonga Process, European Qualification Framework, Learning Outcomes, higher education

\section{BULLYING AND SCHOOL DISRUPTION ASSESSMENT: STUDIES WITH ADOLESCENTS STUDENTS}

\section{Feliciano H Veiga - University of Lisbon, Institute of Education}

Abstract

In many countries, schools are daily faced with levels of indiscipline and violence that make difficult to create a conducive climate to teach and learn. The assessment of these occurrences have been made in various ways and with different types of structure, then for initiatives that took place in schools, now more closely connected to the central power structures. Thus, it is formulated the follow problem: How bullying and the school disruption has been assessed in the research? The propose of this study is to present, as a first point, a review of instruments about the assessment of school disruption, especially findings with the "School Disruption Scale Inferred by Teachers" (SDS-IT, 2006) and the "School Disruption Scale Professed by Students", SDS-PS (Veiga, 2009, 2010). Secondly, this research presents new findings in the bullying assessment, especially with the "Multidimensional Peer Victimization Scale" with adolescent students. Results in these instruments are presented in function of personal, school and familiar variables. This study found a diversity of instruments with many dimensions, underlines conclusions and provides recommendations for future research.

Keywords: School disruption, bullying, peer victimization, assessment.

Teaching Media Psychology and Media Ethnographic Methods in Technical Educations

Lise Busk Kofoed, Department of Architecture, Design and Media Technology, Aalborg University Denmark. Email: lk@create.aau.dk

Eva Petersson Brooks, Department of Architecture, Design and Media Technology, Aalborg University Denmark. Email: ep@create.aau.dk

Problem Statement: To develop a course in media psychology and media etnographical methods for the 6. Semester medialogy students. The course should have relevant theoretical and methodological content and be related to students future professional praksis. The course has to be evaluated during written and oral exams.

Purpose of Study: To develop and design a course in which got students motivated to learn the psychological aspects of the media they are working with. To teach students to use ethnographich methods and especially video ethnography, and to make students work with their gained knowledge in a scientific way.

Research Methods: A case study during 3 years of continious development and improvement of the course, media psychology and media etnographical methods. All study plans, exams results (written and oral) and evaluations are collected. From the last course data from 94 students involvement in the course, their written and oral exams are analyzed. 
Findings:The course design as a workshop did function very well, and the practical aspects of the course was important for the students. The theory was used to a grat extend in the students final exam paper and $80 \%$ of the students were able to discuss and reflect the different theories and methods they have used. The exam results show that $75 \%$ of the students have reached the level of syntheses and evaluation according to Blooms taxonomy.

Conclusions: : It is important to connect the course and the course assignment to the students general semester study (their semester project). The course assignments has to be concrete and with 'hand on' experience. It is also important to find methods for the oral exam so the students psychological and methodological knowledge can be evaluated in relation to their ability to frame it in analytical, critical and reflective ways.

Keywords:

Media psychology - media ethnographic methods - technical educations - problem based learning

\section{Teaching Media Psychology and Media Ethnographic Methods in Technical Educations}

Medialogy Bachelor Programme is a cross-disciplinary education at Aalborg University in Denmark, where engineering and science are combined with humanities and social sciences. The education is centred on knowledge, skills, and competencies related to development, evaluation, and implementation of digital media applications applying an interaction design approach. In this way, technologies, media, and use aspects are intertwined in creative and crossdisciplinary ways.

This paper describes the development of a course (Media Psychology and Media Ethnographic Methods [MEM]) for $3^{\text {rd }}$ year Bachelor students within the Medialogy program. The course has been run and continuously refined during a 3-year period including totally 250 students. The course is developed using a Project Organized Problem Based Learning approach (POPBL) which is the general pedagogical approach at Aalborg University. Social semiotics provides a way of conceptualizing teaching and learning activities emphasizing a primary focus on communicative resources (signs) and the use of such resources within a specific discourse and frame. Many of the students within the Medialogy program consider the media technological aspects of the education most important and the courses including humanities and social features not so crucial, therefore, our concern was to create conditions where the students' agency could be manifested in different creative and communicative activities. Within the framework of the course, students chose a 'case' to wok with, including problem analysis, problem formulation, choice of methods and theories, and, finally, reflection and discussion. The examination was established based on assignments and a written paper combined with individual oral question.

In this paper, the background pedagogical principles (POPBL) are described as well as course development and content, applying a social semiotic perspective. Examination assignments and the evaluation of 250 students written reports and oral examination are discussed. Exams assignments and the evaluation are discussed. Exams results show that more than $75 \%$ of the students have reached the level of syntheses and evaluation according Blooms taxonomy in their written exam assignment (mini-projects). Furthermore, individual transformation and appropriation was apparent from shared (peer) thinking. For example, the mini projects showed a creative use of edited video material, which was related adequately to ethnographic methods and media psychological theories. Data from the oral exam shows that $80 \%$ of the students were able to critically discuss and reflect upon theories and methods they have used. 
The Effect of Task Complexity on EFL learners' Written performance

Asghar Salimi (Ph.D Candidate), English department, Maragheh University, Maragheh, Iran Asgharsalimi356@gmail.com

Tel: +989143802607

Soghra Dadashpour, Hassan Asadollahfam (Ph.D), Islamic Azad University, Bonab Branch, Iran Asadollahfam@yahoo.com

\section{Problem Statement:}

Over the two decades, task-based language teaching, learning, and syllabus design has become a bourgeoning area of research in SLA. Selecting, sequencing, and grading in terms of cognitive factors in tasks have been one of the controversial issues in language teaching and syllabus design.

\section{Purpose of Study:}

This study intends to examine the effects of manipulating task complexity along resources- directing factors based on Robinson's Cognition Hypothesis on L2 learners written performance.

\section{Research Methods:}

For the purpose of the study, the collected written data from 29 female senior college students of ELT were obtained and quantified in terms of measures of accuracy, fluency, and complexity introduced by Ellis (2008). T-test was employed as the statistical means of analysis to compare the means of accuracy, fluency, and complexity between simple and complex tasks.

\section{Findings:}

The results of the analyses showed the significant differences between the performance of learners on simple and complex tasks in terms of accuracy, fluency, and complexity.

\section{Conclusions:}

The results carry important and illuminating pedagogical implications for syllabus and task designers, language teachers, SLA researchers, and language testers.

Thematic Section is Learning Theories and Second Language Teaching.

\section{Keywords:}

Task-based Language Teaching and Learning, Task Complexity, Accuracy, Fluency, Complexity, Cognitive Load 
The efficacy of narrative therapy and storytelling in reducing reading errors of dyslexic children

Parisa Rahmani

Master of art in General Psychology

The member of young researchers club of Islamic Azad University of Tabriz branch

Narrative and stories in education have been the focus of increasing attention in recent years. The idea of narrative is fertile ground for adult educators who know intuitively the value of stories in teaching and learning. Narrative is deeply appealing and richly satisfying to the human soul, with an allure that transcends cultures, centuries, ideologies, and academic disciplines. The present study examined the efficacy of narrative therapy and storytelling in reducing reading errors of dyslexic children. Sample of 30 dyslexic 1st to 3rd graders were identified as dyslexia using the Dyslexia Checklist (Michaeli, 2006). The sample was administered the Wechsler Intelligence Scale for Children (WISC-R,1974) and Diagnostic Reading Test (Bahari Gharahgoz, 2006) and randomly assigned to an experimental and a control group. During a five month period, the experimental group received twenty five, one hour sessions of individual training with the narrative therapy by counselor and storytelling by children. The control group received none. The two group pre-post tests of reading errors were compared using ANCOVA. The results revealed that, controlling for the intelligence variable, the application of narrative therapy accounted for a $60 \%$ reduction in reading errors.

Key_words: narrative therapy, story telling, dyslexia, reading 
The relationship between self-esteem, achievement goals and academic achievement among the primary school students Parisa Rahmani

Master of art in general psychology

The member of young researchers club of Islamic Azad University of Tabriz branch

The aim of present research is studying relations between self-esteem, achievement goals and academic achievement among the primary school children. Self-esteem and achievement goals orientation are the most important factors that effects on academic achievement among the students. For this reason, 200 primary school students (100 male, 100 female) were chosen randomly and then for data collection two questionnaires were used: Eysenck self-esteem questionnaire (Eysenck,1976) and Students' Achievement Goal Orientations check list (Midgely,et al.,1998). The gold standard for academic achievement was their average academic marks during their academic years. Data were computer analyzed, using SPSS 15.1 and running a couple of descriptive and analytical tests including Pearson Correlation and t-student. Result of research showed that self-esteem, goal orientation components (mastery, approach performance and avoidance performance) and academic achievement are correlated $(p<0.05)$.in addition to, Results of $t$-student also show that there are significant differences between male and female students in scores of self-esteem and achievement goals orientation. The results of this present research revealed that selfesteem is an affecting factor on achievement goals among the primary school students.

Keywords: self-esteem, achievement goals, primary school, student

A comparison method of equating Classic and Item Response Theory (IRT): A case of Iranian study in the university entrance exam

Ali Moghadamzadeh

PhD candidate, University of Allameh Tabatabaei, Tehran, Iran

Keyvan Salehi

PhD candidate, University of Tehran, Tehran, Iran

Ebrahim Khodaie

$\mathrm{PhD}$ of Statistic in Economic, Tehran, Iran 
Various tests, or forms, are being used in our professional practices to measure the same attributes. Test scores from these tests, however, cannot be used interchangeably. This is because the scores from different tests may be on different scales. That is, a test equating procedure must be employed (Weimo, 1998). Despite of this importance, there aren't sufficient field researches which compare method of equating Classic and Item Response Theory (IRT).

Purpose of Study:

The purpose of this study is to compare method of equating Classic and Item Response Theory (IRT) to identify the advantages and potential applications of test equating

\title{
Research Methods:
}

Data were collected from the Iranian university candidates who took the university entrance exam in the field of mathematic in 2005 . The sample size is 2000 subjects and SPSS, BILOG were used to analysis data.

Findings:

By using the existing collection of data and the methods of measurement and applying the equating, the test was explained completely by an example which consisted of two other tests. Consequently, these two tests in one common scale were equated and the accuracy of equate was evaluated by both equating the models of surveying of accuracy.

\section{Conclusions:}

Finally, the advantages and potential applications of test equating in the measurement of outputs and movement skill were explained in detail.

\section{Keywords:}

Item-Response Theory (IRT), Classic Theory, equating methods, national university entrance exam, the advantages and potential applications of test equating,

\section{A comparison the information functions of the item and test in one, two and three parametric model of the Item Response Theory (IRT)}

\author{
Ali Moghadamzadeh \\ PhD candidate, University of Allameh Tabatabaei, Tehran, Iran \\ Keyvan Salehi \\ PhD candidate, University of Tehran, Tehran, Iran \\ Ebrahim Khodaie \\ PhD of Statistic in Economic, the National Organization for Educational Testing (NOET), Tehran, Iran
}

Problem Statement:

As every test is composed of a number of items each of which contributes to the accuracy of measurement, one can, through the information function of test items, gauge each test item information function at any given ability level, thereby determining the whole test information function (Hambelton \& Cook, 1977). Also if information value is low, the testee's ability cannot be estimated with accuracy and estimation values will basically be less evenly distributed around the true ability level (Friedrich, 2004). Despite of these evidences, there aren't sufficient field researches which compare test and item function in one-, two-, and three-parameter models in the item response theory. 
The purpose of this study is to compare test and item function in one-, two-, and three-parameter models in the item response theory.

\section{Research Methods:}

Information function is discussed from a theoretical and psychometric perspective. Statistical population was the Iranian university candidates who took the university entrance exam in the field of mathematic in 2005.the sample size was 2000 subject and SPSS, BILOG were use to analysis data.

Findings:

The result obtained indicate that the value of test and item information function in the two- parameter models is higher than the same value in the one-or two -parameter models and that the value of test and item information function in the one -parameter models is not different from the same value in the three - parameter model.

\section{Conclusions:}

The results show that the information value is different in the IRT three models and also there is a reverse relationship between the information value and the standard error of measurement. Finally the reliability indices calculated based on ability levels are different.

\section{Keywords:}

Item-Response Theory (IRT), information function, national university entrance exam, one, two and three parametric model

Factors affecting the probability of academic cheating school students in Tehran

\section{Ebrahim Khodaie}

PhD of Statistic in Economic, the National Organization for Educational Testing (NOET), Tehran, Iran

Ali Moghadamzadeh

PhD candidate, University of Allameh Tabatabaei, Tehran, Iran

Keyvan Salehi

PhD candidate, University of Tehran, Tehran, Iran

\section{Problem Statement:}

Academic cheating is a new study in the field of education in Iran and its consequences are not visible. Cheating is known as an immoral work in the academic environment to learn (Mccabe \& Derinan, 1999). In other countries, in the field of academic research have been many researches, indicating that important factors in the fraudulent behaviour of students are involved (Ludvigon, 1995). Meanwhile, between cheating in universities and professional behaviour in the workplace is a close relationship despite of these evidences, there aren't sufficient field researches which identify the main factors of Cheating in schools.

\section{Purpose of Study:}

The purpose of this study is to identify Factors affecting the probability of academic cheating school students in Tehran

\section{Research Methods:}

Twenty-fold from all regions sampled in Tehran that the method is a class type and groups relatively time is selected. The sample size is approximately 336 people.

\section{Findings:}

Results show that social and economic status, a commitment to discipline and rules and also history of cheating a significant relationship are related with the Possibility of cheating. According to the test 
Regression logistic Factors like education level, age, quantitative study and education of father have a very important role in motivation of cheating.

\title{
Conclusions:
}

According to the results reported in $95 \%$ of students cheated on a test during the school year confessed, the amounts of people who have managed to cheat $70 \%$ have been reported. Understanding the reasons for cheating can be direct responses to people, hard materials, and teacher indifferences and at the end of a serious failure to lack of students study noted. More people who have a history of possible cheating committed fraud in the future for them are more than others.

\section{Keywords:}

Academic cheating, school students, teacher, educational materials, social and economic status

THE EFFECT OF DIGITAL GAMES ON IRANIAN CHLIDREN'S VOCABULARY RETENTION IN FORIEGN LANGUAGE

\section{ACQUISITION}

Laleh Aghlara (MA)

Member of Scientific Association, English Language Teaching, Tabriz Branch, Islamic Azad University, Tabriz, Iran Nasrin Hadidi Tamjid (PhD)

Department of English Language Teaching, Tabriz Branch, Islamic Azad University,

Tabriz, Iran

\begin{abstract}
Computer games, today, occupy an important part of most children's leisure time. However, especially for digital games, a great debate has emerged about how these games influence children's behaviours, and what is the role of these new media in children's learning. It seems that computer games might be powerful new resources to support learning in the information age. Some educators argue that these games have the potential to become powerful motivating digital environments. They study digital games in order to determine how motivational components of popular digital games might be integrated into instructional design. In this study, a digital computer game, called SHAIEx (Agudo et al., 2007), which is designed to facilitate children's English vocabulary learning, was used to investigate its role on promoting Iranian children's vocabulary learning. There were two groups in the study, one experimental and the other control group. In the experimental group, the SHAIEx digital game was used whereas in the control group, English vocabulary was taught through traditional methods. At the end of the teaching period, which lasted 45 days, the participants' performances were compared using an independent samples t-test. The results indicated that the mean score of the children in the experimental group was significantly higher than those in the control group, indicating the positive effect of using digital games in teaching English vocabulary to children. . It is hoped that communicative language games will attract more attention and will be applied more widely in the EFL classrooms.
\end{abstract}

Keywords: Computers, Digital games, Vocabulary retention 
a The 15th of Sha'ban specialized clinic, Tehran, Iran

${ }^{b}$ Department of preschool Education, University of social welfare and rehabilitation siences, Iran

c Pajuheshgaran Training Complex, Tehran, Iran

'University of Al-Zahra, Tehran, Iran

\section{Problem Statement:}

When parents involved in anxiety, can not play important rules in communications, and children learn basic life skills in family,considering that this anxiety influence the Self-efficacy training and poor Academic achievement, Social and Emotional problems.

Purpose of Study:

The aim of the study is to investigate the relation between parents' anxiety and children's emotional -academicsocial self-efficacy, in both genders (girls and boys).

Research Methods:

The design was correlation. The instruments use in this study were: children's self-efficacy questionnaire (SEQ-C), which assessed the self-efficacy of children in three categories : emotional, academic, and social. Cattel anxiety questionnaire, which assessed the parent's anxiety.

Findings:

showed that mother's anxiety and boy's self-efficacy were negatively correlated. $(r=-0 / 242)$ father's and mother's anxiety and girl's self-efficacy were negatively correlated. $(r=-0 / 284, r=-0 / 537)$.

Conclusions:

According to the results parents' anxiety and children's self-efficacy were negatively correlated. Higher parent's anxiety was correlated with lower children's self-efficacy. The maternal anxiety had more effect on this correlation. The results also demonstrated that self-efficacy in girls were more influenced by both parents' anxiety, while self-efficacy in boys was just influenced by mother's anxiety.

\section{Keywords:}


How does systematic motivational counseling affect the students' academic achievement motivation?

Maryam saadat , Azizreza Ghasemzadeh, Elaheh Mazaheri

apajuheshgaran Training Complex, Tehran, Iran

${ }^{b}$ Department of preschool Education, university of social welfare and rehabilitation of Iran

'The 15th of Sha'ban specialized clinic, Tehran, Iran

Problem Statement:

Yearly, a large number of students leave the schools although they are smart and talented. Some factors that are influential in leaving university are academic achievement motivation and test anxiety. Academic achievement motivation is defined in terms of tendency to overcome barriers, utilizing talents and effort to do difficult and challenging works (Petry, 1996). In this research, SMC has been used as performance increasing factor to increase student's motivation.

Purpose of Study:

The main objective of this research is to determine the effect of systematic motivational counseling (SMC) method on high school student academic achievement motivation.

Research Methods:

Thirty students were randomly chosen for this research. These people were divided into two groups of control and intervention. Both groups responded to the inventory of school motivation questionnaire as the pretest. At first 14 sessions of systematic motivational counseling were held for the intervention group and then both groups recompleted the mentioned questionnaire as the post test. After gathering the data, results were analyzed through statistical methods such as Analyzing Co-variance (ANCVOVA) and block variance analysis,

Findings:

Results indicated that SMC has increase the motivation of the participants, toward a better achievement in their academic performance $(p<0.05, F=134.997)$.

Conclusions:

the results of the study are indicatives of the effectiveness of SMC on the Academic motivation of the participants and encourage them to obtain better scores in their academic activities.

Keywords:

Systematic motivational counseling, Achievement motivation, Academic achievement motivation

Investigating Secondary School Students', Student Teachers', and Exemplary Teachers' Experiences and Opinions Regarding Video Games in Education

Dr. David Kaufman, Professor

Faculty of Education

Simon Fraser University

Burnaby, BC, Canada

Problem Statement: The power of video games to engage young people and hold their attention for long periods of time is a subject of great interest to educators and researchers. These games often require strategic thinking, technical language, and sophisticated problem solving skills. However, there is also concern in the educational community about the effectiveness of video games for supporting classroom instruction, how to adapt them into the existing curriculum, the logistics of implementation, and controversy about the possible negative effects of video games. 
Purpose of Study: The purpose of this study was to compare secondary student experiences and opinions about video games and education with those of student teachers enrolled in the Professional Development Program (PDP) in the Faculty of Education at Simon Fraser University (SFU), and exemplary experienced school teachers acting as Faculty Associates (FAs) (i.e., teacher educators) for the PDP program.

Research Methods: Three unique groups were surveyed. The FA group consisted of 24 exemplary and experienced professional teachers selected by the university to act as teacher educators. The PDP group consisted of 15 student teachers enrolled in a one-year teacher education program. The secondary student group comprised 86 students in grades eleven and twelve from four secondary schools. Participants completed an online survey consisting of five sections including 35 multiple choice and open ended questions.

Findings: The results showed that there are significant differences in experiences and opinions among the groups. The results also demonstrate that a majority of secondary school students and PDP teachers think that using video games to help teach in secondary education is a good idea, while a majority of faculty associates do not agree.

Conclusions: The results strongly suggest that professional educators do not have the same level of experience or knowledge about video games compared to secondary students and student teachers and that there is an 'electronic entertainment generation gap' among professional teachers, secondary students, and student teachers. (318 words)

Keywords: videogames, digital games, secondary school, teacher education, educational technology

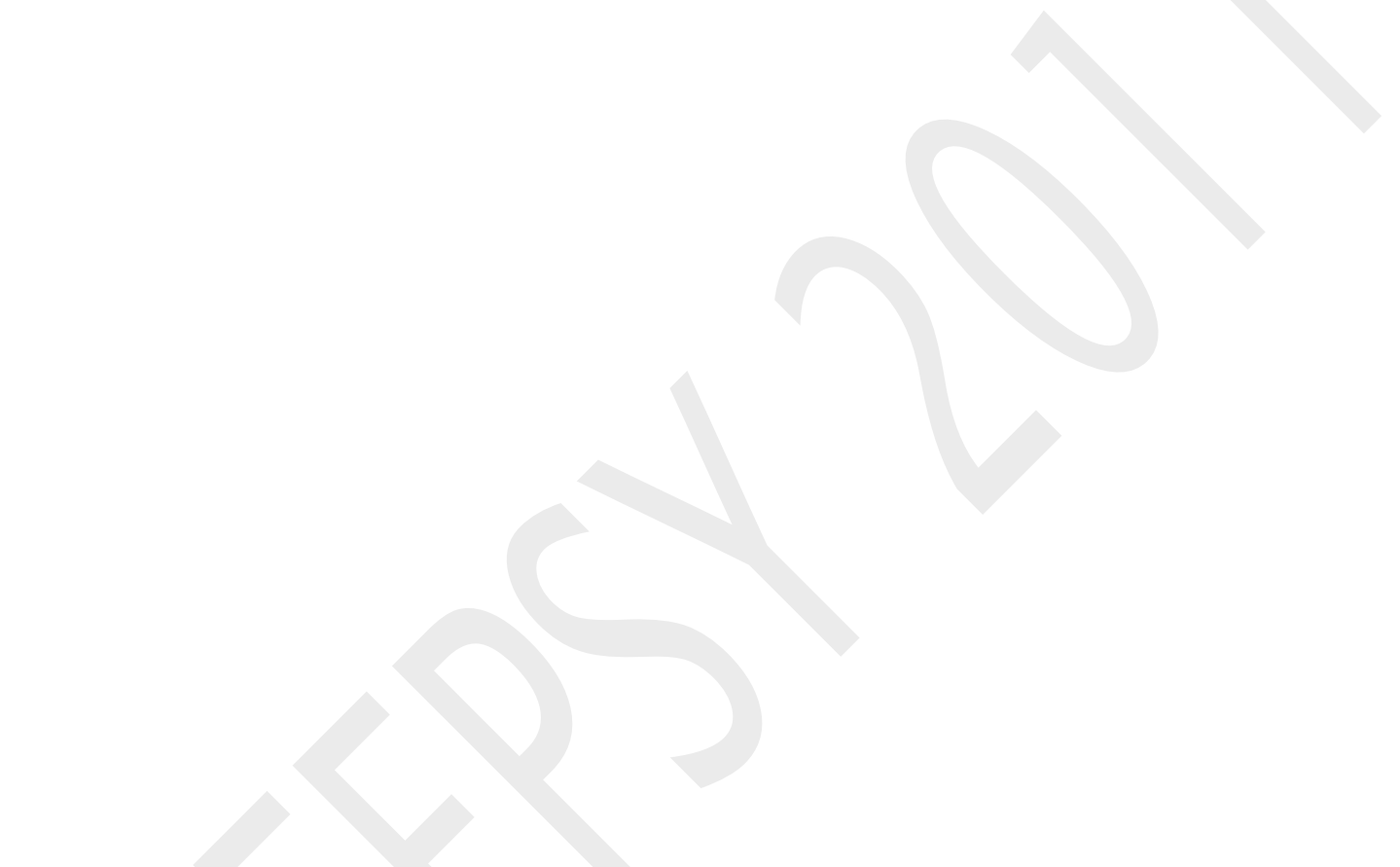

Motivational Predictors of Academic Performance in End Year Examination

Habibah Elias, Sharifah Muzlia Syed Mustafa \& Associate Professor. Dr. Samsilah Roslan

${ }^{1}$ Faculty of Education, University of Technology MARA

Shah Alam, Selangor, MALAYSIA

${ }^{2}$ Faculty of Educational Studies, Universiti Putra Malaysia

Serdang, Selangor, MALAYSIA

${ }^{1}$ shmuzlia@yahoo.com, ${ }^{2}$ hbe@educ.upm.my

Motivation has always been associated with academic performance in school. However, the numerous motivational variables in the literature has yet to identify which types of motivation affects performance best. This study applied multiple regression model to examination results to determine the relative strength of six different motivational variables in predicting performance in year-end examination. The six motivational variables are future time perspective, achievement need, goals, expectancy values, self-efficacy and self-determination. A total of 404 sixteen year old secondary school students were given questionnaires measuring their motivation to perform in the examination. Results showed that all motivation combined explained $18 \%$ of the variance in performance. Among the six motivations, future time perspective is the strongest predictor, followed by self-efficacy. The other four motivations were not found to be statistically significant predictors. The importance of nurturing students' future time prespective and self efficacy is discussed in view of developing adolescents' inner drive to succeed. 
Stress and Academic Achievement Among Undergraduate Students in Universiti Putra Malaysia

by

Habibah Elias(Ph.D)

Universiti Putra Malaysia

Wong Siew Ping

Universiti Putra Malaysia

Maria Chong Abdullah (Ph.D)

Universiti Putra Malaysia

Problem Statement: Research conducted on undergraduate students found that stress affects students' academic achievement. Due to college life transition, first year students are observed to be particularly prone to stress. An individual's adjustment to the environment was found to affect one's learning. With the increase in demand for academic performance and the need to establish new social relations, students may have difficulties in handling these stressors. Few studies have been conducted in the Malaysian context.

Purpose of Study: To investigate the academic achievement and stress of undergraduate students from different faculties in a local university. To examine the relationship between stress and academic achievement of undergraduates.

Research Methods: Through cluster sampling, a total of 376 undergraduate students were selected from 15 faculties. Students were selected based on their year of study as well as their degree programs. Data were collected through questionnaires specifically the College Undergraduate Stress Scale (CUSS) to evaluate the stress level.

Findings: Overall, the undergraduate students showed moderate levels of stress. The Medical students showed the highest level of stress compared to the other degree programs. The first year students experienced low levels of stress compared to the final year students. Most sources of stress come from students' academic tasks. There was a significant though weak and negative relationship between undergraduate students' stress and their academic achievement.

Conclusions: The findings revealed that stress correlated negatively with students' academic achievement. This is consistent with previous studies. This indicate that students especially final year students and students from Medical faculties should be given some coping strategies or other intervention programs to help them develop the coping skills to overcome stress. 


\title{
IMPROVING TEACHERS' AND STUDENTS' ENTREPRENEURIAL SELF-EFFICACY: IMPLICATION FOR EFFECTIVE TEACHING
} PRACTICES

\author{
Zaidatol Akmaliah Lope Pihie \\ zalp@educ.edu.upm.my
}

Afsaneh Bagheri

Problem Statement:

As a developing nation with a strong ambition to become a developed leading country through a knowledge-based and innovative economy by the year 2020, Malaysia has been focusing on entrepreneurship development as an effective means to enact its vision. Furthermore, entrepreneurship education has recently grown all over the country. However, little attention has been directed to measure entrepreneurial efficacy among Malaysian technical school teachers and students.

\section{Purpose of Study:}

The main objective of this study was to determine entrepreneurial self-efficacy of technical secondary school teachers and students in Malaysia.

\section{Research Methods:}

This research utilised a descriptive research design to determine entrepreneurial self-efficacy of technical secondary school teachers and students. A sample of 3000 students and 315 teachers from academic and technical schools were selected in the year 2009 to participate in the study. An instrument to measure entrepreneurial self-efficacy (ESE) was used.

Findings:

Finding indicated that there was a significant difference between teachers' and students' self-efficacy. Vocational and technical students perceived moderately high related to their entrepreneurial self-efficacy, meanwhile, teachers score significantly higher in all six dimensions of Entrepreneurial Self-Efficacy compared to students. The differences between their perception require intervention programs in term of effective teaching and learning in all vocational and technical program to ensure successful implementation of the idea "Entrepreneurship as an alternative career" for vocational education students. 
The findings of this research may be used by policy makers to improve teachers teaching approaches in entrepreneurship education programs for vocational and technical students. Ministry of Education needs to support and promote entrepreneurship education program to provide better entrepreneurial environment and facilitate new business creation in Malaysia.

Keywords:

Entrepreneurial self-efficacy, technical school teachers and students, vocational and technical education

\section{ANALYSIS OF HEAD OF DEPARTMENTS LEADERSHIP STYLES: IMPLICATION FOR IMPROVING RESEARCH UNIVERSITY MANAGEMENT PRACTICES \\ Zaidatol Akmaliah Lope Pihie \\ Amir Sadeghi \\ Habibah Elias}

Problem Statement:

Being an international center of excellence in higher education is considered as a comprehensive goal of the Ministry of Higher Education in Malaysia. In satisfying this goal, Malaysian higher education institutions and specifically Research Universities (RUs) are in center of attention, as they play a crucial role in developing the community. Administrators' leadership styles has influenced on lecturers' job satisfaction and play essential role in materialization of research university's goals and vision.

\section{Purpose of Study:}

This research aims to investigate whether there is a correlation between leadership styles of head departments and job satisfaction of lecturers in Malaysian Research Universities (RUs).

Research Methods:

This study utilizes a descriptive correlational research design to determine head of department's leadership style and its correlation with lecturers' job satisfaction. The target populations were the lecturers of three Malaysian RUs. The MLQ $5 x$ and WFJSDS were used as the instruments of the study. The respondents were the lecturers who were selected based on the stratified proportional random sampling procedure. From the total of 320 returned questionnaires, 298 were qualified for statistical analysis.

Findings:

Based on lecturers' perception, the head of departments applied a combination of three distinct leadership styles in terms of transformational leadership (fairly often), transactional leadership (sometimes), and laissez-faire (once in a while). Among three discernable leadership styles, the transformational and the transactional leadership styles were positively and laissez-faire were negatively correlated with the lecturers' job satisfaction. Result regarding the strength of the relationship showed that the correlation between two leadership styles (transactional and laissez-faire) and the lecturers' job satisfaction were weak, whilst, the transformational leadership style and job satisfaction were moderately correlated with each other. In terms of job satisfaction RUs' lecturers were moderately satisfied. The result of stepwise multiple regressions revealed transformational leadership is significant predictors of job satisfaction.

Conclusions:

The study concludes that head of department in research universities are encouraged to practice transformational leadership since multiple regression analysis revealed that it is a significant predictor of lecturer's job satisfaction.

Keywords:

Research University, Transformational Leadership, Job Satisfaction 
Role of procedural fairness perception, trust in principal and job attitudes in organizational citizenship behaviors (OCBs) of teachers: retesting and merging two tested models in non-educational context

\author{
Hassanreza Zeinabadi \\ Assistant professor, Tarbiat Moallem University, Tehran, Iran \\ Abdolhosein Abbasian \\ PhD student, Shahid Beheshti University, Tehran, Iran \\ Keyvan Salehi \\ PhD student, Tehran University, Tehran, Iran
}

\title{
Problem Statement:
}

Several studies in the context of non-educational organizations have tried to investigate and introduce structural model for direct and indirect effects of procedural fairness perception on organizational citizenship behaviors (OCBs) of employee. Two of the high cited studies have been conducted by Moorman, Niehoff and Organ (1993) and Konovsky and Pugh (1994). According to group value model, in the first study Moorman et al (1993) found that procedural fairness has indirect effect on OCBs through mediating role of job satisfaction and organizational commitment. In the second study Konovsky and Pugh (1994) introduced social exchange model and found that trust in supervisor makes significant mediating role between procedural fairness and OCBs. In educational organizations, empirical evidence is relatively scarce. The evidence suggests that OCB is context specific that is varying from one type of organization to another. Behavior in schools is different from that found in non educational settings.

Purpose of Study:

Current study aims at testing and merging these models in the context of primary school.

Research Methods:

The approach taken was quantitative analyses. 652 teachers were respondents to procedural fairness; trust in principal, job satisfaction and organizational commitment questionnaires and 131 principals were respondents to OCBs questionnaire. Data were collected at regularly planned meetings in schools. Structural equation modelling was performed to determine and compare goodness of fit indexes and direct/indirect effects of models.

Findings:

Results showed that these models have good fit with observed data. Results of testing of merged model demonstrate that this model has better fit with observed data than separate models and all of direct/indirect effects in it were significant.

Conclusions:

In general, the results indicate that attention to the role of procedural fairness perception, trust in principal and job attitude in OCBs of teachers is crucial. Implications of the study are discussed in relation to principals, as well as to policy makers and further research.

Keywords:

Procedural fairness, trust in principal, job attitudes, organizational citizenship behaviors (OCBs), teachers, model

Role of intrinsic job satisfaction, value commitment and extra-role behaviours of teachers in students' performance: testing a model

\author{
Hassanreza Zeinabadi \\ Assistant professor, Tarbiat Moallem University, Tehran, Iran \\ Keyvan Salehi \\ PhD student, Tehran University, Tehran, Iran
}

Problem Statement: 
There is scarce evidence surrounding role of teacher related variables in student performance. Previous studies have shown that teacher's global job satisfaction and organizational commitment, as two important job attitudes, are significant predictors of student performance. Also there is evidence related to significant role of extra-role behaviours of teachers in student performance. Despite of this evidence, there isn't any research which takes in to account collectively role of these variables in student performance. Also very little research exists regarding the effects of specific facets of job satisfaction (intrinsic job satisfaction) and organizational commitment (value commitment) on extra-role behaviours of teachers and students' performance.

Purpose of Study:

The purpose of this study is to test a hypothesis model of casual relationship between intrinsic job satisfaction, value commitment, extra-role behaviours of teachers, and students' performance.

Research Methods:

652 primary school teachers were respondents to intrinsic job satisfaction and value commitment questionnaires and 131 principals were respondents to extra-role behaviours questionnaire. Students' performance was calculated by averaging their scores on district level examination in science and math. Data were collected at regularly planned meetings in schools. Structural equation modelling was performed to determine goodness of fit indexes and direct/indirect effects of hypothesis model.

Findings:

Results showed that hypothesis model has good fit with observed data. Result of direct/indirect effects revealed that intrinsic job satisfaction has significant direct effect on value commitment, extra-role behaviours and students' performance. Direct effect of value commitment on extra-role behaviours and students' performance and direct effect of value commitment and extra-role behaviours on students' performance was also significant. Similar to direct effects, indirect effect of intrinsic job satisfaction on extra-role behaviours; indirect effect of intrinsic job satisfaction on students' performance; and indirect effect of value commitment on students' performance were significant.

Conclusions:

The results indicate that attention to the role intrinsic job satisfaction, value commitment and extra-role behaviours of teachers in students' performance are important. Implications of the study are discussed in relation to principals, teachers, policy makers and further research.

Keywords:

Intrinsic job satisfaction, value commitment, extra-role behaviours, students' performance, teachers, model

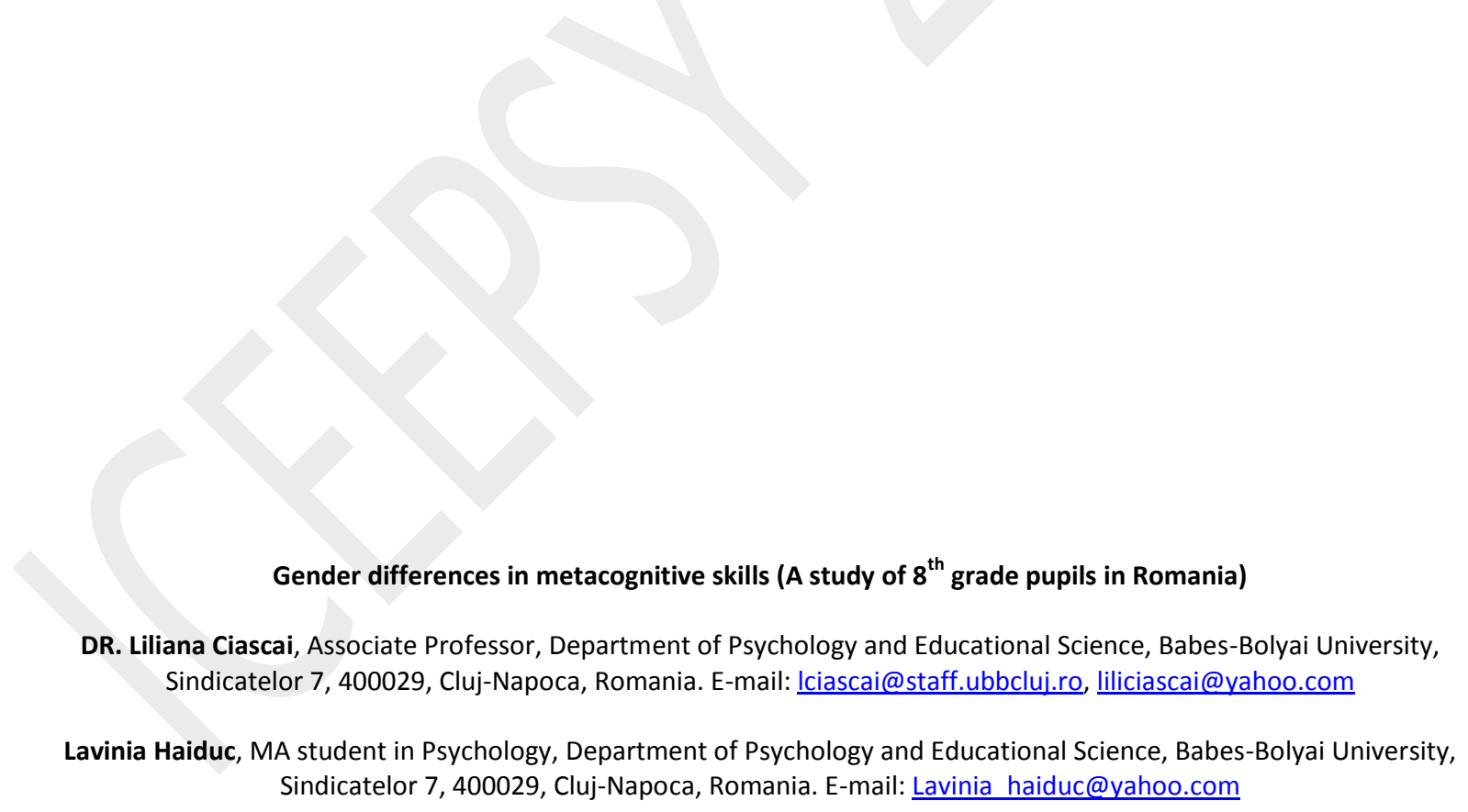

Problem Statement:

Prior research has shown inconsistent results regarding the differences on metacognitive skills between boys and girls. Some research suggest that there are differences regarding boys and girls' metacognitive skills, while others suggest that these differences are not significant. However, steady research is needed regarding this subject since the results of such studies could be used in educational practice.

Purpose of Study:

The purpose of this paper is to investigate if there are significant gender differences regarding the metacognitive skills of $8^{\text {th }}$ graders. 


\title{
Research Methods:
}

91 pupils from three schools in Romania were assessed on their metacognitive skills, using the Junior Metacognitive Awarness Inventory.

\section{Findings:}

The findings indicate that generally both girls and boys use their metacognitive skills in learning. In addition, the results indicate that there are significant differences between boys and girls solely on the following dimensions: the perception of performance as a result of one's will and effort, the perceptions regarding teachers expectations about learning, prior knowledge and monitoring the learning process.

Conclusions:

The results are discussed in relation with implications for future research and educational practice. Further, we emphasize the implications of using self-evaluation methods for assessing metacognitive and self-regulation skills.

\section{Factors that influences secondary school students' attitude to mathematics}

\author{
Iuliana Marchis
}

Babes-Bolyai University

Cluj-Napoca, Romania

e-mail: marchis julianna@yahoo.com

Abstract. Pupils could like, enjoy, or the opposite, could hate mathematics. Attitude could be described as a long-term positive or negative emotional disposition towards mathematics. There is a correlation between pupils' attitude towards mathematics and their mathematical results, thus it is important to develop a positive attitude towards learning mathematics. This attitude could be influenced by many factors.

In this research a questionnaire was developed for identifying the factors that influences secondary school pupils $\left(5^{\text {th }}-8^{\text {th }}\right.$ grade, 11-15 years old) attitude to mathematics. 338 pupils from the north-vest and central part of Romania have completed the questionnaire. The findings show that the most important factor is the teacher: the teachers' attitude to mathematics and the amount of confidence and support he/she gives to the pupils and his/her teaching style is in correlation with pupils' attitude to mathematics. Another important factor is how pupils learn mathematics. Those who know how to learn mathematics and how to solve a problem usually like mathematics.

The results show the importance of developing teachers' skills in order to teach pupils how to learn mathematics, to use teaching methods that support pupils' learning and give them confidence. 


\section{Conceptual Maps as Mediators of Self-Regulated Learning}

Mih Codruta, Babes-Bolyai University, Cluj-Napoca, Romania

Mih Viorel, Babes-Bolyai University, Cluj-Napoca, Romania

Problem Statement: The concept map provides a mechanism for structuring and organizing knowledge into hierarchies and allows for analysis of phenomena as cause-effect relations. Hence, the concept map is a powerful tool that lets students represent their understanding of domain knowledge in a well-organized format. By making thoughts visible, concept map structures can provide a framework for reflection and revision of one's knowledge with the goal of improving learning performance.

Purpose of Study: This study analyses the impact that the use of conceptual maps and training of self-regulated learning have on learning achievement.

Research Methods: The experiment included the manipulation of an independent variable with three conditions (learning of a simple text, development of a conceptual map and training of self-regulated learning using concept maps). The dependent variable is represented by learning achievement determined by answering two types of questions: factual and inferential and, on the other hand, by information transfer capacity.

Findings: Results show that the three types of learning mediation influence the level of comprehension, but the effect emerges only for inferential questions and not for factual questions. Moreover, the mean of correct answers was significantly lower for the simple text condition as compared to all other presentation forms (text and CM; text \& CM \& SRL training). Thus, the proposed formative intervention has a significant effect on in-depth processing.

Conclusions: Concept mapping has considerable utility for tracking change in the course of learning, and has the capacity to distinguish between changes that are meaningful, and those that are not. This is discussed in the wider context of self-regulated learning, and teaching.

Keywords: conceptual maps, self-regulated learning, inhibition processes

Thematic Sections: Learning Theories, Effective Teaching Practices, Second Language Teaching 


\section{The Role of Working Memory Deficits in Children with Poor Comprehension Ability}

Mih Viorel, Babes-Bolyai University, Cluj-Napoca, Romania

Mih Codruta, Babes-Bolyai University, Cluj-Napoca, Romania

Problem Statement: Children with poor reading comprehension ability show difficulties on a range of executive functioning tasks.

Purpose of Study: In this study we have tried to identify one of the skills and abilities that might be implicated in comprehension ability and which, therefore, might be trained. The ability we have identified is working memory. Working memory refers to the cognitive ability to temporarily store and mentally manipulate limited amounts of information for use in guiding behaviour.

Research Methods: Two groups of 10- to 11-year-olds, who were matched for chronological age, reading vocabulary, decoding skills and performance IQ, but who differed in comprehension skill, were selected. We have compared these two groups of children on a verbal and visual-spatial working memory tasks. In the tasks used both storage and processing has been varied systematically.

Findings: Results indicated that poor comprehenders have less functional working memory capacity than their same age counterparts, and this phenomenon should be more strongly associated to combined functions of storage and processing than storage alone. Comprehension disabled children seem to have a general lack of capacity for the concurrent processing and storage of verbal information. We have also found differences between groups on the mean number of intrusion errors: poor comprehenders made more intrusion errors, suggesting the presence of a problem in the inhibition processes (in dual-load condition).

Conclusions: The results are discussed in terms of theoretical and practical implications for working memory research.

Keywords: reading comprehension, working memory, inhibition processes

Thematic Sections: Learning Theories, Effective Teaching Practices, Second Language Teaching 


\title{
CHANGES OF HANDICAPPED and other STUDENTS'SELF-CONCEPT AND MUTUAL ATTITUDES AS A RESULT OF THEIR DIRECTED INTERACTION
}

\author{
Jan Michalik, Palacky University, Faculty of Education Olomouc, Czech Republic \\ Milan Valenta Palacky University, Faculty of Education Olomouc, Czech Republic \\ Alena Petrova Palacky University, Faculty of Education Olomouc, Czech Republic \\ Jan Slavik Faculty of Education Plzeň, Czech Republic \\ Martin Lecbych, Palacky University, Filosofical Faculty Olomouc, Czech Republic
}

\section{Problem Statement}

In this context, the authors of the research team conducted a series of quantitative and qualitative-oriented investigation focused on the description of selected socio-psychological characteristics of caregivers personality specificity (a family member with severe disabilities), integrated, leading to mental development. The research investigation was carried out between 2007 - 2010 and practically implemented through the course and quality analytical design. In this type of investigation the authors used a strategy for coping with stress, the existential variety.

\section{Purpose of Study}

The inquiry was to determine the effectiveness of art therapy and artefiletick consulting practice care for people caring for a family member with severe disabilities

\section{Research Methods}

A quantitative research design was applied using psychometric methods and standardized tests to measure the degree of anxiety and its management and other relevant instruments - SVF-

78, STAI, existential range, Bordnerova range, Logo-test. For data analysis parametric statistical procedures were used.

\section{Findings}

Defection measurement and experiments confirm the benefits of relaxation and therapeutic techniques to enhance the socio-psychological stability of people caring for children with severe disabilities.

\section{Conclusions}

The authors found a statistically significant difference in coping strategy of "control response", which, after completion of the project occurred to a lesser extent. This was assessed as a sign of the strengthening the authenticity and spontaneity of participants, enhancing their openness and the taking off their interpersonal masks. Interesting trends were observed in the reduction strategy of self-blame and resignation, but not statistically significant, it would be interesting to determine in a larger sample in a similar experiment.

\section{Keywords}

Experimental design, qualitative research, caregivers, and art therapy artefiletik

\section{Voices to be heard: What do teachers have to say about the reform of secondary school system in Bahrain?} Khaled Albaker: University of Bahrain, Bahrain Teachers College 
on change in a centralised educational system like the one in Bahrain. It focuses on the perceptions of the teachers on two schools who were involved in reforming secondary educational system in Bahrain took place in 2005.

Purpose of Study:

The study focused on answering the following research questions: What are teachers' perceptions of operationalising government reform? How to capitalize on benefits from the current reform initiative? And finally what are the ways forward to capitalize on benefits from future reforms?

Research Methods:

A multisite case study. The findings from teachers presented in this paper are a result of field analysis, one focus group, 9 interviews, and 109 questionnaires with a 65\% return ratio. The data collected from these methods was triangulated in a thematic structure in a way that presents the perceptions of teachers about the change process from their points of view.

Findings:

The main themes of analysis are the perceptions of teachers about the creation of reform initiative by the government, their perceptions about its preparation and introduction in the school, and finally their perceptions about its implementation.

Teachers have little control over the decision-making process and emphasised their perception that current reform was affected by its relation with their academic life. Several issues relating to the quality and quantity of training, leadership and motivation were raised. In addition, their ambitions and expectations about how any reform should change things in the classroom played a crucial role in shaping their reactions.

Conclusions:

Chronic problems when it comes to the implementation stage existed and, most of the time, were identified even before the implementation. Nevertheless, the lack of empirical evidence contributed to the continuity of these problems. Therefore, this study constitutes a step forward in the educational change literature in Bahrain that is available and accessible to the public.

Keywords:

educational change management, educational reforms, Bahrain educational reforms, teachers perceptions

LEADERSHIP STYLES AND SCHOOL EFFECTIVENESS: EMPIRICAL EVIDENCE FROM SECONDARY LEVEL ljaz Ahmad Tatlah, PhD Scholar in Education, University of Management and Technology Lahore, Pakistan

tatlah333@yahoo.com,092-333-4319981, Fax\#092-42-99220409, postal code: 54600

Muhammad Saeed, PhD Scholar in Education, UMT Lahore, Pakistan. msraipuri@hotmail.com

Prof.Dr.Muhammad Zafar Iqbal,

University of Management and Technology (UMT) Lahore, Pakistan.

Problem Statement:

There is a relationship between school headeteachers` leadership styles and school effectiveness at secondary school level.

Purpose of Study:

School effectiveness is an important focus of research in Education. The research in this area has primarily focused on leadership and school effectiveness in terms of its academic achievement. There are no significant studies looking at the relationship of leadership styles of the school leaders with effectiveness of the school. The main premise of the article is that school factors of effectiveness basically depends upon the different styles of 
leadership being adopted by the headteachers with reference to gender and type of the institutions; public and private sector.

Research Methods:

This article draws on leadership theory to examine the connection between leading styles of school leaders towards learning outcomes of the schools. The study under discussion was a co-relational type of research for which a survey was conducted through two questionnaires. Analysis was conducted on the sample of 300 male and female headteachers, deputy headteachers and senior teachers, and students in the province of Punjab in Pakistan. Findings:

The findings reveal that an important factor that affects the achievement of the school is the extent to which headteachers are participative and adopt the selling leadership style.

Conclusions:

Results showed that there was a significant impact of leadership styles on school effectiveness on the bases of gender both for public and private institutions. Comparatively private sector schools have more significant effect of leadership styles on school effectiveness than public sector.

Keywords:

School effectiveness, leadership styles, comparison, Public sector and private sector

Relation among quality of image of God with somatization and phobic anxiety in college students

Ali Akbar K. Haddadi, M.A.

Clinical Psychology, University of Tehran, School of Psychology \& Education, Tehran, Iran

E-mail: yamola280@yahoo.com

Bagher B. Ghobary, Ph.D.

Associate Professor, University of Tehran, School of Psychology \& Education, Tehran, Iran E-mail: bghobari@ut.ac.ir

Problem Statement: Since in college students are exposed to the variety of stressors that impact their psychological functioning, determining factors associated with psychological health of these individuals is an important research endeavour

Purpose of Study: The aim of the current research was to investigate the relationship between image of God with somatization and phobic anxiety in college students.

Research Methods: To accomplish the stated goal 233 in college students were selected by means of proportional sampling procedure. The Image of God Inventory (IOG, Lawrence, 1997) and Scales of Somatization and Phobic Anxiety in Symptom Checklist90-R (SCL-90R, Deragotis et al., 1973) were administered on them.

Findings: Analysis of data revealed that the magnitude of somatization and phobic anxiety can be predicted from the quality of images of God in college students. Moreover, data revealed that college students who had positive image of God were lower in somatization and phobic anxiety than in college students who had a negative image of God.

Conclusions: Authors concluded that positive image of God were associated with lower somatization and phobic anxiety in college students. Theoretical implication and practical application of the finding are discussed in the original paper. 
Keywords: Image of God, Somatization and Phobic Anxiety, College Students, Iran

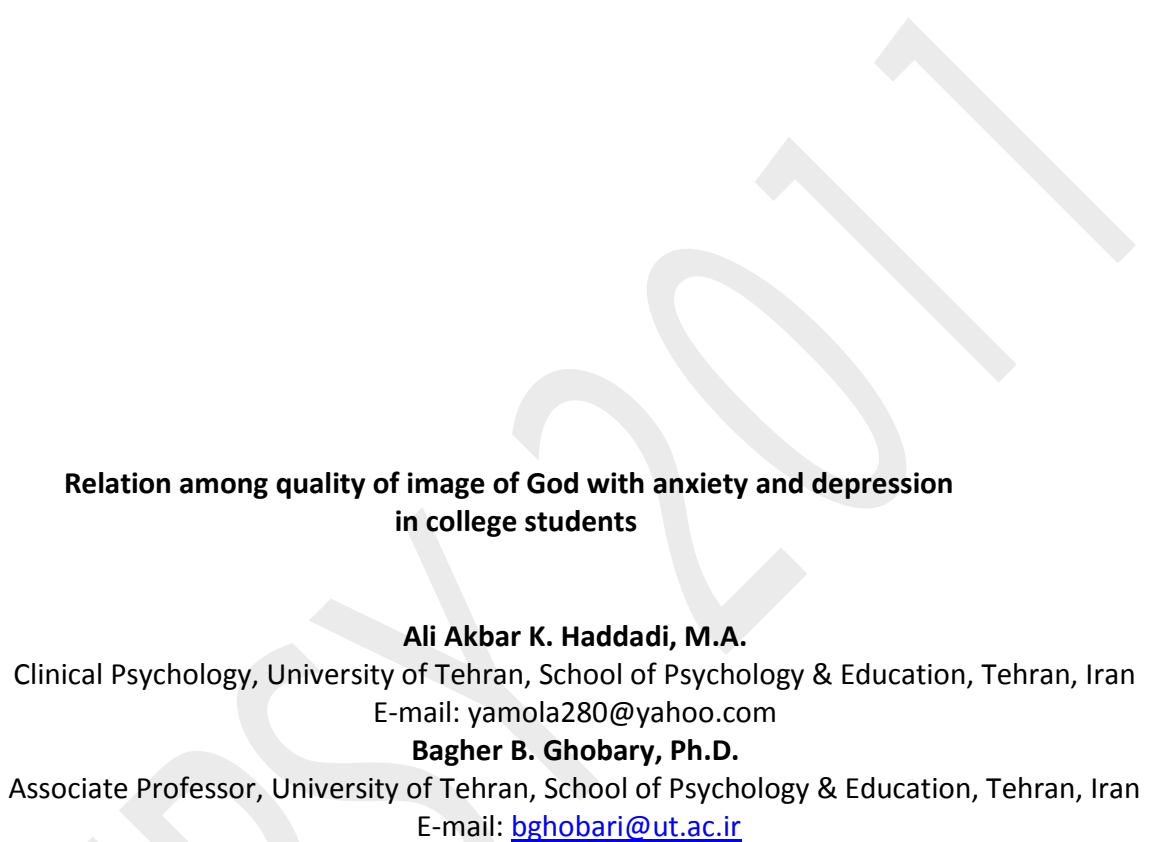

Problem Statement: Since in college students are exposed to the variety of stressors that impact their psychological functioning, determining factors associated with psychological health of these individuals is an important research endeavour

Purpose of Study: The aim of the current research was to investigate the relationship between image of God with anxiety and depression in college students.

Research Methods: To accomplish the stated goal 227 in college students were selected by means of proportional sampling procedure. The Image of God Inventory (IOG, Lawrence, 1997) and Scales of Anxiety and Depression in Symptom Checklist90-R (SCL-90R, Deragotis et al., 1973) were administered on them.

Findings: Analysis of data revealed that the magnitude of anxiety and depression can be predicted from the quality of images of God in college students. Moreover, data revealed that college students who had positive image of God were lower in anxiety and depression than in college students who had a negative image of God.

Conclusions: Authors concluded that positive image of God were associated with lower anxiety and depression in college students. Theoretical implication and practical application of the finding are discussed in the original paper.

Keywords: Image of God, Anxiety, Depression, College Students, Iran 


\section{Relation among quality of image of God with hostility and interpersonal sensitivity in parents of exceptional} children

Bagher B. Ghobary, Ph.D.

Associate Professor, University of Tehran, School of Psychology \& Education, Tehran, Iran

E-mail: bghobari@ut.ac.ir

Ali Akbar K. Haddadi, M.A.

Clinical Psychology, University of Tehran, School of Psychology \& Education, Tehran, Iran

E-mail: yamola280@yahoo.com

Problem Statement: Since parents of exceptional children are exposed to the variety of child raising stressors that impact their psychological functioning, determining factors associated with psychological health of these individuals is an important research endeavour.

Purpose of Study: The aim of the current research was to investigate the relationship between image of God with hostility and interpersonal sensitivity in parents of exceptional children.

Research Methods: To accomplish the stated goal 168 parents of exceptional children were selected by means of proportional sampling procedure. The Image of God Inventory (IOG, Lawrence, 1997) and Scales of Hostility and Interpersonal Sensitivity in Symptom Checklist90-R (SCL-90R, Deragotis et al., 1973) were administered on them.

Findings: Analysis of data revealed that the magnitude of hostility and interpersonal sensitivity can be predicted from the quality of images of God in parents of exceptional children. Moreover, data revealed that parents of exceptional children who had positive image of God were lower in hostility and interpersonal sensitivity than parents of exceptional children who had a negative image of God.

Conclusions: Authors concluded that positive image of God were associated with lower hostility and interpersonal sensitivity in parents of exceptional children. Theoretical implication and practical application of the finding are discussed in the original paper.

Keywords: Image of God, Hostility, Interpersonal Sensitivity, Parents of Exceptional Children, Iran 


\section{Relation between image of God with mental health in college students}

Ali Akbar K. Haddadi, M.A.

Clinical Psychology, University of Tehran, School of Psychology \& Education, Tehran, Iran

E-mail: yamola280@yahoo.com

Bagher B. Ghobary, Ph.D.

Associate Professor, University of Tehran, School of Psychology \& Education, Tehran, Iran

E-mail: bghobari@ut.ac.ir

Problem Statement: Since in college students are exposed to the variety of stressors that impact their psychological functioning, determining factors associated with psychological health of these individuals is an important research endeavour

Purpose of Study: The aim of the current research was to investigate the relationship between image of God with mental health in college students.

Research Methods: To accomplish the stated goal 197 in college students were selected by means of proportional sampling procedure. The Image of God Inventory (IOG, Lawrence, 1997) and Symptom Checklist90-R (SCL-90R, Deragotis et al., 1973) were administered on them.

Findings: Analysis of data revealed that the magnitude of mental health can be predicted from the quality of images of God in college students. Moreover, data revealed that college students who had positive image of God were higher in mental health than in college students who had a negative image of God.

Conclusions: Authors concluded that positive image of God were associated with higher mental health in college students. Theoretical implication and practical application of the finding are discussed in the original paper.

Keywords: Image of God, Mental Health, College Students, Iran 


\section{Relation among quality of image of God with obsessive-compulsive behaviours and phobic anxiety in parents of exceptional children}

\section{Bagher B. Ghobary, Ph.D.}

Associate Professor, University of Tehran, School of Psychology \& Education, Tehran, Iran E-mail: bghobari@ut.ac.ir

Ali Akbar K. Haddadi, M.A.

Clinical Psychology, University of Tehran, School of Psychology \& Education, Tehran, Iran E-mail: yamola280@yahoo.com

Problem Statement: Since parents of exceptional children are exposed to the variety of child raising stressors that impact their psychological functioning, determining factors associated with psychological health of these individuals is an important research endeavour.

Purpose of Study: The aim of the current research was to investigate the relationship between image of God with obsessive-compulsive behaviours and phobic anxiety in parents of exceptional children.

Research Methods: To accomplish the stated goal 167 parents of exceptional children were selected by means of proportional sampling procedure. The Image of God Inventory (IOG, Lawrence, 1997) and Scales of Obsessive-Compulsive Behaviours and Phobic Anxiety in Symptom Checklist90-R (SCL-90R, Deragotis et al., 1973) were administered on them.

Findings: Analysis of data revealed that the magnitude of obsessive-compulsive behaviours and phobic anxiety can be predicted from the quality of images of God in parents of exceptional children. Moreover, data revealed that parents of exceptional children who had positive image of God were lower in obsessive-compulsive behaviours and phobic anxiety than parents of exceptional children who had a negative image of God.

Conclusions: Authors concluded that positive image of God were associated with lower obsessive-compulsive behaviours and phobic anxiety in parents of exceptional children. Theoretical implication and practical application of the finding are discussed in the original paper.

Keywords: Image of God, Obsessive-Compulsive Behaviours, Phobic Anxiety, Parents of Exceptional Children, Iran

Teachers' and parents' perspective as how the social environment of immediate vicinity can affect the academic learning of a Child in 4-6 years age group

${ }^{1}$ Salma Amin Rattani and ${ }^{2}$ Deedar Shah

${ }^{a}$ Aga Khan University School of Nursing and ${ }^{b}$ Aga Khan Education System, Pakistan

Problem Statement: In the process of human development, in usual circumstances, an individual's social environment expands as s/he grows. This expansion may affect on an individual's knowledge, behaviour, skills, values, preferences or understanding.

Purpose of Study: This study aimed to achieve following objectives:

- $\quad$ To explore parents' perceptions as how the social environment of immediate vicinity can affect the academic learning of a child in 4-6 years age group

- To explore teachers' perceptions as how the social environment of immediate vicinity can affect the academic learning of a child in 4-6 years age group 
Constructivist paradigm was used as research framework and descriptive exploratory research design was used to conduct this study. Phandar district Ghizer, Northern areas, Pakistan was the study setting. Participants included parents of 4-6 years old children and school teachers teaching to this age group children in schools located in study setting working under the umbrella of Aga Khan Education System, Pakistan. Purposive sampling methodology was used to recruit these participants. Upon approval from Ethical Review Committee of Aga Khan University, data was collected though in-person interview of the individual participants.

\section{Findings:}

According to study participants' point of view environment affects on academic learning of a child in 4-6 years of age group. The participants shared that environment where children have opportunity to complete home assignments, are provided with recreational and educational resources including electronic and print media they flourish. Participants also viewed that it is also important this age group children to be surrounded by good company and good parenting. Otherwise there are consequences on their success in education and personality development.

\section{Conclusions:}

Human development is vital for the progress of any nation and parents and teachers play a vital role in this developmental process. Therefore, their perceptions and point of view needs to be explored for national strategic planing and development.

Keywords: early child development, accademic learning, social environment

Aga Khan University School of Nursing Enrichment Programme Salma Amin Rattani, Jacqueline Maria Dias and Shahina Noor Aga Khan University, Karachi, Pakistan

\section{Problem Statement:}

Nurses are the major human resource of a health care industry and their development requires education. Institutions which offer nursing education have their quality checks, admission test is one of such initiatives. At times there are promising candidates but require adittional support and facilitation.

\section{Purpose of Study:}

This paper aims to share the outcomes of enrichment programme as one of the capacity building initiatives of Aga Khan University School of Nursing (AKU-SON), Karachi, Pakistan.

\section{Research Methods:}

Candidates who are intersted and meet the eligibility criteria are invited by AKU-SON to apply for nursing education programme. As part of institutional quality indicator applicants are screened through admission test and interview process. Those candidates who are potential but due to certain reasons; being from disadvantage background is one of them, do not perform well in admission test. Therefore, from 2007 onwards they are invited to be enrolled in enrichment programme for capacity building in English language and Mathematics. Upon successful completion in the programme these candidates are admitted in General Nursing Diploma a three year or in a four years Baccalaureate Nursing Degree Programme.

\section{Findings:}

During 2007 to 2010 admission cycle a total of 242 candidates were invited to be enriched among them 48 withdrawn. Out of remaining 194, thirty have graduated rest of 164 are studying.

\section{Conclusions:}

Maintaining quality is responsibility of the institutions which requires concentrated efforts enrichment progamme is one of such initiatives. At AKU-SON, implementing such initiatives has produce favourable results. 


\section{Keywords:}

Capcaity building, nursing education, Quality Assurance and Institutional Effectiveness

Relation between quality of image of God with paranoid ideation in parents of exceptional children

Bagher B. Ghobary, Ph.D.

Associate Professor, University of Tehran, School of Psychology \& Education, Tehran, Iran

E-mail: bghobari@ut.ac.ir

Ali Akbar K. Haddadi, M.A.

Clinical Psychology, University of Tehran, School of Psychology \& Education, Tehran, Iran E-mail: yamola280@yahoo.com

Problem Statement: Since parents of exceptional children are exposed to the variety of child raising stressors that impact their psychological functioning, determining factors associated with psychological health of these individuals is an important research endeavour.

Purpose of Study: The aim of the current research was to investigate the relationship between image of God with paranoid ideation in parents of exceptional children.

Research Methods: To accomplish the stated goal 167 parents of exceptional children were selected by means of proportional sampling procedure. The Image of God Inventory (IOG, Lawrence, 1997) and Scale of Paranoid Ideation in Symptom Checklist90-R (SCL-90R, Deragotis et al., 1973) were administered on them.

Findings: Analysis of data revealed that the magnitude of paranoid ideation can be predicted from the quality of images of God in parents of exceptional children. Moreover, data revealed that parents of exceptional children who had positive image of God were lower in paranoid ideation than parents of exceptional children who had a negative image of God.

Conclusions: Authors concluded that positive image of God were associated with lower paranoid ideation in parents of exceptional children. Theoretical implication and practical application of the finding are discussed in the original paper.

Keywords: Image of God, Paranoid Ideation, Parents of Exceptional Children, Iran 


\section{Relation between quality of image of God and mental health in parents of exceptional children}

Bagher B. Ghobary, Ph.D.

Associate Professor, University of Tehran, School of Psychology \& Education, Tehran, Iran

E-mail: bghobari@ut.ac.ir

Ali Akbar K. Haddadi, M.A.

Clinical Psychology, University of Tehran, School of Psychology \& Education, Tehran, Iran

E-mail: yamola280@yahoo.com

Problem Statement: Since parents of exceptional children are exposed to the variety of child raising stressors that impact their psychological functioning, determining factors associated with psychological health of these individuals is an important research endeavour.

Purpose of Study: The aim of the current research was to investigate the relationship between image of God and mental health in parents of exceptional children.

Research Methods: To accomplish the stated goal 168 parents of exceptional children were selected by means of proportional sampling procedure. The Image of God Inventory (IOG, Lawrence, 1997) and Symptom Checklist90-R (SCL90R, Deragotis et al., 1973) were administered on them.

Findings: Analysis of data revealed that the magnitude of mental health can be predicted from the quality of images of God in parents of exceptional children. Moreover, data revealed that parents of exceptional children who had positive image of God were higher in mental health than parents of exceptional children who had a negative image of God.

Conclusions: Authors concluded that positive image of God were associated with mental health in parents of exceptional children. Theoretical implication and practical application of the finding are discussed in the original paper.

Keywords: Image of God, Mental Health, Parents of Exceptional Children, Iran 


\section{Relation between quality of image of God and psychoticism in parents of exceptional children}

Ali Akbar K. Haddadi, M.A.

Clinical Psychology, University of Tehran, School of Psychology \& Education, Tehran, Iran

E-mail: yamola280@yahoo.com

Bagher B. Ghobary, Ph.D.

Associate Professor, University of Tehran, School of Psychology \& Education, Tehran, Iran

E-mail: $\underline{\text { bghobari@ut.ac.ir }}$

Problem Statement: Since parents of exceptional children are exposed to the variety of child raising stressors that impact their psychological functioning, determining factors associated with psychological health of these individuals is an important research endeavour.

Purpose of Study: The aim of the current research was to investigate the relationship between image of God and psychoticism in parents of exceptional children.

Research Methods: To accomplish the stated goal 167 parents of exceptional children were selected by means of proportional sampling procedure. The Image of God Inventory (IOG, Lawrence, 1997) and Scale of Psychoticism in Symptom Checklist90-R (SCL-90R, Deragotis et al., 1973) were administered on them.

Findings: Analysis of data revealed that the magnitude of psychoticism can be predicted from the quality of images of God in parents of exceptional children. Moreover, data revealed that parents of exceptional children who had positive image of God were lower in psychoticism than parents of exceptional children who had a negative image of God.

Conclusions: Authors concluded that positive image of God were associated with lower psychoticism in parents of exceptional children. Theoretical implication and practical application of the finding are discussed in the original paper.

Keywords: Image of God, Psychoticism, Parents of Exceptional Children, Iran 
FROM DEFICIT APPROACH TO DEVELOPMENTAL LEARNING PARADIGM: A LONGITUDINAL INVESTIGATION OF THE INTERPLAY BETWEEN TEACHER BELIEFS, PRACTICE AND A PROFESSIONAL DEVELOPMENT PROGRAM

\author{
Zuraimi Zakaria \\ Universiti Teknologi MARA (UITM), Malaysia \\ Associate Professor Esther Care \\ University of Melbourne, Australia \\ Professor Patrick Griffin \\ University of Melbourne, Australia
}

Problem Statement:

To many teachers, assessments are still used as the endpoint of instruction. Though scholars and researchers have advocated the use of assessment data as evidence to inform teaching, teachers need to be shown how this is done and involvement in professional development (PD) program that equip teachers with this skills is pertinent. In addition, many authors and researchers (to name a few: Penn-Edwards, 2010; Schulman \& Armitage, 2005 and Zakaria\& Care, 2010) have consistently testified that for PD programs to yield effective results they must also target teacher beliefs.

Purpose of Study:

The study aims to identify how a teachers' professional development program known as the Assessment and Learning Partnerships (ALPs) program changes teacher beliefs, knowledge and teaching practice and the degree to which this occurs. ALPs is currently participated by teachers of more than 200 schools across the state of Victoria, Australia. It promotes the use of a specific style of evidence-based teaching and its operation within a developmental learning paradigm is designed to lead to an improvement of student learning outcomes. Teachers based their teaching on developmental learning framework and evidence is used to identify students' zones of proximal development which illustrate student readiness in learning. Teachers then use this information to scaffold student learning and target intervention.

Research Methods:

Data is collected longitudinally at two points of time over a period of one year. Three domains are tapped onto: teacher beliefs, knowledge and practice through the use of questionnaire, knowledge test and behavioural checklist for teaching observations. Data is then triangulated to provide information about change in beliefs and practice.

Findings:

If is found that there is a significant shift in teacher knowledge but this is translated to practice only to certain extends.

Conclusions:

The findings resonate with the findings by Porter, Garet, Desimone, Kwang and Birman (2000) and by Smith, Hofer, Gillespie, Solomon and Rowe (2003) in which these researchers consider the idea that teachers are changing but the change may take place at a slower pace. They argue that substantial change in teaching practice may take longer than the time frame of the study.

Keywords:

Evidence-based teaching, professional development, developmental learning framework, zone of proximal developments, scaffolding, teacher beliefs

\title{
THE ELECTRONIC BAG FOR THE STUDENTS WITH LOW VISIONS AT SCHOOL
}

The electronic bag is a means which allows students to use IT in class and permits to lighten their school-bags.

\section{The electronic School-Bag: Its definition}

By saying school-bag, we simplify by thinking that each student will be able to have a virtual school-bag that he will bring everywhere giving him the opportunity to have access to a virtual library while maintaining links with teachers and other students. 


\section{What is at stake?}

- $\quad$ to give real equal opportunities to every student

- $\quad$ to modify the practices in the publishing field

- $\quad$ to facilitate accessibility to documentation, creation and research

- $\quad$ to learn and to facilitate the use of new technology

- $\quad$ to modify the pedagogical approach

The aims:

- $\quad$ the use of a modern tool which facilitate work, research, accessibility to knowledge and culture in a more easy way.

- $\quad$ the creation of a personal and creative working space

- $\quad$ the creation of an environment-friendly in class

\section{The materials:}

The materials on in CD-Rom, USB key or Internet when adapted can offer a wider range of accessibility regarding documents and a possibility for the students to be more independent in their study

In France, several schools work with this electronic device, in network, in class with some pedagogical software that need to be adapted for the students visually impaired who are integrated in those classes

This project requires a knowledge of the materials to be adapted. It is the case for some software such as Zoomtext, some electronic assistive devices (computers with Braille terminals, screen readers, screen magnifiers.....,transcription centres using transfers via USB-Keys....)

The use of the electronic bag raises 3 issues:

$$
\begin{aligned}
& \text { - } \quad \text { the training } \\
& \text { - } \quad \text { the technical supports } \\
& \text { - } \quad \text { the norms in the use }
\end{aligned}
$$

Several experiences show us that this electronic device will be effective very soon (Rapport of 3 experiences)

\section{Conclusion:}

The electronic-bag is there to give an answer to a real need for the visually impaired students who are integrated in mainstream schools:

It gives them the opportunity to have an individual computer adapted to their visual impairment which can make their integration easy the mainstream schools by offering them an another way of writing, reading and by facilitating their access to knowledge, culture and communication.

Teachers' Use of Preemptive versus Reactive Focus on Form Feedbac in different Proficiency levels in an Iranian EFL context

Mahnaz Saeidi

Department of Literature and Foreign Languages, Tabriz Branch, Islamic Azad University, Tabriz, Iran

Parvin Safay Mohseny

Department of Literature and Foreign Languages, Tabriz Branch, Islamic Azad University, Tabriz, Iran

\section{Problem Statement:}

There have been a vast number of studies over reactive focus on form. Most of these studies focused on how teachers correct their students' linguistic mistakes, so called reactive focus on form. As far as teachers or their learners can raise attention to language through pre-emptive focus on form, there is a necessity to examine pre-emptive, as well as reactive episodes. Moreover, the issue of proficiency is a critical factor in the optimal employment of focus on form episodes. To the best of the researcher there is no study dealing with the effect of learners' proficiency on teachers' use of pre-emptive versus reactive focus on form. 
This study involves the observation of communicatively oriented classroom activities, identification and analysis of incidental language related episodes (LRES) in teacher learner interaction. The prime objective is to investigate how frequently different types of focus on form, in general, and pre-emptive and reactive kinds, in particular, are used by teachers in different proficiency levels of the students.

\section{Research Methods:}

Three EFL teachers who had almost the same teaching experience and ninety students participated in this study. Two classes of each of these teachers at two proficiency levels were chosen. One of these two classes was an intermediate level and the other was an advanced level.

\section{Findings:}

The findings revealed no significant difference in the frequency of focus on form episodes between two proficiency levels and the existing differences might be related to different teachers on the basis of their points of view and their experiences.

\section{Conclusions:}

It can be concluded that the existing differences can be due to teachers' attitudes towards teaching techniques and methods, which needs to be investigated through further studies.

Keywords: Pre-emptive focus on form, Reactive focus on form, Proficiency level, Feedback

Teacher perceptions on teacher evaluation: The purposes and the assessors within assessment process

Otilia Clipa, "Stefan cel Mare" University, Suceava, Romania ${ }^{1 *}$

Problem Statement: We have approached the main line of the theoretical and investigative characteristics for teacher evaluation such as they appear within scientific literature in the science of education area.

Purpose of Study: The main goal of the paper is to investigate the purposes of teacher evaluation from the perspective of the teachers and the ideal portrait of the assessors for this assessment process.

Research Methods: The investigative part is done through the survey about some aspects of the evaluation process on teacher evaluation. The sample comprises teachers from primary and preschool level.

Findings: The teacher considers the assessment purpose is depending on some factors (educational level, degree and years of experience). The positive corelation was between age, years of experience and the portrait of assessors.

In terms of the gained results we have described the perceived assessor portrait from the teachers' point of view.

Conclusions: The results obtained after the quantitative and qualitative analysis help to figure out more clearly the goals and the desired assessor from the teachers' perspective. The final data helps to build a better system of evaluation for teacher in in-service teacher training and for the optimizing the quality of the teaching and assessment process.

The gained data were correlated with the data derived other research with a same topic. 


\title{
EFFECT OF LEVELS OF FAMILIAL CHARACTERISTICS OF PRIMARY SCHOOL STUDENTS LONELINESS
}

\author{
Bahtiyar Eraslan-Capan, \\ beraslan@anadolu.edu.tr \\ Anadolu U. Psychological Counseling and Guidance Department \\ Yasemin Körler \\ yaseminsbh@gmail.com
}

Problem Statement: In the sense of loneliness in childhood lead to serious problems in the future. Research was supported in the loneliness of childhood is associated with familial factors.

Purpose of Study: In this study, secondary school students' levels of loneliness, parental education, parental employment status, income level, number of siblings differed according to factors such as the family was investigated.

Research Methods: The research in the academic year 2010-2011 Ministry of Education in Eskişehir was connected to the primary schools. The study in primary 6, 7, 8 class 1013 female students, 980 male students participated in 1993. Personal Information Form, and school-based research data Loneliness Scale for Children (ÇOTYÖ) were used. Data, loneliness levels of students, parents'educational level, number of siblings, one-way ANOVA according to income levels, according to their parents tried to work were analyzed by $t$ test.

Findings: As a result of the research, the education level of parents, the father working conditions, income levels and number of siblings affected the students' feelings of loneliness. The lower the educational level of parents of students had experienced more loneliness. In addition, your father's not working, the fall of the level of family income and the increase in the number of siblings of children was seen to increase the levels of loneliness.

Conclusions: Familial characteristics of children affected the level of loneliness. 
Problem Statement:In the present study the role and place of internet, particularly as virtual education, is investigated in the religious education by adapting a philosophical approach. The present study is ontological and hence after an ontological comparison between virtual and personal experience, it analyzes and investigates the role of internet, particularly as virtual education, in religious education.

Purpose of Study: The aim of the present study is to investigate the role of Internet in the religious education. For this purpose religious education is considered as the process in which belief, commitment, and worship-related, social and moral behaviours of the learner are formed and developed in an explanatory, critical, and passionate procedure and through using the criteria of evaluating accuracy or inaccuracy of beliefs, commitments, and actions.

Research Methods: The applied research methods are hermeneutic phenomenology with qualitative content analysis. Findings: Based on the findings of the study the ontological characteristics of virtual experience in relation to face to face experience are: Distantiation of virtual experience; Collapse of place and time borders in virtual experience; Development of virtual relationship; and Expansion of availability to technological information. Then the horizons of the mentioned ontological characteristics in the development of the mentioned characteristics for religious education is analyzed and interpreted. Internet, for example, has eliminated the limitations caused by place and time as well as the hierarchical authority of teacher in information transfer in the process of religious education; it has provided a more expanded and more liberated context for the exchange of religious ideas and beliefs through disseminating virtual relationships. On the other hand and since in the virtual education there is no complete bodily presence and sensational experience, the development of such aspects like internal motivation, belief, internal experience, internal commitment and action faces some shortcomings.

Conclusions: Finally some implications for applying internet in religious education such as the priority of asking about why to using internet over asking about the how to use it in the process of religious education, multi-dimensional view of teacher for using internet, Integrating virtual education with face to face education are offered. 


\title{
The principles of teaching science based on the ideas of Feyerabend regarding the nature of science and the manner of its expansion
}

\author{
Parvin Bazghandi, The MA student of Tarbiat Moallem University \\ Saeid Zarghami Hamrah, The faculty member of Tarbiat Moallem University
}

Problem Statement: If it is assumed that the objective of science education is not merely the transmission of scientific knowledge but it is growing the scientific mentality in the learners just like the mentality of scientists who originated and developed science throughout the history, then investigating the nature of science and the manner of its origination and development and to manage teaching science on this basis seem to be important issue.

Purpose of Study: The aim of the present study is to recommend some principles for teaching science based on investigation of Feyerabend's ideas regarding the nature of science and the manner of its development.

Research Methods: With regard to the aims of the study the qualitative content analysis as well as practical syllogism is used.

Findings: Feyerabend rejects the positivist idea which states that sensational experiences create scientific and reality-based theories and believes that human different achievements, including rationalism, are different forms of life and are incommensurable. He concludes that variation of methods and theories in the different fields of knowledge are necessary for further criticizing and challenging and also the development of knowledge. Therefore, on the one side, the "A priori" role of observation is not acceptable in the formation of science and, on the other side; the origination and developments of science could not be explained based on some simple methodological rules. On this basis, some principles are presented for teaching science. The recommended principles include understanding scientific theories in the context of history, freedom of learner in scientific research beyond common beliefs and present theories and based on aesthetics, metaphysical and even religious tendencies, incommensurability and non-falsifiablity along with the testability of the available theories based on criteria such as coherence, the degree of adaption with the "posteriori" experiential conditions and adventurous approximations, conceptual teaching instead of algorithmic teaching and subject-based teaching.

Conclusions: Drawing on the research findings it is suggested that the educational politicians should base the science education on the novel ideas of philosophy of science and also educate the teachers in agreement with these principles through revising the inductive approach to teaching sciences.

Keywords: Nature of science, Science education, Feyerabend, Principle

Investigating the relationship between virtual education and social aims of education from the viewpoint of existence philosophy with an emphasis on Jaspers thoughts 
Problem Statement: Jaspers, one of the main representatives of the philosophy of existence, have some ideas as educational philosopher. In the present study his ideas regarding the education and the relationship of virtual education with that are investigated.

Purpose of Study: In this paper the aims of education in views of Jaspers as the representative of the existence philosophy and the role of virtual education in relation with the aims is studied.

Research Methods: The research methods used are qualitative content analysis as well as practical syllogism from the philosophical research methods.

Findings: Jaspers believes there are differences between community and society. Community which has been shaped and grown in the historical developments has its own traditions and uniqueness, whereas society that could be planned and formed has no history to be aware of and lacks any uniqueness because of its similarity to other societies that are planned and formed in the same manner. So educating learners as useful members of community means, on one hand, preparing them for future life and job provided by virtual education and on the other hand, it means reviving, preserving and fostering traditions and genuine historical culture of that society to learners through creative relation, day to day life, manner of speaking and social encountering like face to face contact with human character of a teacher. Therefore, the virtual education cannot be replaced face to face education.

Conclusions: On the foundation of research findings the educational systems should educate the teachers who are representative of traditions and authentic historical culture of that specific community. It should also provide the context for interactions between the teacher and learners in the school and community in order to animate the community's traditions and culture in the students and supply the ground for preserving and growing them. Finally and by accepting the priority of the question concerning technological paradigm than question concerning how reforming by using it some applied implications as follow up virtual education beside face to face education and emphasis on holistic view than unilateral one in using virtual education have been mentioned.

Keywords: Virtual education, Existence philosophy, Social aims of education, Jaspers

\section{MODELLING OF INTERPERSONAL COMMUNICATION AND PERSONALITY AMONG PUBLIC INSTITUTE OF HIGHER LEARNING IN MALAYSIA}

\section{Mohd Yusoff Mohamad Wan Abd Aziz Wan Mohd Amin}

\section{Problem Statement:}

The biggest challenge for the institutions is to develop employability enhancing skills and knowledge and make graduates attractive to employers. With the rapidly changing demands in the job requirements, the curriculum component in the institutions need to be reformed and revised to make it more relevant to the workplace. To generate highly competitive graduates with strong personal qualities, interpersonal communication skill and personality should be incorporated, integrated, and implemented across the curriculum.

Purpose of Study:

The purpose of this study is to identify the presence of interpersonal communication and personality amongst students and to develop structural equation modelling based on data collection.

\section{Research Methods:}

The instrument used in this study is divided into three sections; the demographic profile of the students, the interpersonal communication they possess, and the personality. All data were collected through a questionnaire survey of 300 respondents in University Malaysia Terengganu. A stratified random sampling method based on programmes of studies was used to represent the population. All the data were analysed using SPSS programme version 11.0 by applying statistical description, t-test, ANOVA, Pearson correlation and Structural Equation Modelling.

Findings:

The findings of this study indicate that interpersonal communication and personality do have a significant influence on students' counselling need. Another finding of the study shows that there are differences in interpersonal communication and personality acquired by students of different programmes. 


\title{
Conclusions:
}

The institutions of higher learning must ensure that the core business of teaching, research, and services are competitive and achieve an international standard. They also have to identify the need of interpersonal communication, personality and counselling need amongst the student to enable them to be market-driven, competitive, and appropriate to the needs of the nation. To upgrade the quality of the student, a specific training on the application interpersonal skill and personality in classrooms should be conducted amongst the student. Graduates are also recommended to upgrade themselves with various skills, knowledge, competence, and others needed skills that will make them marketable and employable.

\section{SOCIOLOGICAL IMPLICATIONS OF TECHNOLOGY ON SOCIAL CHANGE WITH SPECIAL FOCUS ON KANGAR, MALAYSIA}

\author{
Hamadullah Kakepoto
}

\begin{abstract}
This study investigates the impact of modern technology in bringing social changes in the society with special focus on Bintong Kangar, Perlis. The study is based on field work conducted in Bintong, Kangar. Bintong is the biggest residential area of the Kangar. Kangar is the main town of the Perlis. Perlis is one of the fourteen states of Malaysia. It is also smallest of all the states. In this study a random sample of 190 respondents from around 2,375 total family households in Bintong area has been selected for the study purpose. The sample total selected stands eight percent of the total number of households in the area. For that purpose a well-structured close-ended questionnaire was intentionally developed for data collection. The present research has presented data on important variables. Modern technology has been used as the control variable. All other variables like social change, family life, economic life, community life, social life, and domestic life were exposed to the control variable and changes in other variables were noted and documented. To analyze the hypotheses, statistical methods including SPSS has been applied to the data mentioned in contingency tables. The chi-square test was applied to test the existence of the relationship between the two variables of hypothesis. Correlation co-efficient and p-value has been derived to check the nature of relationship.
\end{abstract}

Social psychological analysis of delinquency of Tehran correction centre clients".

\section{Author:Nasrollah Ansarinezhad Azerbaijan National Academy Of Science}

Problem Statement: There are many explanations analysis of juvenile delinquency. One of the best these explanations is containment theory of Walter.B.Rekles. In this research we examine some most component.

Purpose of Study: comparative survey of self-esteem, attitude toward police, attitude toward law, aggression, and frustration tolerance between delinquent and normal groups.

Research Methods: The samples are 100 boys and 30 delinquent girls and 100boys and 30 student girls. The design of this research is ex-post facto, and theoretical model of this research is containment theory. The instruments of research are Cooper-Smith self-esteem scale, questionaire of attitude toward police, questionaire of attitude toward law, aggression questionaire, frustration tolerance test.

Findings: The self-esteem of normal group is higher than delinquent group.

The attitude toward police in normal group is positive than delinquent group.

The attitude toward law in normal group is positive than delinquent group.

Aggression level in delinquent group is higher than normal group.

Frustration tolerance in normal group is higher than delinquent group.

Self esteem in normal girls is higher than other groups.

Attitude toward police in normal girls has positive than other groups.

Attitude toward law in normal boys is positive than other groups.

Frustration tolerance in normal boys is higher than other groups.

Between self esteem and attitude toward police in normal boys and delinquent boys and delinquent girls has been meaningful relationships.

Between self esteem and attitude toward law in normal boys and delinquent boys and delinquent girls has been meaningful relationships.

Between self esteem and aggression in normal boys and delinquent boys and delinquent girls has been meaningful negative relationships.

Between self esteem and frustration tolerance in normal and delinquent groups has not been meaningful relationships.

Between frustration tolerance and aggression in normal girls and delinquent boys has been meaningful relationships. Self esteem and attitude toward law meaningfully predict delinquency. 
Conclusions: It is nessary that rehabilitation of juvenile delinqents concenterate on reinforcement of self-esteem and changing attitude toward law.

Keywords: : Social psychological analysis, delinquency, correction centre 


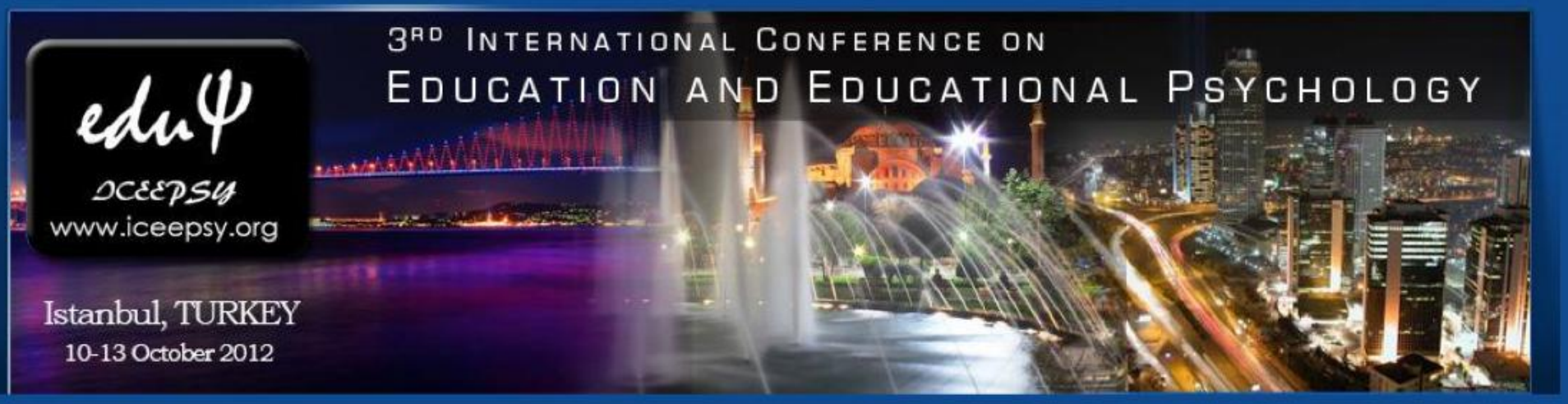

\section{Third International Conference on Education and Educational Psychology ICEEPSY 2012 \\ Istanbul - Turkey \\ $10-13$ October 2012}

Papers are solicited in the following and related areas:

- Psychology

- Educational Psychology

- Guidance and Counseling Psychology

- Early Years Education

- Special Education

- Education and Technology

- ICT

- Distance Learning

- Effective Teaching Practices

- Assessment and Evaluation

- Quality Assurance and Institutional Effectiveness Leadership and Collaborative Policy

- Adult and Continuing Education

- Vocational and Technical Education

- Lifelong Learning

- Higher Education

- Teaching and Learning

- Learning Theories

- Intercultural Education

- Models of Teaching

- Equity, Learner diversity and Inclusion

Important Dates:

Early Registration:

Standard Registration:

Late Registration:
01 December 2011- 29 February 2012

01 March 2012 - 30 April 2012

01 May 2012 - 30 June 2012

\section{Confirmed Keynote Speakers:}

Jan Vermunt, Ph.D., Professor

Utrecht University, The Netherlands

Associate Editor: British Journal of Educational

Psychology (Thomson Scientific Social Sciences Citation Index $-\mathrm{SSCl}$ listed)

Keynote Title: "The Power of Teaching Methods in

Fostering the Quality of Learning"

Hilary Cremin, Ph.D., University Senior Lecturer University of Cambridge, The United Kingdom Editor: British Educational Research Journal (Thomson Scientific Social Sciences Citation Index -SSCI listed) Keynote Title: "Behaviour Management in Schools, and How This Impacts on Wellbeing"

Demetrios G Sampson, Ph.D., Associate Professor University of Piraeus, Greece

Editor: The Journal of Educational Technology \& Society (Thomson Scientific Social Sciences Citation Index -SSCI listed)

Keynote Title: "Preparing papers for Publication in Professional Journals"

All participants are welcome to attend the Keynote Speakers' Presentations during ICEEPSY 2012.

All accepted papers of the ICEEPSY will be published in Procedia-Social and Behavioral Journal - ISSN: 1877-0428 (ELSEVIER) and will be indexed ScienceDirect, Scopus, and Thomson Reuters Conference Proceedings Citation Index (ISI, Web of Science)

For more information visit us at: www.iceepsy.org

You wouldn't want to miss this conference. Mark those dates in your diary now and make plans to be there.

Dr. James Ogunleye, Ph.D., FRSA

Middlesex University, The United Kingdom

Chairman ICEEPSY 2012 